\title{
The Potential for Criticality
}

Following Disposal of

Uranium at Low-Level Waste

Facilities

\author{
RECEIVED \\ JUL 211997 \\ OSTI
}

Uranium Blended with Soil

Prepared by

L. E. Toran, C. M. Hopper, M. T. Naney, ORNL

C. V. Parks, J. F. McCarthy, B. L. Broadhead, ORNL

V. A. Colten-Bradley, NRC

Oak Ridge National Laboratory

Prepared for

U. S. Nuclear Regulatory Commission
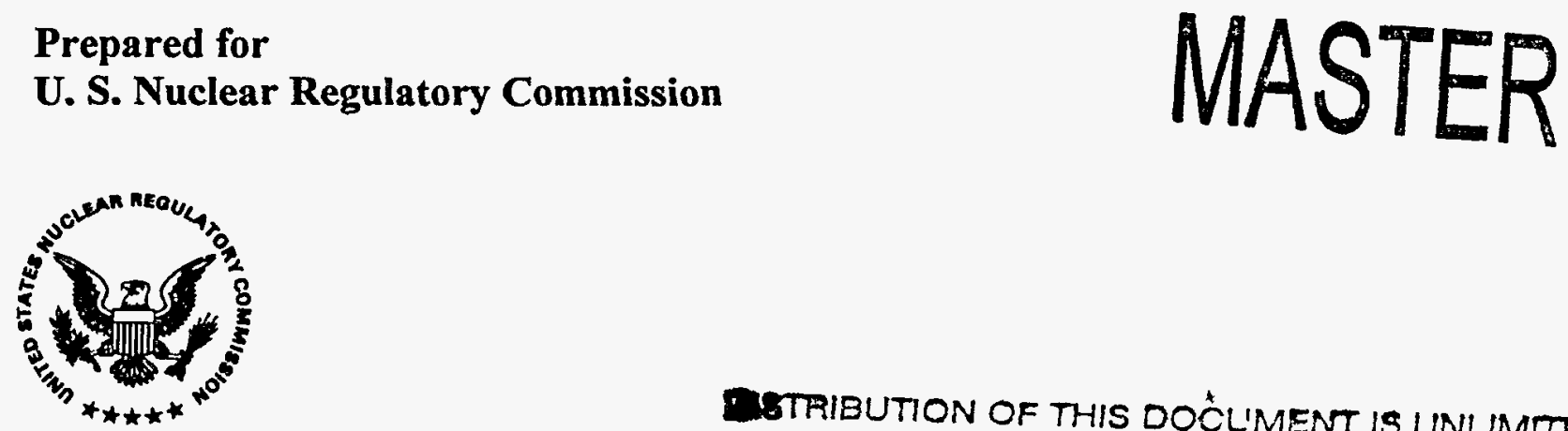


\section{AVAILABILITY NOTICE}

\section{Availability of Reference Materials Cited in NRC Publications}

Most documents cited In NRC publications will be available from one of the following sources:

1. The NRC Public Document Room, 2120 L Street, NW., Lower Level. Washington. DC 20555-0001

2. The Superintendent of Documents, U.S. Government Printing Office, P. O. Box 37082, Washington, DC 20402-9328

3. The National Technical Information Service. Springfield, VA 22161-0002

Although the listing that follows represents the majority of documents cited in NRC publications, it is not intended to be exhaustive.

Referenced documents available for inspection and copying for a fee from the NRC Public Document Room include NRC correspondence and internal NRC memoranda: NRC bulletins, circulars, information notices, inspection and investigation notices; licensee event reports; vendor reports and correspondence; Commission papers: and applicant and licensee documents and correspondence.

The following documents in the NUREG series are available for purchase from the Government Printing Office: formal NRC staff and contractor reports, NRC-sponsored conference proceedings, international agreement reports, grantee reports, and NRC booklets and brochures. Also available are regulatory guides, NRC regulations in the Code of Federal Regulations, and Nuclear Regulatory Commission Issuances.

Documents avallable from the National Technical Information Service include NUREG-series reports and technical reports prepared by other Federal agencies and reports prepared by the Atomic Energy Commission, forerunner agency to the Nuclear Regulatory Commission.

Documents available from public and special technical libraries include all open literature items, such as books, journal articles, and transactions. Federal Register notices. Federal and State legislation, and congressional reports can usually be obtained from these libraries.

Documents such as theses, dissertations, foreign reports and translations, and non-NRC conference proceedings are available for purchase from the organization sponsoring the publication cited.

Single coples of NRC draft reports are available free, to the extent of supply. upon written request to the Office of Administration, Distribution and Mail Services Section. U.S. Nuclear Regulatory Commission, Washington, DC 20555-0001.

Copies of industry codes and standards used in a substantive manner in the NRC regulatory process are maintalned at the NRC Library. Two White Flint North, 11545 Rockville Pike. Rockville. MD 20852-2738. for use by the public. Codes and standards are usually copyrighted and may be purchased from the originating organization or, if they are American National Standards. from the American National Standards Institute. 1430 Broadway, New York, NY 10018-3308.

\section{DISCLAIMER NOTICE}

This report was prepared as an account of work sponsored by an agency of the United States Government. Neither the United States Govemment nor any agency thereof, nor any of their employees, makes any warranty, expressed or implied, or assumes any legal liability or responsibility for any third party's use, or the results of such use, of any information, apparatus, product, or process disclosed in this report, or represents that its use by such third party would not infringe privately owned rights. 
NUREG/CR-6505, Vol. 1

ORNL/TM-13323/V1

\section{The Potential for Criticality Following Disposal of \\ Uranium at Low-Level Waste \\ Facilities}

Uranium Blended with Soil

Manuscript Completed: January 1997

Date Published: June 1997

Prepared by

L. E. Toran, C. M. Hopper, M. T. Naney, ORNL

C. V. Parks, J. F. McCarthy, B. L. Broadhead, ORNL

V. A. Colten-Bradley, NRC

Oak Ridge National Laboratory

Managed by Lockheed Martin Energy Research Corporation

Oak Ridge National Laboratory

Oak Ridge, TN 37831-6370

Prepared for

Division of Waste Management

Office of Nuclear Material Safety and Safeguards

U.S. Nuclear Regulatory Commission

Washington, DC 20555-0001

NRC Job Code L1376
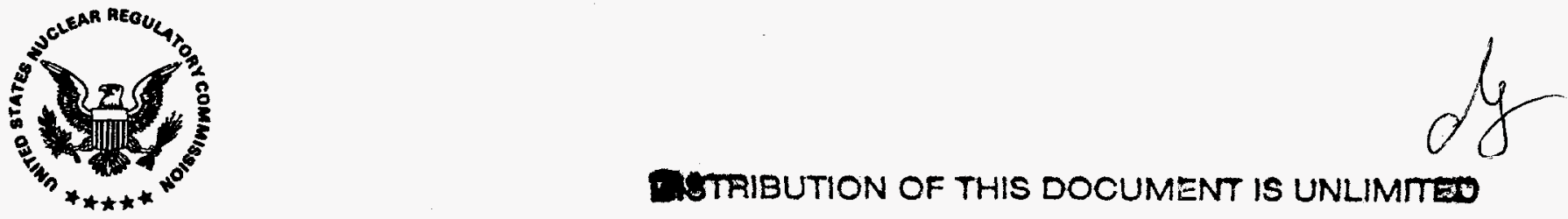


\section{DISCLAMMER}

Portions of this document may be illegible in electronic image products. Images are produced from the best available original documert. 


\begin{abstract}
The purpose of this study was to evaluate whether or not fissile uranium in low-level-waste (LLW) facilities can be concentrated by hydrogeochemical processes to permit nuclear criticality. A team of experts in hydrology, geology, geochemistry, soil chemistry, and criticality safety was formed to develop achievable scenarios for hydrogeochemical increases in concentration of special nuclear material (SNM), and to use these scenarios to aid in evaluating the potential for nuclear criticality. The team's approach was to perform simultaneous hydrogeochemical and nuclear criticality studies to (1) identify some achievable scenarios for uranium migration and concentration increase at LLW disposal facilities, (2) model groundwater transport and subsequent concentration increase via sorption or precipitation of uranium, and (3) evaluate the potential for nuclear criticality resulting from potential increases in uranium concentration over disposal limits. The analysis of SNM was restricted to ${ }^{235} \mathrm{U}$ in the present scope of work. The outcome of the work indicates that criticality is possible given established regulatory limits on SNM disposal. However, a review based on actual disposal records of an existing site operation indicates that the potential for criticality is not a concern under current burial practices.
\end{abstract}





\section{CONTENTS}

$\underline{\text { Page }}$

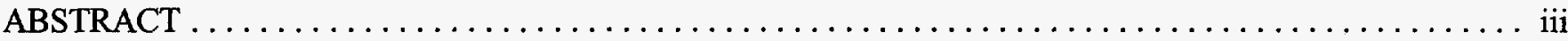

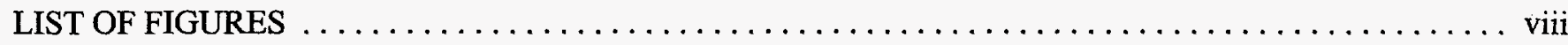

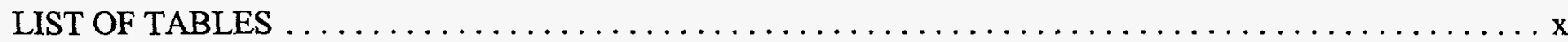

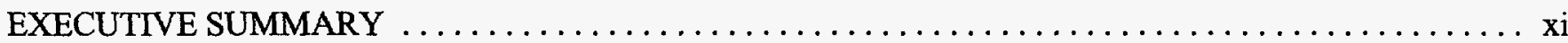

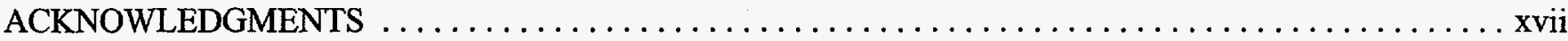

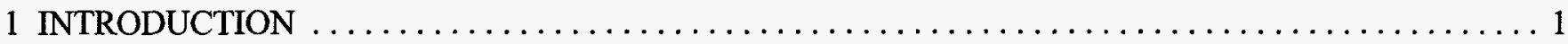

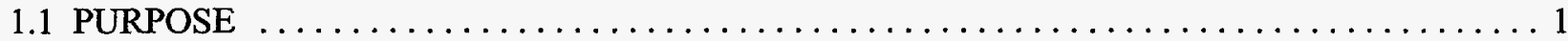

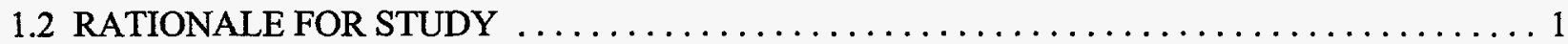

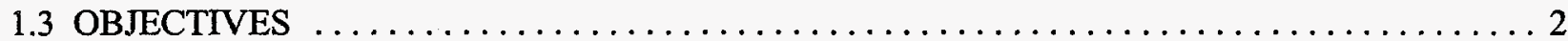

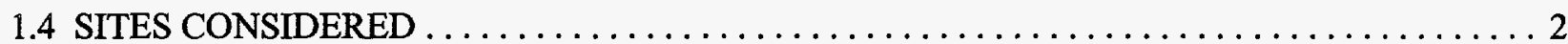

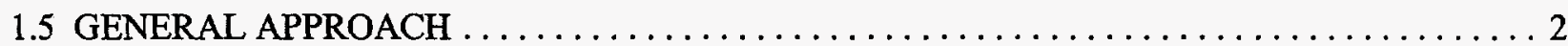

1.5.1 Hydrogeochemical Reactive Transport Modeling $\ldots \ldots \ldots \ldots \ldots \ldots \ldots \ldots \ldots \ldots$

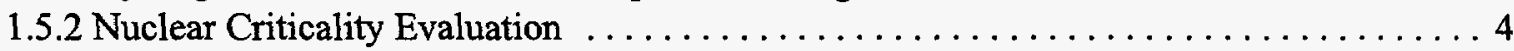

1.5.3 Direct Dose Radiation Transport Analysis for Criticality Consequences . . . . . . . . 7

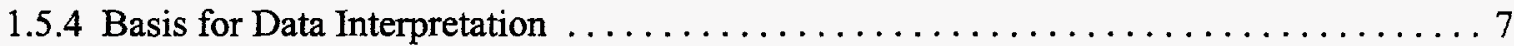

1.6 ORGANIZATION OF REPORT $\ldots \ldots \ldots \ldots \ldots \ldots \ldots \ldots \ldots \ldots \ldots \ldots \ldots \ldots \ldots \ldots$

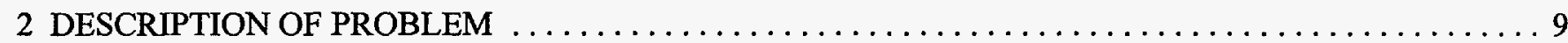

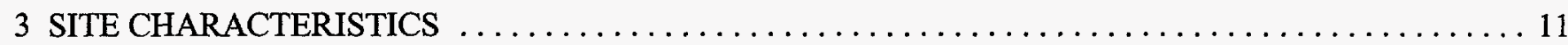

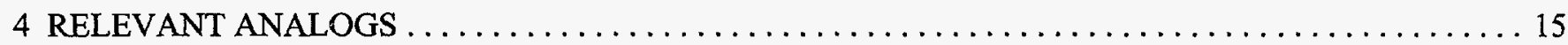

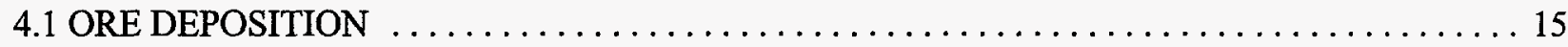

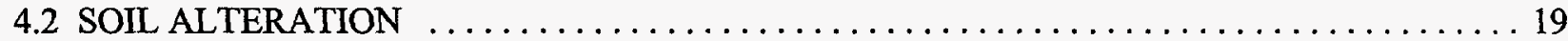

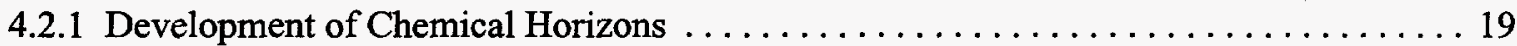

4.2.2 Implications of Soil Alteration in LLW Disposal Facilities $\ldots \ldots \ldots \ldots \ldots \ldots \ldots \ldots 20$

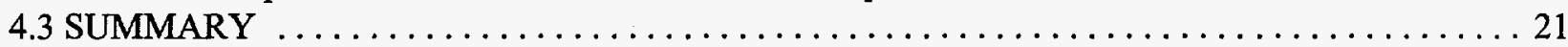

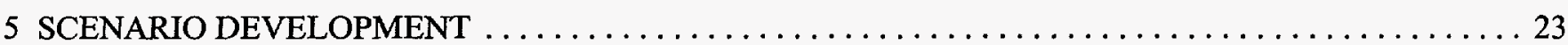

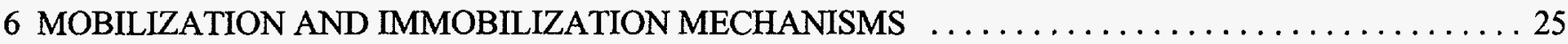

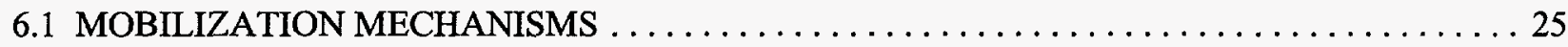

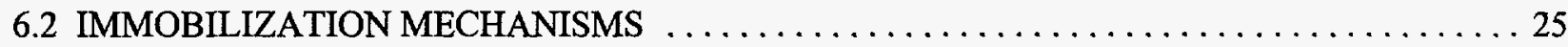

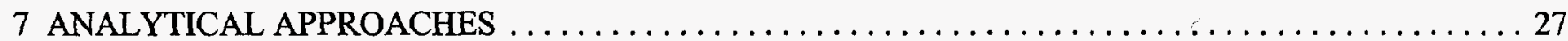

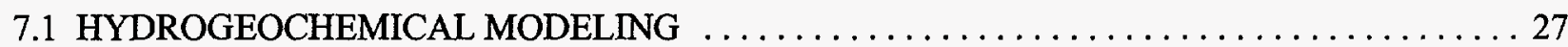

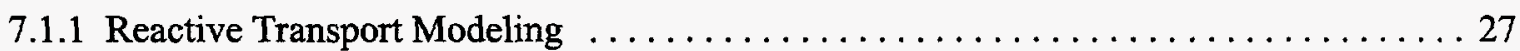

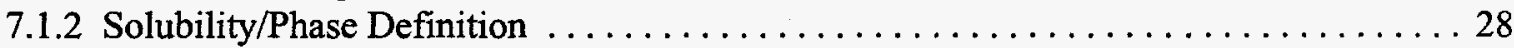




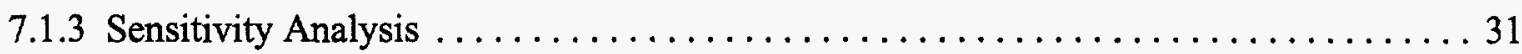

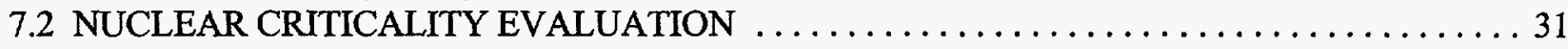

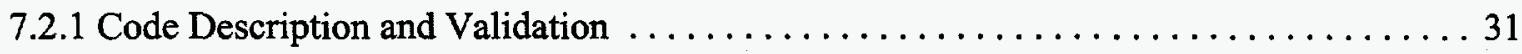

7.2.2 Analytical Approach . . . . . . . . . . . . . . . . . . 32

7.3 CRITICALITY CONSEQUENCES: DIRECT DOSE FROM RADIATION TRANSPORT $\ldots . \ldots 33$

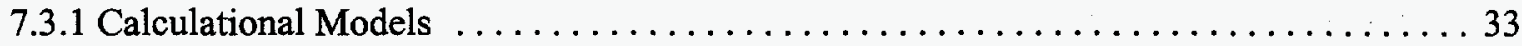

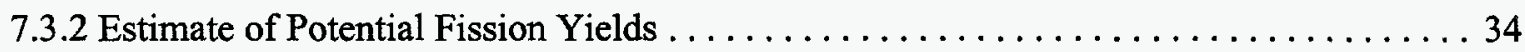

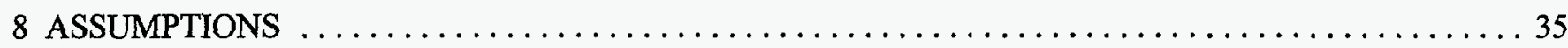

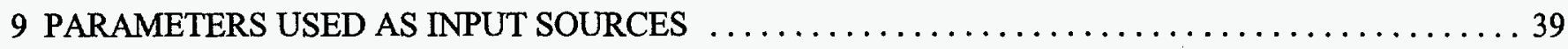

9.1 PARAMETERS USED IN HYDROGEOCHEMICAL SIMULATIONS $\ldots \ldots \ldots \ldots \ldots \ldots$

9.2 PARAMETER RANGES OF SOIL COMPOSITION AND

POROSITY FOR CRITICALITY ASSESSMENT $\ldots \ldots \ldots \ldots \ldots \ldots \ldots \ldots \ldots \ldots \ldots \ldots$

9.3 PARAMETRIC INPUT FOR THE DIRECT-DOSE CRITICALITY CONSEQUENCE EVALUATION $\ldots \ldots \ldots \ldots \ldots \ldots \ldots \ldots \ldots \ldots \ldots \ldots \ldots \ldots \ldots \ldots \ldots \ldots \ldots \ldots$

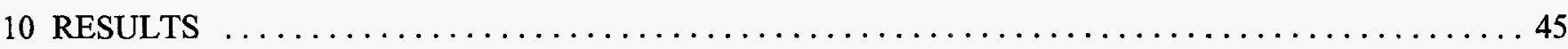

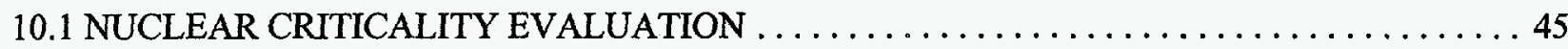

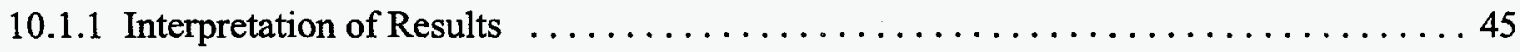

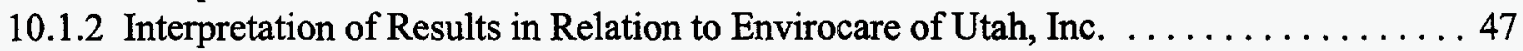

10.1.3 Discussion of Results in Relation to the NRC Division of

Fuel Cycle Safety and Safeguards Proposed Limits $\ldots \ldots \ldots \ldots \ldots \ldots \ldots \ldots$

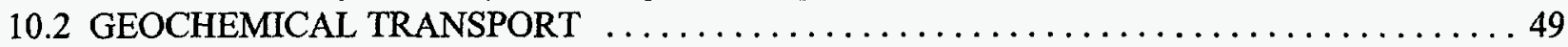

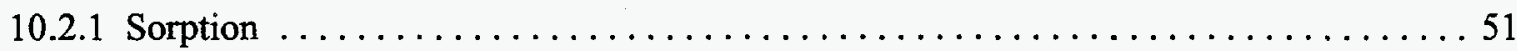

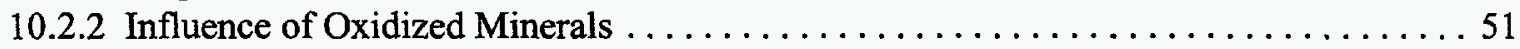

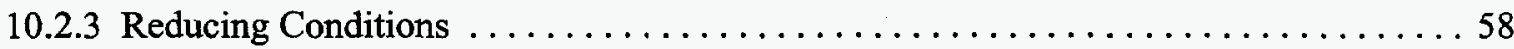

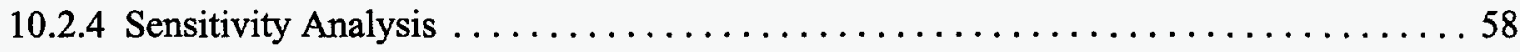

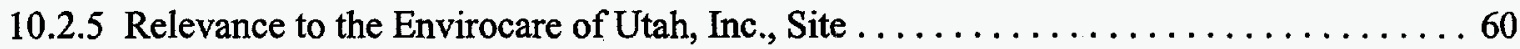

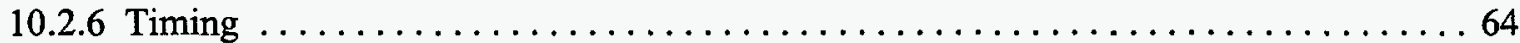

10.3 INTEGRATION OF GEOCHEMICAL MODELING AND

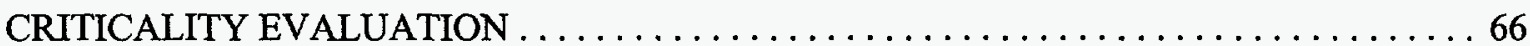

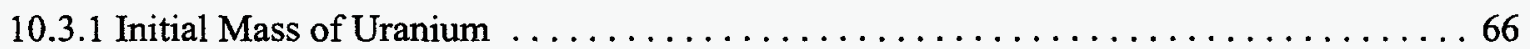

10.3.2 Calculated Thicknesses . . . . . . . . . . . . . . . . . . . . . 66

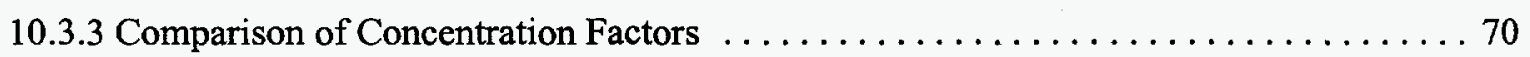

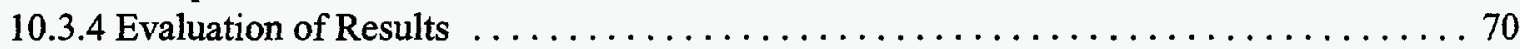

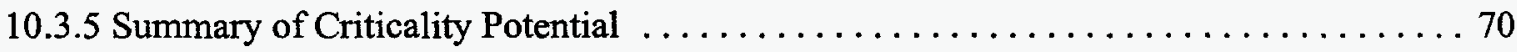

10.4 CRITICALITY CONSEQUENCES: DIRECT DOSE FROM RADIATION TRANSPORT $\ldots 71$

11 DISCUSSION OF LIMITATIONS ASSOCIATED WITH THE ANALYSIS $\ldots \ldots \ldots \ldots \ldots \ldots$

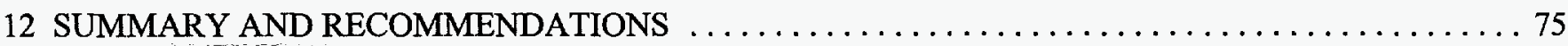

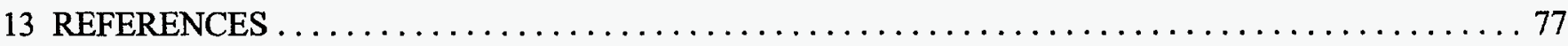

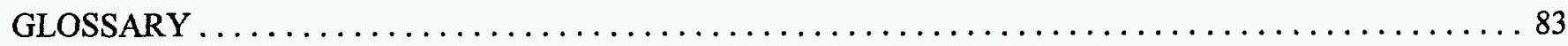

NUREG/CR-6505,

Vol. 1 
APPENDIX A: Conceptual Configurations for Nuclear Criticality Evaluations $\ldots \ldots \ldots \ldots \ldots \ldots \ldots$ APPENDIX B: Envirocare of Utah Disposal Records $\ldots \ldots \ldots \ldots \ldots \ldots \ldots \ldots \ldots \ldots \ldots \ldots \ldots$

APPENDIX C: Expanded Tables $10.1-1$ and $10.1-2 \ldots \ldots \ldots \ldots \ldots \ldots \ldots \ldots \ldots \ldots \ldots \ldots \ldots$

APPENDIX D: Surface Response Figures for Tables A-1 and A-2 Data $\ldots \ldots \ldots \ldots \ldots \ldots 1$ 


\section{LIST OF FIGURES}

Figure

1.5-1 Possible outcomes for uranium transport in hypothetical columns $\ldots \ldots \ldots \ldots \ldots \ldots \ldots$

1.5-2 Schematic illustration of waste soil column evaluated by hydrogeochemical reactive transport

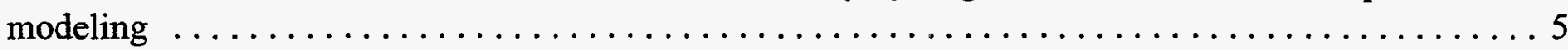

7.1-1 Eh-pH diagram for the $\mathrm{U}-\mathrm{O}_{2}-\mathrm{CO}_{2}-\mathrm{H}_{2} \mathrm{O}$ system at $25^{\circ} \mathrm{C}$ for $\mathrm{P}_{\mathrm{CO} 2}=10^{-2}$ atm $\ldots \ldots \ldots \ldots \ldots$

10.2-1 Example of flushing of uranium in solution and on sorption sites $\ldots \ldots \ldots \ldots \ldots \ldots \ldots \ldots$

10.2-2 Example of sorption on zone at bottom of column with lower $\mathrm{CO}_{3}{ }^{2-}$ concentration than shown

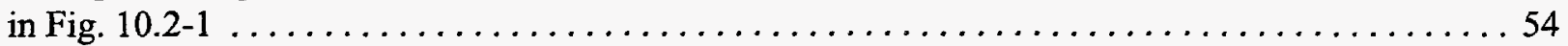

10.2-3 Example of sorption on multiple zones of high sorption within the column $\ldots \ldots \ldots \ldots \ldots$

10.2-4 The effect of column length (or source thickness) on increase in uranium concentration $\ldots \ldots \ldots 57$

10.2-5 Example of uranium demobilization on sorption sites vs a mineral precipitate $\left[\mathrm{UO}_{2}(\mathrm{OH})_{2}-\right.$ beta $] \ldots 59$

10.2-6 Initial uranium (in terms of ${ }^{235} \mathrm{U}$ enrichment relative to $6 \times 10^{-4} \mathrm{~g} / \mathrm{cm}^{3}$ limit on ${ }^{235} \mathrm{U}$ ) vs $\mathrm{CF}$ for

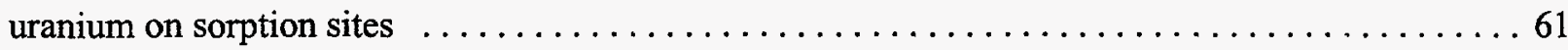

10.2-7 Absolute values of the multivariate regression coefficients on the CF for mobilization of uranium

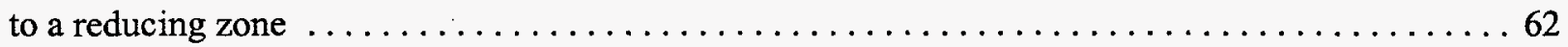

10.2-8 Initial uranium (in terms of ${ }^{235} \mathrm{U}$ enrichment relative to $6 \times 10^{-4} \mathrm{~g} / \mathrm{cm}^{3}$ limit on ${ }^{235} \mathrm{U}$ ) vs $\mathrm{CF}$ for mobilization to a reducing zone

10.2-9 Results of a scenario with worst-case conditions for sorption (high concentration), but low initial concentration of uranium (based on disposal conditions reported at Envirocare, Utah) $\ldots \ldots \ldots 65$

10.3-1 Calculated thicknesses for slabs with a critical configuration $\ldots \ldots \ldots \ldots \ldots \ldots \ldots \ldots \ldots$

10.3-2 Initial disposal thicknesses needed for concentration to a critical slab as a function of uranium areal

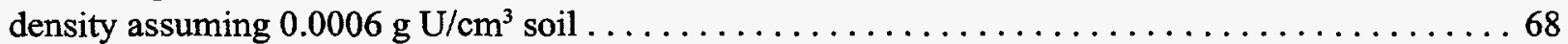

10.3-3 Uranium areal density for a critical slab (see Table C-1) as a function of concentration factor at

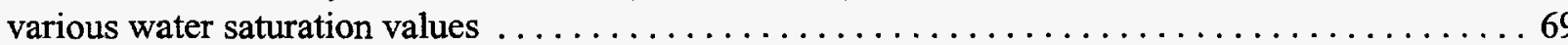

A.1-1 Conceptual configurations for nuclear criticality evaluations $\ldots \ldots \ldots \ldots \ldots \ldots \ldots \ldots$

B.1-1 Yearly and six-year average (TOT) ${ }^{235} \mathrm{U}$ enrichment of uranium disposed of at Envirocare of Utah .90

B.1-2 Yearly and six-year average (TOT) of the concentration of ${ }^{235} U$ disposed of at Envirocare of Utah. . 91

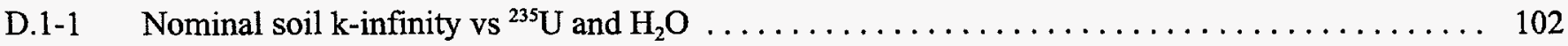


D.1-2 Nominal-soil critical sphere diameter vs ${ }^{235} \mathrm{U}$ and $\mathrm{H}_{2} \mathrm{O}$ concentration $\ldots \ldots \ldots \ldots \ldots$

D.1-3 Nominal-soil critical sphere mass vs ${ }^{235} \mathrm{U}$ and $\mathrm{H}_{2} \mathrm{O}$ concentration $\ldots \ldots \ldots \ldots \ldots \ldots \ldots \ldots$

D.1-4 Nominal-soil critical infinite cylinder diameter $v{ }^{235} \mathrm{U}$ and $\mathrm{H}_{2} \mathrm{O}$ concentration $\ldots \ldots \ldots \ldots$

D.1-5 Nominal-soil critical infinite cylinder linear density vs ${ }^{235} \mathrm{U}$ and $\mathrm{H}_{2} \mathrm{O}$ concentration $\ldots \ldots \ldots 106$

D.1-6 Nominal-soil critical infinite slab thickness vs ${ }^{235} \mathrm{U}$ and $\mathrm{H}_{2} \mathrm{O}$ concentration $\ldots \ldots \ldots \ldots \ldots$

D.1-7 Nominal-soil critical infinite slab areal density vs ${ }^{235} \mathrm{U}$ and $\mathrm{H}_{2} \mathrm{O}$ concentration $\ldots \ldots \ldots \ldots \ldots$

D.1-8 $\mathrm{SiO}_{2}$-soil k-infinity vs $\mathrm{H}_{2} \mathrm{O}$ and ${ }^{235} \mathrm{U}$ concentration linear plot $\ldots \ldots \ldots \ldots \ldots \ldots \ldots \ldots \ldots$

D.1-9 $\mathrm{SiO}_{2}$-soil k-infinity vs $\mathrm{H}_{2} \mathrm{O}$ and ${ }^{235} \mathrm{U}$ concentration $\log$ plot $\ldots \ldots \ldots \ldots \ldots \ldots \ldots \ldots \ldots \ldots \ldots \ldots \ldots \ldots \ldots \ldots$

D.1-10 $\mathrm{SiO}_{2}$-soil critical infinite slab thickness vs $\mathrm{H}_{2} \mathrm{O}$ and ${ }^{235} \mathrm{U}$ concentration linear plot $\ldots \ldots \ldots \ldots 11$

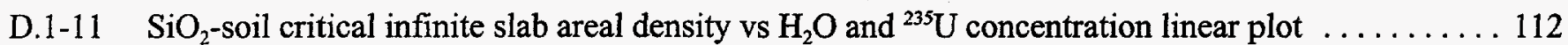

D.1-12 $\mathrm{SiO}_{2}$-soil critical infinite slab areal density vs $\mathrm{H}_{2} \mathrm{O}$ and ${ }^{235} \mathrm{U}$ concentration $\log$ plot $\ldots \ldots \ldots 113$

D.1-13 $\mathrm{SiO}_{2}$-soil critical infinite cylinder diameter vs $\mathrm{H}_{2} \mathrm{O}$ and ${ }^{235} \mathrm{U}$ concentration linear plot $\ldots \ldots \ldots 114$

D.1-14 $\mathrm{SiO}_{2}$-soil critical infinite cylinder linear density vs $\mathrm{H}_{2} \mathrm{O}$ and ${ }^{235} \mathrm{U}$ concentration linear plot $\ldots \ldots 115$

D.1-15 $\mathrm{SiO}_{2}$-soil critical infinite cylinder linear density vs $\mathrm{H}_{2} \mathrm{O}$ and ${ }^{235} \mathrm{U}$ concentration $\log$ plot $\ldots \ldots 116$

D.1-16 $\mathrm{SiO}_{2}$-soil critical sphere diameter vs $\mathrm{H}_{2} \mathrm{O}$ and ${ }^{235} \mathrm{U}$ concentration linear plot $\ldots \ldots \ldots \ldots \ldots 117$

D.1-17 $\mathrm{SiO}_{2}$-soil critical sphere mass vs $\mathrm{H}_{2} \mathrm{O}$ and ${ }^{235} \mathrm{U}$ concentration linear plot $\ldots \ldots \ldots \ldots \ldots \ldots$

D.1-18 $\mathrm{SiO}_{2}$-soil critical sphere mass vs $\mathrm{H}_{2} \mathrm{O}$ and ${ }^{235} \mathrm{U}$ concentration $\log$ plot $\ldots \ldots \ldots \ldots \ldots \ldots \ldots$ 


\section{LIST OF TABLES}

Table

Page

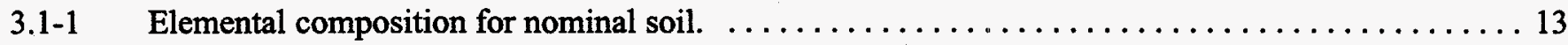

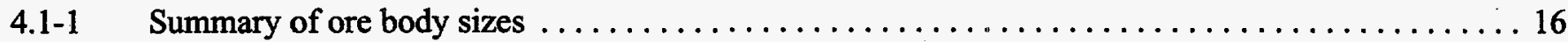

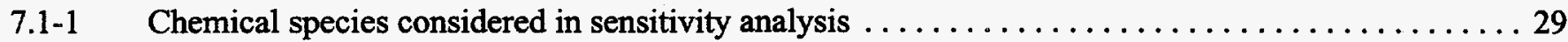

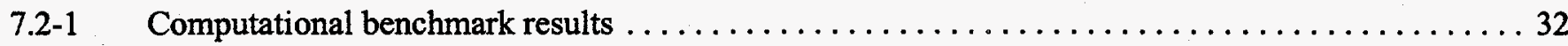

9.1-1 Assumptions and calculations for conversion from milligrams of uranium per gram of soil to moles

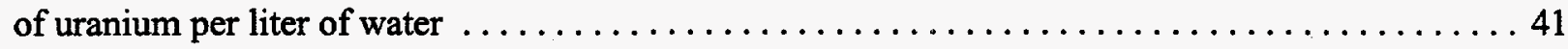

9.2-1 Mean and range of elemental compositions in soil. $\ldots \ldots \ldots \ldots \ldots \ldots \ldots \ldots \ldots \ldots \ldots \ldots$

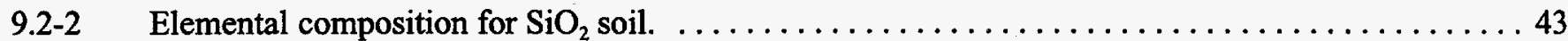

10.1-1 Extracted nominal-soil (N-S) results $\ldots \ldots \ldots \ldots \ldots \ldots \ldots \ldots \ldots \ldots \ldots \ldots \ldots \ldots \ldots \ldots \ldots$

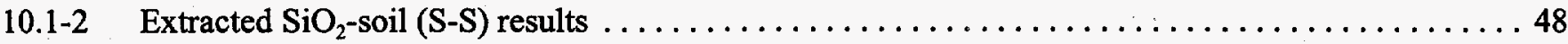

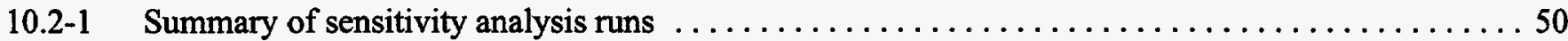

10.4-1 Dose results for assumed high and low CFs at locations near and far from

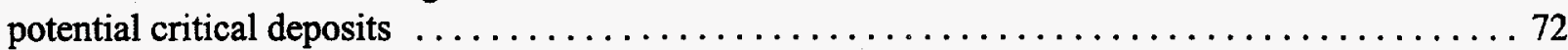

B-1 Envirocare of Utah disposal records, $\mathrm{mCi} . \ldots \ldots \ldots \ldots \ldots \ldots \ldots \ldots \ldots \ldots \ldots \ldots \ldots \ldots$

B-2 Envirocare of Utah disposal records, grams and volumetric. $\ldots \ldots \ldots \ldots \ldots \ldots \ldots \ldots \ldots$

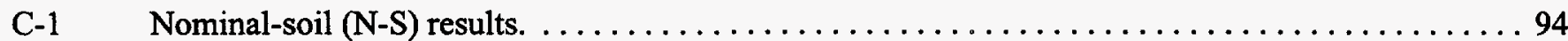

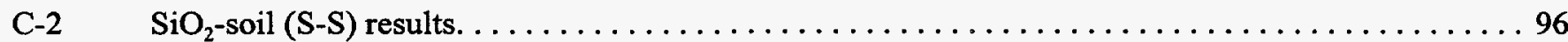




\section{EXECUTIVE SUMMARY}

The purpose of this study was to evaluate whether or not fissile uranium in low-level-waste (LLW) facilities can be concentrated by hydrogeochemical processes to permit nuclear criticality. This investigation presents the first attempt to jointly study the potential for nuclear criticality at LLW facilities using both quantitative hydrogeochemical processes and nuclear criticality safety calculations.

The study was initiated because of a rule change petition (Federal Register, 1993) requesting a predisposal concentration limit for special nuclear material (SNM) in soil to amend the present mass limit specified by Title 10, Code of Federal Regulations, Part 150 (10 CFRP. 150). Preliminary analysis by the U.S. Nuclear Regulatory Commission (NRC) suggested that concentrations of SNM in geometries that constitute nuclear criticality safety concerns are plausible. The NRC staff subsequently determined that further analysis was needed to evaluate the hydrogeochemical processes that might lead to an increase in concentration of SNM, and to evaluate the potential for nuclear criticality under conditions representative of LLW disposal facilities. The NRC asked Oak Ridge National Laboratory (ORNL) to form a team of experts in hydrology, geology, geochemistry, soil chemistry, and criticality safety to develop possible scenarios for hydrogeochemical increases in concentrations of SNM and to use these scenarios to aid in evaluating the potential for nuclear criticality.

The team's approach was to perform simultaneous hydrogeochemical and nuclear criticality studies to

(1) identify some realistic scenarios for uranium migration and concentration increase at LLW disposal facilities,

(2) model groundwater transport and subsequent concentration increase via sorption or precipitation of uranium,

(3) evaluate the potential for nuclear criticality resulting from potential increases in uranium concentration over disposal limits, and (4) estimate potential radiation exposures to personnel resulting from criticality consequences. The analysis of SNM was restricted to ${ }^{235} \mathrm{U}$ in the present scope of work. Three outcomes of uranium concentration are possible:

1. Uranium concentration is increased to levels that do pose a criticality safety concern.

2. Uranium concentration is increased, but levels do not pose a criticality safety concern.

3. Uranium concentration does not increase

There are numerous combinations of variables that may lead to or support nuclear criticality in a waste matrix, herein referred to as soil. These variables include

- the composition of the soil (e.g., $\mathrm{SiO}_{2}$, concrete debris, contaminated combustibles, iron scrap);

- the enrichment of ${ }^{235} \mathrm{U}$ mass relative to the total uranium mass (e.g., less than $5 \mathrm{wt} \%{ }^{235} \mathrm{U}$ from commercial power reactor fuel fabrication processes, $\sim 93 \mathrm{wt} \%{ }^{235} \mathrm{U}$ from research reactor fuel fabrication processes, $0.7 \mathrm{wt} \%$ from natural uranium processes, and less than about $0.2 \mathrm{wt} \%$ from enrichment process tails);

- the density of the soil (e.g., grams of compacted debris per cubic centimeter, tons of compacted debris per cubic yard);

- the density of the ${ }^{235} \mathrm{U}$ within the soil (e.g., grams of ${ }^{235} \mathrm{U}$ per cubic centimeter);

- the degree of neutron moderation in the soil (e.g., typically grams of $\mathrm{H}_{2} \mathrm{O}$ per cubic centimeter, grams of $\mathrm{H}_{2} \mathrm{O}$ per gram of soil, and hydrogen-to- ${ }^{235} \mathrm{U}$ atom ratio); 
- the degree of neutron reflection (e.g., thickness and density of reflecting materials such as concrete, soil, moist or saturated soil);

- the geometry or distribution of the ${ }^{235} \mathrm{U}$ in the soil (e.g., neutronically infinite deposits, finite geometries typically characterized as spheres, infinite-length cylinders, and finite thickness slabs of infinite length and width); and

Because of the numerous combinations of parameters that could be considered in nuclear criticality evaluations, bounding and simplifying assumptions were used. Nuclear criticality evaluations were performed for simple finite-media geometries and infinite media assuming various densities of the ${ }^{235} \mathrm{U}$ isotope and water for two generic soil media (both having a dry and uncontaminated density of $1.6 \mathrm{~g}$ of soil media per cubic centimeter): " $\mathrm{SiO}_{2}$ soil" (the most conservative media because pure $\mathrm{SiO}_{2}$ is the least likely soil composition to absorb neutrons, thereby enhancing the potential for criticality) and a "nominal soil" composed of minerals and secondary phases representative of a world-average soil composition. The infinite-media neutron-multiplication constant, $\mathrm{k}_{\infty}$, was determined for mixtures of nominal soil/ $/{ }^{235} \mathrm{U} /$ water and $\mathrm{SiO}_{2}$ soil/235 $\mathrm{U} /$ water. Additionally, sphere diameters, infinitely long cylinder diameters, and thicknesses of slabs (infinite in two dimensions) were determined for finite-media geometry neutron-multiplication constants, $\mathrm{k}_{\text {eff }}$, equal to a fiducial "critical" value of 0.95 . The value of 0.95 , rather than 1.0 , was selected as a critical value to conservatively account for methods and data uncertainty. The finite-media geometry calculations included a 2-m-thick "neutron reflector" on the surfaces of each type geometry. The neutron reflector consisted of uncontaminated soil having a water content identical to the contaminated soil. The calculations were performed with a one-dimensional (1-D) discreteordinates neutron transport theory code in SCALE (1995) using two sets of realistic geologic parameters for various densities of ${ }^{235} \mathrm{U}$. Calculated critical densities of ${ }^{235} \mathrm{U}$ for various finite-media geometries were translated into concentration factors (CF) (i.e., the ratio of the required ${ }^{235} \mathrm{U}$ density to sustain criticality divided by the maximum authorized ${ }^{235} U$ density allowed for burial at Envirocare of Utah, Inc.). These CFs were then compared with results from the hydrogeochemical modeling to determine if criticality is plausible for various uranium-concentrating hydrogeochemical scenarios.

Potential, direct radiation exposures were estimated for two postulated simple types of criticalities based upon the hydrogeochemical concentration of fully enriched uranium disposed of within an assumed $\mathrm{SiO}_{2}$-soil waste matrix. The locations of the estimated personnel radiation exposures were for positions centered over the concentrated deposit $1 \mathrm{~m}$ directly above the disposal-site grade and $1 \mathrm{~m}$ above the disposal-site grade but displaced about $90 \mathrm{~m}$ from the assumed critical concentrated disposals. The concentrated disposals were assumed to have disklike cylindrical geometries with vertical axes. Also, the disklike deposits were assumed to be centered between the disposal trench floor and the disposal-site grade (i.e., about $5 \mathrm{~m}$ below the surface of the disposal-site grade). The selected disklike deposits had uranium concentrations consistent with uranium CFs of 3.6 and 10.5 observed from the hydrogeochemical scenarios. Since the postulated critical events are sustained by optimum neutron moderation from water in the soil, the potential fission yields of each event were estimated from the thermal fission energy required to vaporize a sufficient quantity of soil moisture and to "shut down" the criticality. The estimated fission yield estimates were $2.8 \times 10^{21}$ and $4.1 \times 10^{21}$ fissions for CFs of 3.6 and 10.5 , respectively. The estimated integrated radiation exposures for the two postulated criticalities $\left(2.8 \times 10^{21}\right.$ and $4.1 \times 10^{21}$ fissions) ranged from about 150 to $56 \mathrm{rem}$ at $1 \mathrm{~m}$ above the disposal-site grade and about 57 to $165 \mathrm{mrem}$ at $1 \mathrm{~m}$ above the disposal-site grade but displaced $90 \mathrm{~m}$ from the cylindrical axes of the postulated concentrated disposals. The seemingly anomalous estimates of higher radiation exposures for smaller fission yields are the result of the lower density disposal (CF of 3.6) being nearer to the surface of the disposal-site grade than the higher density disposal (CF of 10.5). 
Likewise, simplifying assumptions were used for the hydrogeochemical simulations because of the numerous combinations of parameters that can affect the mobilization of ${ }^{235} \mathrm{U}$. The hydrogeochemical scenarios that were considered were generalized representations of plausible conditions at LLW disposal sites. However, several site-specific concerns were incorporated. The study was directed at permissible disposal practices by the Utah Department of Environmental Quality, Division of Radiation Control, Radioactive Material License as applied to Envirocare of Utah, Inc. Disposal practices at this site were examined to suggest transport distances, likely chemical agents, and where possible, initial concentrations. Two approaches to bounding the initial concentration of ${ }^{235} \mathrm{U}$ were used. First, it was assumed that disposal was at the licensed maximum permissible concentration of ${ }^{235} \mathrm{U}\left(770 \mathrm{pCi} / \mathrm{g}\right.$ of soil or $0.0006 \mathrm{~g}$ of ${ }^{235} \mathrm{U} / \mathrm{cm}^{3}$ of soil assuming $1.6 \mathrm{~g}$ of soil/ $\left./ \mathrm{cm}^{3}\right)$. Consideration of the maximum permissible levels allows the worst-case concentrations to be evaluated and can also be used as a basis for evaluating a possible rule change to increase permissible concentrations. Second, actual disposed of quantities, estimated from disposal records, were used. This analysis provided a realistic envelope and assessment of present conditions.

Because the spectrum of geochemical and hydrologic processes and conditions that could be relevant to increasing uranium concentration is extremely broad, examining all resulting potential scenarios in detail is not feasible. Therefore, to constrain the range of geologically reasonable scenarios, uranium ore and soil formation processes were reviewed to identify realistic processes, geometry, and time frames that might be expected in LLW disposal cells. The size and shape of ore bodies, or mineral concentrations, in soils placed bounds on realistic geometries for both the first stage of criticality calculations and on scenarios developed with steadystate, equilibrium modeling.

Hydrogeochemical scenarios were developed in conjunction with NRC staff. Hydrogeochemical modeling considered two processes: (1) mobilization of the uranium presently sorbed in the soil and (2) immobilization and increase in concentration of the uranium at a new location. These processes were modeled in a simple 1-D flow system. The simulated column was $10 \mathrm{~m}$ long and represented a waste cell plus sorption zone with vertical infiltration of water. Water flow was modeled as a slug of water that entered through the cell cap. The simulated column contained one or several zones of different chemistry that could concentrate uranium. These zones included (1) a single zone at the bottom of the column with a greater abundance of adsorption sites than the rest of the soil column, (2) multiple zones of higher sorption distributed at different levels within the column, or (3) a reducing zone at the bottom of the column.

Simulation of uranium transport and fate in LLW sites requires a computer code that includes multiple uranium species and sorption or precipitation that vary in time and space along flow paths. Thus, a multispecies reactive transport code was used to examine the behavior of uranium [Parallel Aquifer and Reservoir Simulator, or PARSim (Arbogast et al., 1994)]. In addition, the U.S. Geological Survey code PHREEQE (Parkhurst, Thorstenson, and Plummer, 1982) was used to calculate chemical equilibria (without transport) for initial conditions and for reducing conditions.

The mobilizing agents, competing complexes, and mineral and sorption equilibria used in the analysis are only a subset of conditions that could exist at a site. They were selected as a first test case but do not represent actual conditions at a particular site. As such, further consideration of site conditions is needed to evaluate whether the modeling represents a worst-case scenario. A sensitivity analysis was performed to examine the effect of varying the values of uranium and total inorganic carbon concentrations, $\mathrm{pH}$, velocity, density of sorption sites and number of sorption zones.

The key assumptions in the study were as follows: 


\section{Executive Summary}

- Saturated flow occurs through a 1-D column with uniform porosity under equilibrium conditions [Transport times will be much slower in unsaturated soil, and enhanced concentration of uranium caused by lateral transport-that is, two-dimensional (2-D) or three-dimensional (3-D) flow-is ignored.]

- Selection of "most likely" complexes and mineral phases is limited. (Other mobilization and demobilization agents should be modeled to evaluate their importance.)

- Water content and ${ }^{235} \mathrm{U}$ concentration for the criticality assessment span a broad range of values.

- Simplistic deposit geometries, having no density gradients, were used in the criticality assessment. (Smaller quantities of fissile material within equivalent volumes may be required to reach criticality for certain density gradients.)

The criticality concern at the Envirocare site, as currently used, is judged to be vanishingly small because of the historic burial practices (tamping of materials to eliminate significant voids), recorded inventories and inferred low uranium enrichments (evidenced from provided records), and the CFs required for criticality concern. Although the Envirocare site was not explicitly modeled, the maximum disposal concentrations of ${ }^{235} U$ that are licensed by Utah were enveloped within the criticality evaluations. The average weight percent concentration of ${ }^{235} \mathrm{U}$ in the LLW inventory at Envirocare over the years $1988-95$ was estimated to be $0.42 \%$. This average enrichment is below the minimum enrichment of $1 \%{ }^{235} \mathrm{U}$ required to achieve nuclear criticality in a watermoderated, homogeneous media. Even if slightly higher enrichments occurred locally, large uranium CFs would be required to reach nuclear criticality.

The results of comparing the hydrogeochemical modeling simulations and criticality safety evaluations indicated that the increase of uranium concentration to levels of concern is not expected but is theoretically possible for current regulatory limits. This result is not unexpected since it has been observed that uranium ores occur in nature, and soil-forming processes concentrate other elements. What is useful about this work is that the sensitivity analysis identified factors that lead to increases in uranium concentration, the methods to evaluate other conditions have been tested, and the limitations of this type of work are now better known. For example, to concentrate uranium, a mobilizing agent must be sufficiently concentrated to transport uranium but not so high that immobilization cannot occur.

Nevertheless, the current and proposed regulatory limits do not exclude the possibility of concentrating uranium to critical densities. The recommendation from this work is that the NRC extend the approach described here to help formulate regulatory positions (regulations, guidelines, operating criteria, etc.) that will limit the potential for criticality within LLW disposal cells. Uranium concentration increase and criticality must be explored over a broader range of LLW disposal-site environments. Parameter ranges, and possibly key mobilization and immobilization mechanisms, relevant to a dry, carbonate-rich disposal cell in Clive, Utah, may be very different from those relevant to a disposal cell in a humid, highly weathered soil environment. Furthermore, uncertainties in hydrogeochemical model outcomes must be reduced, both within the scope of work presented here and in any future work exploring other hydrogeochemical settings. This reduction will require an iterative process that first examines a broad range of parameter values, followed by further analyses within a more refined range of parameters based on conditions that appear to raise the greatest safety concerns.

Specific operational recommendations to prevent reconfiguration of uranium are also suggested from this preliminary work. Inhibiting water infiltration would inhibit mobility and lengthen travel times by orders of magnitude. Soil caps, if not properly designed and maintained, may not provide an adequate barrier during storm events. Avoiding redox zonation would minimize the potential for concentration increase because redox fronts

NUREG/CR-6505,

Vol. 1

xiv 
can cause changes in uranium mobility and concentration. For example, avoiding disposal of reducing material in the unsaturated zone could help maintain oxidizing conditions. Maintaining a reducing zone and precipitating uranium would not be expected to occur in this setting. However, under oxidizing conditions, uranium could be immobilized by other minerals or mobilized and dispersed outside the disposal cell. Reducing the areal density of fissile material within a waste cell reduces the possible density within a concentrated slab. Areal density can be reduced by limiting disposal thicknesses or disposal concentrations. Nuclear criticality safety calculations can provide the maximum areal densities for fissile material that are acceptably subcritical. Avoiding disposal of highly enriched waste similarly reduces the fissile mass available to concentrate uranium to levels of concern.

\section{SUMMARY OF CONCLUSIONS}

- A small number of unexpected, but theoretically possible, scenarios indicate that criticality at a LLW facility is possible based on licensing disposal limits at Envirocare of Utah, Inc.

- Configurations evaluated are geologically reasonable but tend toward worst-case scenarios. The evaluation indicates that a somewhat narrow range of conditions is required for criticality to be of concern. Further characterization of site-specific parameters would better define the range of conditions.

- Under unsaturated conditions, long times would be required to reconfigure uranium (on the order of thousands of years).

- Conditions presenting criticality safety concerns do not currently exist at the Envirocare site based on disposal records that imply dispersal and dilution of the ${ }^{235} \mathrm{U}$ isotope with very large quantities of natural $\left(0.7 \mathrm{wt} \%{ }^{235} \mathrm{U}\right)$ and depleted $\left(\sim 0.2 \mathrm{wt} \%{ }^{235} \mathrm{U}\right)$ uranium.

\section{SUMMARY OF RECOMMENDATIONS}

- The analysis presented here suggests that rule changes to provide for concentration limits on SNM should consider the potential for concentration increases of SNM by hydrogeochemical processes.

- Further analysis of scenarios, site-specific data, and recommendations to prevent reconfiguration of SNM should be made for existing and proposed rules.

- Reconfiguration of SNM should be prevented by inhibiting water infiltration, maintaining uniform redox conditions, and adding demobilizing agents. Areal density limits for disposal of ${ }^{235} \mathrm{U}$ and uranium enrichment limits, based upon possible hydrogeochemical uranium-concentrating processes, should be considered. 



\section{ACKNOWLEDGMENTS}

This work was supported by the NRC under Task 14, Reconcentration of SNM in Low-Level Disposal Facilities, of JCN L1376, Technical Support for Design, Construction, Operation, and Performance Reviews for Low-Level Waste. V. Colten-Bradley of the NRC provided technical direction and contributed substantially to the work throughout the duration of this project.

The authors would like to acknowledge the helpful assistance provided by Patricia B. Fox and Lester M. Petrie, Jr., for the modeling of numerous neutronic calculations and graphic representations of the computational results and Robert $\mathrm{L}$. Childs for the modeling and interpretation of the radiation transport computations. Assistance with hydrogeochemical modeling and visualization of results was provided by Lianfa Song. Soil chemistry data were provided by Baohua $\mathrm{Gu}$, detailed description of soil genesis was provided by David Lietzke, and technical advice on modeling was provided by Mark Elless, Phil Jardine, and Fredrik Saaf. We also acknowledge thoughtful reviews of this manuscript by Gary Jacobs, Liyuan Liang, and Ellen Smith. 


\section{INTRODUCTION}

This task was undertaken to evaluate the potential for nuclear criticality at low-level waste (LLW) disposal facilities. Simultaneous studies of hydrogeochemical simulations and of nuclear criticality parametric evaluations were performed to determine the parametric phase space (hydrogeochemical and neutronic) that would mutually indicate nuclear criticality in two different "soil" matrices.

\subsection{PURPOSE}

The purpose of this study was to evaluate the potential for hydrogeochemical processes to mobilize and concentrate special nuclear material (SNM) contained in soil and construction debris disposed of in LLW facilities into configurations of sufficient density and geometry to permit nuclear criticality. The evaluation of increases in SNM concentration is restricted to criticality safety concerns associated with the ${ }^{235} \mathrm{U}$ isotope of uranium. Consideration of fissile radioisotopes other than ${ }^{235} \mathrm{U}$ are beyond the scope of this study.

\subsection{RATIONALE FOR STUDY}

A rule change petition (Federal Register, 1993) requested that the U.S. Nuclear Regulatory Commission (NRC) develop a concentration limit for SNM in soil to amend the present mass limit specified by Title 10, Code of Federal Regulations, Part 150 (10 CFR P. 150). Under the proposed rule, a licensee would be authorized to possess an unlimited quantity of SNM if the mass ratio of soil to SNM is greater than specified values. The Division of Fuel Cycle Safety and Safeguards has proposed the following SNM limits:

- $11500 \mathrm{~g}$ soil per $1 \mathrm{~g}{ }^{239} \mathrm{Pu}$,

- $\quad 5000 \mathrm{~g}$ soil per $1 \mathrm{~g}^{235} \mathrm{U}(100 \%$ enriched), and

- $\quad 250 \mathrm{~g}$ soil per $1 \mathrm{~g}{ }^{235} \mathrm{U}(10 \%$ enriched).

These limits ensure subcritical conditions, provided the concentrations do not change. The following assumptions were used to obtain the limits:

1. uniform distribution of SNM in soil,

2. silicon dioxide $\left(\mathrm{SiO}_{2}\right)$ as soil model, and

3. spherical geometry and optimal water content for nuclear criticality.

In determining these limits, no consideration was made for increases in concentration of SNM resulting from solution transport to produce new chemical compounds and geometry.

To support this rule-making activity that would add concentration limits of SNM in soil to the possession limits set by 10 CFR P. 150, the NRC performed a preliminary conservative analysis to evaluate the potential for SNM at a LLW disposal facility to be dissolved, transported in solution, and concentrated as a precipitate. The impetus for this analysis is the potential for such concentrated SNM to result in a nuclear criticality. The results of the preliminary analysis performed by the NRC staff suggest that, under the assumptions of the postulated scenarios, concentration of SNM in geometries that constitute nuclear criticality safety concerns is plausible. 
Introduction

Subsequent to the preliminary evaluation, the NRC staff determined that further analysis was needed to assess the criticality safety concern. Specifically, the NRC judged that additional studies are required to address the potential of SNM disposed of at an LLW facility to become sufficiently concentrated by hydrogeochemical processes to form a critical mass. Thus, Oak Ridge National Laboratory (ORNL) was asked to develop plausible scenarios for changes to SNM concentration and configuration at an LLW site and to evaluate the potential for nuclear criticality on the basis of these scenarios.

\subsection{OBJECTIVES}

The objectives of this project are to (a) identify achievable scenarios for hydrogeochemical migration accompanied by increases in the concentration of SNM disposed of at LLW disposal facilities, (b) quantitatively model the geochemical scenarios for increasing the concentration of SNM by solute transport in groundwater and subsequent sorption or precipitation of uranium from solution, and (c) evaluate the potential for nuclear criticality under the hydrogeochemical scenarios modeled by using chemical and physical conditions representative of those existing at an LLW disposal site.

\subsection{SITES CONSIDERED}

This study focuses on two specific circumstances at the LLW facility operated by Envirocare of Utah, Inc., in Clive, Utah. First, the study was directed at disposal practices that are permissible under the Utah Department of Environmental Quality, Division of Radiation Control, Radioactive Material License as applied to Envirocare (i.e., construction of waste cell liners, fill, and caps; the physical form of waste; limitations on compactible and noncompactible debris; and specifications for compaction). Second, the study was limited to maximum ${ }^{235} U$ concentrations authorized by this license. The maximum average concentration of ${ }^{235} \mathrm{U}$ permitted in disposed waste is $770 \mathrm{pCi} / \mathrm{g}$ (Envirocare of Utah, Inc., license UT 2300249), which equates to $\sim 0.6 \mathrm{~g}$ of ${ }^{235} \mathrm{U}$ per liter of soil or $1.6 \mathrm{~kg}$ of soil with an assumed reference density of $1.6 \mathrm{~g} / \mathrm{cm}^{3}$ based upon Sposito (1989) and Shacklette and Boerngen (1984). The average reported ${ }^{235} U$ concentrations disposed of at the site were also considered based on Envirocare disposal manifest records. No other specific LLW sites were evaluated. However, the same analysis methods can be used to evaluate other site-specific conditions.

Because information was not available to verify that concentration processes are active at the Envirocare site, and because concentration of uranium may require long periods of time, natural analogs were also considered to provide a broader perspective. Consideration of analogs provides bounds on the sizes and shapes likely to be assumed by the concentrated uranium and on the time scales required to produce these naturally formed concentrations. Analogs included soil genesis and ore deposition.

\subsection{GENERAL APPROACH}

To approach this problem, a series of reasonable hydrogeochemical scenarios for increasing uranium concentration were developed for which three outcomes are possible (Fig. 1.5-1):

1. uranium concentration is increased to levels that $d o$ pose a safety concern; 
Introduction

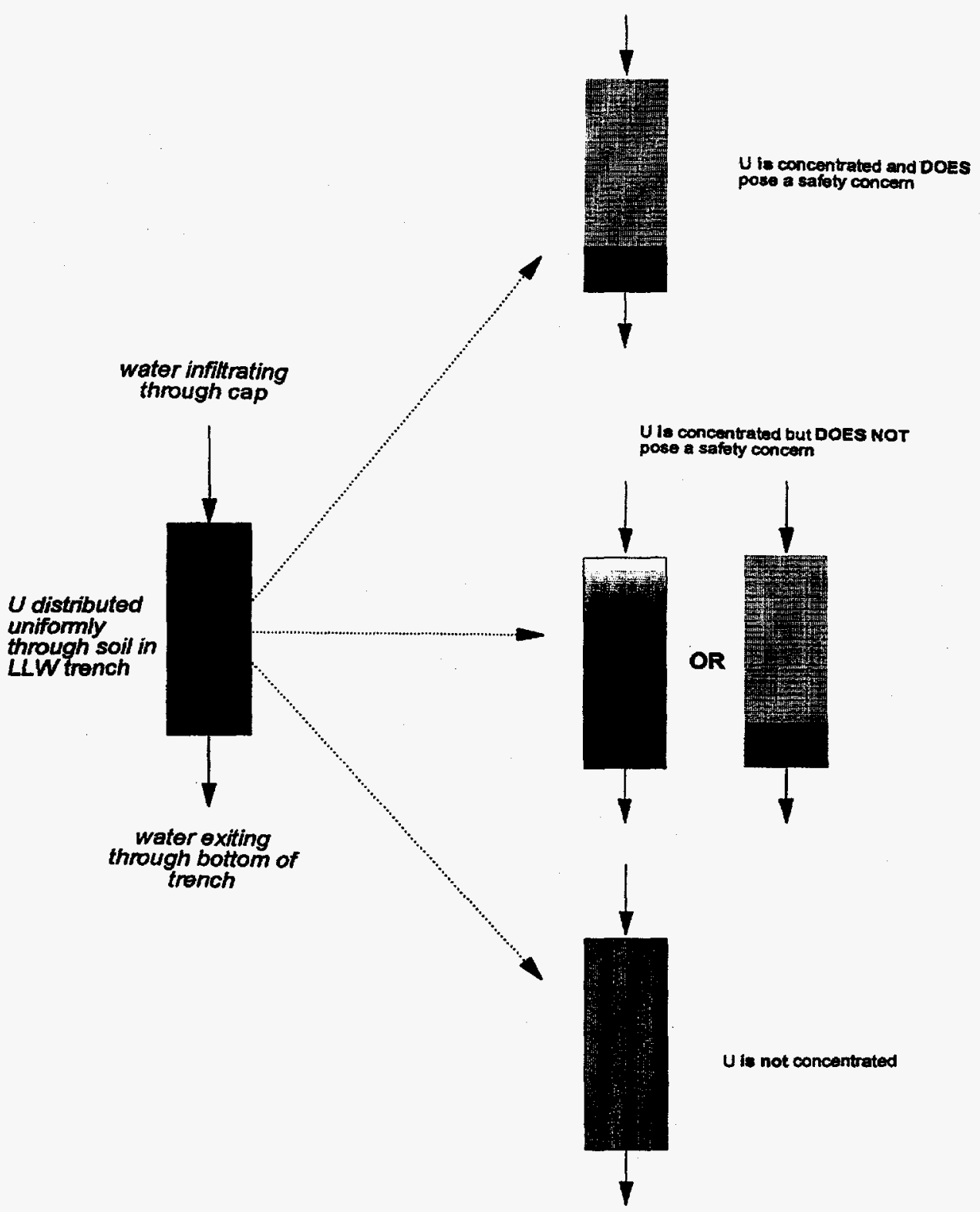

Figure 1.5-1 Possible outcomes for uranium transport in hypothetical columns. Degree of shading indicates relative concentration of uranium. When uranium is concentrated but does not pose a criticality concern, it may be because of (a) insufficient concentration during mobilization or (b) insufficient initial concentration 
Introduction

2. uranium concentration is increased, but levels do not raise a safety concern; or

3. uranium concentration is not increased.

Specific task elements followed in this work included (a) criticality safety evaluations that simulated geologically realistic soil mineral compositions, uranium concentrations, and physical configurations; (b) simulation of realistic, albeit simplified, scenarios of interacting hydrologic and geochemical processes that could mobilize and concentrate uranium; and (c) integration of the criticality and hydrogeochemical results to interpret the likelihood of nuclear criticality over a range of uranium concentrations and configurations bounded by hydrogeochemical modeling or by comparison with geological analogs.

\subsubsection{Hydrogeochemical Reactive Transport Modeling}

Hydrogeochemical scenarios that can reasonably permit increasing the concentration of uranium involve (1) mobilization of uranium in the disposed of soil followed by (2) subsequent immobilization of the migrating uranium into a localized zone. Mobilization processes include uranium ligand dissolution, desorption, and complexation, especially as carbonate or phosphate complexes. Immobilization mechanisms include evaporation, colloid coagulation, adsorption, and precipitation. Precipitation is particularly relevant under reducing conditions because uranium species have low solubility at low redox potential. The problem was conceptualized as the one-dimensional (1-D) vertical transport of uranium through a 10 -m-long column, which represented the uranium-contaminated soil in a disposal cell (Fig. 1.5-2). Water, which represented the composition of rainwater leachate infiltrating the 2-m-thick cap of the cell, entered the top of the $10-\mathrm{m}$ column.

Immobilization was conceptualized as (1) a single zone with a greater abundance of adsorption sites at the bottom of the column, (2) multiple zones of higher sorption distributed at different levels within the column, or (3) a reducing zone at the bottom of the column. The effect of varying the leachate composition on uranium mobilization and concentration under oxidizing conditions was examined by using a formal sensitivity analysis (described in Sect. 7.1.3).

Simulation of the complex geochemical processes that can lead to mobilization and increases in concentration of uranium requires a treatment that deals explicitly with the presence of multiple uranium species, each capable of undergoing adsorption or precipitation processes that vary in time and space along hydrologic flow paths. A multispecies reaction code, designed for parallel supercomputers [PARSim (Arbogast, Dawson, and Wheeler, 1994)], was used to examine the behavior of uranium. All model runs assumed saturated flow, and the number of pore volumes needed to mobilize and concentrate uranium provided a temporal tracing of the processes. Because unsaturated conditions would result in a lower permeability and longer travel times (see Sects. 7 and 8 for additional discussion of the implications of modeling saturated conditions), consideration of saturated conditions for the disposal environment represents a worst-case scenario.

\subsubsection{Nuclear Criticality Evaluation}

To provide a relevant exchange and coupling of technical information between the nuclear criticality safety and hydrogeochemical analyses, the criticality safety calculations were performed in two stages. The first stage began with hydrogeochemical estimates of geometry and physicochemical parameters (e.g., mineral chemistry, soil density, and soil moisture) as input for the initial criticality safety evaluations. Parameter estimates were based on assumptions about site geology and analogs from soil-forming processes and uranium ore deposition. 


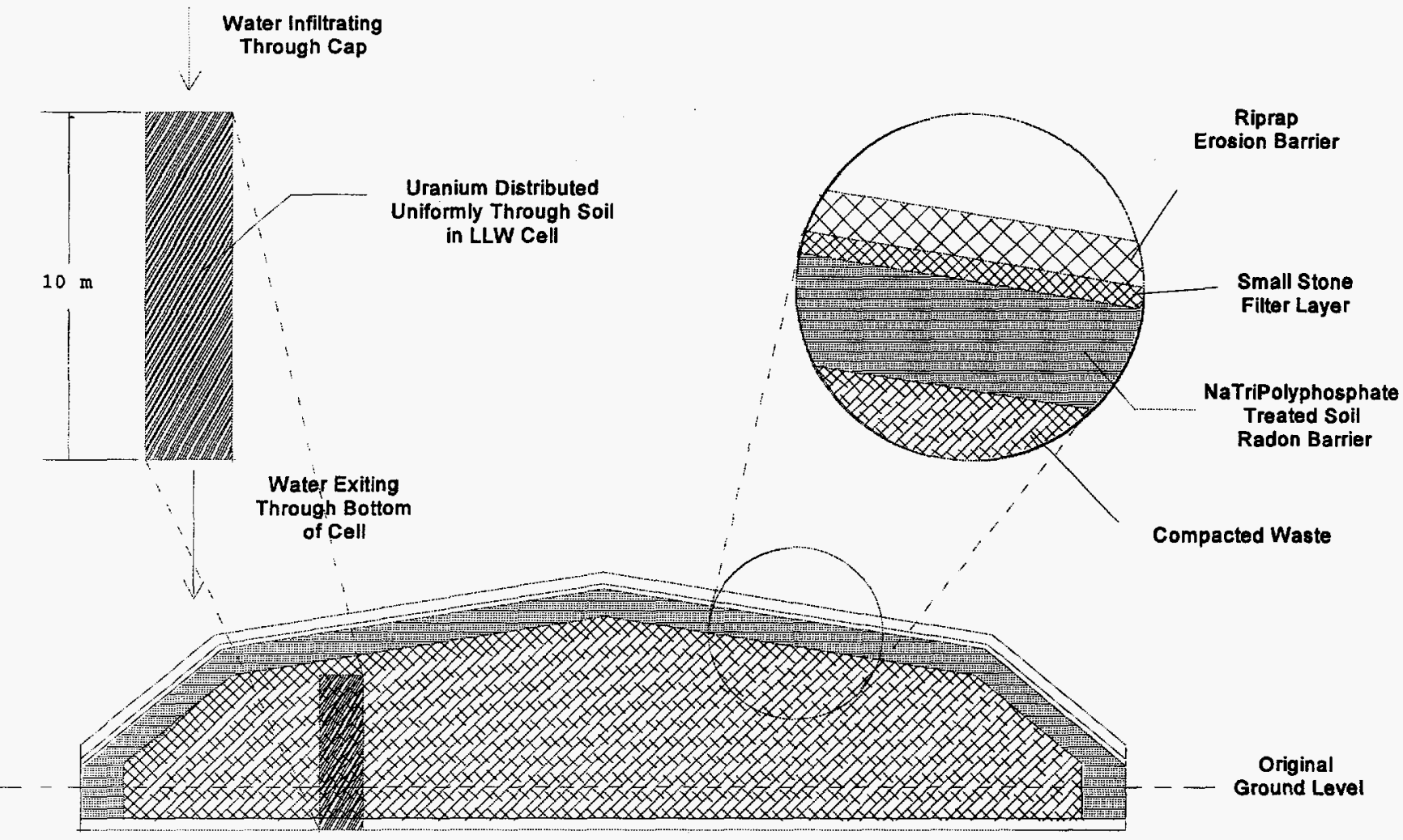

\section{NOT TO SCALE}

Figure 1.5-2 Schematic illustration of waste soil column evaluated by hydrogeochemical reactive transport modeling 


\section{Introduction}

These calculations provided some preliminary estimates of the infinite-media neutron multiplication constant $\left(\mathrm{k}_{\infty}\right)$ by using realistic geologic parameters and "nominal soil" but not accounting for the likelihood that increases in concentration of uranium could occur. The second stage incorporated the limitations suggested by the hydrogeochemical modeling of scenarios to increase the concentration, which supported alternative simple geometries, and expanded to include an $\mathrm{SiO}_{2}$ waste matrix. This afforded additional realism and conservatism in the assessment of the criticality risk.

There are numerous combinations of variables that may lead to or support nuclear criticality in a waste matrix, herein referred to as soil. They include

- the composition of the soil (e.g., $\mathrm{SiO}_{2}$, concrete debris, contaminated combustibles, and iron scrap),

- the enrichment of ${ }^{235} \mathrm{U}$ mass relative to the total uranium mass (e.g., less than $5 \mathrm{wt} \%{ }^{235} \mathrm{U}$ from commercial power reactor fuel fabrication processes, $\sim 93 \mathrm{wt} \%{ }^{235} \mathrm{U}$ from research reactor fuel fabrication processes, 0.7 wt $\%$ from natural uranium, and less than about $0.2 \mathrm{wt} \%$ from enrichment process tails),

- the density of the soil (e.g., grams of compacted debris per cubic centimeter or tons of compacted debris per cubic yard),

- the density of the ${ }^{235} U$ within the soil (e.g., grams of ${ }^{235} U$ per cubic centimeter),

- the degree of neutron moderation in the soil (e.g., typically grams of $\mathrm{H}_{2} \mathrm{O}$ per cubic centimeter, grams of $\mathrm{H}_{2} \mathrm{O}$ per gram of soil, and hydrogen-to- ${ }^{235} \mathrm{U}$ atom ratio),

- the degree of neutron reflection (e.g., thickness and density of reflecting materials such as concrete, soil, and moist or saturated soil),

- the geometry or distribution of ${ }^{235} \mathrm{U}$ in the soil (e.g., neutronically infinite deposits, finite geometries typically characterized as spheres, infinite-length cylinders, and finite thickness slabs of infinite length and width), and

- critical configurations were assumed to be at trench half-depth positions as opposed to near trench bottom positions, thereby reducing the thickness of overburden that could provide additional radiation shielding.

The nuclear criticality evaluations began with the permissible state of Utah license condition limit for ${ }^{235} \mathrm{U}$ contamination in waste (i.e., $770 \mathrm{pCi}$ of ${ }^{235} \mathrm{U}$ per gram of soillike waste) at the Envirocare facility in Clive, Utah. Because of the permissive license condition, the nuclear criticality evaluations considered $100 \mathrm{wt} \%$ enriched uranium (i.e., pure ${ }^{235} U$ ), thereby safely bounding lesser uranium enrichments.

Because of the numerous combinations of parameters that could be considered in the nuclear criticality evaluations, bounding and simplifying assumptions were used. Nuclear criticality evaluations were performed for simple finite-media geometries and infinite media assuming various densities of the uranium ${ }^{235} \mathrm{U}$ isotope and water for two generic soil media (both having a dry and uncontaminated density of $1.6 \mathrm{~g}$ of soil media per cubic centimeter): " $\mathrm{SiO}_{2}$ soil" (the most conservative media because $\mathrm{SiO}_{2}$ is the least likely soil composition to absorb neutrons, thereby enhancing the potential for criticality) and a nominal soil composed of minerals and secondary phases representative of a world-average soil composition. The infinite-media neutron-multiplication constants, $\mathrm{k}_{\infty}$, were determined for each mixture of nominal soil ${ }^{235} \mathrm{U} /$ water and $\mathrm{SiO}_{2}$ soil//235 $\mathrm{U} /$ water. Additionally, sphere diameters, infinitely long cylinder diameters, and thicknesses of slabs (infinite in two dimensions) were determined for finite-media geometry neutron-multiplication constants, $\mathbf{k}_{e f f}$, equal to a fiducial "critical" value of 0.95 . 
(Here, and throughout this report, 0.95 is used as the upper limit for neutron-multiplication factors because it provides a 5\% margin of subcriticality that accounts for bias and uncertainties in the calculational methods and data.) The finite-media geometry calculations included a 2-m-thick "neutron reflector" on the surfaces of each type geometry. The neutron reflector consisted of uncontaminated soil having identical water content as the contaminated soil. The calculations were performed with a 1-D discrete-ordinates neutron transport theory code in SCALE (1995) using two sets of realistic geologic parameters for various densities of ${ }^{235} \mathrm{U}$. Calculated critical densities of ${ }^{235} U$ for various finite-media geometries were translated into CFs (i.e., the ratio of the required ${ }^{235} U$ density to sustain criticality divided by the maximum authorized ${ }^{235} \mathrm{U}$ density allowed for burial at Envirocare).

\subsubsection{Direct Dose Radiation Transport Analysis for Criticality Consequences}

Criticality is not likely to occur at the Envirocare LLW facility because of the small likelihood for sufficient hydrogeochemical concentration of uranium and because of the low enrichment of uranium indicated by historic records. However, because there are no license operating constraints on the enrichment of the uranium disposed, there is a theoretical possibility for criticality. Therefore, direct-dose radiation transport calculations were performed to estimate the neutron and gamma radiation doses near the soil surface as a consequence of two postulated critical configurations at the Envirocare facility-one at near minimum ${ }^{235} \mathrm{U}$ critical density and the other at the near maximum ${ }^{235} \mathrm{U}$ density. Both were assumed to be large-diameter (i.e., $18 \mathrm{~m}$ ), disklike cylindrical deposits of overly water-moderated uranium in $\mathrm{SiO}_{2}$. Both configurations were vertically centered in a trench. Both configurations were constrained by the maximum allowable $0.0006 \mathrm{~g}{ }^{235} \mathrm{U} / \mathrm{cm}^{3}$ disposal value (based upon a soil density of about $1.6 \mathrm{~g} \mathrm{soil} / \mathrm{cm}^{3}$ ) that corresponds to an areal density of about $5.7 \mathrm{~kg}{ }^{235} \mathrm{U} / \mathrm{m}^{2}$ as projected to the bottom of a trench. The first postulated critical configuration was an 18-m-diam disk that was approximately $2.5 \mathrm{~m}$ in thickness, which corresponds to a $\mathrm{CF}$ of about 3.6. The second postulated critical configuration was an 18-m-diam disk that was approximately $0.9 \mathrm{~m}$ in thickness, which corresponds to a CF of about 10.5 .

The direct-dose evaluations were performed for two different locations, both at $1 \mathrm{~m}$ above the ground surface, for both critical configurations. The first location was directly above the center of the cylindrical deposit, and the second location was $90 \mathrm{~m}$ from the first.

The maximum direct total dose was estimated to be about 160 rem at $1 \mathrm{~m}$ above ground level directly above the center of the low-density, 2.5-m-thick cylindrical deposit. The minimum direct total dose was estimated to be about $0.06 \mathrm{rem}$ at $1 \mathrm{~m}$ above ground level, $\sim 90 \mathrm{~m}$ from the center of the $0.9-\mathrm{m}$-thick cylindrical deposit. Though the estimated fission yield $\left(4.1 \times 10^{21}\right.$ fissions) for the $0.9-\mathrm{m}$-thick deposit was nearly twice the estimated fission yield $\left(2.8 \times 10^{21}\right.$ fissions) for the 2.5 -m-thick deposit, the maximum direct doses were observed from the lower

${ }^{235} \mathrm{U}$ density $2.5-\mathrm{m}$-thick deposit because of the smaller thickness of $\mathrm{SiO}_{2}$ overburden that provided less shielding for the fission radiation.

\subsubsection{Basis for Data Interpretation}

Both the nuclear criticality safety analysis and the hydrogeochemical modeling assume that the maximum permissible limits for ${ }^{235} \mathrm{U}$ are disposed of $\left(0.0006 \mathrm{~g} / \mathrm{cm}^{3}\right)$. For the hydrogeochemical modeling, ${ }^{235} \mathrm{U}$ enrichment is not a factor in transport behavior, but total uranium concentration could influence uranium mobilization. Therefore, the total uranium concentration was increased above $0.0006 \mathrm{~g} / \mathrm{cm}^{3}$ to an upper limit of $0.06 \mathrm{~g} / \mathrm{cm}^{3}$. Thus, assuming a fixed ${ }^{235} \mathrm{U}$ concentration of $0.0006 \mathrm{~g} / \mathrm{cm}^{3}$, the range of uranium concentrations used in the hydrogeochemical modeling can be interpreted to span the ${ }^{235} \mathrm{U}$ enrichment range of 1 to $100 \mathrm{wt} \%$. However, because LLW regulations do not limit enrichment, a worst-case scenario of $100 \%$ enrichment is assumed in the nuclear criticality safety analysis. 
The criticality safety analysis provided information on the concentrations of uranium (grams of uranium per grams of soil) in various shapes and sizes that would be required to achieve $\mathrm{k}_{e f f}=0.95$ in nominal and $\mathrm{SiO}_{2}$ soil. The hydrogeochemical modeling provided information on the extent to which uranium would be mobilized and concentrated under varying hydrologic and geochemical conditions. The analogs (ore deposits, soil genesis) provided additional information on geologically reasonable sizes and shapes of concentrated uranium. By comparing these data, the potential for reasonable hydrogeochemical mechanisms to configure uranium in a concentration and geometry that pose a criticality safety concern was evaluated.

Radiation exposures were calculated for postulated criticalities that were based upon geometric models that could conservatively envelop uranium concentrations in disposals that were considered in the hydrogeochemical scenarios.

\subsection{ORGANIZATION OF REPORT}

This report is organized into 12 sections. The introduction describes the purpose, rationale, and objectives of the study and outlines the general approach to integrating the results of the hydrogeochemical process modeling, criticality safety analyses, and postulated criticality radiation transport consequence evaluation. The background of the problem is outlined in more detail in Sect. 2. The background section emphasizes the concern that regulatory limits may not adequately address the potential effect of hydrogeochemical processes on mobilization and the increase in concentration of SNM in a disposal cell. The NRC, in commissioning this study, expressed special interest in the LLW disposal facility at Clive, Utah, operated by Envirocare of Utah, Inc. This study addressed some site-specific conditions at that facility, which are described in Sect. 3.

The spectrum of possible geochemical and hydrologic processes that could be relevant to an increase in uranium concentration is broad, and it is not feasible to examine all these potential scenarios. Therefore, to limit the range of geologically reasonable scenarios, uranium hydrogeochemical processes were reviewed (Sect. 4) to provide a realistic frame of reference for key processes, geometry, and time frames that might be expected in LLW disposal cells. Following consideration of natural analogs, scenarios for the mobilization and concentration increase of SNM were developed by ORNL staff and approved by the NRC. The approved scenarios were tested by hydrogeochemical and criticality safety modeling over a range of conditions to evaluate the likelihood of an increase in uranium concentration to densities that pose a criticality safety issue. These scenarios are described in Sect. 5.

The processes of uranium mobilization and concentration increase considered in the modeled scenarios are described in Sect. 6. The details of hydrogeochemical process modeling and nuclear criticality evaluation are described in Sect. 7, and the assumptions underlying the modeling and the parameters used in the models are addressed in Sects. 8 and 9, respectively. The results of the model simulations are presented in Sect. 10 and are discussed within the context of site-specific conditions at the Envirocare site and as they pertain to the more general issue of developing regulatory guidelines to minimize criticality safety risks.

The geological realism and complexity of the modeled geochemical transport processes incorporated into this study exceed that of previous analyses of the potential for concentrated SNM to reach nuclear criticality. However, simplifications still exist that create uncertainties in estimating risks. Limitations of the models and the consequences of uncertainties associated with interpretation of the results are discussed in Sect. 11, and the data required to reduce the uncertainties are identified. Finally, Sect. 12 provides a summary and statement of the conclusions of the study.

NUREG/CR-6505, Vol. 1 


\section{DESCRIPTION OF PROBLEM}

The amount of SNM that can be received, possessed, or transferred by a licensee is restricted by 10 CFR P. 150 to quantities not sufficient to form a critical mass. Part 150.11, Critical Mass, specifically defines limits as follows:

uranium enriched in the isotope ${ }^{235} \mathrm{U}$ in quantities not exceeding 350 grams of contained ${ }^{235} \mathrm{U}$; ${ }^{233} \mathrm{U}$ in quantities not exceeding 200 grams; plutonium in quantities not exceeding 200 grams; or any combination of them in accordance with the following formula: For each kind of special nuclear material, determine the ratio between the quantity of that special nuclear material and the quantity specified above for the same kind of special nuclear material. The sum of such ratios for all kinds of special nuclear materials in combination shall not exceed unity.

These restrictions are applicable to waste materials in individual waste packages (e.g., 55-gal drums and boxes) or soil prior to burial. However, the total inventory of SNM contained in all buried waste packages or contaminated soils at a disposal facility can greatly exceed the critical mass limits stated previously.

If disposal packages remain sealed or the disposal facility remains dry, no potential exists for significant movement of SNM. Low probability, potential exceptions include site disturbance or modification caused by tornado, earthquake accompanied by liquefaction of soil, and deliberate or accidental excavation. The potential for movement of SNM increases when the disposal facility is wet. Under wet conditions, uranium can potentially be transported with the advecting fluid as dissolved uranium in a variety of oxidation states: as cationic or anionic complexes with inorganic or organic ligands; as colloidal particles formed by homogeneous precipitation of hydrolyzed uranium or plutonium; or by adsorption or precipitation of the SNM on natural colloids such as layer silicates, mineral oxides, or natural organic material. Physical and chemical characteristics at a waste site may vary both spatially and temporally, effecting changes that block physical migration of solutions or promote chemical exchange, sorption, or precipitation reactions. Both physical barriers and chemical reactions may have the potential to concentrate SNM sufficiently to pose a criticality safety concern. Waste form degradation accompanied by the transport and increase in concentration of SNM form the basis of postulated scenarios that have raised concerns regarding criticality safety at high-level waste facilities (Bowman and Venneri 1994). However, previous analyses have not attempted to account for the hydrogeochemical feasibility of increases in SNM concentration. 



\section{SITE CHARACTERISTICS}

The site characteristics described here are limited to those of the Envirocare site near Clive, Utah. General descriptive remarks were excerpted from the NRC Final Safety Evaluation Report (1994). Additional site information used in this evaluation (including waste cell water leachate chemistry, native soil mineralogy and chemistry, Utah Radioactive Material License to Envirocare of Utah, and SNM inventory) was obtained from the state of Utah, Department of Environmental Quality, Division of Radiation Control, or from Envirocare of Utah, Inc., at the request of the Division of Radiation Control. NRC and ORNL staff conducted a site visit on August 8,1995, to obtain additional information on site characteristics and LLW disposal operations.

The Envirocare site near Clive, Utah, is located approximately $120 \mathrm{~km}$ west of Salt Lake City, Utah, at the eastern margin of the Great Salt Lake Desert in the Basin and Range province of North America. Topography in the Basin and Range is controlled by block-faulted, north-south trending mountain ranges separated by alluvialfilled basins. The lithology of the mountains includes limestone, dolomite, shale, quartzite, and sandstone. Basin sediments consist of Quaternary lacustrine Lake Bonneville deposits and Tertiary colluvial and alluvial materials eroded from adjacent mountains. Unconsolidated to semiconsolidated valley fill sediments are 240 to $300 \mathrm{~m}$ thick in the central portions of valleys within the Great Salt Lake Desert. The materials consist of intercalated colluvium, alluvium, lacustrine, and fluvial deposits with some aeolian material.

Precipitation records from Wendover, Utah, provide an estimate of $13 \mathrm{~cm} /$ year average annual total precipitation at the Clive site, indicative of a dry climate.

Topographic relief at the South Clive site is $\sim 3 \mathrm{~m}$ over the 250 -ha tract, sloping from northeast to southwest. The Envirocare facility is underlain by Quaternary lake bed deposits of Lake Bonneville. On-site logs of the subsurface indicate that these lake deposits extend to depths of at least $75 \mathrm{~m}$. Soils at the facility have been mapped as Iosepa silt loam by the U.S. Soil Conservation Service. Translocated clay and sodium minerals are concentrated 10 to $38 \mathrm{~cm}$ below the surface, resulting in a relatively impervious soil.

The design of waste cells is modeled after that used by the U.S. Department of Energy (1984) for disposal of uranium mill tailings in the adjacent "Vitro Cell" at the South Clive, Utah, site. The waste cell is constructed in a continuous cut and fill operation such that excavation, fill, and capping take place in a limited area of the planned waste cell. Design features of the waste disposal cells relevant to the evaluation of SNM mobilization and concentration increase (Fig. 1.5-2 schematically illustrates this design) are summarized as follows:

(1) The existing low-relief terrain is excavated to a depth of $2.4 \mathrm{~m}$, and the native soil materials removed are stockpiled for use in incremental capping of the filled waste embankment.

(2) A 0.6-m-thick liner is constructed. The liner consists of scarified and recompacted native soil. The liner is designed to be more permeable than the soil cap to prevent retention of infiltrated water.

(3) Waste material is placed on the liner in $0.3-\mathrm{m}$ (1-ft) lifts and compacted in place to a maximum fill height of $11 \mathrm{~m}$ above the original ground elevation. (Note: The vertical dimensions of the Envirocare waste cells presented in various schematic design illustrations obtained from the Utah Division of Radiation Control are not consistent. For modeling purposes, an 8-m source thickness plus a 2-m-thick sorption zone was selected in consultation with NRC staff). 


\section{Site Characteristics}

(4) A 2-m-thick layer of native soil treated with sodium tripolyphosphate and compacted in 0.3-m lifts is placed on top of the compacted waste to form a radon and water infiltration barrier. This cap is constructed incrementally as portions of the waste cell are filled to design capacity.

(5) An erosion protection barrier is placed over the radon barrier. The erosion barrier consists of a $0.15-\mathrm{m}-$ thick bedding layer of fine gravel that acts as a filter zone. This is overlain by a $0.46-\mathrm{m}(1.5-\mathrm{ft})$-thick layer of riprap having a minimum medium-sized rock size $\left(\mathrm{D}_{50}\right)$ of $2.5 \mathrm{~cm}$ on the top slope and $8.75 \mathrm{~cm}$ on the side slopes to complete erosion protection. $\left(D_{50}=2.5 \mathrm{~cm}\right.$ and $D_{50}=8.25 \mathrm{~cm}$ designate effective rock size for an aggregate having a distribution of sizes with $50 \%$ of the "particles" less than 2.5 or $8.25 \mathrm{~cm}$ in diameter, respectively.)

Because wastes disposed of at the site may originate anywhere in the United States, mean world soil compositions were used for modeling (Table 3.1-1). The composition of water percolating through the waste was modeled as rainwater equilibrated with the chemically treated and compacted native soil cap. These water compositions compared well with the chemistry of "leachate" runoff waters collected at the margins of active, uncovered portions of the disposal cell (based on data obtained from L. Morton, State of Utah, Department of Environmental Quality). The model water compositions were used in place of the state of Utah site water chemistry because the site water analyses were not charge balanced. Waste disposed of is limited to less than $10 \%$ by volume of debris distributed uniformly in a 0.3-m lift (Utah Department of Environmental Quality, 1995, p. 14). Noncompactible debris (i.e., concrete, metal, and stone) distributed uniformly to minimize voids may compose up to $25 \%$ by volume of a $0.3-\mathrm{m}$ lift (Utah Department of Environmental Quality, 1995, p. 14). In practice, waste exceeding these criteria are mixed with native soil to reduce the debris content of a lift.

The mineralogy and chemistry of the native soil used to construct the liner and radon barrier cap is dominated by carbonates ( $4 \%$ dolomite, $8 \%$ calcite, and $53 \%$ aragonite). Clays are secondary ( $2 \%$ kaolinite, $1 \%$ illite, $15 \%$ smectite), and feldspars and quartz are relatively minor constituents (2\% plagioclase, $3 \% \mathrm{~K}$-feldspar, and $12 \%$ quartz). The analysis was provided to Envirocare by Applied Geotechnical Engineering Consultants, Inc., as part of an evaluation of the long-term permeability of the waste cell liner. The high proportion of carbonates contained in the native soil supported the selection of $\mathrm{CO}_{3}^{2-}$ as the most significant complexing ion for geochemical modeling. The addition of sodium tripolyphosphate as a flocculating agent indicated the need to include $\mathrm{PO}_{4}^{2-}$ in geochemical modeling. 
Table 3.1-1 Elemental composition for nominal soil

\begin{tabular}{cc} 
Element & $\begin{array}{c}\text { Weight percent of dry bulk } \\
\text { density }\left(1.6 \mathrm{~g} / \mathrm{cm}^{3}\right)\end{array}$ \\
\hline Carbon & 4.290 \\
Oxygen & 49.000 \\
Sodium & 0.680 \\
Magnesium & 0.600 \\
Aluminum & 7.100 \\
Silicon & 33.000 \\
Potassium & 1.360 \\
Calcium & 1.370 \\
Iron & 2.600 \\
\hline
\end{tabular}





\section{RELEVANT ANALOGS}

Naturally occurring processes have mobilized (dissolution and hydrogeochemical transport) and concentrated (sorption and precipitation) uranium and other elements to form ore deposits or other mineral segregations (concretions, clay-enriched soils, caliche layers, and fracture fillings). Some of these processes can serve as analogs for migration and concentration of uranium in an LLW facility. The size and shape of these naturally occurring deposits, as well as the time scale required to increase the concentration, place broad bounding limits on the geometry and time periods expected for concentration of uranium in an LLW facility. Literature describing uranium ore and soil-forming processes were reviewed to identify the processes and mechanisms responsible for producing natural mineral concentrations.

After completing the first-stage criticality safety analyses with realistic soil constituents, the sizes and shapes of the predicted critical masses were compared with the geometry of naturally occurring mineral deposits. This comparison was done to evaluate the potential for obtaining the calculated shape and mass of uranium in a waste cell. Planar shapes can be compared to development of enriched clay layers and cement fillings in sedimentary rocks, or salt beds of evaporative deposits, which are natural manifestations of mechanisms to increase concentrations. Planar shapes may be produced by vertical transport and subsequent immobilization of uranium in planar horizons created by variations in chemistry of the thin layers (lifts) making up the waste cell. Transport accompanying flow of surface water through a breech in the radon barrier cap can be anticipated to be dominantly vertical. Spherical shapes may be compared to concretionary nodules that have developed in subsoil horizons. Cylindrical shapes can develop as a result of mineral replacement of organic material accompanying petrification of trees. Spherical and cylindrical concentrations of uranium of sufficient size and density needed to attain nuclear criticality are considered to have a lower probability of formation in LLW facilities; both vertical and lateral transport of uranium would be required. Furthermore, the size of spherical concretions that are observed to develop in soil horizons are not large enough to include a critical mass of uranium, and the limitations on the size of debris included in the waste precludes formation of a cylindrical critical mass by replacement reactions. Spheres and cylinders are not modeled using the 1-D hydrogeochemical codes but were evaluated using nuclear criticality safety codes that treat infinite slabs, infinite cylinders, and spheres.

The following sections discuss uranium ore formation processes and aspects of the processes relevant to increasing uranium concentration in an LLW facility (4.1) and soil genesis processes (4.2) that concentrate minerals, their time scales of operation (4.2.1), and the implications of soil genesis for disposal of SNM in LLW facilities (4.2.2).

\subsection{ORE DEPOSITION}

A review by Kimberley (1978; Table 4.1-1) summarizes uranium deposit size and geometry. Planar ore deposits range from a few centimeters to several meters in thickness. The horizontal extent is typically kilometers.

According to Nash, Granger, and Adams (1981), sandstone is the most common host rock for economic deposits of uranium in the United States ( $95 \%$ of U.S. resources) and worldwide ( $41 \%$ of world's resources). These are generally deposits formed as a result of precipitation of uranium under reducing conditions, although examples of concentrations of oxidized uranium in sorption zones have also been found. Methane and sulfur are believed to be the most common reducing agents involved in uranium precipitation (see also Raffensberger and Garvin 1995). Methanogenic reduction was treated in hydrogeochemical modeling of precipitation under chemically reducing conditions (see Sect. 10.2.1). 
Table 4.1-1 Summary of ore body sizes ${ }^{\mathrm{a}}$

\begin{tabular}{lll}
\hline \multicolumn{1}{c}{ Thickness } & \multicolumn{1}{c}{ Extent } & \multicolumn{1}{c}{ Name } \\
\hline $36 \mathrm{~cm}$ & About $35 \mathrm{~km}$ & Basal Welkom, South Africa \\
$3 \mathrm{~cm}$ & N/A & Dominion, South Africa \\
$1-3 \mathrm{~m}$ & $13 \mathrm{~km}$ & Elliot Lake, Ontario \\
$>50 \mathrm{~cm}$ & $80 \mathrm{~km}$ & Serra De Jacobin, Brazil \\
$1.5 \mathrm{~cm}$ & Not continuous & Moeda, Brazil \\
Several meters & N/A & Mt. Eclipse, Australia \\
Several meters & $11 \mathrm{~km}$ & Fieberbrunn, Austria \\
$8 \mathrm{~m}$ & $6 \mathrm{~km}$ & Yellirrie, Australia \\
$5-10 \mathrm{~m}$ & $1 \mathrm{~km}{ }^{2}$ & Sabatini, Italy \\
$<15 \mathrm{~m}$ & N/A & Pene Blanca, Mexico \\
\hline
\end{tabular}

${ }^{\mathrm{a}}$ Source: Kimberley, 1978.

Nash, Granger, and Adams (1981) state that since oxygenation of the earth's atmosphere 2.2 billion years ago, the genesis of uranium ore deposits has been dominated by three geochemical processes: (1) oxidation of uranium to soluble U(VI) species that are transported in aqueous solutions, commonly as uranyl-carbonate complexes; (2) reduction of U(VI) by $\mathrm{C} \mathrm{S}^{2-}$, or $\mathrm{Fe}^{2+}$ species to U(IV) accompanied by precipitation of uraninite $\left(\mathrm{UO}_{2}\right)$ and coffinite $\left(\mathrm{USiO}^{4}\right)$; and (3) igneous and metamorphic differentiation resulting from the exclusion of uranium from the crystal structure of most rock-forming minerals. The first two processes are relevant to potential mobilization and increase in concentration of uranium in LLW disposal facilities such as the Envirocare facility. Uranyl-carbonate complexes are emphasized in this report because of their importance in ore-forming processes and as a component of "leachate" waters at the Envirocare facility.

Langmuir (1978) found that results of equilibrium calculations for uranium species in groundwater solutions typical of those in the Eocene Wind River Formation of Wyoming are dominated by the $\mathrm{UO}_{2}\left(\mathrm{HPO}_{4}\right)_{2}{ }^{2-}$ complex in the $\mathrm{pH}$ range of 4 to 7.5 when even small amounts $(0.1 \mathrm{ppm})$ of $\mathrm{PO}_{4}{ }^{2-}$ are present. The same groundwater compositions are in general dominated by uranyl-carbonate complexes for $\mathrm{pHs}$ higher than 7.5. In the presence of cations, such as $\mathrm{Na}^{+}, \mathrm{K}^{+}, \mathrm{Ca}^{2+}, \mathrm{Mg}^{2+}, \mathrm{Cu}^{2+}$, and $\mathrm{Fe}^{2+}$, the stability of uranyl complexes decreases and uranyl minerals precipitate. These uranium minerals form a series of decreasing solubility: carbonates $>$ sulfates $>$ phosphates and arsenates $>$ silicates $>$ vanadates. Uranyl ions are also removed from solution by sorption or coprecipitation from dilute solutions by silicate gels, clays, zeolites, iron hydroxides, and oxyhydroxides.

Nash, Granger, and Adams (1981), in summarizing the interaction of uranium with organic materials, state that although low concentrations of uranium $(<100 \mathrm{ppb})$ can be dissolved in the presence of humic and fulvic acids, higher uranium concentrations $(1000 \mathrm{ppm})$ promote precipitation of uranyl humates and fulvates from neutral or weak acid solutions. Andreyev and Chumachenko (1964) note that in environments containing abundant humic material and $\mathrm{H}_{2} \mathrm{~S}$, the organic matter will initially concentrate uranium by adsorption, and, subsequently, the uranium is reduced by the combined effects of $\mathrm{H}_{2} \mathrm{~S}$ and organic matter. 
Nash, Granger, and Adams (1981) describe the genesis of sandstone-type uranium deposits that may serve as one analogue for the increase in concentration of uranium at LLW facilities. Sandstone-type deposits are hosted by sandstones created by the deposition of fine-to-medium grain sands in rivers and lakes adjacent to eroding mountains. The resulting sedimentary layers are porous and permeable. These sandstones typically contain organic matter and fossilized wood that reflect rapid burial and preservation under anaerobic conditions below the groundwater table. Important physical and chemical factors controlling the deposition of uranium from groundwater solutions in these sedimentary units are (1) permeability of the sediments, (2) the presence of adsorptive constituents such as coalified wood, humic material, and titanium oxides in the sediments, and (3) reducing agents such as carbonaceous matter and sulfur species produced by biogenic sulfate reduction or partial oxidative destruction of sulfide minerals (pyrite-marcasite). The most important ore minerals are uraninite $\left(\mathrm{UO}_{2}\right)$, coffinite $\left(\mathrm{USiO}_{4}\right)$, and uraniferous organic matter composed of reduced uranium, $\mathrm{U}(\mathrm{IV})$. Ore bodies are typically tabular, sheetlike, or tubular and are bounded by the original sedimentary layers of the host sandstone. In one minor variety of sandstone-type uranium ore deposits, uranium is apparently sorbed as U(VI) by iron hydroxides, zeolites, or clays.

The physical and chemical factors described previously exist in part at the Envirocare site. The waste materials in currently active cells contain dark soils (suggesting the presence of organic matter) and can contain a variety of debris (including wood). Anaerobic conditions may be imposed when the waste cell is capped by the compacted soil radon barrier and subsequent bacterial activity produces $\mathrm{CH}_{4}$. The permeability of the waste materials is significantly less than for a porous sand because of the average grain size of waste soils and compaction that accompanies waste disposal. The existence of naturally occurring uranium ore deposits formed as a result of U(VI) sorption is an important natural analog that is evaluated with respect to the concentration of uranium at the Envirocare facility.

Another type of uranium ore deposit described by Nash, Granger, and Adams (1981) is associated with calcrete (caliche). Calcrete is gravel, sand, or desert debris cemented by porous calcium carbonate. Calcrete develops below the ground surface in response to solution transport of calcium carbonate during alternating wet and dry cycles. When fully developed, a calcrete layer may be more than $15 \mathrm{~cm}$ thick and is impervious to further groundwater flow. Host rocks for the calcrete uranium deposits are lenticular bodies of alluvium, soil, or detritus cemented by carbonate and other minerals. Uranium, usually as carnotite $\left[\mathrm{K}_{2}\left(\mathrm{UO}_{2}\right)_{2} \mathrm{~V}_{2} \mathrm{O}_{8} \bullet 3 \mathrm{H}_{2} \mathrm{O}\right]$, is deposited in voids and fractures in calcrete and is disseminated in underlying clay-quartz-bearing rocks. Similar uranium deposits occur in salt lakes.

In Australia, economic calcrete uranium deposits occur in Quaternary or modern playa lakes or river trunk valleys (Mann and Deutscher 1978) in areas of internal drainage where evaporation exceeds rainfall. In these environments, carnotite precipitates where groundwater flow is restricted by barriers and is caused to move upward, becoming oxidized or mixing with deeper groundwater that contains reducing agents [i.e., vanadium (IV)]. Carnotite precipitates when vanadium is oxidized to $\mathrm{V}(\mathrm{V})$ and/or mixed with a solution containing U(VI). An alternate mechanism for carnotite precipitation in calcrete is advocated by Hambleton-Jones and Toens (1978), who believe that carnotite precipitates above the water table in response to upward diffusion caused by evaporative soil suction accompanied by dissociation of uranyl complexes. The groundwater solutions are undersaturated with respect to carnotite, but metastable nucleation on montmorillonite is postulated. The discussion of carnotite precipitation is included here as an example of uranium mineralization associated with calcrete layers in natural systems. Carnotite precipitation was not modeled because vanadium is not reported as a constituent of leachate water at the Envirocare facility. However, the disposal of uranium mill tailings (or similar waste, e.g., from Formerly Utilized Sites Remedial Action Program sites) and fissile uranium materials in the same disposal cell could provide the chemical constituents required for carnotite precipitation. 
The development of calcrete layers is discussed in Sect. 4.2, which describes soil genesis processes (movement of soluble components in soils, such as calcium carbonate and calcic horizons) and provides insight from studies of natural soils concerning the physical conditions and time required for generation of calcium carbonate concentrations in soils.

The Oklo uranium deposits in the Gabon Republic were the site of a natural fission reactor 2 billion years ago. Cowan (1976) summarizes the isotopic and geochemical investigations that led to the discovery of this natural fission reactor. Nash, Granger, and Adams (1981) categorize the uranium deposits at Oklo as related to unconformity-type deposits. This type of ore probably formed in many stages, spanning more than a billion years, and its genesis is complex. The long history of ore body formation and the hydrothermal processes involved preclude the Oklo deposits from consideration as a natural analog for the mobilization and increase in concentration of uranium at an LLW disposal facility. However, characteristics of the Oklo deposits and the interpreted operational history of natural fission reactors do provide important implications for nuclear criticality in an LLW facility. A descriptive scenario of a critical event(s) and the magnitude of the event at a radioactive waste facility that has been compared to nuclear criticality at Oklo is provided in Apps et al. (1983).

Magnitude of a critical event. The attainment of a critical configuration may be expected to be a slow process resulting from a gradual accumulation of fissile material. To achieve criticality, a flow of water must be introduced into the repository. This water is necessary to move the fissile nuclides and to moderate and reflect neutrons. A system approaching criticality will produce energy at an increasing rate, and this will cause the temperature and pressure in the critical region to increase. When the pressure exceeds the hydrostatic gradient of the local formation, the influx of water will cease and the reactor will go subcritical. The maximum temperature that can be reached is the saturation temperature at the hydrostatic pressure in the repository. A temperature in excess of this would evaporate the water from the critical region.

The power level limit is that which maintains these limiting temperature and pressure conditions. The critical system is thus maintained in a quasi-steady-state condition. Consequently, an explosive reaction, like that associated with the rapid accumulation of fissile material and moderator, is not possible. The event would be more like that which occurred at Oklo.

For shallow burial, such as that provided by the Envirocare waste cells, the limiting temperature and pressure conditions are those that produce saturated steam from modified rainwater entering the waste. These conditions are essentially $\mathrm{P}=100 \mathrm{kPa}(1$ atmosphere $)$ and $\mathrm{T}=100^{\circ} \mathrm{C}$. The Oklo reactor may have operated at $\mathrm{P}=8000 \mathrm{kPa}$ ( 80 atmospheres) to $100 \mathrm{MPa}\left(1000\right.$ atmospheres) and $\mathrm{T}=400$ to $700^{\circ} \mathrm{C}$ in a high-grade ore zone estimated to contain greater than $800 \mathrm{~m}^{3}$ of $70 \%$ uranium (Brookins, 1979).

Another factor limiting applicability of the Oklo natural reactor to disposal sites is that the estimated ${ }^{235} \mathrm{U}$ concentration is many times higher than disposal limits or practices. For example, 1.9 million $\mathrm{g}^{235} \mathrm{U}$ at $\mathrm{Oklo}$ is estimated to be present in $800 \mathrm{~m}^{3}$ (or $2400 \mathrm{~g} / \mathrm{m}^{3}$ ). At the Envirocare facility, the disposal limit is $6 \mathrm{~g} / \mathrm{m}^{3}$ (or $0.0006 \mathrm{~g} / \mathrm{cm}^{3}$ ) and disposal practices are estimated to be on the order of $0.03 \mathrm{~g} / \mathrm{m}^{3}$, both well below Oklo concentrations.

Alteration of uraninite $\left(\mathrm{UO}_{2}\right)$ at the Nopal I uranium deposit in the Pena Blanca District of Mexico has been compared by Pearcy et al. (1994) to degradation of spent fuel in the proposed Yucca Mountain, Nevada, highlevel nuclear waste repository. Two features of secondary mineralization at Pena Blanca, Mexico, suggested that uranium silicates should be included in the hydrogeochemical modeling conducted for this evaluation: (1) the alteration of uraninite $\left(\mathrm{UO}_{2}\right)$ having a low trace element content in an oxidizing environment above the water 
table and (2) the presence of uranium silicate phases as secondary minerals. Soddyite $\left[\left(\mathrm{UO}_{2}\right)_{2} \mathrm{SiO}_{4} 2 \mathrm{H}_{2} \mathrm{O}\right]$ was used as a model for uranium silicates.

\subsection{SOIL ALTERATION}

The following discussion of soil-forming processes is provided to introduce the reader to relevant chemical and physical processes and the probable periods of time required to modify the chemistry and physical configuration of engineered soil caps and underlying waste at the Envirocare facility. The soil-forming or modifying processes that can be anticipated to take place in a waste cell include those resulting from biocolonization, physical changes that control the influx of water, and chemical changes that affect the transport of uranium.

Soil-forming processes operate at highly variable rates that are largely dependent on interactions of soil parent material with climate. The soil profile is the product of a net integration of various processes during hundreds to many thousands of years. Five basic factors control development of a soil and the associated chemical, physical, and mineralogical properties: parent material, relief, climate, biology, and time (Wilding, Smeck, and Hall, 1983a and 1983b).

\subsubsection{Development of Chemical Horizons}

The development of chemical horizons in subsoils may be analogous to processes of uranium mobilization and immobilization in waste cells.

A way to visualize soil genesis is to consider soil, at a given location in the landscape, as a chromatographic column with rainfall as the fluid medium. At time $=0$, the column is filled with parent material, which may be quite uniform in composition or very heterogeneous or even stratified. In a humid environment where water is available for leaching, visible changes occur that can be observed within less than 50 years. One of the earliest changes is the addition of organic matter to the soil surface and to the upper soil via root mass. This produces the genetic " $A$ " horizon, which is defined as the surficial soil that has been darkened by organic matter. As time proceeds in a leaching system, soluble components or very fine clay particles are translocated or deleted from the soil column. In the humid parts of the United States, which have net leaching, a clay-enriched subsoil "B" horizon forms within 1800 to 2000 years. As time continues, and without climate changes that alter the basic soil-forming process, soil horizons become more visually evident and thicker. Subsoil horizons move downward into the column as time increases, as long as surface geomorphic stability exists or until a steady state is reached. At depth, saturated water flow becomes channelized along preferred pathways. This movement of water causes increased chemical weathering and the subsequent translocation of soluble components deep into the soil; while in those areas without water movement or with unsaturated water flow, little transport occurs (Wilson et al., 1991; Jardine, Jacobs, and Wilson, 1988 and 1990; Luxmoore et al., 1990).

Gile, Peterson, and Grossman (1966) started an intensive study of how carbonate moves in soils and how long it takes for carbonate to be either removed or translocated to certain depths to form carbonate-enhanced genetic soil horizons. These authors identified several stages that describe the movement and subsoil accumulation of calcium carbonate:

Stage 1: Scattered grain coatings in gravely soils and filaments in fine-grained soils 


\section{Relevant Analogs}

Stage 2: Carbonate nodules separated by lower carbonate content soil

Stage 3: Subsoil horizon of accumulation plugged throughout

Stage 4: An indurated laminar horizon formed above the plugged horizon

While working on the Desert Project located near Las Cruces, New Mexico, Gile, Hawley, and Grossman (1970) were able to correlate the stages of subsoil carbonate accumulations with dateable geomorphic surfaces. The following general time frame has been established on the basis of the Desert Project:

Stage 1: $<1000$ to about 5000 years

Stage 2: 5000 to 15,000 years

Stage 3: $>15,000$ years

Stage 4: $>100,000$ years

Gile (1995) estimated that the average rate of carbonate accumulation was about $5.1 \mathrm{~kg} / \mathrm{m}^{2}$ per 1000 years.

The formation of clay-enriched subsoil horizons has been studied for many years. While studying soils in Pennsylvania, Bilzi and Ciolkosz (1977) found that between 2000 and 3000 years were required on a stable geomorphic surface and in noncalcareous parent materials for processes of soil genesis to translocate enough clay particles from surface soil horizons to form a detectable subsoil clay-enriched horizon. Cremeens (1995) reported the results of a study of soil genesis on a 2100-year-old Native American mound in southwest West Virginia. On the geomorphically stable mound crest, soil genesis had produced horizons to a depth of 0.75 to $1.0 \mathrm{~m}$. He found that very little clay movement took place during 2100 years. Cremeens also documented the presence of redoximorphic features in the mound, including both areas depleted in iron-manganese and areas of concentration increase. He also found iron-manganese nodules, but these may have been inherited from the older alluvium used to construct the mound.

\subsubsection{Implications of Soil Alteration in LLW Disposal Facilities}

Factors that may accelerate soil genesis processes include the following.

1. Rainfall will eventually infiltrate into a compacted surface cap, resulting in subsurface transport and initiating soil genesis/modification processes. LLW mound sideslopes are subject to accelerated rates of erosion. Impervious caps on LLW mounds eventually crack or otherwise become breached. Impervious caps greatly increase the rate of erosion, especially on lower sideslopes, because all rainfall must flow off.

2. LLW must be compacted to the same extent as the final impervious cap. If not, differential settlement of the waste will occur as well as eventual settlement of the cap, resulting in cracks forming or in the ponding of water, reducing the time before water penetrates.

3. Rates of infiltration and alteration may be slow, on the order of thousands of years. 


\subsection{SUMMARY}

The evaluation of natural mineral concentration processes (ore deposit formation and soil genesis) places constraints on the shape and size of zones of increased uranium concentration in LLW facilities and on the time scale of the chemical and physical concentrating processes. Processes that form ore-deposit grade concentrations of uranium are dominated by precipitation reactions, but chemical sorption is also a plausible mechanism for increasing concentrations.

Under present climatic conditions, the high evaporation-transportation rates relative to rainfall accumulation at the Utah site will limit the depth of carbonate accumulation to less than $1 \mathrm{~m}$ below the top of the waste cell (Jenny and Leonard, 1934). Therefore, in the event that uranium and calcium carbonate accumulate in sufficient quantity to form a subsoil horizon greater than $15 \mathrm{~cm}$ thick (stage 3 subsoil carbonate accumulation, $>15000$ years), the top $1 \mathrm{~m}$ of waste soil fill will have an insufficient uranium inventory to produce a critical mass of ${ }^{235} \mathrm{U}$. In this same environment, spherical nodules greater than a few centimeters in diameter are unlikely to form during accumulation of carbonates in the top $1 \mathrm{~m}$ of the waste cell. Subsequent analysis will show that this dimension is too small for spherical shapes to form a criticality safety concern. The infinite cylinder might be postulated to form by chemical reduction and replacement of organic material such as wood. The state of Utah license for Envirocare limits the size of debris to less than $25 \mathrm{~cm}$ in at least one dimension and no longer than $2.4 \mathrm{~m}$ in any dimension. This limit will minimize the potential for uranium accumulation by chemical replacement of carbonaceous material because subsequent analysis will show at least $20.8 \mathrm{~cm}$ diam or greater are needed for criticality safety concern.

The evaluation of ore deposits and mineral-concentrating processes operating during soil genesis provides insight concerning the general processes and mechanisms that are operating to produce mineral concentrations. However, each ore deposit or mineral concentration has site-specific characteristics that require a generic set of analytical tools to be applied to understand the details of its genesis. In the same manner, a set of generic tools must be applied to evaluate the migration and increase in concentration of SNM in a waste disposal cell. 



\section{SCENARIO DEVELOPMENT}

SNM in contaminated soils that are buried and not contained or protected from meteorological, chemical, and geological influences could migrate and subsequently concentrate at sites of natural opportunity (adsorption zones, reducing zones, or zones of low permeability that result in a concentration of perched water) within the buried media. Though such migration and increase in concentration can occur laterally, the gravity-driven flow of moisture and chemicals through the buried media is expected to be vertically downward under conditions of transient saturation. For some circumstances where disposal of permitted concentrations of SNM occurs by burial, potentially critical areal densities of SNM may be predicted if the mass of SNM in the vertical profile of the contaminated soil migrates to the floor of waste cells or other natural heterogeneous features. The redistributed SNM could concentrate into a spherelike region because of some chemically extractant material or a void region permitting the influx of solutions containing SNM. Another assumption could be that the location of concentrated material along the intersection of a burial-cell wall with the burial-cell floor forms a cylinderlike region. The last assumed simple geometry results from the downward migration and increase in concentration of SNM into a generally horizontal slab. The horizontal slab geometry was produced by 1-D hydrogeochemical modeling of vertical flow in a column. Spherical and cylindrical geometry cannot be formed using a 1-D hydrogeochemical model.

Material can be concentrated into a semirandom geometry that is dependent upon the waste matrix geometry. However, information concerning the details of geochemistry and geometry of the waste matrix typically will not be available. Therefore, reasonable parameters must be determined that may lead to increases in concentration, given existing license conditions, and bounding models must be approximated for performing nuclear criticality calculations.

Hydrogeochemical modeling and criticality safety assessment modeling were conducted over a range of parameters to evaluate the likelihood of each of the outcomes given in Sect. 1.5. The parameters considered in these analyses reflect the range of possible parameter values for hydrologic and geochemical conditions at the LLW disposal sites where soils are nonnative and for which little geochemical or hydrologic data are available.

Hydrogeochemical modeling considered two events. First, the uranium present in the soil must be mobilized. Second, the uranium moves to a new location where it is immobilized and concentrated. These processes were modeled in a 10-m-long simulated column (Fig. 1.5-2). Column length was determined from probable waste cell construction.

- The study assumed vertical infiltration of water through a 10-m-deep cell of uranium-contaminated soil.

- The uranium was considered to be initially distributed uniformly throughout the soil profile; both adsorption and precipitation were considered to be the mechanisms for the initial association of uranium with the soil matrix.

- Mobilization of sorbed uranium was modeled as a (slug) volume of water (rain events) entering through the cell cap. The range of aqueous chemistry ( $\mathrm{pH}$, ionic strength, and composition) of the water entering the top of the simulated column was selected on the basis of the assumption that rainwater infiltrating through the 2-m-thick cap over the cells reached chemical equilibrium with the minerals in the cap before entering the soil column. The validity of that assumption was tested by comparing calculated equilibrium concentrations to an analysis of the chemistry of leachate at the Envirocare site. 
Scenario Development

- The simulated column contained one or several zones of altered chemistry that could serve as a zone for an increase in uranium concentration, including

- a single zone at the bottom of the column with a greater abundance of adsorption sites than the rest of the soil column;

- $\quad$ multiple zones of higher sorption distributed at different levels within the column; or

- $\quad$ a reducing zone at the bottom of the column.

The zonation modeled is not based on observed site conditions but is considered an evaluation of configurations of maximum uranium concentration. A zone of higher sorption at the base of a cell could be the result of material used as a soil. Thickness and sorption capacity of liners can be determined for specific sites. Multiple zones of sorption could be the result of variable chemical and physical properties of waste disposed of in different lifts (layers) within the waste cell. Formation of redox zones is known to occur in aquifers, but there have been few studies of landfill zonation. Reducing zones are typically associated with degradation of organic waste (Christensen et al., 1994; Baedecker, Cozzarelli, and Eganhouse, 1993; Lyngkilde and Christensen, 1992; and Baccini, 1989), which is unlikely to be a significant factor in LLW facilities. These zones can be on the order of meters thick. Redox gradients of $40 \mathrm{mV} / \mathrm{m}$ have been observed in groundwater (Barcelona et al., 1989).

Chemical changes and parameter values considered in these simulations are discussed in more detail in subsequent sections. 


\section{MOBILIZATION AND IMMOBILIZATION MECHANISMS}

\subsection{MOBILIZATION MECHANISMS}

Mobilization of uranium can occur as a result of ligand complexation, and this can be enhanced under conditions of subneutral $\mathrm{pH}$ and high $\mathrm{Eh}$. Complexation by $\mathrm{CO}_{3}{ }^{2-}$ will be considered in detail and can be considered as a surrogate for other complexing agents such as organic ligands, although different concentrations of organic ligands may be required to bring about a similar mobilizing effect. Like carbonate, organic ligands are postulated to increase the solubility of uranium minerals and enhance the transport of uranium (because of mobile complexed uranium cations). For example, natural organic matter (NOM) has been shown to complex actinides and promote their transport in groundwater downgradient of transuranic disposal cells at ORNL in Oak Ridge, Tennessee (McCarthy, Marsh, and Tipping, 1995). At the same site, lanthanides-which have a chemistry similar to many actinides - injected in a groundwater tracer experiment were complexed with NOM and moved rapidly downgradient at rates similar to those of nonreactive tracers (Knowles et al., 1995). Anthropogenic organic complexants disposed in shallow soil trenches at ORNL also mobilized cobalt and uranium, and the uranium-EDTA complex was recovered in monitoring wells outside the disposal cell (Means, Crerar, and Duguid, 1978). The assumption that organically complexed uranium will be transported in a manner similar to carbonate complexes is a worst-case scenario. The NOM-uranium complex can possibly be retarded as a result of adsorption of NOM on the soil particles, thus reducing the extent of uranium migration (McCarthy, Marsh, and Tipping, 1995).

The eluant in the model column was based on leachate chemistry at disposal sites and at other landfills where more detailed waste chemistry is available. The site data were obtained from reports on groundwater sampling or from equilibration of water with the matrix. The production of $\mathrm{CO}_{2}$, caused by microbial activity would be important in potential uranium complexation and was estimated from other sites. A range of concentrations was tested because of uncertainty in parameter estimates and model sensitivity. For example, knowing if a particular range of $\mathrm{pH}$ and ionic strengths were uniquely effective in uranium mobilization would be useful.

Colloids have also been considered, at least conceptually, as a potential transport mechanism. However, a preliminary analysis indicated that colloid transport would not be a significant mobilization mechanism, especially under oxidizing conditions. Colloid transport is important only for highly insoluble or strongly adsorbing species whose transport as a dissolved species is limited. Because of the high solubility of the carbonate complex of uranium, colloids would not contribute significantly to transport under oxidizing conditions. Colloids could, however, contribute to some vertical spreading of uranium under reducing conditions. Furthermore, colloids may play a much more significant role for other SNM such as plutonium, whose aqueous solubility may limit transport of the dissolved species.

\subsection{IMMOBILIZATION MECHANISMS}

Immobilization of uranium in zones of altered chemistry or porosity can occur through a variety of mechanisms, including adsorption, precipitation, filtration, and evaporation, and it can occur with and without changes in aqueous chemistry of the advecting fluid ( $\mathrm{pH}, \mathrm{Eh})$. Although fundamental understanding of transport processes suggests that these are reasonable mechanisms, the quantitative effect of these processes on the increase in concentration of uranium cannot be predicted a priori. The zones of altered chemistry were modeled as zones within the column that have a different sorption capacity or as reducing zones. The modeling was designed with adsorption as the primary potential mechanism for increasing the concentration under oxidizing conditions 


\section{Mechanisms}

(although the significance of precipitation under oxidizing conditions was considered). Precipitation was emphasized as the potential mechanism for increasing concentration under reducing conditions.

Filtration and evaporation mechanisms were not formally modeled. The potential importance of these processes is addressed in the discussion of natural analogs of increasing uranium concentration (Sect. 4). 


\section{ANALYTICAL APPROACHES}

Because nuclear criticality can exist over a broad range of ${ }^{235} \mathrm{U}$-contaminated soil parameters and because a broad range of hydrogeochemical processes can affect the concentration of ${ }^{235} \mathrm{U}$, both analytical approaches required the development of parametric surface responses to examine intersections of these surfaces that could mutually define parameter space that can potentially lead to nuclear criticality. In addition, other ${ }^{235} \mathrm{U}$ concentrations were evaluated to span less likely, yet credible, concentrations independent of the hydrogeochemical values.

\subsection{HYDROGEOCHEMICAL MODELING}

\subsubsection{Reactive Transport Modeling}

Uranium geochemistry is complex and requires a sophisticated modeling approach that considers simultaneous and interacting processes of complexation, sorption, and precipitation occurring under conditions of $\mathrm{pH}, \mathrm{Eh}$, ionic strength, and composition that vary over time and space (Langmuir, 1978; Toran, 1994). An increase in uranium concentration is postulated to result from sequential processes of mobilization of uranium by formation of soluble complexes, followed by immobilization of the soluble species by processes of adsorption and precipitation. Geochemical modeling can calculate the distribution of soluble, adsorbed, and precipitated uranium species under a given aqueous chemistry and mineral composition, but this type of modeling will not account for how the uranium moves and interacts with chemicals along a flow path; transport modeling is required to account for those processes. However, most transport codes do not account for detailed geochemical reactions but simply lump multiple geochemical processes into a term called the retardation factor. Because the retardation factor only slows transport and does not consider mobilization mechanisms or variable chemistry along a flow path, concentrations greater than initial conditions in solution cannot be obtained by using such a simplified approach.

Hence, a multispecies transport code was used to examine the speciation and transport behavior of uranium. A multispecies transport code models groundwater flow, chemical dispersion, and a suite of selected geochemical reactions. Reactive transport modeling has not yet reached the application stage in groundwater modeling. Most of the available codes are considered research codes (van der Heijde and Elnawaway, 1993; National Research Council, 1992; Mangold and Tsang, 1991), which are primarily used by the developers (or someone working closely with developers). Only a handful of examples exist of the use of these codes on problems based on real sites. Furthermore, reactive transport modeling is computationally intensive (Yeh and Tripathi, 1991a) because a full suite of geochemical calculations must be conducted at each node in the problem domain.

A parallelized version of a reactive transport code was used with the assistance of the code developers in setting up problems. PARSim (Arbogast, Dawson, and Wheeler, 1994) was developed by researchers from the Computational Mathematics Department at Rice University (the group has recently moved to the University of Texas at Austin). PARSim was developed as an efficient flow and transport model designed to run on a supercomputer configured with a parallel processor architecture to speed simulations having repetitive calculations. A chemical reaction code, KEMOD, (Yeh et al., 1995) based on MINTEQ was coupled to PARSim to create a multispecies reactive transport code. The user defines which chemicals, complexes, and solids are to be considered by the model. For the flow and transport code, the domain is divided into a finite element mesh. 
At every node in the mesh, the full set of selected geochemical reactions are modeled. All parallel runs were conducted on a 66-processor Intel Paragon supercomputer at ORNL. Run times were typically 1 to 2 hours.

Results from PARSim have been compared to results from other multispecies transport codes (HYDROGEOCHEM, Yeh and Tripathi, 1991b; DYNAMIX, Liu and Narasimhan, 1989) to test its reliability. Analytical solutions do not exist for this type of problem; therefore, the only way to test a code is to compare its results with those produced by other codes. PARSim matched trends well and matched absolute concentrations in most cases. Some discrepancies occurred for processes that were not used in this modeling.

In addition to PARSim, geochemical modeling without transport was performed using the U.S. Geological Survey code PHREEQE (Parkhurst, Thorstenson, and Plummer, 1982), which is a well-established code for modeling chemical speciation and reactions. This modeling was used to establish initial conditions and identify important complexes and appropriate phases for the precipitation. Stability diagrams (as discussed in Sect. 7.1.2) were also used to select geochemical phases to model. PHREEQE was especially important for consideration of redox reactions, where it was used as the primary tool for chemical reactions. Redox reactions occur over such a wide range of concentrations that the reactive flow and transport models frequently become unstable. PHREEQE could thus be used more efficiently than a full multispecies transport code. Although this model does not include transport or mixing caused by hydrodynamic dispersion, the key features of the scenario are adequately captured by this approach, and any error introduced by this simplification is small relative to other model uncertainties.

In summary, PARSim was used to model mobilization and transport of uranium as well as immobilization under oxidized conditions. PARSim was again used for mobilization studies under initially oxidized conditions, but PHREEQE was used to determine reactions in the reduced zones.

\subsubsection{Solubility/Phase Definition}

The study used phase diagrams and geochemical modeling with PHREEQE to select key components and minerals in the model (Table 7.1-1). Results of this modeling and other modeling indicates only certain species dominate. A variety of possible species was included to cover changing geochemical conditions, but some limitations had to be imposed on the number of species to prevent the model convergence time from becoming prohibitive.

Dominant uranium complexes of hydroxyl and carbonate have been identified by Langmuir (1978) and Tripathi (1983). The dominant uranyl-phosphate complex at circum-neutral $\mathrm{pH}$ has been identified by Tripathi (1983), Nash, Granger, and Adams, 1981, and Lee, Elless, and Hoffman, 1993, as $\mathrm{UO}_{2}\left(\mathrm{HPO}_{4}\right)_{2}{ }^{2-}$. Several solid phases were considered in modeling, as suggested by stability diagrams. The oxidized uranium minerals modeled included rutherfordine $\left(\mathrm{UO}_{2} \mathrm{CO}_{3}\right)$, and for selected runs, soddyite $\left[\left(\mathrm{UO}_{2}\right)_{2} \mathrm{SiO}_{4} 2 \mathrm{H}_{2} \mathrm{O}\right]$ and U-hydroxide $\left[\mathrm{UO}_{2}(\mathrm{OH})_{2}\right.$-beta]. Reliable thermodynamic data could not be obtained for some uranium minerals \{e.g., uranophane $\left.\left[\mathrm{Ca}\left(\mathrm{H}_{2} \mathrm{O}\right)_{2}\left(\mathrm{UO}_{2}\right)_{2}\left(\mathrm{SiO}_{2}\right)_{2}(\mathrm{OH})_{6}\right]\right\}$. For the reduced mineral phase, uraninite $\left(\mathrm{UO}_{2}\right)$ was the selected phase (Fig. 7.1-1), although others were considered in preliminary calculations. Uraninite is a frequently cited mineral in ore zones and precipitates readily under modeled conditions.

For other complexes, standard carbonate and hydroxyl species were considered. Calcite $\left(\mathrm{CaCO}_{3}\right)$ and hydroxyapatite $\left[\mathrm{Ca}_{5} \mathrm{OH}\left(\mathrm{PO}_{4}\right)_{3}\right]$ were selected as solubility controls for $\mathrm{CO}_{3}{ }^{2-}$ and $\mathrm{PO}_{4}{ }^{2-}$, respectively.

NUREG/CR-6505, Vol. 1 
Table 7. 1-1 Chemical species considered in sensitivity analysis ${ }^{\mathrm{a}}$

\begin{tabular}{|c|c|c|c|c|c|c|c|}
\hline \multirow[t]{2}{*}{ Species } & \multirow[t]{2}{*}{$\log K$} & \multicolumn{6}{|c|}{ Stoichiometry } \\
\hline & & Component & Value & Component & Value & Component & Value \\
\hline $\mathrm{H}^{+}$ & 0 & $\mathrm{H}$ & & & & & \\
\hline $\mathrm{CO}_{3}^{-2}$ & 0 & $\mathrm{CO}_{3}$ & & & & & \\
\hline $\mathrm{Ca}^{+2}$ & 0 & $\mathrm{Ca}$ & & & & & \\
\hline $\mathrm{UO}_{2}^{+2}$ & 0 & $\mathrm{UO}_{2}$ & & & & & \\
\hline $\mathrm{Si}(\mathrm{OH})_{4}$ & 0 & $\mathrm{Si}(\mathrm{OH})_{4}$ & & & & & \\
\hline $\mathrm{HPO}_{4}^{-2}$ & 0 & $\mathrm{HPO}_{4}$ & & & & & \\
\hline $\mathrm{SOH}$ & 0 & SO-H & & & & & \\
\hline $\mathrm{OH}^{-}$ & -14 & $\mathrm{H}$ & & & & & \\
\hline $\mathrm{CaCO}_{3}(\mathrm{aq})$ & 3.22 & $\mathrm{Ca}$ & 1 & $\mathrm{CO}_{3}$ & 1 & & \\
\hline $\mathrm{CaHCO}_{3}^{+}$ & 11.43 & $\mathrm{Ca}$ & 1 & $\mathrm{CO}_{3}$ & 1 & $\mathbf{H}$ & 1 \\
\hline $\mathrm{CaHPO}_{4}(\mathrm{aq})$ & 2.74 & $\mathrm{Ca}$ & 1 & $\mathbf{P}$ & 1 & & \\
\hline $\mathrm{CaOH}^{+}$ & -12.85 & $\mathrm{Ca}$ & 1 & H & -1 & & \\
\hline $\mathrm{UO}_{2} \mathrm{OH}^{+}$ & -5.3 & $\mathrm{UO}_{2}$ & 1 & H & -1 & & \\
\hline$\left(\mathrm{UO}_{2}\right)_{2}(\mathrm{OH})_{2}^{+2}$ & -5.68 & $\mathrm{UO}_{2}$ & 2 & $\mathrm{H}$ & -2 & & \\
\hline$\left(\mathrm{UO}_{2}\right)_{3}(\mathrm{OH})_{4}^{+2}$ & -11.88 & $\mathrm{UO}_{2}$ & 3 & $\mathrm{H}$ & -4 & & \\
\hline$\left(\mathrm{UO}_{2}\right)_{3}(\mathrm{OH})_{5}^{+}$ & -15.82 & $\mathrm{UO}_{2}$ & 3 & $\mathrm{H}$ & -5 & & \\
\hline$\left(\mathrm{UO}_{2}\right)_{4}(\mathrm{OH})_{7}^{+}$ & -21.9 & $\mathrm{UO}_{2}$ & 4 & $\mathrm{H}$ & -7 & & \\
\hline$\left(\mathrm{UO}_{2}\right)_{3}(\mathrm{OH})_{7}^{-}$ & -28.34 & $\mathrm{UO}_{2}$ & 3 & $\mathrm{H}$ & -7 & & \\
\hline $\mathrm{UO}_{2} \mathrm{CO}_{3}(\mathrm{aq})$ & 9.65 & $\mathrm{UO}_{2}$ & 1 & $\mathrm{CO}_{3}$ & 1 & & \\
\hline $\mathrm{UO}_{2}\left(\mathrm{CO}_{3}\right)_{2}^{-2}$ & 17.08 & $\mathrm{UO}_{2}$ & 1 & $\mathrm{CO}_{3}$ & 2 & & \\
\hline $\mathrm{UO}_{2}\left(\mathrm{CO}_{3}\right)_{3}^{-4}$ & 21.7 & $\mathrm{UO}_{2}$ & 1 & $\mathrm{CO}_{3}$ & 3 & & \\
\hline$\left(\mathrm{UO}_{2}\right)_{2} \mathrm{CO}_{3}(\mathrm{OH})_{3}^{-}$ & -1.18 & $\mathrm{UO}_{2}$ & 2 & $\mathrm{CO}_{3}$ & 1 & $\mathrm{H}$ & -3 \\
\hline $\mathrm{UO}_{2}\left(\mathrm{HPO}_{4}\right)_{2}^{-2}$ & 18.56 & $\mathrm{UO}_{2}$ & 1 & $\mathrm{HPO}_{4}$ & 2 & & \\
\hline $\mathrm{HCO}_{3}^{-}$ & 10.32 & $\mathrm{H}$ & 1 & $\mathrm{CO}_{3}$ & 1 & & \\
\hline $\mathrm{H}_{2} \mathrm{CO}_{3}(\mathrm{aq})$ & 16.67 & $\mathrm{H}$ & 2 & $\mathrm{CO}_{3}$ & 1 & & \\
\hline $\mathrm{H}_{3} \mathrm{PO}_{4}$ & 9.35 & H & 2 & $\mathrm{HPO}_{4}$ & 1 & & \\
\hline $\mathrm{SO}^{-}$ & -10.3 & SO-H & 1 & $\mathrm{H}$ & -1 & & \\
\hline $\mathrm{SOH}_{2}^{+}$ & 5.4 & SO-H & 1 & $\mathrm{H}$ & 1 & & \\
\hline SO-UOO $\mathrm{OH}^{+}$ & -7.1 & SO-H & 1 & $\mathrm{UO}_{2}$ & 1 & $\mathbf{H}$ & -2 \\
\hline $\mathrm{SOH}_{2}^{+}\left(\mathrm{UO}_{2}\right)_{3}(\mathrm{OH})_{7}^{-}$ & -31 & SO-H & 1 & $\mathrm{UO}_{2}$ & 3 & $\mathrm{H}$ & -8 \\
\hline Rutherfordine $\left(\mathrm{UO}_{2} \mathrm{CO}_{3}\right)$ & 14.4 & $\mathrm{CO}_{3}$ & 1 & $\mathrm{UO}_{2}$ & 1 & & \\
\hline Calcite $\left(\mathrm{CaCO}_{3}\right)$ & 8.48 & $\mathrm{Ca}$ & 1 & $\mathrm{CO}_{3}$ & 1 & & \\
\hline
\end{tabular}

${ }^{a}$ Source: Yeh and Tripathi, 1991b. 
Analytical Approaches

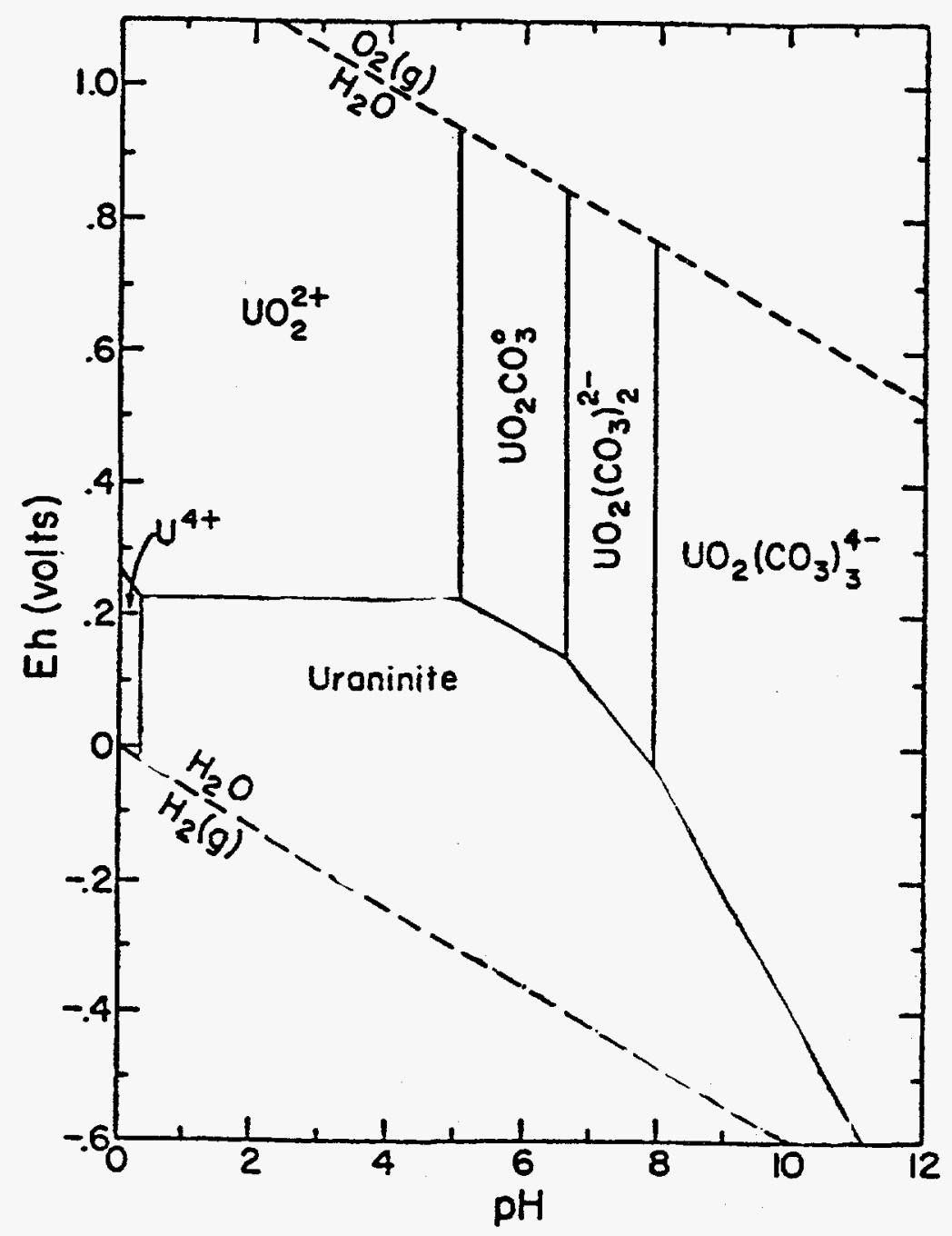

Figure 7.1-1 Eh-pH diagram for the $\mathrm{U}-\mathrm{O}_{2}-\mathrm{CO}_{2}-\mathrm{H}_{2} \mathrm{O}$ system at $25^{\circ} \mathrm{C}$ for $\mathrm{P}_{\mathrm{CO} 2}=10^{-2}$ atm. Uraninite, $\mathrm{UO}_{2}(\mathrm{c})$, solution boundaries are drawn at $10^{-6} M(0.24 \mathrm{ppm})$ dissolved uranium species. (After: Langmuir, 1978) 


\subsubsection{Sensitivity Analysis}

A sensitivity analysis was needed for this model because a large number of the parameters (e.g., concentrations of carbonate and uranium and abundance of sorption sites) could vary over a range of values. This uncertainty created a large number of conditions that needed to be considered to adequately evaluate the potential for increasing uranium concentration. The sensitivity analysis addresses the question of which parameters create the most variation in model output. A common method of conducting a sensitivity analysis is to change one parameter at a time while holding other parameters constant. This method may neglect parameter sensitivity if the constant parameters fix the system in a particular range.

To avoid creating gaps in the sensitivity analysis, all uncertain parameters were varied systematically to better analyze sensitivity to parameter ranges. A Latin Hypercube sampling selected parameter values for six uncertain parameters (see Sect. 9.1 on parameters for more details). The Latin Hypercube sampling maximizes the relationship between parameters because no value is selected more than once, but it also minimizes the total number of runs required (McKay, Beckman, and Conover, 1979). The number of runs should be at least five times the number of parameters tested. The Monte-Carlo-like set of runs that were created contained 40 simulations for 6 parameters. The results are analyzed by calculating the multivariate regression between parameters and a selected output variable (such as uranium concentration). A rank regression, which is more robust than a linear regression (Iman and Conover, 1979), was used.

\subsection{NUCLEAR CRITICALITY EVALUATION}

\subsubsection{Code Description and Validation}

The SCALE (1995) code system was used to calculate the $\mathrm{k}_{\text {eff }}$ of the designated systems. SCALE is a modular system of codes that provides criticality safety analysis sequences (CSAS) to calculate the neutron-multiplication factor of a system. Problem-dependent processing of the cross sections to account for temperature effects and resonance self-shielding are performed using the NITAWL and BONAMI codes. For this study, the XSDRNPM code was executed by the CSAS module to provide the $\mathrm{k}_{\text {eff }}$ values used in this study. XSDRNPM is a deterministic code that solves the Boltzmann equation for neutron transport in a 1-D system using a discrete-ordinates approach. SCALE was used because of its historic and recognized success in the performance of benchmark and applications analyses for licensing activities.

The stationary system of the SCALE codes used for this study and validation, CSAS, BONAMI, NITAWL, XSDRNPM, and KENO V.a, were created on May 30, 1995. The Brookhaven Evaluated Nuclear Data File B Version V point cross-section library, which was collapsed to a 238 neutron-energy group library (Greene et al., 1994), named REF01.XN238, was created on May 26, 1995, and resided on the same hardware platform as the SCALE suite of codes during the period of this study. The 238-energy group library was used because of its currency of evaluation, testing, and benchmarking. The hardware platform, the SCALE computational codes, and the 238-energy group library used were validated through the computation of verification and validation benchmarks involving ${ }^{235} \mathrm{U}$ systems before and after the evaluations performed for this study. The verification and validation benchmark calculations provided identical results for calculations performed both before and after the study, thereby demonstrating the stability of the software and data throughout the study. The bias and uncertainties of the benchmark calculations were within $\sim 0.5 \%$ of the experimental values; that is, the calculated 
Analytical Approaches

$\mathrm{k}_{e f f}$ of the 14 critical experiment benchmarks were between 0.9954 and 1.0064 . Results of the calculations are provided in Table 7.2-1. Note that the $\mathrm{k}_{\text {eff }}$ for some of the cases in Table 7.2-1 were obtained using the KENO V.a code, a code that uses the Monte Carlo approach to solve the Boltzmann transport equation for multidimensional systems.

Table 7.2-1 Computational benchmark results

\begin{tabular}{cc}
\hline XSDRNPM result filename & \multicolumn{1}{c}{$\mathbf{k}_{\text {eff }}$} \\
17CSB.OUTPUT $^{a}$ & 1.00350 \\
18CSB.OUTPUT $^{a}$ & 1.00639 \\
19CSB.OUTPUT $^{a}$ & 1.00316 \\
110CSB.OUTPUT $^{a}$ & 1.00453 \\
111CSB.OUTPUT $^{a}$ & 1.00129 \\
ORNL1.OUTPUT $^{a}$ & 0.998680 \\
ORNL2.OUTPUT $^{a}$ & 0.998468 \\
ORNL3.OUTPUT $^{a}$ & 0.995463 \\
ORNL4.OUTPUT $^{a}$ & 0.996905 \\
ORNL10.OUTPUT $^{a}$ & 0.997975 \\
KENO V.a result filename $^{a}$ & $\mathbf{k}_{\text {eff }} \pm$ sigma \\
OR260901.OUTPUT $^{b}$ & $1.0059 \pm 0.0014$ \\
OR260906.OUTPUT $^{b}$ & $1.0041 \pm 0.0012$ \\
ORFP2710R.OUTPUT $^{c}$ & $1.0025 \pm 0.0021$ \\
RFP2710U.OUTPUT $^{c}$ & $1.0047 \pm 0.0023$ \\
\hline
\end{tabular}

${ }^{a}$ See Brookhaven National Laboratory, 1974.

${ }^{b}$ See J. K. Fox, 1958.

${ }^{c}$ See R. E. Rothe, 1978.

\subsubsection{Analytical Approach}

The analytical approach used for the nuclear criticality evaluation was performed in two segments. The first segment was to evaluate the infinite-media multiplication constant, $\mathbf{k}_{\infty}$, of two fixed-density soil matrices having differing degrees of ${ }^{235} \mathrm{U}$ and water contents or densities within the soils. These results provided indications of the combinations of ${ }^{235} \mathrm{U}$, soil, and water that could support self-sustaining nuclear fission chain reactions in an

NUREG/CR-6505,

Vol. 1 
essentially infinite sea of material (i.e., $\mathbf{k}_{\boldsymbol{\alpha}} \geq 1.0$ ). The second segment involved examining three geometries that have relevance to the evaluation: spheres, cylinders of infinite length, and slabs of infinite extent. Conceptual configurations of the geometries are provided in Fig. A.1-1 of Appendix A. The evaluations of the infinite slabs approximate the effects of the ${ }^{235} \mathrm{U}$, contaminating the soillike waste and settling vertically onto a waste-cell floor, and are consistent with previous evaluations (Hopper et al., 1995) performed for reviewing LLW facilities.

The two waste matrices assumed for the evaluations were nominal soil and $\mathrm{SiO}_{2}$. The nominal soil was an approximation of soils reported by Sposito (1989) and Shacklette and Boerngen (1984). Before contamination with water and ${ }^{235} \mathrm{U}$, both waste matrices were assumed to have fixed densities of $1.6 \mathrm{~g} / \mathrm{cm}^{3}$, thereby leaving void space for variable densities of ${ }^{235} \mathrm{U}$ contaminant and water. For the nominal soil (N-S) cases, seven ${ }^{235} \mathrm{U}$ densities (i.e., grams of ${ }^{235} \mathrm{U} / \mathrm{cm}^{3}$ of soil) or concentrations (i.e., grams of ${ }^{235} \mathrm{U} / \mathrm{g}$ soil) were evaluated. Six different densities (i.e., $\mathrm{g} \mathrm{H}_{2} \mathrm{O} / \mathrm{cm}^{3}$ of soil) or concentrations (i.e., $\mathrm{g} \mathrm{H}_{2} \mathrm{O} / \mathrm{g}$ soil) of water were assumed for each of the seven ${ }^{235} \mathrm{U}$ concentrations. For the $\mathrm{SiO}_{2}$ soil (S-S) cases, $18{ }^{235} \mathrm{U}$ densities or concentrations were evaluated. Seven different water densities or concentrations were assumed for each of $7{ }^{235} \mathrm{U}$ densities or concentrations, and 13 different water densities or concentrations were assumed for each of $11{ }^{235} \mathrm{U}$ densities or concentrations.

\subsection{CRITICALITY CONSEQUENCES: DIRECT DOSE FROM RADIATION TRANSPORT}

\subsubsection{Calculational Models}

Direct-dose radiation transport calculations were performed to estimate the neutron and gamma radiation doses near the soil surface as a consequence of two postulated critical configurations at the Envirocare facility-one at near-minimum ${ }^{235} \mathrm{U}$ critical density and the other at the near-maximum ${ }^{235} \mathrm{U}$ density. Both were assumed to be large-diameter (i.e., $18 \mathrm{~m}$ ), disklike cylindrical deposits of overly water-moderated uranium in $\mathrm{SiO}_{2}$. Both configurations were selected so that they would be subcritical when void of the water moderation. Both configurations were vertically centered in a trench. Both configurations were constrained by the maximum allowable $5.7 \mathrm{~kg}$ of ${ }^{235} \mathrm{U}$ per $\mathrm{m}^{2}$ areal density in a disposal trench. The first postulated critical configuration was an 18-m-diam disk that was $2.5 \mathrm{~m}$ in thickness, which corresponds to a CF of about 3.6. The second postulated critical configuration was an 18 -m-diam disk that was $\sim 0.9 \mathrm{~m}$ in thickness, which corresponds to a CF of about 10.5. The calculations were performed using the DORT code (Rhoades and Childs, 1988), which solves the 2-D discrete-ordinates radiation transport equations and the SCALE 27-neutron/18-gamma group cross-section library. The code was utilized in a two-step procedure for computational efficiency. The first step solved an effectively 1-D criticality problem to obtain the magnitude and energy distribution of the neutrons and gamma rays leaking through the ground above the deposit. The second step solved the 2-D air-over-ground problem with the leakage source (a tabulation of the neutrons/gamma rays leaking from the ground) from the first step. This second step determines the population of neutrons/gamma rays both in the ground and at all modeled locations above ground. The specific doses were then read from the code output at locations corresponding to $1 \mathrm{~m}$ above the ground surface, directly over the center of the assumed deposit and $90 \mathrm{~m}$ away from the vertical centerline of the assumed deposit. 


\subsubsection{Estimate of Potential Fission Yields}

The actual number of fissions that occur (the so-called fission yield) is a difficult quantity to determine. The approach taken in this study was to assume that the concentration of fissile material occurs under wet conditions, followed by a dryout period in which the critical conditions are met, with event termination due to the evaporation of the full inventory of water. Using a widely accepted rule of thumb that $10^{17}$ fissions are required to remove $1 \mathrm{~L}$ water (G. Tuck, 1974), the amounts of water present under the various cases were used to estimate postulated fission yields. The resulting fission yield estimates were $4.1 \times 10^{21}$ and $2.8 \times 10^{21}$ fissions for the high and low concentrations, respectively. 


\section{ASSUMPTIONS}

The assumptions implicit in the approach to the problem are specified as follows. All models are simplifications of reality, and the processes not explicitly modeled in the simulations must be evaluated. Beneath each assumption the significant implications of the assumptions to the realism and general applicability of the results are identified in italics.

The flow-field was 1-D (simple in-one-end and out-the-other hydraulics).

One-dimensional flow neglects tortuous paths and reduces travel times. Concentration of uranium into a slab was the only configuration tested with the flow-field. One-dimensional flow requires vertical recharge, which may be limited in arid environments. Furthermore, uranium can be flushed out of the bottom of the column, reducing the mass available for concentration within the column. A corollary assumption is that any uranium leaving the engineered barriers of the disposal cell will disperse or be concentrated by mechanisms similar to those within the disposal cell. This assumption may require further examination, and the modeling here did not consider transport outside the disposal cell.

For the sensitivity analysis, uranium was disposed of at the maximum allowable concentration of ${ }^{235} \mathrm{U}$.

Lower disposal concentrations (such as those reported at the Utah site) require greater CFs to reach levels of concern. This relationship is essentially linear. The worst-case scenario was modeled with some additional runs at values reported from the Utah site.

The hydraulic conductivity was uniform (which resulted in assumed values for velocity, under saturated and unsaturated conditions).

Velocities had little effect on peak concentrations and were not the most important control; the possible range in travel times for variations in saturation are so extreme as to make heterogeneity an insignificant factor. That is, uncertainty in saturation conditions is the most important unknown variable in estimating travel times.

Unsaturated travel times can be estimated from consideration of saturated travel times.

This assumption creates one of the largest sources of uncertainty. Travel times increase greatly in unsaturated conditions, but how much to increase them is unknown because of uncertainty in unsaturated conditions.

Unsaturated concentrations can be approximated by a saturated model.

Some errors in the prediction of uranium concentration will occur because of different hydrodynamic dispersion and transient effects, but these are expected to be small compared to errors resulting from the uncertainty in saturation conditions.

Steady-state conditions were attained.

By limiting the model to a specified number of time steps, an early or late peak of uranium may have been missed. After evaluating this factor, only limited cases were found that require shorter or longer run times.

A fixed, stable reducing zone is assumed.

In reality, redox zones can change as a result of infiltrating water. Although sustained reducing conditions can occur, this was not evaluated, and thus the worst-case scenario was modeled. 
Assumptions

Selection of the solid phases (e.g., minerals and sorption surfaces) introduces uncertainty.

Other mobilization and demobilization agents should be modeled to evaluate the importance of alternate scenarios. The modeling here provides a general approach.

A limited number of complexes were considered.

The most influential complexes were considered, and significant error is not anticipated. Mobility would be greater than modeled as a result of neglecting important complexes and competition for sorption sites. Mobility would be overpredicted if precipitation or sorption were neglected.

Chemical equilibrium conditions were attained during transport.

Consideration of kinetic factors could change estimates of travel time. However, the time frame modeled is fairly long, so equilibrium is likely to be approached. Little or no kinetic data are available to evaluate this factor.

The EQ3/EQ6 and PHREEQE databases were used for most equilibrium constants and provided self-consistent, appropriate datasets.

Well-known databases were used when possible, and no major errors are expected to occur. Again, increases or decreases in mobility could occur depending on the magnitude and direction of the errors in the databases. Uranophane $\left[\mathrm{Ca}\left(\mathrm{H}_{2} \mathrm{O}\right)_{2}\left(\mathrm{UO}_{2}\right)_{2}\left(\mathrm{SiO}_{2}\right)_{2}(\mathrm{OH})_{6}\right]$ was not used in calculations because of $a$ reported error in its equilibrium constant.

The soil matrix (at a bulk density of $1.6 \mathrm{~g} / \mathrm{cm}^{3}$ ) with varying degrees of ${ }^{235} \mathrm{U}$ contamination and varying degrees of water content was chosen as a realistic bounding composition for the purpose of this scoping study. Discrete values were selected for evaluation.

The primary influence affecting the nuclear criticality evaluation is the density of the ${ }^{235} U$ contaminant in the soil. There are two secondary influences affecting the nuclear criticality evaluation; the water content within the soil and the composition of the soil. The water content and ${ }^{235} U$ were chosen arbitrarily to span the parameter ranges of interest to this scoping study. A third secondary influence affecting the nuclear criticality evaluation is the enrichment of the ${ }^{235} U$. There are, however, no licensed constraints on uranium enrichment at the Envirocare facility. Therefore, $100 \mathrm{wt} \%{ }^{235} \mathrm{U}$ was assumed for these evaluations. Lesser enrichments require greater concentrations of uranium (to increase ${ }^{235} U$ concentrations to compensate for ${ }^{238} U$ neutron absorption) and more restrictive water concentrations to permit nuclear criticality. The discrete values chosen do not provide all the necessary intermediate parametric values to evaluate nuclear criticality. That is, the transition from subcritical infinite soil matrices to realistically dimensioned disposal/burial sites having burial depths greater than about $4 \mathrm{~m}$, and ${ }^{235} \mathrm{UCFs}$ less than 3 have not been characterized in detail. Additionally, soil and waste matrix conditions can be substantially different, chemically and neutronically; therefore, this study has limited or no applicability to other waste matrices involving bulk quantities of polyethylene, carbon/graphite, beryllium, or heavy hydrogen compounds.

Simplistic deposit geometries, having no density gradients, were used in the criticality assessment.

Smaller quantities of fissile material in equivalent volumes may be required to reach criticality for certain density gradients. An extreme, but actual, critical experiment performed by Morfitt (1953), was the assembly of five concentric cylindrical uranyl fluoride solution regions having variable densities of $93 \mathrm{wt}$ $\%$ enriched uranium. Solution uranium densities were selected to produce a nearly uniform thermal neutron core flux. Doing so produced a critical system with $1061 \mathrm{~g}{ }^{235} \mathrm{U}$ as compared to a homogeneous core mass of $1162 \mathrm{~g}^{235} \mathrm{U}$ in an equal volume.

NUREG/CR-6505,

Vol. 1 
Assumptions

The radiation transport models that were used for the criticality consequence evaluation assumed that the concentrated uranium deposits were vertically centered at the midplane of the disposal trenchs and were shaped like cylindrical disks having vertical axes.

More conservative models (deposit at surface of disposal trench) or less conservative (deposit at floor of disposal trench) could be assumed regarding radiation dose determination at the surface of the disposal trench. Justifying such models would require extended periods of study. The midplane location was selected as a compromise to issues regarding uranium density gradients and unlikely alternative uranium transport/concentration mechanisms.

The two uranium deposit concentrations (minimum and maximum) selected for the criticality consequence evaluation were those that were determined to be practical by the hydrogeochemical scenarios and that would also permit criticality.

More precise limiting deposit concentrations could be determined and selected for the evaluation, but the probability of such precise conditions to support criticality were not judged worthy of further criticality safety analyses. 



\section{PARAMETERS USED AS INPUT SOURCES}

The range of input parameters of potentially mutual concern to the hydrogeochemical simulations and nuclear criticality evaluations was established for this task. A nominal soil composition was used for both analytical studies. Chemistries of water contained in soil considered within the hydrogeochemical simulations were not considered significant to the neutronic calculations because the dry nominal soil composition contains the overwhelming fractions of elemental constituents for damp or water-saturated soils. However, water content (i.e., grams of $\mathrm{H}_{2} \mathrm{O} /$ grams of soil concentration or water density, grams of $\mathrm{H}_{2} \mathrm{O} / \mathrm{cm}^{3}$ of bulk soil density) was considered significant and was included in the neutronic calculations.

\subsection{PARAMETERS USED IN HYDROGEOCHEMICAL SIMULATIONS}

The only SNM included in this study was ${ }^{235} \mathrm{U}$, which is the most abundant fissile isotope at the disposal site being considered. Furthermore, because the thermodynamic databases are far less reliable for plutonium than for uranium, the results of model simulation with plutonium would be subject to far greater uncertainties than with uranium.

Flow of water and other chemicals occurred into the top and out of the bottom of the 10-m-long column. A 1-m grid spacing simulated transport, with a dispersion coefficient of 0.1 , which is typical for this scale (Gelhar, Welty, and Rehfeldt, 1992). The velocity and hydraulic conductivity were uniform within the column, but a range of parameter values were examined. All model runs were conducted in the saturated mode. The travel times and pore volumes for different simulations are reported. Travel times for unsaturated conditions would be longer and were calculated as a simple linear reduction factor (as discussed subsequently). Output was obtained for up to 14,600 time steps for all runs. Selected runs were modeled for 73,000 time steps to determine when steady-state conditions had been achieved; many of the runs reached steady state by 14,600 time steps. Because of the small time step ( 0.5 days) needed for reactive transport, longer run times were not part of the standard output. Again, this time step does NOT represent travel times for unsaturated conditions.

Six aqueous components $\left(\mathrm{H}^{+}, \mathrm{CO}_{3}{ }^{2-}, \mathrm{Ca}^{2+}, \mathrm{UO}_{2}{ }^{2+}, \mathrm{Na}^{+}\right.$, and $\left.\mathrm{HPO}_{4}^{-}\right), 1$ surface component, 18 aqueous species, 4 surface species, and 2 minerals were considered in most of the simulations. The equilibrium constants and stoichiometric relationship of the species and minerals were input to the model (Table 7.1-1). The primary mobilizing agent was $\mathrm{CO}_{3}^{2-}$. The $\mathrm{pH}$ is important in determining the extent of uranium complexation by $\mathrm{CO}_{3}^{2-}$, and $\mathrm{Ca}^{2+}$ and $\mathrm{Na}^{+}$were included as cations to balance the $\mathrm{CO}_{3}{ }^{2-}$. An additional complexing agent included was $\mathrm{PO}_{4}^{2-}$ because tripolyphosphate was used to stabilize caps at the Envirocare site. The initial conditions were equilibrated with PHREEQE under oxidizing conditions, and the phosphate concentration was limited by hydroxyapatite solubility; the $\mathrm{CO}_{3}^{2-}$ was limited by calcite solubility.

The parameters selected for sensitivity analysis were uranium concentration on initial sorption sites, $\mathrm{CO}_{3}^{2-}$ concentration of the influent water, $\mathrm{pH}$ of the influent water, velocity, concentration of high adsorption sites, and the pattern of the adsorption sites (one or multiple sorption zones). In general, the ranges of parameters were chosen on the basis of typical soil and waste site conditions, not any particular site data. Except for the sorption pattern, the parameters were sampled uniformly from their logarithmic values to cover the full range of expected values.

The total uranium was equal to or greater than the maximum allowable ${ }^{235} \mathrm{U}$ for disposal. Because the geochemical transport behavior of uranium is independent of the isotope, enrichment is not an influence on 
hydrogeochemical processes. Increasing the total uranium concentration, while assuming a fixed ${ }^{235} U$, means the total uranium used in the hydrogeochemical transport models can be interpreted to span a range of ${ }^{235} U$ enrichments.

The model input was relative to pore water (even for sorbed species), so uranium concentrations are converted to molar as follows. The state of Utah regulatory limit for ${ }^{235} \mathrm{U}$ is $770 \mathrm{pCi} / \mathrm{g}$ soil. Assuming a soil density of $1.6 \mathrm{~g} / \mathrm{cm}^{3}$ and using the specific activity for ${ }^{235} \mathrm{U}$ to be $2.16 \times 10^{6} \mathrm{pCi} / \mathrm{g}{ }^{235} \mathrm{U}$, then the allowable concentration of ${ }^{235} \mathrm{U}$ in the soil is $0.0006 \mathrm{~g} / \mathrm{cm}^{3}$. If the saturated porosity of the soil is $33 \%$, the concentration is $1.2 \mathrm{~g}{ }^{235} \mathrm{U} / \mathrm{L}$ of pore water or $5 \times 10^{-3} \mathrm{M}$. Uranium concentrations representative of ${ }^{235} \mathrm{U}$ enrichments of 100 to $1 \%$ were modeled. Thus the full range of uranium is $5 \times 10^{-3} M$ for $100 \%{ }^{235} \mathrm{U}$ to $0.5 \mathrm{M}$ for $1 \%{ }^{235} \mathrm{U}(0.0006$ to $0.06 \mathrm{~g} / \mathrm{cm}^{3}$ ). Initially, uranium was sorbed to the soil with a low sorption capacity (see the following). Some runs were conducted using a uranium mineral as the initial form of uranium in the soil.

In addition, a series of runs were conducted with the uranium concentration reported at the Envirocare site. The total uranium concentration (with the same soil density assumptions) is $4.02 \times 10^{-3} \mathrm{M}$ with an estimated ${ }^{235} \mathrm{U}$ enrichment of only $0.42 \%$. These concentrations are below the range used in the sensitivity analysis, so the sensitivity analysis concentration presented a test of regulatory concerns, not site conditions. A summary of Envirocare disposal records on an annual basis is provided in Appendix B.

The expected range of total inorganic carbon in landfill leachate is from $1 \times 10^{-4}$ to $1 \times 10^{-2} \mathrm{M}$ (the range of compositions reported by Baedecker and Back, 1979; Staubitz et al., 1989; and data from L. Morton, State of Utah, Department of Environmental Quality). Although high $\mathrm{CO}_{3}{ }^{2-}$ levels increase mobility of uranium, they also can maintain the uranium as a soluble complex under otherwise immobilizing conditions. Thus it was not clear a priori what the effects of high vs low $\mathrm{CO}_{3}{ }^{2-}$ would be. The concentration of available $\mathrm{CO}_{3}{ }^{2-}$ is also controlled by $\mathrm{pH}$, so the $\mathrm{pH}$ was varied from $6.5\left(\mathrm{HCO}_{3}{ }^{-}\right.$dominant $)$to $9.5\left(\mathrm{CO}_{3}{ }^{2-}\right.$ dominant $)$. This was considered a reasonable range for $\mathrm{CO}_{3}{ }^{2-}$-buffered systems, although slightly wider ranges could be considered.

The flow velocity was varied over two orders of magnitude for the sensitivity analysis, although natural soils can vary over an even wider range. However, this range provided information on model sensitivity, and extremely low velocities take a long time to run. Thus a fast upper value was selected to speed run times, $0.5 \times 10^{-3}$ to $0.5 \mathrm{~m} / \mathrm{d}$. The approach used to estimate transport times under unsaturated conditions was based on simulations under saturating conditions that necessarily involve simplifications and relatively large uncertainties. To calculate unsaturated conditions, a decrease in velocity of 2 to 3 orders of magnitude was assumed (Baver, Gardner, and Gardner, 1971; Hillel, 1991) because of lower hydraulic conductivities (but higher gradients, which limit the reduction in velocities). This estimate was crude, but the uncertainty in velocities points to the need to better understand hydraulic conditions at specific sites. Although this approach neglects the effects of dispersion under unsaturated conditions (which could increase concentrations somewhat; Jardine, Jacobs, and Wilson, 1993) and does not account for conditions of transient saturation, the calculation does provide a rough estimate of travel times. To conduct transient, saturated/unsaturated modeling would (1) require significantly more model input (for soil conditions), (2) increase model uncertainty (because the soil data are not available), and (3) be more computationally intensive. Furthermore, no test problems are available for saturated/unsaturated multispecies transport to provide confidence in model calculations.

Two scenarios for immobilization and increase in concentration of uranium were considered to encompass both oxidizing and reducing conditions. The first scenario is sorption of uranium within a zone having a higher adsorption capacity than the bulk soil. The sorption site equilibria were obtained from Yeh and Tripathi (1991b). Concentrations of sorption sites were compared to literature values for uranium sorption on iron hydroxides.

NUREG/CR-6505,

Vol. 1 
Reported values range from 0 to $2.4 \mathrm{mg}$ uranium/g soil (Hsi and Langmuir, 1985), which is equivalent (see Table 9.1-1) to a maximum concentration of binding sites of $3.2 \times 10^{-2} \mathrm{~mol} / \mathrm{L}$ (units relative to pore water were required by the model). A slightly higher upper range was considered, and sensitivity was examined over 2 orders of magnitude by using a range of sorption site density from $1.0 \times 10^{-3}$ to $1.0 \times 10^{-1} \mathrm{M}$.

Table 9.1-1 Assumptions and calculations for conversion from milligrams of uranium per gram of soil to moles of uranium per liter of water

\begin{tabular}{ll}
\hline \multicolumn{1}{c}{ Concentration of uranium } & \multicolumn{1}{c}{ Comment } \\
\hline $2.4 \mathrm{mg} \mathrm{U} / \mathrm{g}$ soil & Maximum reported value \\
$1 \times 10^{-4} \mathrm{mmol} \mathrm{U} / \mathrm{g}$ soil & $235 \mathrm{~g} / \mathrm{mol} \mathrm{U}$ \\
$1 \times 10^{-4} \mathrm{mmol} \mathrm{U} / 0.625 \mathrm{~cm}^{3}$ soil & Assuming soil density of $1.6 \mathrm{~g} / \mathrm{cm}^{3}$ \\
$1 \times 10^{-4} \mathrm{mmol} \mathrm{U} / 0.937 \mathrm{~cm}^{3}$ porous media & $\begin{array}{l}\text { Assuming soil volume of } 67 \% \text { gives the } \\
\text { calculated total volume }\end{array}$ \\
$1 \times 10^{-4} \mathrm{mmol} \mathrm{U} / 0.312 \mathrm{~cm}^{3}$ water & Assuming porosity of $33 \%$, water saturated \\
$3.2 \times 10^{-2} \mathrm{~mol} / \mathrm{L}$ & $\mathrm{cm}^{3}=\mathrm{ml}, 1000 \mathrm{ml}=\mathrm{L}$ \\
\hline
\end{tabular}

Some runs under oxidizing conditions were conducted with mineral precipitation as the immobilizing mechanism. Rutherfordine $\left(\mathrm{UO}_{2} \mathrm{CO}_{3}\right)$ was used in all runs in conjunction with high sorption zones because of the importance of $\mathrm{CO}_{3}{ }^{2-}$ species. Soddyite $\left[\left(\mathrm{UO}_{2}\right)_{2} \mathrm{SiO}_{4} 2 \mathrm{H}_{2} \mathrm{O}\right]$ and $\mathrm{UO}_{2}(\mathrm{OH})_{2}$-beta were used in conjunction with sorption for some runs, but these minerals did not concentrate uranium because sorption dominated; these were not considered further. Precipitation of $\mathrm{UO}_{2}(\mathrm{OH})_{2}$-beta without sorption was also modeled in one run.

For the second immobilization scenario, reduction and precipitation were considered. Presumably, essentially all the uranium precipitated when it reached the reducing zone at the end of the column. This assumption was based on stability diagrams (e.g., Langmuir, 1978) as well as modeling using PHREEQE, which indicated that less than $1 \times 10^{-9} \mathrm{M}$ uranium was in equilibrium with reduced uraninite $\left(\mathrm{UO}_{2}\right)$. The mobilization portion of this scenario made use of the existing runs with the parameters described previously.

\subsection{PARAMETER RANGES OF SOIL COMPOSITION AND POROSITY FOR CRITICALITY ASSESSMENT}

The first step in the criticality safety assessment involved selection of a composition of a nominal geologically realistic soil for the initial neutronics calculations. The elemental composition of soils can vary greatly depending on individual soils. The composition (mean and range) of major elements in soil are listed in Table 9.2-1 and served as a basis for selection of the composition of the nominal soil. For neutronic calculations, the weight percents of individual elements were selected to minimize neutron capture and maximize neutron moderators to create a soil that is highly reactive from a criticality perspective. 
Table 9.2-1 Mean and range of elemental compositions in soil

\begin{tabular}{ccc}
\hline Element & $\begin{array}{c}\text { Range of reported "mean" } \\
\text { soil composition }(\mathrm{wt} \%)^{\mathrm{a}}\end{array}$ & $\begin{array}{c}\text { Range of soil composition } \\
(\mathrm{wt} \%)^{\mathrm{b}}\end{array}$ \\
\hline $\mathrm{O}$ & 49 & - \\
$\mathrm{Si}$ & $31-33$ & $1.6-45$ \\
$\mathrm{Al}$ & $7.1-7.2$ & $0.07->10$ \\
$\mathrm{Fe}$ & $2.6-3.8$ & $0.01->10$ \\
$\mathrm{Ca}$ & $1.4-2.4$ & $0.01-32$ \\
$\mathrm{Na}$ & $0.68-1.2$ & $<0.05-10$ \\
$\mathrm{~K}$ & $1.36-1.5$ & $0.005-6.3$ \\
$\mathrm{Mg}$ & $0.6-0.9$ & $0.005->10$ \\
$\mathrm{~B}$ & $0.001-0.003$ & $0.002-0.03$ \\
$\mathrm{C}$ & $1.0-2.5$ & $0.06-37$
\end{tabular}

${ }^{2}$ Ermolenko (1972); Bohn, McNeal, and O'Connor (1985); Sposito (1989); Shacklette and Boerngen (1984).

bShacklette and Boerngen (1984).

The water content of the soils is limited by the porosity of the matrix containing the waste. The lower limit on porosity could be zero, or potentially could be the percent water contained by the clay mineral structure ( 5 to $20 \%$ ). A typical mean porosity of $33 \%$ was assumed. Thus each bulk "soil" composition could accommodate approximately $0.33 \mathrm{~g}$ of $\mathrm{H}_{2} \mathrm{O} / \mathrm{cm}^{3}$ or $\sim 0.21 \mathrm{~g}$ of $\mathrm{H}_{2} \mathrm{O} / \mathrm{g}$ soil. Because of the high theoretical density of ${ }^{235} \mathrm{U}$ and ${ }^{235} \mathrm{UO}_{2}\left(\sim 18 \mathrm{~g}\right.$ and $\sim 9 \mathrm{~g}$ of $\mathrm{U} / \mathrm{cm}^{3}$, respectively), the void fraction within the soil could easily accommodate upwards to $0.5 \mathrm{~g}$ of ${ }^{235} \mathrm{U} / \mathrm{cm}^{3}$ with little impact on available void fraction for water.

The nuclear criticality calculations were performed by merely inserting fiducial values of water and ${ }^{235} U$ densities into the input of a calculation and determining the $\mathrm{k}_{\infty}$ of the mixture. These fiducial values were selected to span the considered range of $\mathrm{SiO}_{2}$ water and uranium densities (i.e., $0 \leq \mathrm{g}$ of $\mathrm{H}_{2} \mathrm{O} / \mathrm{cm}^{3} \leq 0.4$, and about $0.0005 \leq \mathrm{g}$ of $\left.{ }^{235} \mathrm{U} / \mathrm{cm}^{3} \leq 1.0\right)$. The same mixtures were then used to determine the dimensions of "critical" $\left(\mathrm{k}_{\text {eff }}=0.95\right)$ single spheres, single infinitely long cylinders, and single infinitely distributed planes surrounded with $2 \mathrm{~m}$ of the same soil mixture without the ${ }^{235} \mathrm{U}$ contaminant (see Appendix A for schematics of computational models). The 0.95 value was assumed for the critical condition to account for uncertainties in the modeling and evaluation.

The two soil compositions used for this study were the "nominal" soil (derived from data in Table 9.2-1) and an " $\mathrm{SiO}_{2}$ " soil, both of which were taken to have a dry bulk density of $1.6 \mathrm{~g} / \mathrm{cm}^{3}$. The elemental composition of these soils is provided in Tables 3-1 and 9.2-2. 
Table 9.2-2 Elemental composition for $\mathrm{SiO}_{2}$ soil

\begin{tabular}{cc}
\hline Element & $\begin{array}{c}\text { Weight percent of dry bulk } \\
\text { density }\left(1.6 \mathrm{~g} / \mathrm{cm}^{3}\right)\end{array}$ \\
\hline Oxygen & 53.257 \\
Silicon & 46.743 \\
\hline
\end{tabular}

\subsection{PARAMETRIC INPUT FOR THE DIRECT-DOSE CRITICALITY CONSEQUENCE EVALUATION}

\section{Assumed Deposit Conditions}

Two postulated criticalities were defined that corresponded to high and low concentration factors of 10.5 and 3.6 relative to the regulatory limit of $0.0006 \mathrm{~g}$ of ${ }^{235} \mathrm{U}$ per $\mathrm{cm}^{3}$. The high concentration factor (HCF) corresponds to the upper limit indicated as possible based on hydrogeochemical scenarios. The low concentration factor (LCF) roughly corresponds to the minimal concentration conditions under which a criticality can occur. The criticality events were assumed to occupy a localized region with a thickness equal to the slab geometry thickness defined as "critical" (actually $\mathrm{k}=0.95$ ) for the purposes of this study. While the cases studied for criticality purposes allowed for both dry and wet systems, the radiation transport studies to determine criticality consequences only analyzed dry systems. The dry systems are assumed to be limiting since water is a very good shield for the large number of neutrons released from a criticality event. 



\section{RESULTS}

Observations of the consolidated results and intersections of parameter surface responses from the hydrogeochemical scenarios and nuclear criticality evaluations yielded a small number of simulated geological circumstances that could potentially support nuclear criticality. That is, few sets of hydrogeological conditions yielded ${ }^{235} \mathrm{U}$ CFs greater than 3, and CFs greater than 10 are not judged credible based upon the stated hydrogeochemical simulation assumptions. Criticality cannot be achieved with less than a $\mathrm{CF}$ of about 2 for the assumed $\mathrm{SiO}_{2}$ soil or less than a CF of about 6 for the assumed nominal soil. Results of the two criticality consequence evaluations provide ranges of radiation dose estimates at the ground surface centered above the disklike concentrated uranium deposits ( 56 to $157 \mathrm{rem}$ ) and at the ground surface but translated $90 \mathrm{~m}$ from the vertical axes of the disklike concentrated uranium deposits (57 to $165 \mathrm{mrem}$ ).

\subsection{NUCLEAR CRITICALITY EVALUATION}

Specific values from the nuclear criticality evaluations are presented in tabular format in Appendix C (Table C-1 for the nominal soil and Table $\mathrm{C}-2$ for the $\mathrm{SiO}_{2}$ soil). Corresponding 3-D surface plots (Appendix D) provide a broader view of the relationship and responses of the systems to the water and ${ }^{235} U$ content in the soils; the figures in Appendix D are cited in the column headings of the tables in Appendix C.

\subsubsection{Interpretation of Results}

The state of Utah provides a license disposal limit of $770 \mathrm{pCi}$ of ${ }^{235} \mathrm{U} / \mathrm{g}$ of soil-like waste for Envirocare. Assuming a soil-like waste density of $1.6 \mathrm{~g} / \mathrm{cm}^{3}$ of soil, this translates to $0.0006 \mathrm{~g} \mathrm{of}{ }^{235} \mathrm{U} / \mathrm{cm}^{3}$ of soil, subsequently referred to as the state of $U$ tah limit. Although increases in concentrations of ${ }^{235} \mathrm{U}$ densities are limited by hydrogeochemical conditions, CFs ten times the authorized initial uranium elemental density could result in critical systems having densities of about $0.006 \mathrm{~g}$ of ${ }^{235} \mathrm{U} / \mathrm{cm}^{3}$ of soil (see line entries 13 through 17 in Table C-1 and line entries 34 and 158 through 164 in Table C-2, which are extracted in the following).

Additional critical densities and infinite-media multiplication constants are provided in Tables C-1 and C-2. As acknowledged by the state of Utah (1994), the licensee may construct disposal cells to accommodate 10-m depths of waste materials. Under the assumption that the soillike materials have a density of about $1.6 \mathrm{~g} / \mathrm{cm}^{3}$, the permitted parameters for the burial cell can result in an areal density (i.e., the mass of ${ }^{235} \mathrm{U}$ projected downward to any $1-\mathrm{m}^{2}$ area on the floor of the cell) of about $5.2 \mathrm{~kg} / \mathrm{m}^{2}$. Given hydrogeochemical CFs of 3 or 10 for allowed ${ }^{235} \mathrm{U}$ disposal densities, critical ( $\mathrm{k}_{\text {eff }} \geq 0.95$ in this study) infinite-slab systems of "SiO ${ }_{2}$ " or "Nominal Soil," respectively, can be created (see Tables $\mathrm{C}-1$ and $\mathrm{C}-2$ ).

In nominal soil, the vertical migration of ${ }^{235} \mathrm{U}$ into infinite planar configurations can produce critical concentrations, as shown in Table 10.1-1, line entries 16 and 17. Although spherical or cylindrical geometries can also occur in the waste matrix, they require greater concentrations of ${ }^{235} \mathrm{U}$ to become critical because of the geometric effect of increased neutron leakage from cylinders and spheres. For example, the areal density of an infinite slab of nominal soil at $0.006 \mathrm{~g}$ of ${ }^{235} \mathrm{U} / \mathrm{cm}^{3}$ (line entry 15 ) is critical at $5.286 \mathrm{~kg}$ of ${ }^{235} \mathrm{U} / \mathrm{m}^{2}$ (very nearly the assumed critical value of $5.2 \mathrm{~kg}$ of ${ }^{235} \mathrm{U} / \mathrm{m}^{2}$ ) in a planar configuration. However, the ${ }^{235} \mathrm{U}$ linear density of the infinite cylinder in line entry 15 requires a projected areal density of about $7.8 \mathrm{~kg}$ of ${ }^{235} \mathrm{U} / \mathrm{m}^{2}$ (i.e., $12.9 \mathrm{~kg}$ of ${ }^{235} \mathrm{U} / 1.65-\mathrm{m}$ cylinder diameter $\times 1-\mathrm{m}$ cylinder length $=12.9 / 1.65 \mathrm{~kg}$ of ${ }^{235} \mathrm{U} / \mathrm{m}^{2}$, or $7.8 \mathrm{~kg}$ of ${ }^{235} \mathrm{U} / \mathrm{m}^{2}$ ). Thus achieving criticality in a cylindrical geometry requires substantial lateral migration as well as vertical migration of the ${ }^{235} U$. 
Table 10.1-1 Extracted nominal-soil (N-S) resultsa

\begin{tabular}{|c|c|c|c|c|c|c|c|c|c|c|c|c|}
\hline \multirow[b]{2}{*}{$\begin{array}{l}\text { Line } \\
\text { entry }\end{array}$} & \multirow[b]{2}{*}{$\begin{array}{l}\text { Conc. } \\
\text { factor }\end{array}$} & \multicolumn{2}{|c|}{${ }^{235} \mathrm{U}$ content } & \multicolumn{2}{|c|}{ Water content } & \multirow[b]{2}{*}{$\begin{array}{c}\mathrm{k}_{\infty} \\
\text { or } \\
\text { k-infinity }\end{array}$} & \multicolumn{2}{|c|}{ Critical infinite slab ${ }^{\mathbf{b}}$} & \multicolumn{2}{|c|}{ Critical infinite cylinder ${ }^{b}$} & \multicolumn{2}{|c|}{ Critical sphere $^{\mathrm{b}}$} \\
\hline & & $\begin{array}{l}\mathrm{g}^{235} \mathrm{U} \\
\text { per } \\
\mathrm{cm}^{3}\end{array}$ & $\begin{array}{l}g{ }^{235} \mathrm{U} \\
\text { per } \\
\mathrm{g} \mathrm{N}-\mathrm{S}\end{array}$ & $\begin{array}{c}\mathrm{g} \mathrm{H}_{2} \mathrm{O} \\
\text { per } \\
\mathrm{cm}^{3}\end{array}$ & $\begin{array}{c}\mathrm{g} \mathrm{H}_{2} \mathrm{O} \\
\text { per } \\
\mathrm{g} \mathrm{N}-\mathrm{S}\end{array}$ & & $\begin{array}{l}\text { Thickness } \\
\text { (cm) }\end{array}$ & $\begin{array}{c}{ }^{235} \mathrm{U} \text { areal } \\
\text { density } \\
\left(\mathrm{kg} / \mathrm{m}^{2}\right)\end{array}$ & $\begin{array}{l}\text { Diameter } \\
\quad(\mathrm{cm})\end{array}$ & $\begin{array}{c}{ }^{235} \mathrm{U} \text { linear } \\
\text { density } \\
(\mathrm{kg} / \mathrm{m})\end{array}$ & $\begin{array}{l}\text { Diameter } \\
\quad(\mathrm{cm})\end{array}$ & $\begin{array}{l}{ }^{235} \mathrm{U} \\
\text { mass } \\
(\mathrm{kg})\end{array}$ \\
\hline & & & & & & Fig. D-1 & Fig. D-2 & Fig. D-3 & Fig. D-4 & Fig. D-5 & Fig. D-6 & Fig. D-7 \\
\hline 7 & 3.3 & 0.0020 & 0.001250 & 0.000 & 0.000000 & 0.825 & & & & & & \\
\hline 8 & 3.3 & 0.0020 & 0.001250 & 0.020 & 0.012500 & 0.803 & & & & & & \\
\hline 9 & 3.3 & 0.0020 & 0.001250 & 0.040 & 0.025000 & 0.770 & & & & & & \\
\hline 10 & 3.3 & 0.0020 & 0.001250 & 0.080 & 0.050000 & 0.706 & & & & & & \\
\hline 11 & 3.3 & 0.0020 & 0.001250 & 0.160 & 0.100000 & 0.602 & & & & & & \\
\hline 12 & 3.3 & 0.0020 & 0.001250 & 0.330 & 0.206250 & 0.457 & & & & & & \\
\hline 13 & 10.0 & 0.0060 & 0.003750 & 0.000 & 0.000000 & 1.292 & 142.950 & 8.577 & 270.140 & 34.389 & 382.220 & 175.424 \\
\hline 14 & 10.0 & 0.0060 & 0.003750 & 0.020 & 0.012500 & 1.310 & 101.720 & 6.103 & 192.520 & 17.466 & 272.700 & 63.710 \\
\hline 15 & 10.0 & 0.0060 & 0.003750 & 0.040 & 0.025000 & 1.292 & 88.100 & 5.286 & 165.280 & 12.873 & 233.480 & 39.985 \\
\hline 16 & 10.0 & 0.0060 & 0.003750 & 0.080 & 0.050000 & 1.239 & 78.040 & 4.682 & 143.000 & 9.636 & 200.600 & 25.360 \\
\hline 17 & 10.0 & 0.0060 & 0.003750 & 0.160 & 0.100000 & 1.131 & 78.860 & 4.732 & 137.920 & 8.964 & 190.040 & 21.562 \\
\hline 18 & 10.0 & 0.0060 & 0.003750 & 0.330 & 0.206250 & 0.946 & & & & & & \\
\hline
\end{tabular}

${ }^{a}$ Figures presented in Appendix D.

${ }^{b}$ Dimensions based on system $k_{\text {eff }}=0.95$ rather than $k_{\text {eff }}=1.0$ to conservatively account for methods and data uncertainty. 
Achieving criticality in a spherical geometry requires a projected areal density of about $9.34 \mathrm{~kg}$ of ${ }^{235} \mathrm{U} / \mathrm{m}^{2}$ (i.e., $39.985 \mathrm{~kg}$ of ${ }^{235} \mathrm{U} / 4.28 \mathrm{~m}^{2}$ of projected area of the sphere $=39.985 / 4.28 \mathrm{~kg}$ of ${ }^{235} \mathrm{U} / \mathrm{m}^{2}$, or $9.34 \mathrm{~kg}$ of ${ }^{235} \mathrm{U} / \mathrm{m}^{2}$ ), a density that requires significant lateral migration of ${ }^{235} \mathrm{U}$. In summary, a unidirectional migration of SNM into a slablike configuration requires less concentration of ${ }^{235} U$ to pose nuclear criticality safety concerns than do cylinders and spheres.

The $\mathrm{SiO}_{2}$-soil results are similar to the nominal soil results. For line entry 160 in Table $10.1-2$, the critical areal density for the infinite slab is $3.156 \mathrm{~kg} / \mathrm{m}^{2}$. The approximate projected areal density of the infinite cylinder is $4.85 \mathrm{~kg}$ of ${ }^{235} \mathrm{U} / \mathrm{m}^{2}$ (i.e., $4.748 \mathrm{~kg}$ of ${ }^{235} \mathrm{U} / 0.9796 \mathrm{~m}^{2}$ of projected area). The approximate projected areal density of the sphere is $5.87 \mathrm{~kg}$ of ${ }^{235} \mathrm{U} / \mathrm{m}^{2}$ (i.e., $9.106 \mathrm{~kg}{ }^{235} \mathrm{U} / 1.55 \mathrm{~m}^{2}$ of projected area).

For cases in which localized voids (e.g., such as under slabs of broken concrete that cannot be compacted) might provide regions for ${ }^{235} \mathrm{U}$-bearing solutions (e.g., aqueous or organic based) to collect without soil dilution, another reference exists (Paxton and Pruvost, 1987) for predicting critical masses and volumes with concentrations greater than $0.013 \mathrm{~g}$ of ${ }^{235} \mathrm{U} / \mathrm{cm}^{3}$. The concentration yielding the smallest critical mass is approximately $0.05 \mathrm{~g} \mathrm{of}{ }^{235} \mathrm{U} / \mathrm{cm}^{3}$ for a critical mass of $\sim 0.83 \mathrm{~kg}$ of ${ }^{235} \mathrm{U}$ in an $\sim 17-\mathrm{L}$ volume; such a mass yields a projected areal density of about $10.38 \mathrm{~kg}$ of ${ }^{235} \mathrm{U} / \mathrm{m}^{2}$. The larger critical masses observed for the soils is due to the dilution of fissile material increased neutron leakage and some neutron capture.

The seemingly anomalous circumstances where nominal soil or $\mathrm{SiO}_{2}$ soil can produce more sensitive results (i.e., lesser critical concentrations) than pure aqueous solutions of ${ }^{235} \mathrm{U}$ is founded in the low neutron-capture values for the assumed soils in comparison with the values for aqueous solutions. In dilute systems, the neutron capture in hydrogen can offset the hydrogen influence in slowing down and thermalizing neutrons for more effective thermal fission. Table 10.1-2 shows that for relatively dilute systems, the addition of water to the ${ }^{235} \mathrm{U}$ and $\mathrm{SiO}_{2}$ systems reduces the infinite-media multiplication constant, $\mathrm{k}_{\infty}$.

\subsubsection{Interpretation of Results in Relation to Envirocare of Utah, Inc.}

The uranium concentration in soil was estimated from reports provided by D. L. Finefrock of the State of Utah, Department of Environmental Quality. The inventory reports provide estimates of picocuries of uranium and volume of soil for the years 1988-95 (Appendix B). These data have been converted into the overall average concentration of $9.5 \times 10^{-4} \mathrm{~g} / \mathrm{cm}^{3}$ total $U$. The calculated average enrichment from the inventory is estimated at only $0.42 \%$. This average enrichment is below the minimum $1 \%$ enrichment required to achieve nuclear criticality in a homogeneous water-moderated system. The inventory of the waste pit would need to be examined to further evaluate nuclear criticality safety. However, this concentration $\left(9.5 \times 10^{-4} \mathrm{~g} / \mathrm{cm}^{3}\right)$ was used to model site conditions and to provide an evaluation for slightly larger enrichments that could exist in disposal cells.

This study did not evaluate the validity of the "unity rule" prescribed with either the state of Utah license condition 16.A for combinations of fissile nuclides (i.e., ${ }^{235} \mathrm{U},{ }^{239} \mathrm{Pu}$, and ${ }^{241} \mathrm{Pu}$ ) or license condition 16.B for quantities of other sole fissile nuclides that contaminate soils (i.e., ${ }^{239} \mathrm{Pu}$ and ${ }^{241} \mathrm{Pu}$ ). However, the authorized concentrations of ${ }^{239} \mathrm{Pu}$ and ${ }^{241} \mathrm{Pu}$ are nearly seven orders of magnitude smaller than the permissible concentration of ${ }^{235} \mathrm{U}$. Because the critical masses of ${ }^{239} \mathrm{Pu}$ and ${ }^{241} \mathrm{Pu}$ are not much less than one quarter that of ${ }^{235} \mathrm{U}$, it is highly improbable that ${ }^{239} \mathrm{Pu}$ or ${ }^{241} \mathrm{Pu}$ will pose a nuclear criticality hazard at the Envirocare site at the specified disposal limits. 
Table 10.1-2 Extracted $\mathrm{SiO}_{2}$-soil (S-S) results ${ }^{\mathrm{a}}$

\begin{tabular}{|c|c|c|c|c|c|c|c|c|c|c|c|c|}
\hline \multirow{3}{*}{$\begin{array}{l}\text { Line } \\
\text { entry }\end{array}$} & \multirow{3}{*}{$\begin{array}{l}\text { Conc. } \\
\text { factor }\end{array}$} & \multicolumn{2}{|c|}{${ }^{235} \mathrm{U}$ content } & \multicolumn{2}{|c|}{ Water content } & \multirow[b]{2}{*}{$\begin{array}{c}\mathrm{k}_{\infty} \\
\text { or } \\
\mathrm{k} \text {-infinity }\end{array}$} & \multicolumn{2}{|c|}{ Critical infinite slab ${ }^{b}$} & \multicolumn{2}{|c|}{ Critical infinite cylinder ${ }^{b}$} & \multicolumn{2}{|c|}{ Critical sphere $^{\mathrm{b}}$} \\
\hline & & $\begin{array}{c}\mathrm{g}^{235} \mathrm{U} \\
\text { per } \\
\mathrm{cm}^{3}\end{array}$ & $\begin{array}{l}g^{235} \mathrm{U} \\
\text { per } \\
\mathrm{g} \mathrm{S-S}\end{array}$ & $\begin{array}{c}\mathrm{g} \mathrm{H}_{2} \mathrm{O} \\
\text { per } \\
\mathrm{cm}^{3}\end{array}$ & $\begin{array}{c}\mathrm{g} \mathrm{H}_{2} \mathrm{O} \\
\text { per } \\
\mathrm{g} \mathrm{S}-\mathrm{S}\end{array}$ & & $\begin{array}{l}\text { Thick- } \\
\text { ness } \\
\text { (cm) }\end{array}$ & $\begin{array}{c}{ }^{235} \mathrm{U} \\
\text { areal } \\
\text { density } \\
\left(\mathrm{kg} / \mathrm{m}^{2}\right)\end{array}$ & $\begin{array}{l}\text { Diameter } \\
(\mathrm{cm})\end{array}$ & $\begin{array}{c}{ }^{235} \mathrm{U} \\
\text { linear } \\
\text { density } \\
(\mathrm{kg} / \mathrm{m})\end{array}$ & $\begin{array}{l}\text { Diameter } \\
(\mathrm{cm})\end{array}$ & $\begin{array}{c}{ }^{235} \mathrm{U} \\
\text { mass } \\
(\mathrm{kg})\end{array}$ \\
\hline & & & & & & Fig. D-8 & Fig. D-9 & Fig. D-10 & Fig. D-11 & Fig. D-12 & Fig. D-13 & Fig. D-14 \\
\hline 34 & 3.00 & 0.0011250 & 0.0011250 & 0.00000 & 0.00000 & 1.060 & 367.1300 & 6.6083 & 621.5 & 54.6065 & 844.74 & 355.0752 \\
\hline 35 & 3.00 & 0.0018000 & 0.0011250 & 0.05800 & 0.03625 & 0.894 & & & & & & \\
\hline 36 & 3.00 & 0.0018000 & 0.0011250 & 0.11900 & 0.07438 & 0.751 & & & & & & \\
\hline 37 & 3.00 & 0.0018000 & 0.0011250 & 0.18300 & 0.11438 & 0.642 & & & & & & \\
\hline 38 & 3.00 & 0.0018000 & 0.0011250 & 0.25100 & 0.15688 & 0.556 & & & & & & \\
\hline 39 & 3.00 & 0.0018000 & 0.0011250 & 0.32400 & 0.20250 & 0.487 & & & & & & \\
\hline 40 & 3.00 & 0.0018000 & 0.0011250 & 0.40000 & 0.25000 & 0.431 & & & & & & \\
\hline 158 & 10.50 & 0.0063000 & 0.0039375 & 0.00000 & 0.00000 & 1.512 & 94.2100 & 5.9352 & 205.28 & 20.8508 & 303.38 & 92.1086 \\
\hline 159 & 10.50 & 0.0063000 & 0.0039375 & 0.05800 & 0.03625 & 1.478 & 54.5300 & 3.4354 & 113.3 & 6.3517 & 165.3 & 14.8990 \\
\hline 160 & 10.50 & 0.0063000 & 0.0039375 & 0.11900 & 0.07438 & 1.367 & 50.1000 & 3.1563 & 97.96 & 4.7482 & 140.28 & 9.1060 \\
\hline 161 & 10.50 & 0.0063000 & 0.0039375 & 0.18300 & 0.11438 & 1.261 & 50.9400 & 3.2092 & 94.72 & 4.4393 & 133.44 & 7.8379 \\
\hline 162 & 10.50 & 0.0063000 & 0.0039375 & 0.25100 & 0.15688 & 1.163 & 55.9600 & 3.5255 & 99.6 & 4.9085 & 138.1 & 8.6880 \\
\hline 163 & 10.50 & 0.0063000 & 0.0039375 & 0.32400 & 0.20250 & 1.075 & 68.4900 & 4.3149 & 117.08 & 6.7826 & 159.62 & 13.4153 \\
\hline 164 & 10.50 & 0.0063000 & 0.0039375 & 0.40000 & 0.25000 & 0.995 & 111.8700 & 7.0478 & 174.66 & 15.0945 & 246.4 & 49.3471 \\
\hline
\end{tabular}

${ }^{3}$ Figures presented in Appendix D.

bimensions based on system $k_{\text {eff }}=0.95$ rather than $k_{\text {eff }}=1.0$ to conservatively account for methods and data uncertainty. 
Results

\subsubsection{Discussion of Results in Relation to the NRC Division of Fuel Cycle Safety and Safeguards Proposed Limits}

Results of this nuclear criticality evaluation demonstrate that the ${ }^{235} \mathrm{U}$ limit proposed in the rule change petition (Federal Register, 1993) will yield subcritical conditions based on three specified assumptions:

1. the SNM is uniformly distributed throughout the soil,

2. the soil matrix is $\mathrm{SiO}_{2}$, and

3. the SNM-contaminated soil matrix has a spherical geometry and an optimal water content for nuclear criticality.

As noted in Sect. 1.2, the basic assumption for uniform distribution at the proposed SNM limit of $5000 \mathrm{~g}$ of soil/ $1 \mathrm{~g}$ of ${ }^{235} \mathrm{U}$ (100\% enriched), or $0.0002 \mathrm{~g}$ of ${ }^{235} \mathrm{U} / \mathrm{g} \mathrm{SiO}$, cannot be assured through hydrogeochemical influences, but the SNM limit does provide a factor of 3 reduction from the Utah license limit. However, the probability of transporting the ${ }^{235} \mathrm{U}$ and concentrating it into a suitable geometry and density to achieve criticality is very low. The results do confirm that $\mathrm{SiO}_{2}$ is a conservative soil matrix for nuclear criticality evaluations.

The fact that a spherical geometry requires multidirectional, convergent movement and greater concentrations than a slab geometry of ${ }^{235} \mathrm{U}$ indicates that a sphere may not be representative of realistic migrations of SNM within a disposal cell. In fact, since total mass is not restricted at an LLW site, a slab configuration seems the most likely to yield a potential for criticality (see Sect. 10.2, Geochemical Transport, and Sect. 4, Relevant Analogs).

\subsection{GEOCHEMICAL TRANSPORT}

The nuclear criticality safety analysis above makes it clear that a key uncertainty in evaluating safety is the potential for redistributing SNM to zones of higher concentration by hydrogeochemical processes. The likelihood that uranium would concentrate to levels of concern for criticality safety analysis must be evaluated to determine whether specific configurations of uranium can occur. Through hydrogeochemical modeling, project participants examined uranium's potential to mobilize and concentrate as a slab. Results are presented in terms of the extent to which uranium is concentrated by immobilization processes. Results are also described in terms of the spatial distribution of mobile uranium (dissolved species) or immobilized uranium (adsorbed species) in the simulated columns as a function of the number of pore volumes of eluant passing through the soil profile; the number of pore volumes is related to time and flow velocity. Data from 40 simulations were examined as part of the formal sensitivity analysis (Table 10.2-1). Note that each run had unique input variables of $\mathrm{pH}$, etc. Output is summarized as CFs resulting from sorption and from flushing. The definitions of these CFs are given in the table. The results of the 40 simulations are discussed in Sects. 10.2.1 and 10.2.3 and are discussed within the context of the sensitivity analysis in 10.2.4. In addition, the effects of some alternate scenarios were examined, such as precipitation of oxidized minerals and uranium disposal at levels below the regulatory limit (i.e., from disposal records at the Envirocare site). 
Results

Table 10.2-1 Summary of sensitivity analysis runs

\begin{tabular}{|c|c|c|c|c|c|c|c|c|c|}
\hline \multicolumn{8}{|c|}{ Input data } & \multicolumn{2}{|c|}{ Output } \\
\hline $\begin{array}{l}\text { Run } \\
\text { No. }\end{array}$ & $\mathrm{pH}$ & $\begin{array}{c}\log \\
\mathrm{CO}^{-2}\end{array}$ & $\begin{array}{c}\mathrm{U} \text { conc, } \\
M\end{array}$ & $\begin{array}{c}\text { Enrich } \\
\%\end{array}$ & $\begin{array}{l}\text { log sorp } \\
\text { conc, } M\end{array}$ & $\begin{array}{l}\text { Sorp } \\
\text { patt }\end{array}$ & $\begin{array}{l}\text { Vel } \\
\text { m/day }\end{array}$ & $\begin{array}{r}\text { Flush } \\
\text { CF }\end{array}$ & $\begin{array}{r}\text { Sorp } \\
\text { CF }\end{array}$ \\
\hline 1 & 7.27 & -3.23 & 0.0539 & 4.64 & -2.18 & 2 & 0.0090 & 1.72 & 0.09 \\
\hline 2 & 9.50 & -3.18 & 0.1385 & 1.80 & -2.33 & 1 & 0.2462 & 1.86 & 0.78 \\
\hline 3 & 7.81 & -2.00 & 0.0092 & 27.28 & -1.31 & 2 & 0.0080 & 7.84 & 1.38 \\
\hline 4 & 8.81 & -2.87 & 0.1754 & 1.43 & -1.51 & 1 & 0.3509 & 2.73 & 0.79 \\
\hline 5 & 6.81 & -2.51 & 0.0209 & 11.94 & -3.00 & 2 & 0.1535 & 8.00 & 0.81 \\
\hline 6 & 8.88 & -3.74 & 0.0025 & 100.00 & -1.56 & 2 & 0.0419 & 3.48 & 1.04 \\
\hline 7 & 7.73 & -3.33 & 0.0057 & 43.75 & -2.38 & 2 & 0.0372 & 3.01 & 0.80 \\
\hline 8 & 7.96 & -2.26 & 0.0036 & 70.18 & -2.79 & 2 & 0.2188 & 8.00 & 0.00 \\
\hline 9 & 9.19 & -3.90 & 0.0103 & 24.24 & -1.10 & 1 & 0.1364 & 2.04 & 0.99 \\
\hline 10 & 8.50 & -2.41 & 0.0972 & 2.57 & -1.00 & 1 & 0.1212 & 5.43 & 0.87 \\
\hline 11 & 9.27 & -2.92 & 0.2500 & 1.00 & -1.41 & 2 & 0.0261 & 1.66 & 0.90 \\
\hline 12 & 8.12 & -3.69 & 0.0081 & 30.70 & -1.36 & 1 & 0.0294 & 7.91 & 0.02 \\
\hline 13 & 7.88 & -3.64 & 0.0298 & 8.38 & -2.54 & 2 & 0.0183 & 0.34 & 0.92 \\
\hline 14 & 7.04 & -4.00 & 0.1974 & 1.27 & -2.49 & 1 & 0.0471 & 1.70 & 0.87 \\
\hline 15 & 8.19 & -3.85 & 0.0682 & 3.67 & -1.77 & 1 & 0.0063 & 1.31 & 0.90 \\
\hline 16 & 6.58 & -3.28 & 0.0032 & 78.96 & -2.08 & 1 & 0.0114 & 4.05 & 0.88 \\
\hline 17 & 7.65 & -2.36 & 0.2221 & 1.13 & -1.97 & 2 & 0.0206 & 2.07 & 0.90 \\
\hline 18 & 9.04 & -2.05 & 0.0236 & 10.61 & -1.67 & 2 & 0.0129 & 6.30 & 1.11 \\
\hline 19 & 7.19 & -2.77 & 0.1559 & 1.60 & -1.21 & 2 & 0.0756 & 2.45 & 1.06 \\
\hline 20 & 7.35 & -3.03 & 0.0864 & 2.89 & -1.62 & 2 & 0.0102 & 1.47 & 0.97 \\
\hline 21 & 7.12 & -2.62 & 0.0147 & 17.01 & -1.72 & 2 & 0.1944 & 8.00 & 1.09 \\
\hline 22 & 8.42 & -2.15 & 0.0265 & 9.43 & -2.59 & 1 & 0.0050 & 3.06 & 0.86 \\
\hline 23 & 6.73 & -2.72 & 0.0040 & 62.36 & -2.23 & 2 & 0.3948 & 8.00 & 0.00 \\
\hline 24 & 6.50 & -2.97 & 0.0336 & 7.44 & -1.46 & 2 & 0.3118 & 8.00 & 0.39 \\
\hline 25 & 8.58 & -3.95 & 0.0479 & 5.22 & -2.74 & 1 & 0.0597 & 1.94 & 0.90 \\
\hline 26 & 9.12 & -2.67 & 0.1231 & 2.03 & -2.69 & 1 & 0.0232 & 1.94 & 0.89 \\
\hline 27 & 8.04 & -2.56 & 0.0768 & 3.26 & -1.15 & 1 & 0.1728 & 3.77 & 0.68 \\
\hline 28 & 7.42 & -2.31 & 0.0606 & 4.12 & -2.85 & 1 & 0.5000 & 8.00 & 0.78 \\
\hline 29 & 8.27 & -3.38 & 0.0378 & 6.61 & -1.05 & 2 & 0.0530 & 1.85 & 1.14 \\
\hline 30 & 7.50 & -3.59 & 0.0072 & 34.55 & -1.87 & 1 & 0.0957 & 2.66 & 0.73 \\
\hline 31 & 8.73 & -2.46 & 0.0186 & 13.43 & -2.13 & 1 & 0.0851 & 8.00 & 0.78 \\
\hline 32 & 7.58 & -3.44 & 0.1094 & 2.29 & -2.44 & 2 & 0.0071 & 1.28 & 0.90 \\
\hline 33 & 6.96 & -3.08 & 0.0045 & 55.41 & -2.28 & 1 & 0.0163 & 4.79 & 0.83 \\
\hline 34 & 9.35 & -2.21 & 0.0064 & 38.88 & -1.92 & 2 & 0.0331 & 8.00 & 1.02 \\
\hline 35 & 8.65 & -2.82 & 0.0131 & 19.15 & -2.03 & 2 & 0.0672 & 4.52 & 0.98 \\
\hline 36 & 9.42 & -3.79 & 0.0165 & 15.12 & -2.90 & 1 & 0.1077 & 1.74 & 0.81 \\
\hline 37 & 6.65 & -2.10 & 0.0116 & 21.54 & -1.82 & 1 & 0.0056 & 5.22 & 0.84 \\
\hline 38 & 8.35 & -3.54 & 0.0028 & 88.86 & -2.64 & 1 & 0.0145 & 4.52 & 0.57 \\
\hline 39 & 6.88 & -3.13 & 0.0051 & 49.24 & -1.26 & 1 & 0.2771 & 8.00 & 0.81 \\
\hline 40 & 8.96 & -3.49 & 0.0425 & 5.88 & -2.95 & 2 & 0.4443 & 2.00 & 0.00 \\
\hline
\end{tabular}

KEY: Enrich $\%=$ effective enrichment $=100 \times$ (regulatory limit)/(total $U$ input) where the regulatory limit is $0.005 \mathrm{M}$

$\mathrm{U}$ conc $* 2=$ total concentration on sorption sites.

Sorp patt $=$ the pattern for sorption sites.

1 is high sorption zone at the end of the column.

2 is four high sorption zones interspersed with low sorption zones.

$\mathrm{Vel}=$ velocity.

Sorp $\mathrm{CF}=$ conc factor on sorption sites

$=$ (peak concentration)/(input $U$ concentration).

Flush $\mathrm{CF}=$ conc factor calculated after flushing.

NUREG/CR-6505,

Vol. 1 


\subsubsection{Sorption}

The effect of sorption on uranium mobilization and immobilization was examined in 40 simulations, summarized in Table 10.2-1. Sorption of uranium did not produce a sufficient increase in concentration to be of concern for nuclear criticality in these simulations. The CF of concern for criticality safety was between 3 and 10 (see Table $\mathrm{C}-1)$. Interpolation within the tables revealed that an approximately sixfold concentration is the lowest $\mathrm{CF}$ to raise a criticality safety concern. None of the simulations had CFs above 6 for the time period modeled (Table 10.2-1). The CFs were less than 2 for all cases modeled, and most were less than 1 , indicating that uranium has flushed past the sorption zone. The mobilization of uranium was dominant over sorption of uranium.

In the presence of high concentrations of $\mathrm{CO}_{3}{ }^{2-}$, most of the uranium is quickly flushed out the column. Formation of highly mobile uranium-carbonate complexes is favored, even in the zone with the higher concentrations of sorption sites; under these conditions, $\mathrm{CO}_{3}{ }^{2-}$ complexation outcompetes the sorption sites. This result can be seen in plots of concentration vs distance in the column for various times (breakthrough curves). Time was expressed as a relative unit termed as pore volumes or the number of times the column is flushed with water. The breakthrough curves of dissolved and sorbed uranium move down the model column with time. After only 24 pore volumes, the break-through curves are becoming flat and the uranium is nearly flushed from the column (Fig. 10.2-1). Modest $\mathrm{CO}_{3}{ }^{2-}$ concentrations produce favorable conditions for concentration because uranium can be mobilized, but $\mathrm{CO}_{3}{ }^{2-}$ does not outcompete sorption sites. With these lower $\mathrm{CO}_{3}{ }^{2-}$ concentrations, uranium becomes sorbed in the 8- to 10-m range of the column by the high concentration of sorption sites (Fig. 10.2-2). The concentration of dissolved uranium remains fairly constant through time (pore volumes) when $\mathrm{CO}_{3}{ }^{2-}$ concentrations are lower. At the first time step shown, the dissolved uranium is higher at the bottom of the column because it is still flushing out. The sorbed uranium has not increased over the initial concentration of $0.02 \mathrm{~g} \mathrm{U}$ total $/ \mathrm{cm}^{3}$, but the concentration is higher at the bottom of the column than at the top.

Multiple zones of sorption in the column were modeled to see the effect of intermediate accumulation of uranium. The peak concentration at each zone of high sorption (at 3,5, 7, and $9 \mathrm{~m}$ ) in the column reached nearly the same level; as a result, the changes between the values in the high- and low-sorption concentration zones creates a sawtooth pattern (Fig. 10.2-3). The peak concentration was lower than the run with only one sorption zone. During flushing, the concentration in the third zone increased slightly for some simulations.

Another factor influencing the CF in the sorption zone is the size of the fissile uranium source term. The role of the cell depth (column length) was examined in more detail in additional simulations. There is an 8-m column with an even distribution of initial ${ }^{235} \mathrm{U}$ for the sensitivity analysis. For a simulation based on run 9 except with $0.004 M$ total U (a lower concentration than in Table 10.2-1), this column length produced a CF of 3.5. When the source column increased to $14 \mathrm{~m}$ in length, the CF increased to 4.8 ; for a $19-\mathrm{m}$ column the $\mathrm{CF}$ is 5.8 . Although the increase in CF does not cause a 1:1 linear increase (Fig. 10.2-4), the column length is a significant influence.

\subsubsection{Influence of Oxidized Minerals}

When mineral precipitation was included in the model, little or no change occurred in the uranium concentrations on the sorption sites. For the minerals examined \{rutherfordine $\left(\mathrm{UO}_{2} \mathrm{CO}_{3}\right)$, soddyite $\left[\left(\mathrm{UO}_{2}\right)_{2} \mathrm{SiO}_{4} 2 \mathrm{H}_{2} \mathrm{O}\right]$, and $\mathrm{UO}_{2}(\mathrm{OH})_{2}$-beta $\}$, adsorption dominated precipitation as an immobilizing mechanism in oxidizing conditions. 
Results

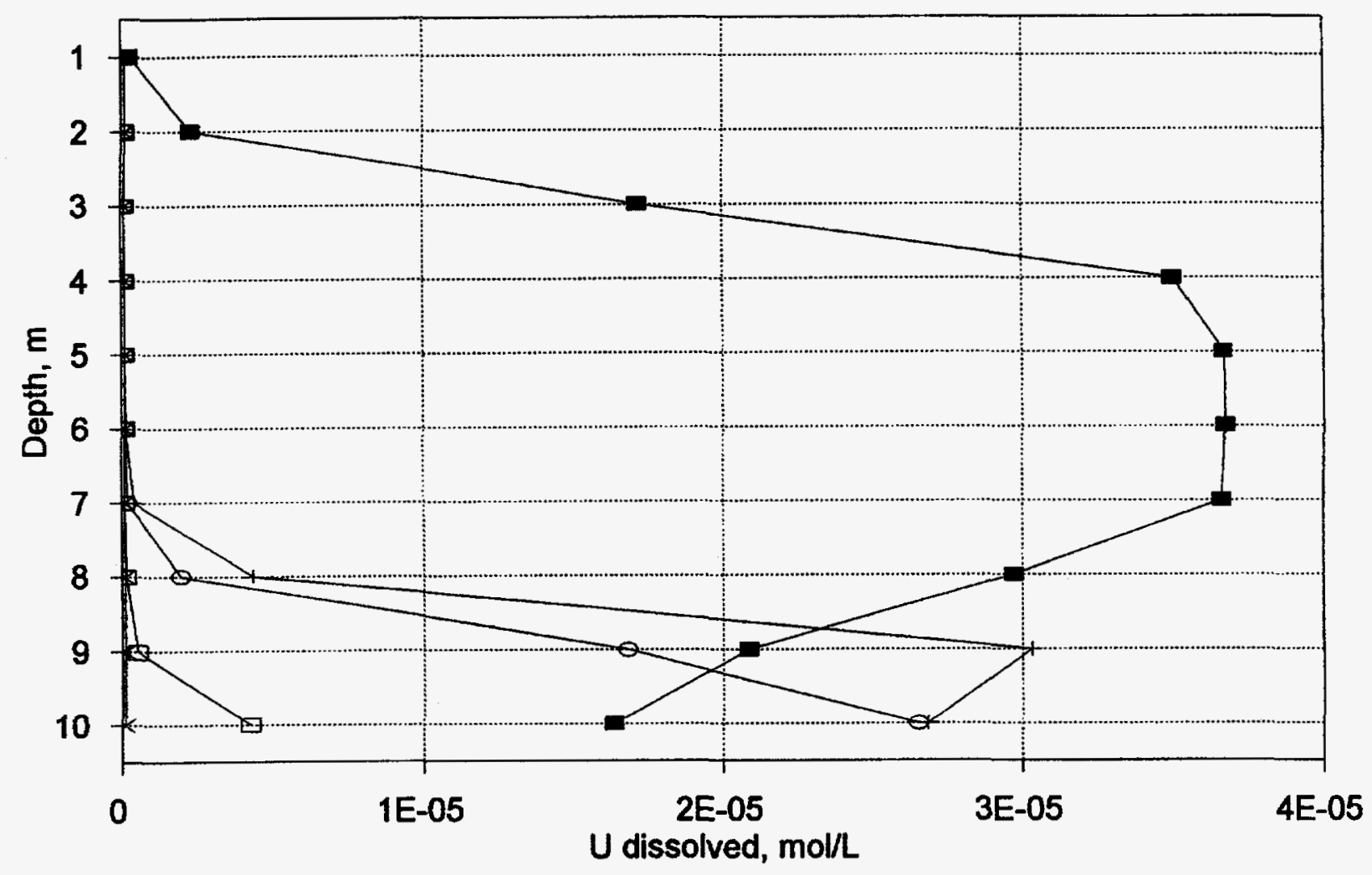

3 pore vol +9 pore vol $\odot 15$ pore vol $\square 21$ pore vol $\nleftarrow 24$ pore vol

Figure 10.2-1 Example of flushing of uranium in solution and on sorption sites. Breakthrough curves are shown for several different time steps, expressed as the number of pore volumes that have passed through the column. The last timestep (8) is essentially flat. Run conditions are those for run number 39 which has an initial $\mathrm{U}_{\text {TOT }}=0.01 M$. 


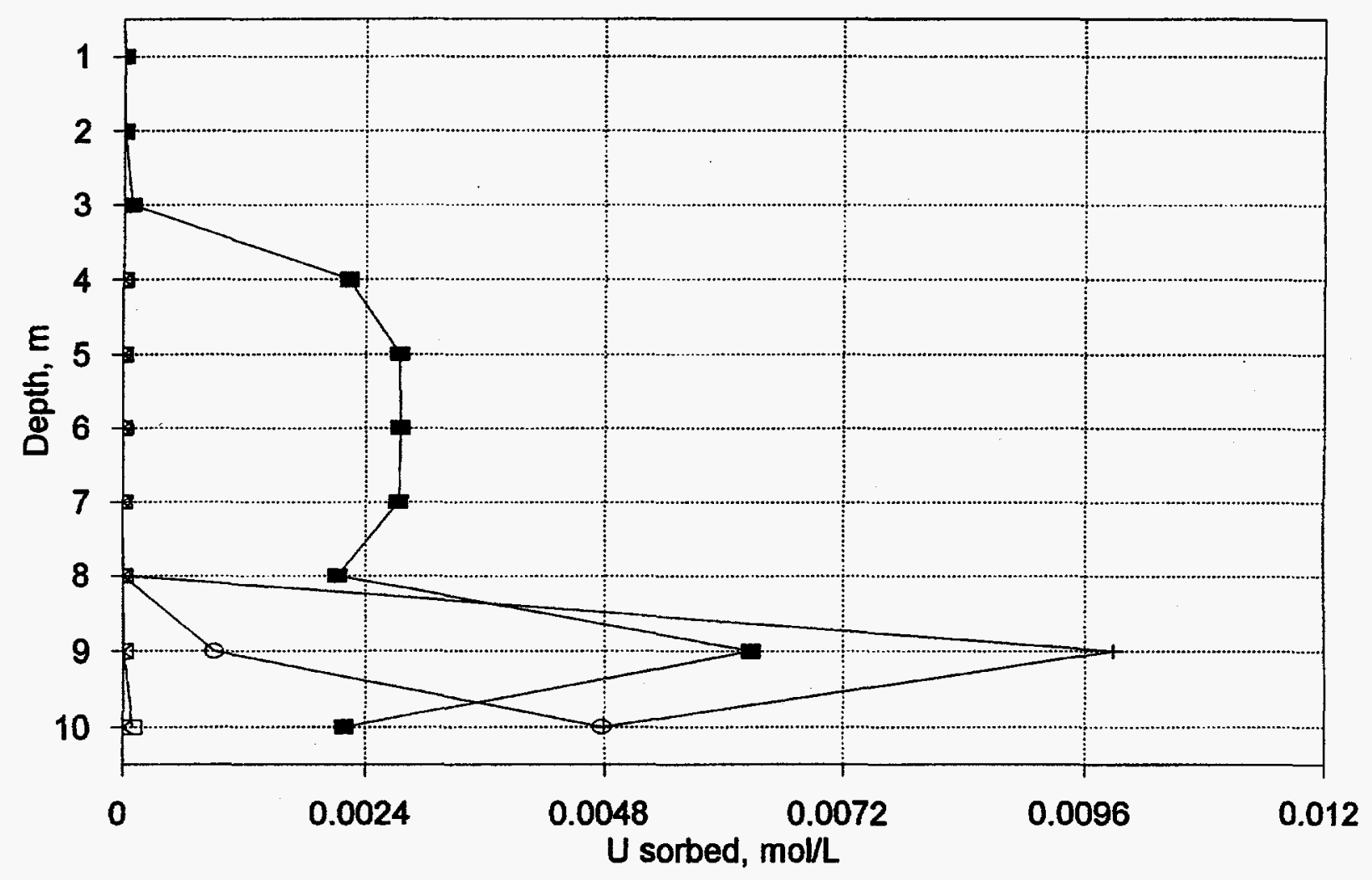

3 pore vol $\longrightarrow 9$ pore vol $\odot 15$ pore vol $\square 21$ pore vol $\rightarrow 24$ pore vol

Figure 10.2-1 (continued) 
Results

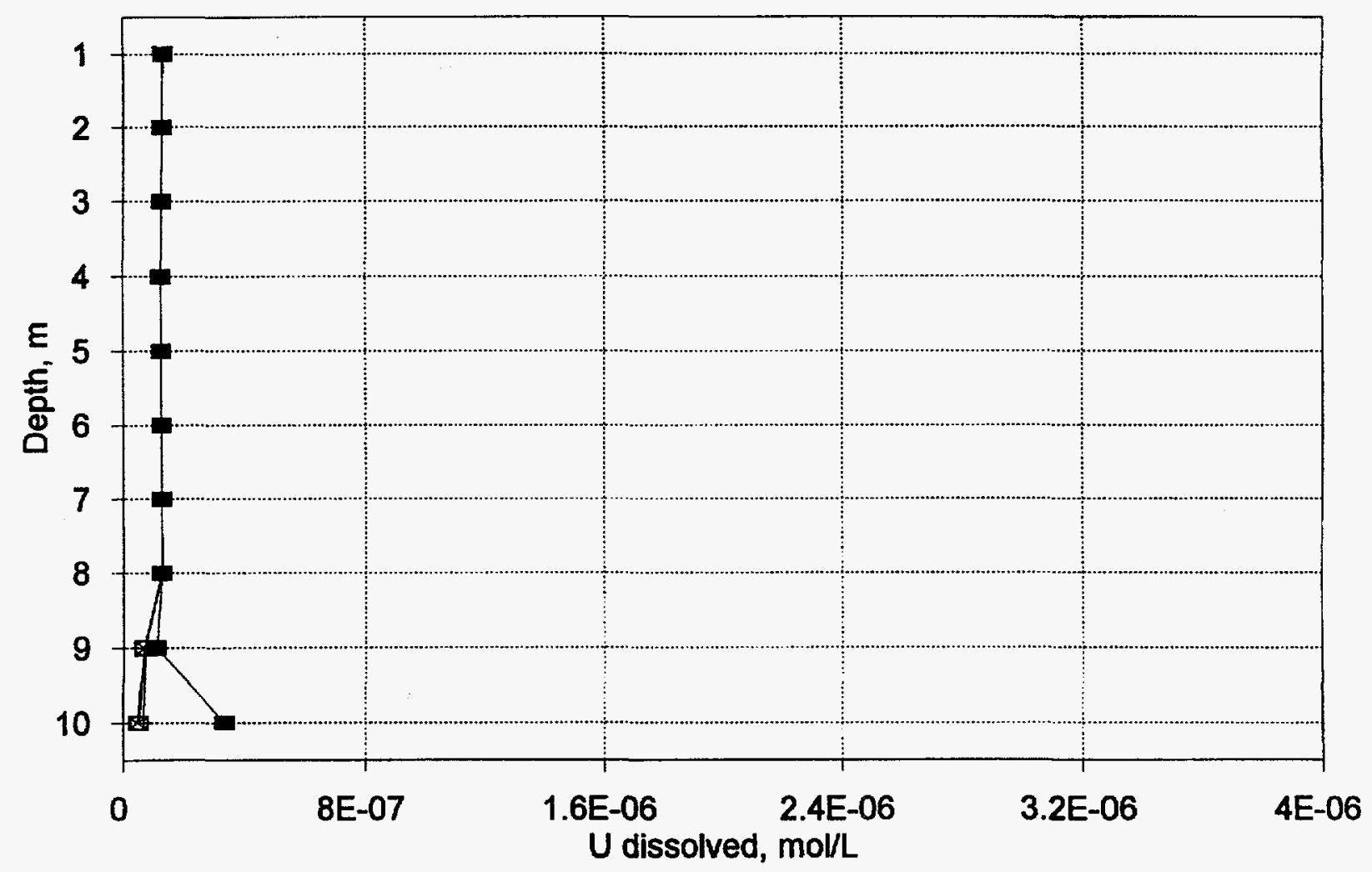

5 pore vol $\rightarrow 10$ pore vol $\odot 15$ pore vol $\square 20$ pore vol $\rightarrow-25$ pore vol

Figure 10.2-2 Example of sorption on zone at bottom of column with lower $\mathrm{CO}_{3}^{-2}$ concentration than shown in Fig. 10.2-1. Breakthrough curves are shown for several different time steps, expressed as the number of pore volumes that have passed through the column. The sorbed uranium concentrates in a localized zone shown by the peak, but the dissolved uranium has a fairly level concentration. Run conditions are for run number 9 which has an initial $\mathrm{U}_{\text {тот }}=0.02 M$. Note the change in scale for dissolved uranium relative to Fig. 10.2-1. 
Results

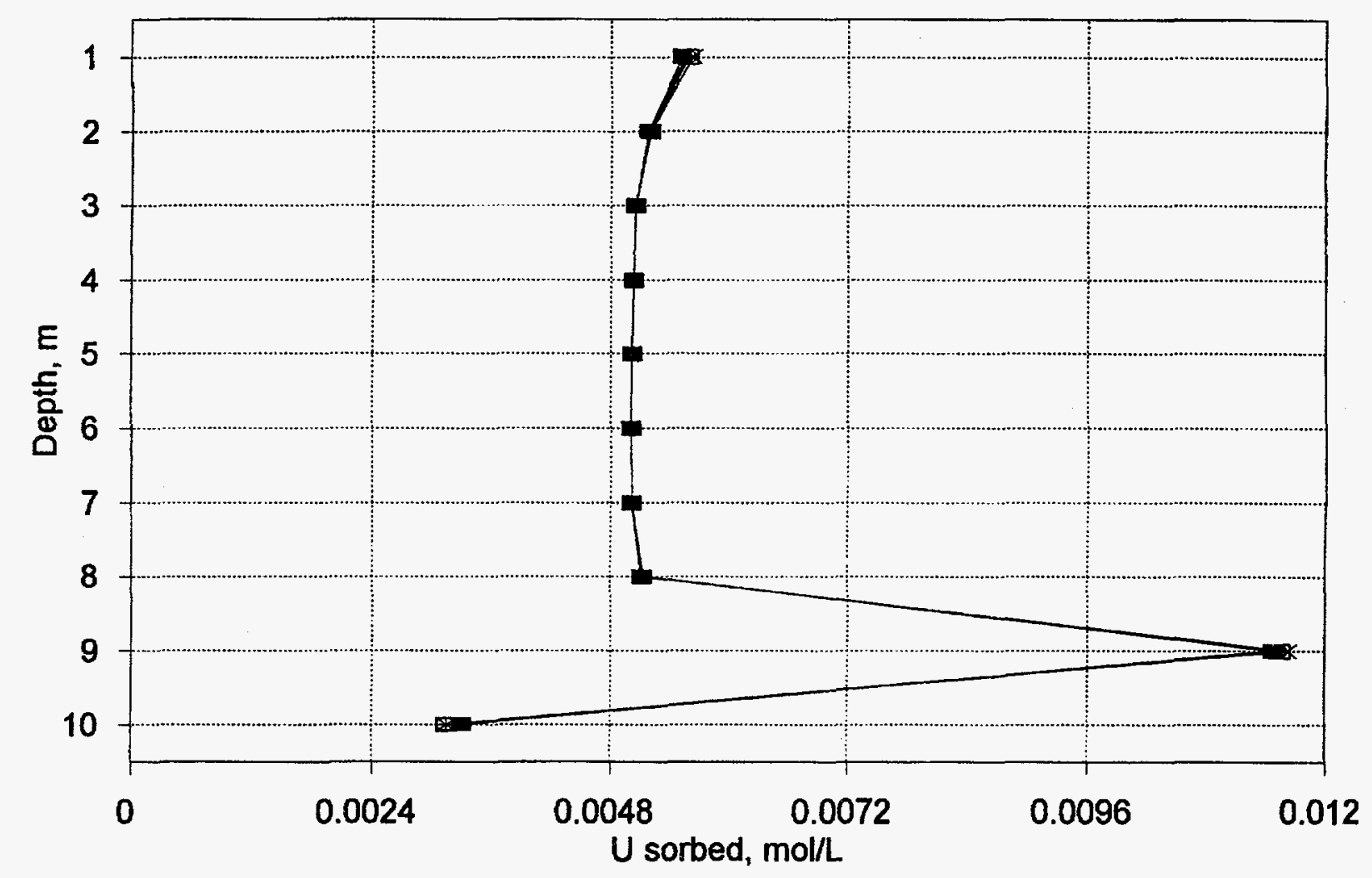

5 pore vol $\rightarrow 10$ pore vol $\oslash 15$ pore vol $\square 20$ pore vol $\rightarrow 25$ pore vol

Figure 10.2-2 (continued) 
Results

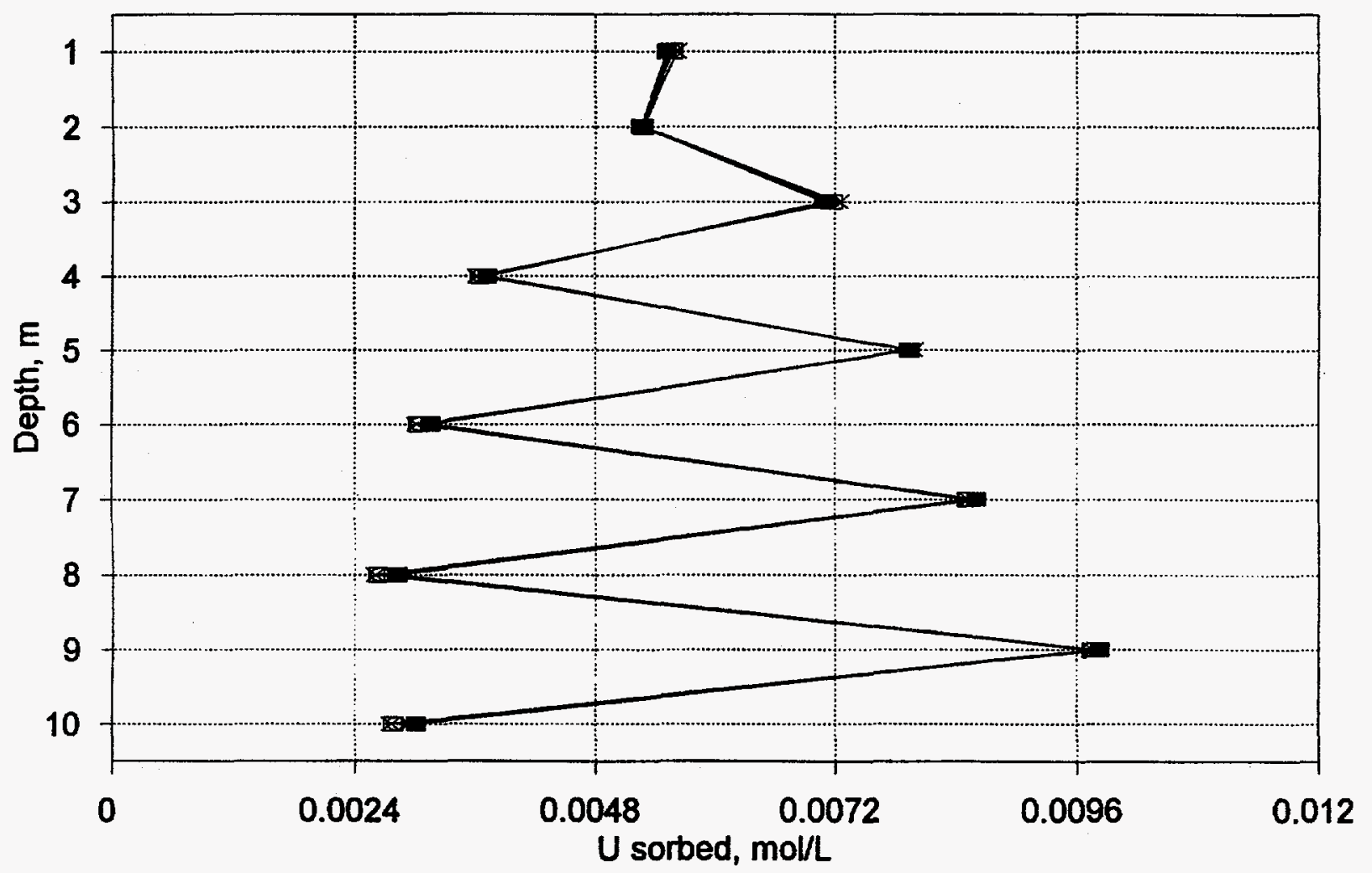

5 pore vol $\rightarrow 10$ pore vol $\oslash 15$ pore vol $\boxminus 20$ pore vol $\rightarrow-25$ pore vol

Figure 10.2-3 Example of sorption on multiple zones of high sorption within the column. The sawtooth pattern is created by alternation of high- and low-sorption site concentrations. The run is based on run 9 with an initial $\mathrm{U}_{\text {TOT }}=0.02 M$. The peak concentration was similar in the different zones and lower than the run with only one sorption zone (Fig. 10.3-2)

NUREG/CR-6505,

Vol. 1 
Results
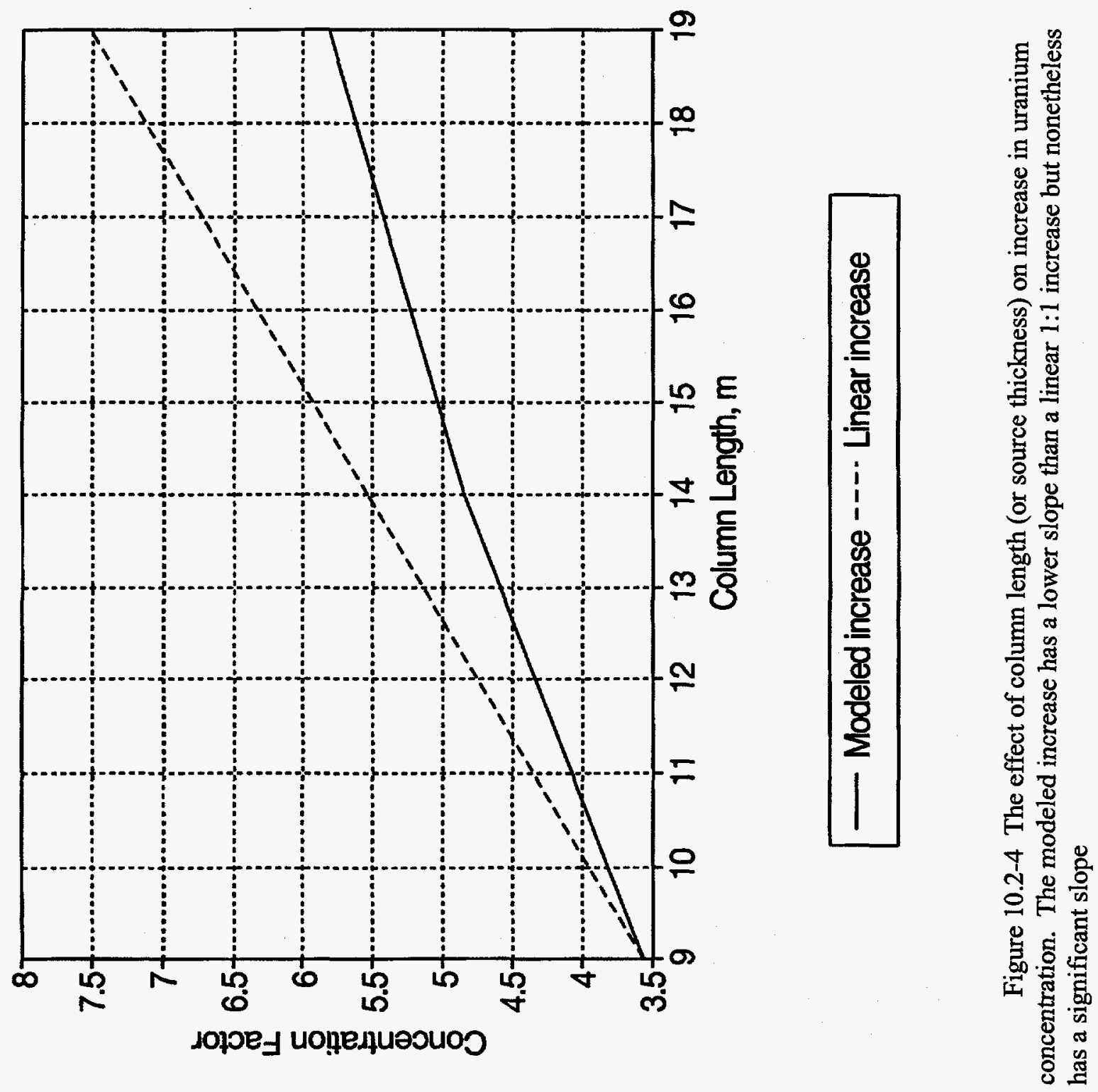
Results

The minerals did not precipitate because the equilibration of uranium with sorption sites left little uranium in solution. When the sorption zone was at the end of the column, the mobile uranium concentrated into a smaller zone than the initial configuration throughout the column, and the concentration reached $0.004 \mathrm{~g}$ of total $\mathrm{U} / \mathrm{cm}^{3}$ for the example shown (Fig. 10.2-5). However, when the solution was equilibrated with $\mathrm{UO}_{2}(\mathrm{OH})_{2}$-beta in the absence of sorption sites, precipitation occurred throughout the column. The concentration reached only $0.00032 \mathrm{~g}$ of total $\mathrm{U} / \mathrm{cm}^{3}$ for this same example because the precipitate was spread over the top $8 \mathrm{~m}$ of the model columns.

\subsubsection{Reducing Conditions}

The presence of zones with reducing conditions constitutes an important immobilization scenario because the geochemical CF is not limited by the availability of sites as in the sorption scenario. Furthermore, complexation with the mobilizing agent $\left(\mathrm{CO}_{3}{ }^{2-}\right)$ is less important given the low solubility of reduced uranium minerals. Of the 40 runs shown in Table 10.2-1, 12 runs had potential for increasing the concentration of uranium.

Transport was not modeled explicitly in the reducing scenario because of stability problems in redox zones for the first version of the code. Instead, the increase in uranium concentration in a reducing zone was estimated by evaluating the factors that would enhance the mobilization of uranium so that uranium would flush to the bottom of the column and concentrate in the reducing zone. This strategy was based on two factors: (1) the nearly complete demobilization of uranium by precipitation of reduced phase minerals and (2) the need to mobilize a large portion of the uranium initially spread out in the model column. Geochemical modeling of the extent of precipitation of uranium under reducing conditions (pe of -4 or less) clearly demonstrated that most uranium entering a reduced zone would be immobilized (e.g., Fig. 7.1-3). Reducing zones precipitate uranium readily. However, a strongly reducing (e.g., methanogenic) environment is preferable for precipitating reduced uranium (Raffensberger and Garvin, 1995). Because of the low concentrations of uranium $\left(<1 \times 10^{-9} M\right)$ in solution when equilibrated with reduced minerals, it was assumed that all of the uranium in a reducing zone was precipitated. The second hypothesis, that nearly all of the uranium in the disposal cell needed to be mobilized, is based on the geometry of the zones. For an 8-m thickness of initially uniformly distributed uranium to concentrate in a $1-\mathrm{m}-$ thick reducing zone, the maximum CF is 8 (if all of the uranium is mobilized). This geometric CF has the potential to produce nuclear criticality under some conditions (Tables 10.1-1 and 10.1-2). With these assumptions, the problem was reduced to mobilizing the uranium and flushing nearly all of it to a hypothetical reducing zone.

The amount of uranium mobilized was estimated by doing a mass balance on uranium in the model. The modeled uranium concentration was summed over each of the model cells. The total initial uranium minus the final uranium gave the amount mobilized. The concentration of mobilized uranium is multiplied by the geometric factor of 8 to give the concentration in a hypothetical reducing zone. Then it is divided by the initial concentration to obtain the total CF (Table 10.2-1). For 12 of the 40 runs, this CF is greater than 6, and most of these are close to the maximum of 8 allowed by the geometry. Additional flushing could occur at longer times, but this sampling is fairly representative. Thus mobilization to a reducing zone seems to be a possible scenario for increasing uranium concentration.

\subsubsection{Sensitivity Analysis}

A sensitivity analysis was conducted to evaluate uranium mobility over a range of parameter values and to try to quantify the influence of different parameters. The effects of six parameters were evaluated for sorption of uranium and four parameters (excluding the two parameters related to sorption) for flushing of uranium.

NUREG/CR-6505,

Vol. 1 
Results

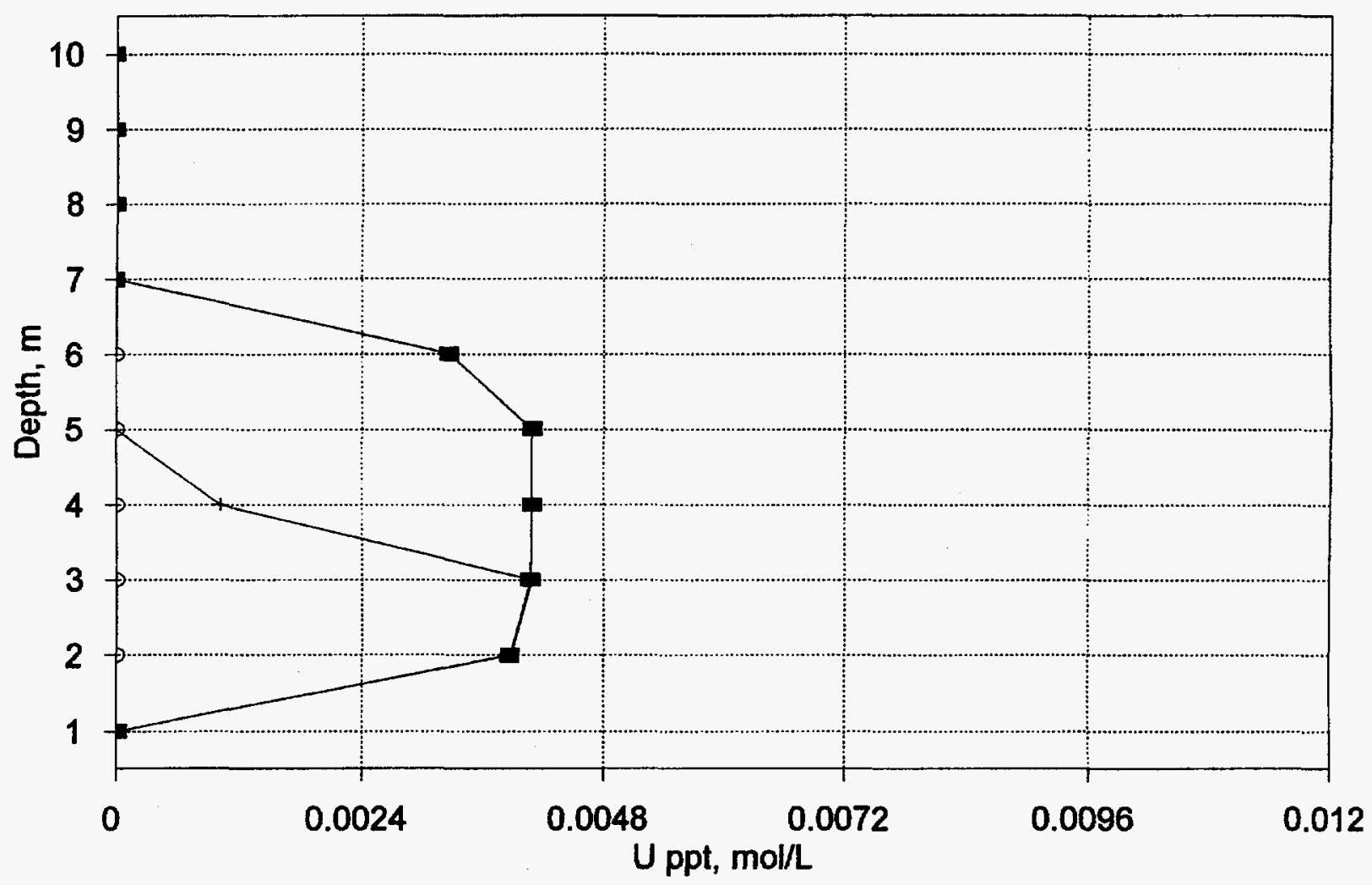

\section{5 pore vol +5 pore vol $\odot 7.5$ pore vol}

Figure 10.2-5 Example of uranium demobilization on sorption sites vs a mineral precipitate $\left[\mathrm{UO}_{2}(\mathrm{OH})_{2}{ }^{-}\right.$ beta]. Sorption sites at the end of the model column concentrate uranium. Precipitation occurs throughout the column and results in a lower concentration of uranium. High sorption sites are omitted from the run with mineral equilibration only. Run conditions are for run 9 with an initial $\mathrm{U}_{\text {Tот }}=0.02 \mathrm{M}$. 
Results

Multivariate analysis was used to calculate regression coefficients for each variable. The higher the coefficient, the greater the influence of the variable. Rank regression was used.

The multivariate regression was not used to evaluate the importance of parameters for sorption. Although coefficients were calculated for the CFs from sorption, the correlation coefficient is low $(0.65)$, indicating a poor fit to data. The CFs are low, and the data are clustered. See, for example, the relationship between initial uranium (input as uranium molarity) and the CF resulting from uranium absorption (Fig. 10.2-6).

The multivariate regression for CFs from mobilization to a reducing zone had a correlation coefficient of 0.9 . The most important factor in moving the uranium to the reducing zone is the $\mathrm{CO}_{3}{ }^{2-}$ concentration, which is the primary mobilizing complex. The $\mathrm{CO}_{3}{ }^{2-}$ was directly correlated with a coefficient of 0.59 (Fig. 10.2-7). Uranium concentration was also significant but had an inverse correlation coefficient of -0.52 . This inverse relationship suggests that high concentrations of uranium can limit the CF because more uranium must be mobilized. However, it is important to note that the relationship between initial uranium and flushing is influenced by other factors as well and cannot provide the only limit on resulting CFs, as evidenced by some scatter in the plot of Fig. 10.2-8. Velocity is also a significant variable, and slower velocities mobilized less uranium. It is possible that longer times would eventually lead to additional mobilization to the reducing zone in these cases. The $\mathrm{pH}$ was not as important, apparently because the total $\mathrm{CO}_{3}{ }^{2-}$ concentration was sufficient to create free anions for uranium complexation.

In summary, the sensitivity analysis was useful in examining the interplay between various parameters. The behavior over the range of parameters modeled indicated that a narrow combination of factors led to conditions that could be of concern for criticality for the case of flushing uranium to a reducing zone. For the case of sorption, no runs resulted in CFs of concern, but longer disposal columns (i.e., thicker waste disposal cells) could cause larger increases in uranium concentration. No single variable dominated the behavior of uranium, so it is important to evaluate multiple factors.

\subsubsection{Relevance to the Envirocare of Utah, Inc., Site}

The Envirocare site was not explicitly modeled; however, the sensitivity analysis and one additional set of simulations provided useful information for evaluating the site and suggested that the concentration of ${ }^{235} \mathrm{U}$ at the site is unlikely to be a nuclear safety concern. A site-specific model of the Envirocare site would require more detailed information on hydraulics (e.g., can recharge occur and lead to significant downward migration of solutions?) and geochemistry (e.g., what are the available mobilizing and binding agents? what are the competing complexes?). The present analysis assumes vertical flow through a 10-m column and sorption at the bottom of the column.

For the simulations here, the sorption site concentration was set at a high value to model a worst-case scenario. The $\mathrm{CO}_{3}{ }^{2-}$ concentration was varied. Other selected parameter values presented worst-case scenarios: (1) high $\mathrm{pH}$ to dissociate $\mathrm{CO}_{3}{ }^{2-}$ complexation from $\mathrm{HCO}_{3}{ }^{-}$and (2) high velocity. However, the total concentration of uranium was modeled with a low value that approximated site-specific conditions. The determined uranium concentration estimated from disposal records tabulated in Appendix B is $9.5 \times 10^{-4} \mathrm{~g} / \mathrm{cm}^{3}\left(8 \times 10^{-3} \mathrm{M}\right.$ total U) and the estimated average enrichment is $0.42 \%$ or only $4 \times 10^{-6} \mathrm{~g} / \mathrm{cm}^{3}\left(3.3 \times 10^{-5} \mathrm{M}\right){ }^{235} \mathrm{U}$.

NUREG/CR-6505,

Vol. 1 


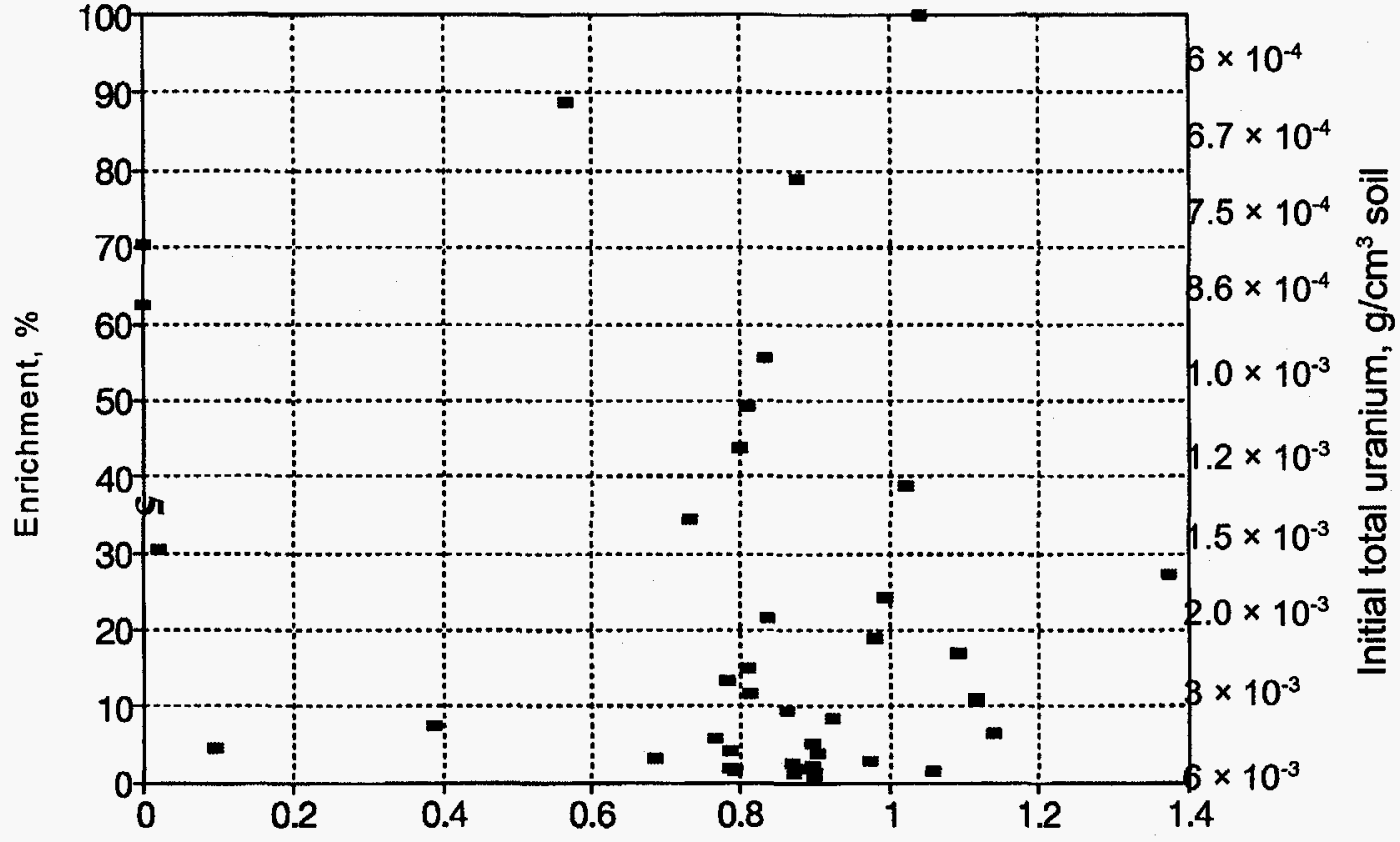

Concentration Factor on Sorption Sites

Figure 10.2-6 Initial uranium (in terms of ${ }^{235} \mathrm{U}$ enrichment relative to $6 \times 10^{-4} \mathrm{~g} / \mathrm{cm}^{3}$ limit on ${ }^{235} \mathrm{U}$ ) vs $\mathrm{CF}$ for uranium on sorption sites. There is no distinct trend because most of the runs showed uranium flushing past the sorption sites 


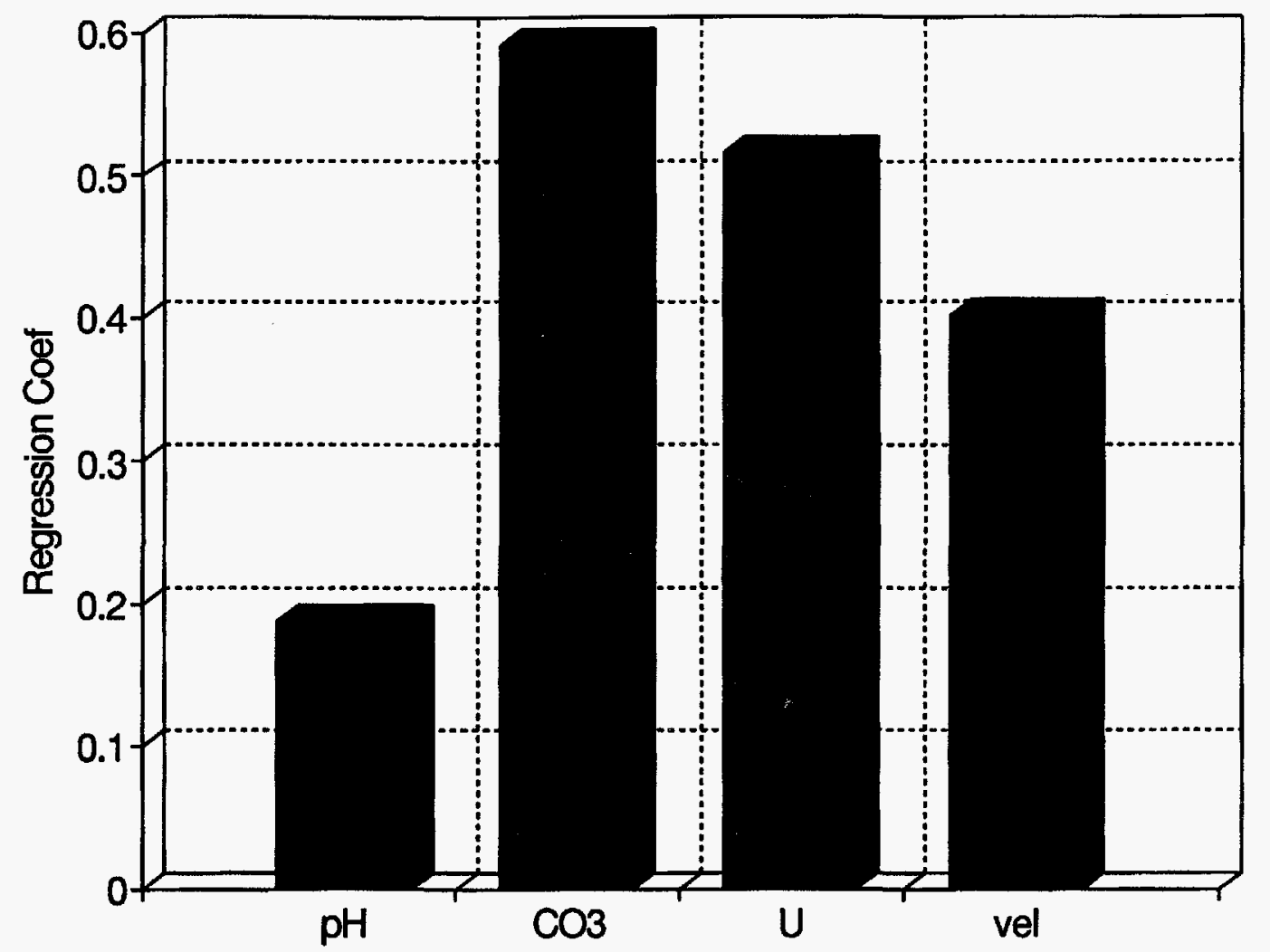

Figure 10.2-7 The absolute values of the regression coefficients for multivariate regression on the $\mathrm{CF}$ for mobilization of uranium to a reducing zone shows that several parameters were important in predicting the $\mathrm{CF}$. The height of the bar shows the relative importance of the parameters 


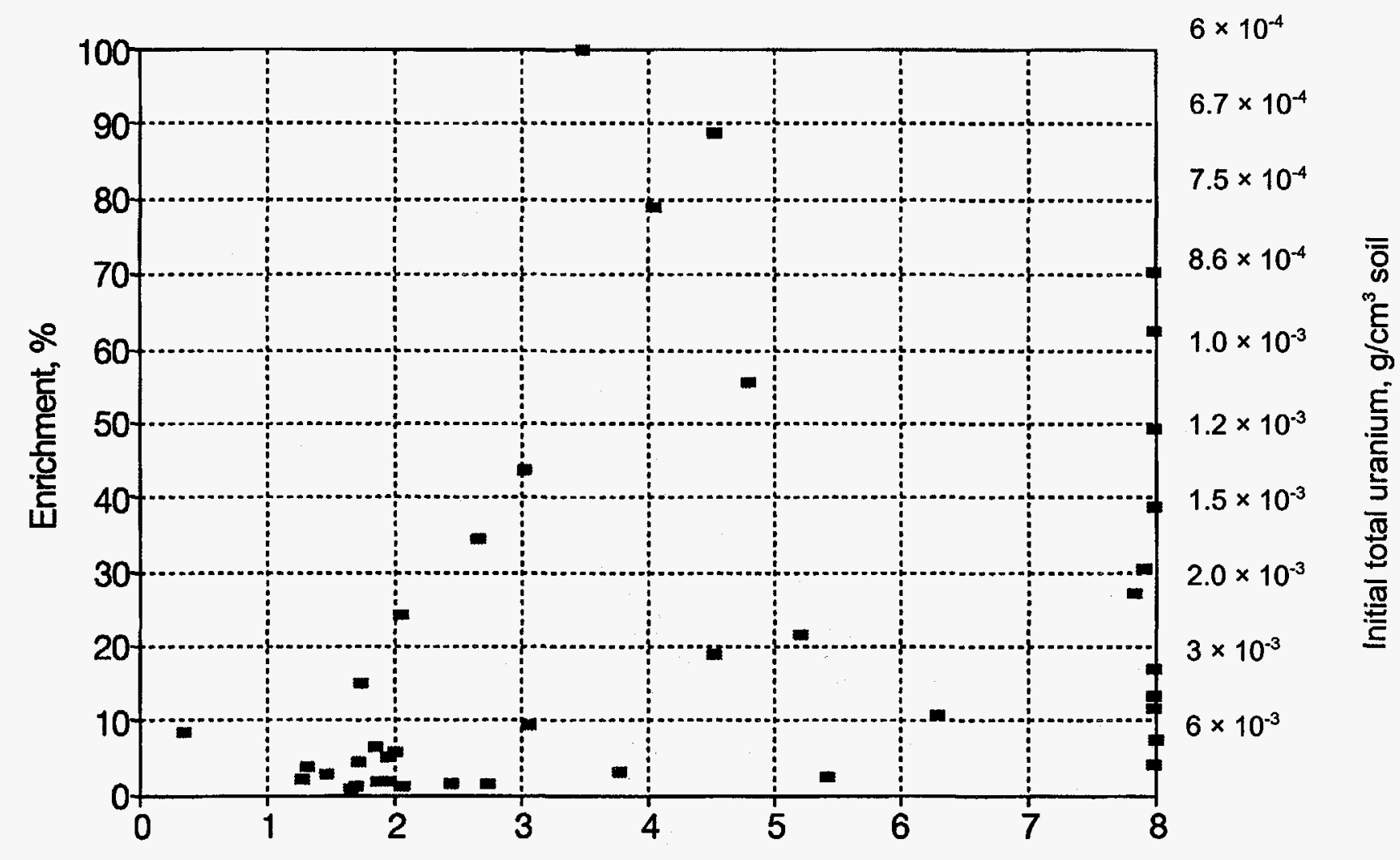

Concentration Factor for Mobilization to a Reducing Zone

Figure 10.2-8 Initial uranium (in terms of ${ }^{235} \mathrm{U}$ enrichment relative to $6 \times 10^{-4} \mathrm{~g} / \mathrm{cm}^{3}$ limit on ${ }^{235} \mathrm{U}$ ) vs CF for mobilization to a reducing zone shows that the $\mathrm{CF}$ tends to increase with reduced initial uranium loading (higher enrichment), but there is considerable scatter in the data. This scatter indicates the importance of other parameters as well in predicting the CF for mobilization to a reducing zone. A single parameter did not dominate the trends 
Results

The breakthrough curves of uranium concentration in the modeled column (Fig. 10.2-9) showed different peaks for the various concentrations of $\mathrm{CO}_{3}{ }^{2-}$ (the mobilizing agent). The largest peak observed with the reported disposal concentrations was $0.085 \mathrm{M}$. Although this is an increase of a factor of about 10 using the low $0.42 \%$ enrichment, the ${ }^{235} \mathrm{U}$ concentration is only $3.6 \times 10^{-4} M$ (or $0.4 \times 10^{-5} \mathrm{~g} / \mathrm{cm}^{3}$ ). This concentration is about two orders of magnitude below any concentration of concern for nuclear criticality.

For ${ }^{235} \mathrm{U}$ at this initial concentration $\left(4 \times 10^{-6} \mathrm{~g} / \mathrm{cm}^{3}\right)$ to be of concern in criticality safety analysis, the concentration would have to increase to a value between 0.0036 and $0.006 \mathrm{~g} / \mathrm{cm}^{3}$ or a CF (CF) from 900 to 1500 . An increase in uranium concentration of this magnitude is not possible. First, it would exceed the sorption capacity of the soil. Secondly, even assuming immobilization by precipitation in a reducing zone, there simply is not a sufficient mass of uranium in a vertical column of the waste cell. For example, line $42(\mathrm{CF}=833.3)$ and line 49 $(\mathrm{CF}=1666.7)$ in Table $\mathrm{C}-1$ require areal densities of 28.8 and $38.7 \mathrm{~kg} / \mathrm{m}^{2}$ to reach nuclear criticality.

These areal densities exceed the available source of uranium. Other scenarios can and should be considered, but any analysis will have to overcome the very low initial concentrations of ${ }^{235} U$. Scenarios might increase the $C F$ by including precipitation in a reducing zone; however, the site is unsaturated and likely has oxidizing conditions through most of the soil. Scenarios that might also increase the CF include the migration of uranium from multiple directions (e.g., creation of a spherical body) to increase the source mass. In any case, the unsaturated conditions would greatly increase travel time at the site, although behavior during storm events should be studied. As seen from the example given here, the low initial mass is a significant inhibition to the increase in concentration of ${ }^{235} \mathrm{U}$ at this site for any scenario.

\subsubsection{Timing}

In these simulations, the number of pore volumes required to flush uranium from the oxidized zone varied from 2 to 50. Corresponding travel times are from 1 to 10 years for saturated conditions. For a setting that is typically unsaturated, these fast travel times represent unrealistic, worst-case scenarios. Travel times in the unsaturated zone are assumed to be two to three orders of magnitude slower than for saturated conditions. This assumption results in a range of unsaturated travel times from about 100 to 10,000 years. These estimates contain considerable uncertainty but are comparable to the long times observed for formation of concentration zones in soil (Sect. 4). Velocities drop sharply as soil moisture content drops, but the exact relationship between soil moisture content and velocity is nonlinear and dependent on the particular soil. Furthermore, unsaturated conditions are inherently transient; thus, velocity will vary over time. If a few periods of saturation occur, solutes can move quickly and then remain stable for a period of time. It has been estimated at ORNL that up to $90 \%$ of contaminant flushing occurs during brief periods of saturation. Although modeled sorption of uranium did not produce increases in uranium sufficient for criticality, peak uranium concentration was reached at times similar to flushing times.

NUREG/CR-6505, Vol. 1 
Results

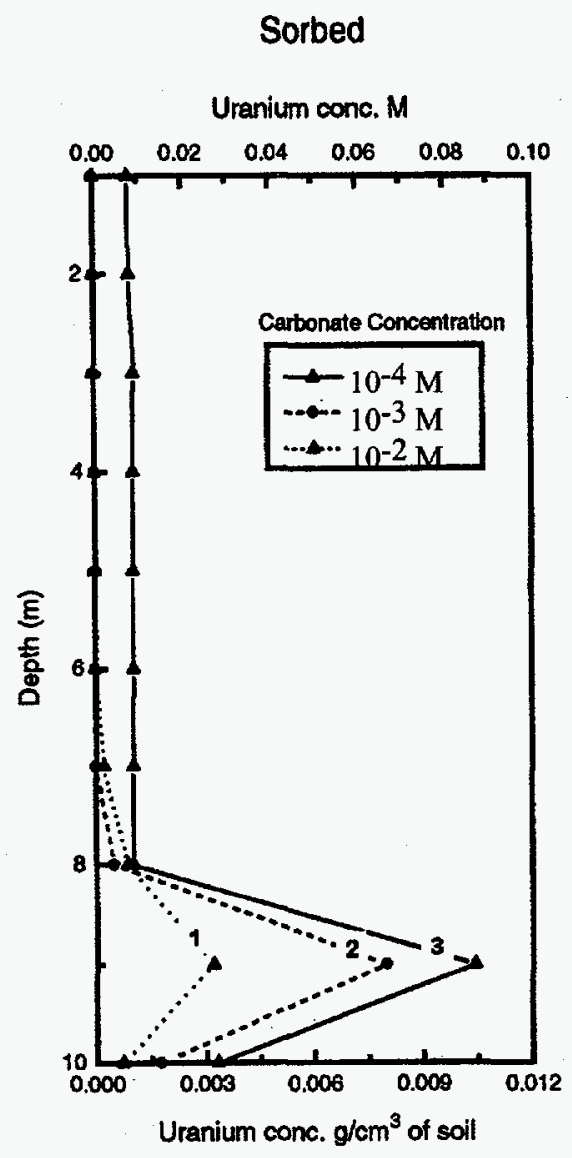

Figure 10.2-9 Results of a scenario with worst-case conditions for sorption (high concentration), but low initial concentration of uranium (based on disposal conditions reported at Envirocare, Utah); breakthrough curve of uranium concentration on sorption sites vs distance for three different carbonate concentrations. The low carbonate concentration of carbonate produces the highest peak. The inflow to the model column is at the top, and outflow is at the bottom 
Results

\subsection{INTEGRATION OF GEOCHEMICAL MODELING AND CRITICALITY EVALUATION}

There are four questions to address in integrating the geochemical modeling and the criticality evaluation:

1. Is the initial mass of uranium sufficient to provide the mass calculated for critical configurations?

2. Are the thicknesses calculated for critical configurations reasonable in comparison to analogs seen in nature?

3. Are the CFs calculated for critical configurations comparable to hydrogeochemical CFs? Do the observed CFs for geochemical processes produce criticality safety concerns?

4. How do the transport rates modeled affect approach to criticality? How does the hypothesized approach to criticality affect the criticality event?

These questions are discussed in the following sections, along with a summary of the implications of the presented work.

\subsubsection{Initial Mass of Uranium}

The criticality calculations for slab geometry provide a thickness and also a density of uranium needed to reach nuclear criticality. The density of uranium in a critical thickness can be evaluated to consider whether disposal levels provide a sufficient source term. The areal density can be converted to a disposal thickness, assuming a soil concentration of $0.0006 \mathrm{~g} / \mathrm{cm}^{3}$ (Fig. 10.3-2).

The areal density for the nominal soil varied between 4.7 and $8.6 \mathrm{~kg} / \mathrm{m}^{2}$ to attain critical conditions for a CF of 10 (Table C-1). If the dry soil areal density is spread out through a volume of soil to attain a volume density of $0.0006 \mathrm{~g} / \mathrm{cm}^{3}$, then the thickness needs to be greater than $15 \mathrm{~m}$. This is somewhat greater than the average thickness of an Envirocare disposal cell. The average thickness of a disposal cell is approximately $10 \mathrm{~m}$. The cell thickness required as a source for the minimum areal density under wet conditions for CFs of 10 and 33 (Tables $\mathrm{C}-1$ and $\mathrm{C}-2$ ) is somewhat less than 10 (Fig. 10.4-2). All of the other CFs would require greater thicknesses to provide sufficient uranium for a critical thickness (Fig. 10.3-3). The areal densities for $\mathrm{SiO}_{2}$ soil tend to be lower; thus they don't require as large a thickness for the initial deposit of uranium. In summary, the disposal thickness limits the range of configurations that can reach a critical concentration, but there is sufficient uranium mass for criticality safety concern.

\subsubsection{Calculated Thicknesses}

Evaluation of reasonable thicknesses can be addressed through consideration of analogue studies of ore deposits and landfills. For the slab shapes, the calculated thicknesses are less than $2 \mathrm{~m}$ (Fig. 10.3-1). Layers of mineral concentration exceeding this thickness are observed in soils and mineral deposits. In landfill construction, liners 


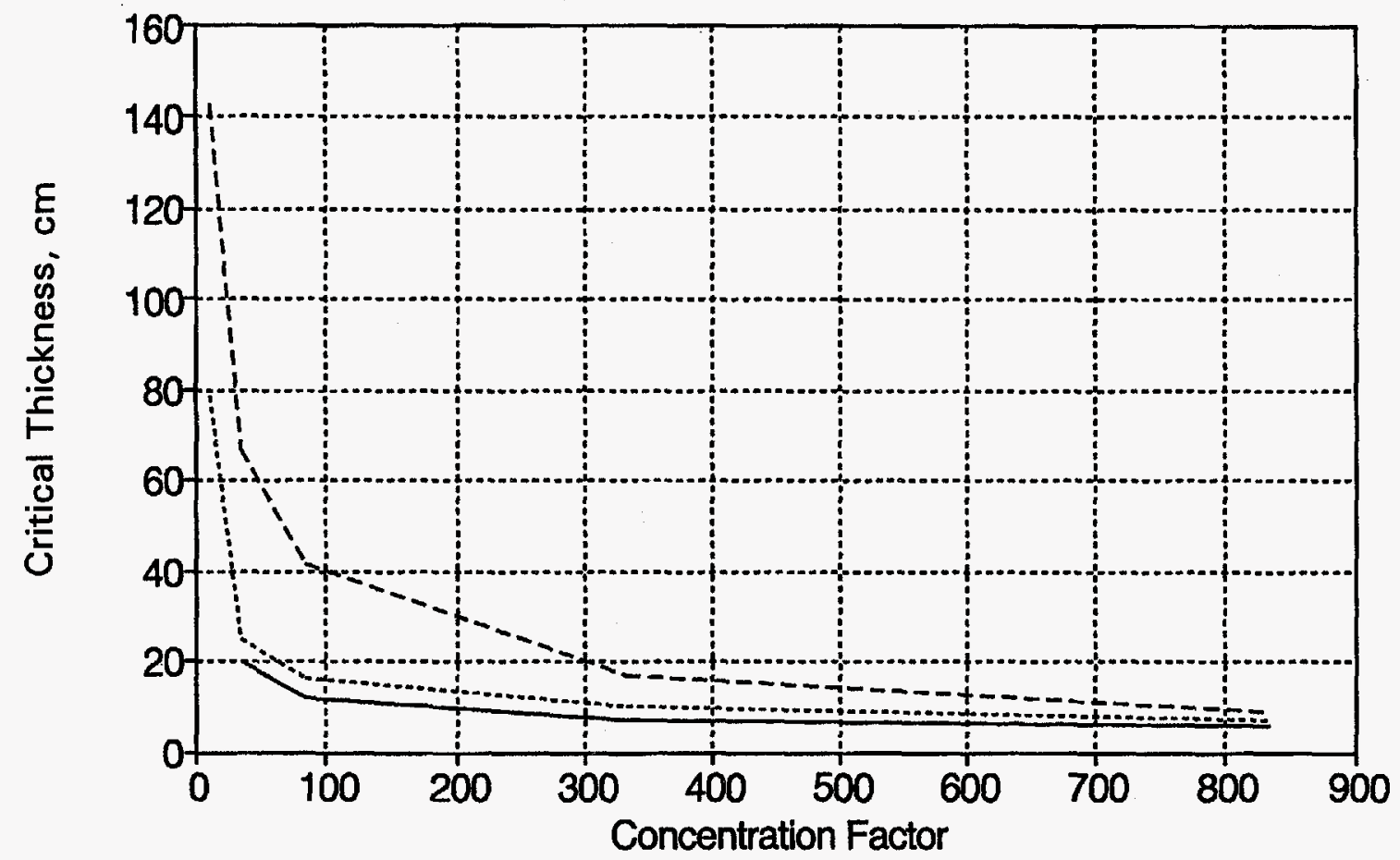

$$
-\cdots 0 \text { sat } \quad \cdots \cdots \cdot 0.16 \text { sat }-0.33 \text { sat }
$$
than $2 \mathrm{~m}(200-\mathrm{cm})$ in thickness are needed, even for low CFs. Three different water saturation contents are shown; dry configurations require somewhat thicker slabs 


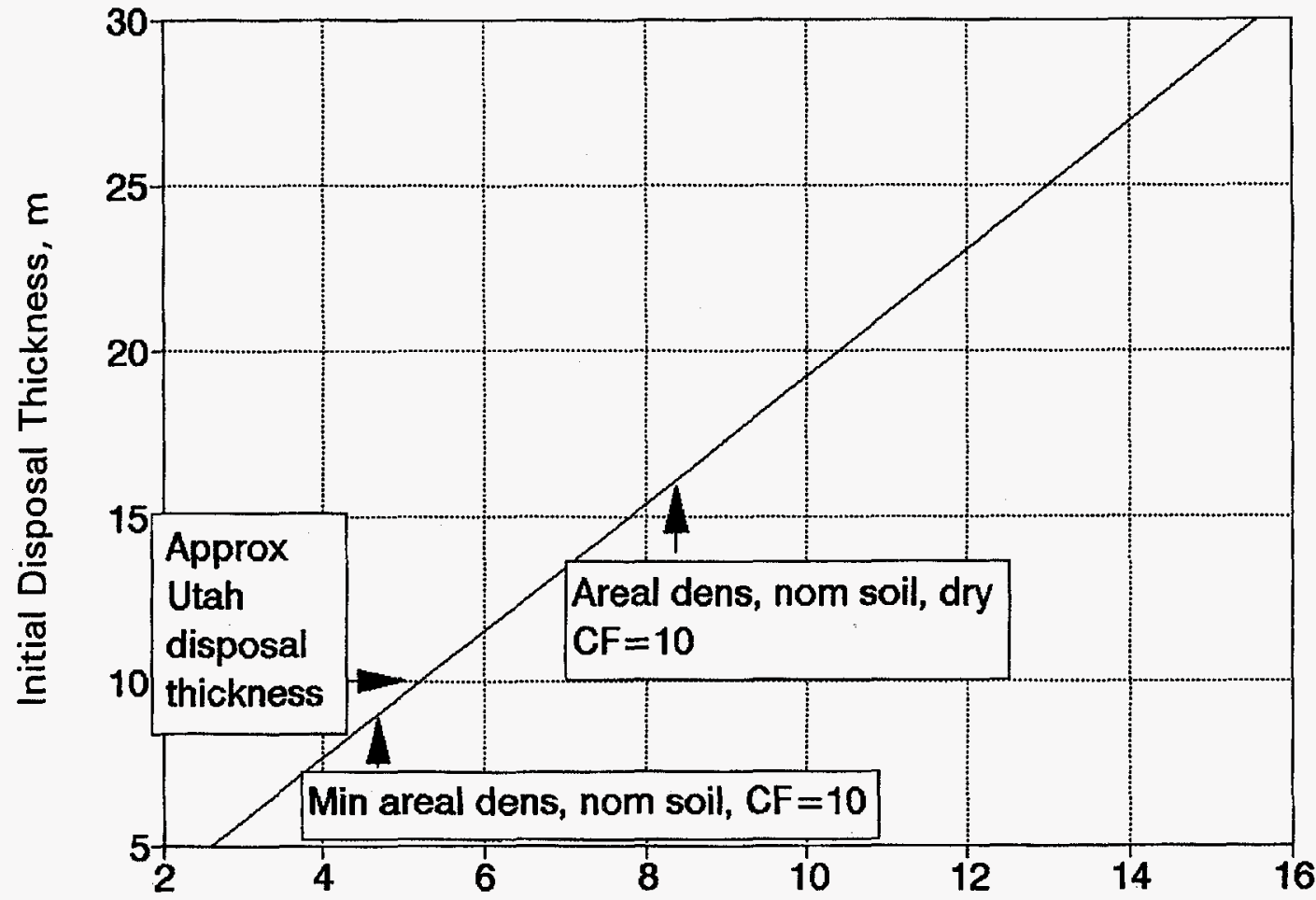

Uranium Areal Density, $\mathrm{kg} / \mathrm{m}^{2}$

Figure 10.3-2 Initial disposal thickness needed for concentration to a critical slab as a function of uranium areal density assuming $0.0006 \mathrm{~g} \mathrm{U} / \mathrm{cm}^{3}$ soil. The figure shows that fairly large disposal-cell thicknesses would be required for many of the critical configurations summarized in Table $\mathrm{C}-1$. This information could be used to place limits on disposal-cell thicknesses 


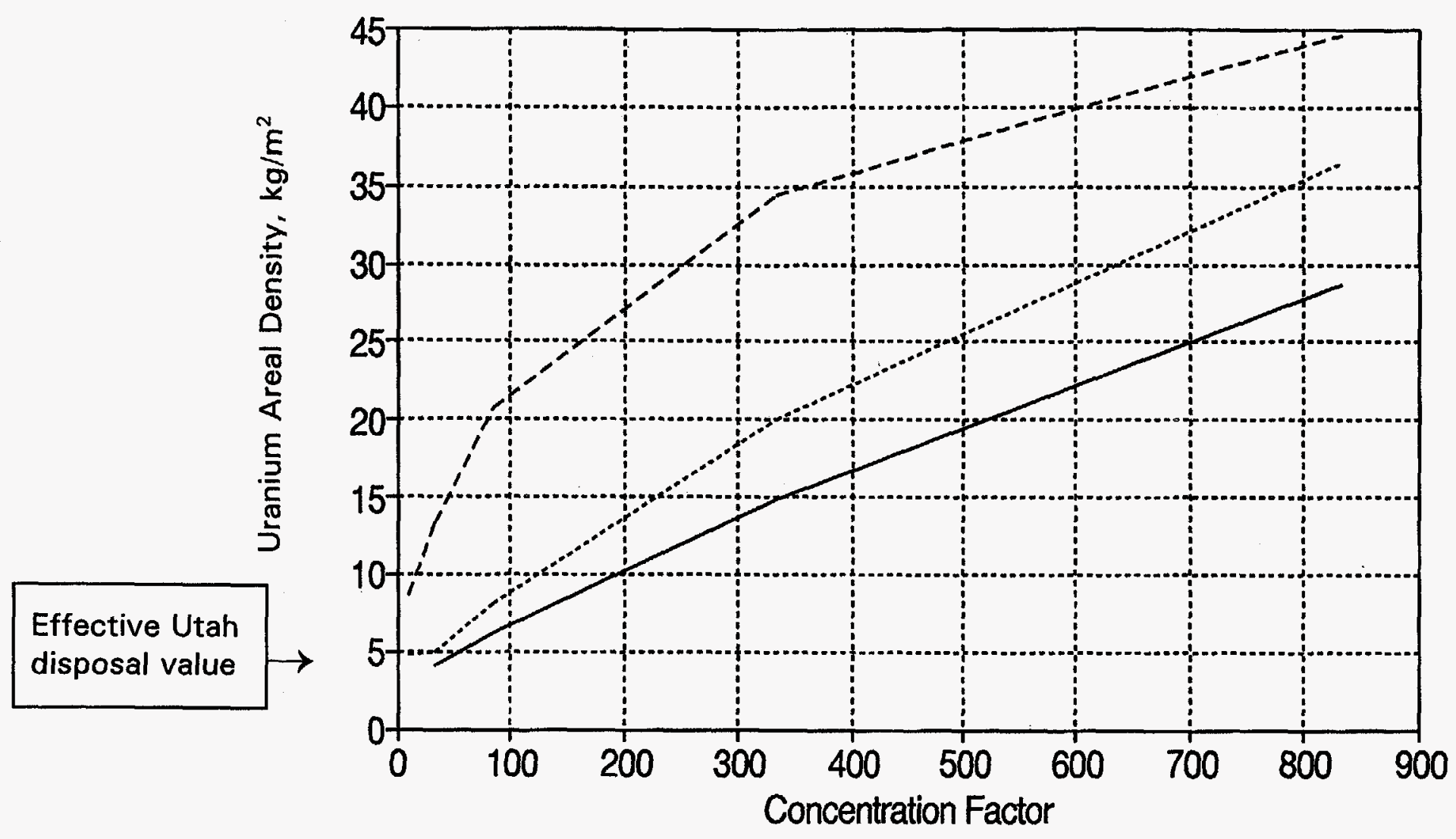

帘

Figure 10.3-3 Uranium areal density for a critical slab (see Table C-1) as a function of CF at various water saturation values. The figure shows that areal density (and hence disposal thickness) increases as the water saturation content decreases, and that it usually increases with the CF. The regulatory disposal limit for Utah is shown to indicate there are some areal densities at or below the limit with potential for criticality safety concern. 
Results

of this thickness that create geochemical differentiation could also be found. For cylindrical and spherical shapes, the sizes are somewhat larger than observed bodies in soil-forming processes.

\subsubsection{Comparison of Concentration Factors}

Two geochemical processes were considered: concentration in a zone of higher sorption and concentration in a redox zone. The modeled processes were sorption and flushing of the uranium.

For the case of sorption, the modeled CFs did not produce critical configurations. The CFs were less than 2 for all cases modeled. The mobilization of the uranium overwhelmed the sorption process.

However, mobilization of uranium can lead to precipitation in reducing zones, if they exist. The extent of mobilization calculated by the models provides a limit to the concentration in the reducing zone. Mobilization and redeposition of uranium uniformly distributed in an 8-m thickness of contaminated soil into a 1-m-thick reducing zone results in a geometric maximum CF of 8 . If uranium is deposited instead over a 2 -m-thick zone, then a maximum CF is 4 . Other waste thicknesses can also be considered. The case modeled here is an $8-\mathrm{m}-$ thick section of waste and a hypothetical 1 -m-thick reducing zone. For 12 of the 40 runs evaluated, sufficient uranium is flushed to reach CFs between 6 and the geometric maximum of 8 . The other runs did not flush sufficient uranium to reach CFs that could attain criticality within the model time.

\subsubsection{Evaluation of Results}

One additional question that needs to be addressed is what is the probability that a criticality event would occur? This question cannot be addressed quantitatively with the present data. However, some general sense about confidence can be gained by evaluating the different states of modeling and events. The first stage to consider is the model processes that lead to an increase in uranium concentration. The present modeling indicates that a narrow set of conditions would lead to significant concentration increases. This narrow set of conditions may imply a low probability for occurrence, but site-specific data would be the key to evaluating probability. The probability could be zero at some sites. Hence, there is a high degree of uncertainty in this modeling because of gaps in data and possible large variations between specific sites. For the criticality calculation, there is also a narrow set of conditions that lead to a criticality event when geologically reasonable configurations are considered. The calculations have a high degree of certainty when evaluated from a mathematical viewpoint, but there is again uncertainty in whether the full range of natural conditions has been considered. For instance, concentration regions have been assumed to have sharp boundaries, and moisture content has been assumed to be uniform. Natural variations are likely to occur, which have not yet been evaluated. A third stage of releasing fissile uranium that presents a dose health threat could occur before or after a criticality event.

\subsubsection{Summary of Criticality Potential}

Although only a small number of cases reached CFs of concern, these cases modeled realistic ranges of geochemical conditions. Further analysis should examine the realism of the hydraulic conditions and any geochemical factors that have been neglected that could inhibit increases in concentration (e.g., competing complexes that prevent mobilization or inhibit precipitation). At Envirocare, the reported low initial mass of ${ }^{235} \mathrm{U}$ and the low enrichment were important considerations for ensuring subcriticality. 
Because many hydrogeochemical simulations do not present CFs of concern, these examples also suggest measures that can be taken to inhibit increases in concentration of uranium. Limiting water content can prevent fast flow and help maintain oxidizing conditions (avoid local reducing zones). Limiting the enrichment increases the total amount of uranium that must be mobilized, and in some cases nonfissile uranium limits the CFs attained. Limitations on the source available for mobilization through the disposal-cell dimensions (related to the density of uranium in critical configurations) can also be calculated.

\subsection{CRITICALITY CONSEQUENCES: DIRECT DOSE FROM RADIATION TRANSPORT}

The purpose of this study was to evaluate whether or not fissile uranium concentration in LLW facilities can be increased by hydrogeochemical processes to permit nuclear criticality. Criticality is a precise condition wherein the rate of neutron production, excluding neutron sources whose strengths are not a function of fission rate, is equal to the rate of neutron loss. Because criticality is affected by delayed neutrons (neutrons that are produced at delayed times following the fission process), it is possible to change from subcritical to supercritical through the delayed neutron contribution. However, a very slow approach to criticality can produce substantial, nearly infinite, neutron multiplication as revealed in the subcritical relationship for neutron source multiplication, $\mathbf{M}_{\mathbf{n}} \approx$ $\left[1 /\left(1-k_{\alpha, e f f}\right)\right]$. This is to say that whatever inherent neutron source is present (e.g., spontaneous fission from ${ }^{235} \mathrm{U}-6.6 \times 10^{-1}$ neutrons $/ \mathrm{kg}$-min, ${ }^{238} \mathrm{U}-8.1 \times 10^{2}$ neutrons $/ \mathrm{kg}$-min, or other nuclides present) would be multiplied by $\mathbf{M}_{\mathrm{n}}$. Depending on the initial neutron flux density within the system at the time of an increase in system reactivity from an action such as the slumping of a deposit, the criticality "switch" could be "snapped on" resulting in rapid fission heating and feedbacks that tend to expand and "turn off" the criticality.

An element in the depletion of the critical condition is whether or not water moderation is required for criticality. If so, approximately $10^{16}$ fissions are required to raise $1 \mathrm{~L}$ of water from room to boiling temperature, and a total of about $10^{17}$ fissions are required to vaporize $1 \mathrm{~L}$ of water. If criticality were approached from an overly watermoderated condition, it is conceivable that a fairly rapid fission process would occur until sufficient water is removed, via evaporative steam or physical expulsion, to render the system subcritical. Such energy releases could mimic geyser behavior cycling over longer time periods or a single steam explosion within a few tenths of a second. For the purposes of the direct-dose radiation transport evaluations, the "first-pulse" fission yields correspond to the thermal fission energy required to remove that quantity of water/moisture providing the overmoderated condition. Therefore, further migration of water back into such a deposit could result in further fissions for extended periods-well beyond the original estimated fission yields. The radioactive-decay half-life of ${ }^{235} \mathrm{U}$ is $7 \times 10^{8}$ years. Depending upon the beginning enrichment and the excess mass of ${ }^{235} \mathrm{U}$ available to continue to contribute to the fission process, radioactive decay in geological time may or may not be a contributor to the termination of criticality. A large number of scenarios preventing or supporting criticality may be postulated.

Postulating that a criticality event could occur at an LLW site, the immediate consequences of such an event to the public were considered as part of this study. Using the models, methods, and sources described in Sect. 7.3, the dose results under the assumed fission yields for the high concentration factor $(\mathrm{HCF})$ case (i..e, $4.1 \times 10^{21}$

fissions) and the low concentration factor (LCF) case (i.e., $2.8 \times 10^{21}$ fissions) were determined. The results are shown in Table 10.4-1 for all conditions analyzed. 
Results

Table 10.4-1 Dose results for assumed high and low CFs at locations near and far from potential critical deposits

\begin{tabular}{c|c|c|c|c}
\hline $\begin{array}{c}\text { High or low } \\
\text { concentration }\end{array}$ & $\begin{array}{c}\text { Distance (m) } \\
\text { from deposit } \\
\text { center }^{\mathrm{a}}\end{array}$ & $\begin{array}{c}\text { Neutron dose } \\
(\mathrm{rem})^{\mathrm{b}}\end{array}$ & $\begin{array}{c}\text { Gamma-ray dose } \\
\text { (rem) }\end{array}$ & $\begin{array}{c}\text { Total dose } \\
\text { (rem) }\end{array}$ \\
\hline High & 0 & 34.4 & 21.7 & 56.1 \\
Low & 0 & 98.6 & 58.8 & 157.4 \\
High & 90 & 0.045 & 0.012 & 0.057 \\
Low & 90 & 0.131 & 0.034 & 0.165 \\
\hline
\end{tabular}

${ }^{\mathrm{a} A l l}$ detector locations assumed to be located $1 \mathrm{~m}$ above ground.

${ }^{b}$ ANSI/ANS-6.1.1-1977, 1977.

These results show that total doses are higher for the LCF case than for the HCF case by about a factor of 3 . The total dose-per-fission values (not shown) for the LCF are about a factor of 4 higher than for the HCF. This higher dose is because the LCF deposit is thicker and hence closer to the ground surface. This higher LCF dose per fission is somewhat offset by the LCF fission yield, which is about $30 \%$ smaller than the HCF fission yield.

Also shown in Table 10.4-1 are the neutron and gamma-ray dose components. These values sum to the total dose and are given primarily for completeness. Note that the neutron doses near the deposit account for about $60 \%$ of the total dose for both HCF and LCF cases, while the neutrons comprise about $80 \%$ of the total dose at the $90-\mathrm{m}$ location. Thus it appears that the neutron dose portion of the total dose increases with distance away from the deposit, although the total dose decreases at a rapid rate with increasing distance from the axis of the critical deposit. 


\section{DISCUSSION OF LIMITATIONS ASSOCIATED WITH THE ANALYSIS}

Because of the broad parametric phase space of the study (i.e., soil types, soil densities, range of ${ }^{235} U$ contamination density in soil, degree of water moderation, and geometric configurations) and various combinations of the parameters, the study was confined to the grid of parameters used in the nuclear criticality evaluation (Tables 10.1-1 and 10.1-2). The parameter grid was selected to span the parametric ranges of concern but was, by necessity, limited in the number of cases evaluated. The results of this scoping study provide general bounds for parametric combinations of criticality safety concern. For the simple case of vertical migration, a prior study (Hopper et al., 1995) of SNM burial limits should be considered for addressing licensing issues.

The overall limitations of the geochemical transport modeling were the necessary simplifications to develop a model and the many assumptions and estimates that had to be made for unknown parameters. A large number of unknowns existed because of the complexity of the problem. These uncertainties ranged from the hydrologic conditions (moisture content, velocities, and inlets and outlets of the system) to geochemical conditions. Many complexes and minerals can be considered for this problem. However, the thermodynamic database quality is sometimes questionable, which can limit consideration of some complexes and some potentially important scenarios (e.g., involving organic complexation). A further problem is that coupled models are time consuming to debug and run. In particular, simulations evaluating variable redox conditions present calculation convergence problems because of the extreme concentration ranges involved. The 1-D flow-field modeled here limits analysis to formation of slabs in a single disposal cell.

Despite these limitations, this work is an important first step toward gaining an understanding of the principles of study. Starting with simple cases was important to determine constraining factors. The range in possible conditions of concern can be narrowed by further study of the key factors identified here. Some additional tasks . for future work include the following:

- conduct criticality calculations for other soil matrices suggested at specific sites;

- $\quad$ conduct criticality calculations for plutonium;

- $\quad$ search for databases to evaluate the potential to increase plutonium concentration;

- $\quad$ search for databases to evaluate organic complexation/colloids;

- consider other mobilizing agents, such as colloids;

- further consider redox scenarios to examine the stability of redox fields;

- consider lateral flow to transport uranium from several disposal cells to a zone of increased concentration beneath the cells;

- consider precipitation under oxidizing conditions by evaluating geochemical factors that could change to create precipitating and nonprecipitating zones;

- $\quad$ model saturated and unsaturated conditions; and 


\section{Discussion}

- conduct laboratory or field work to evaluate site conditions: study thermodynamics, zonation, and saturation conditions.

NUREG/CR-6505,

Vol. 1 


\section{SUMMARY AND RECOMMENDATIONS}

Nuclear criticality evaluations based upon licensed soil-contamination limits specified for Envirocare reveal a theoretical possibility of a nuclear criticality accident, given reasonable soil assumptions and hydrogeochemical influences on the concentration of SNM, specifically ${ }^{235} \mathrm{U}$. The length of time required to concentrate uranium is expected to be long (e.g., many years). This slow approach to criticality will further mitigate rapid approaches to critical or supercritical conditions.

However, reviews of disposal/burial records from Envirocare reveal that concentrations of ${ }^{235} U$ in the waste material are more than a factor of 10 less than licensed concentrations of ${ }^{235} \mathrm{U}$ and that the average enrichment is below the minimum $1 \%$ required to achieve nuclear criticality. Thus the likelihood of a criticality accident is vanishingly small.

The results presented here identify important factors in uranium concentration within a disposal cell, for example, the concentration of the mobilizing agent $\left(\mathrm{CO}_{3}{ }^{2-}\right.$ in our simulations) and the size (thickness) of the source term. Although these processes were modeled under saturated conditions, the study estimates that relatively long time frames (perhaps thousands of years) would be needed to concentrate uranium under unsaturated conditions. Much uncertainty exists in these temporal estimates because soil conditions have not been explicitly modeled and can vary both spatially and temporally. Analogs provided by studies of soil-forming processes suggest that increasing the concentration is a long-term process (e.g., requiring thousands of years).

This study results in the following recommendations for consideration of license review of LLW facilities.

1. Minimize those factors that enhance the concentration of uranium.

- Reduce water infiltration. Water increases mobilization and transport rates; unsaturated conditions greatly reduce opportunities for concentration.

- Where possible, reduce enrichment of ${ }^{235} \mathrm{U}$. The presence of nonfissile uranium decreases the extent of ${ }^{235} \mathrm{U}$ mobilization. The regulations do not specify any enrichment factors, so $100 \%$ enrichment is permissible.

- Minimize opportunities to create isolated zones of extreme reducing potential if possible because uranium precipitates readily under reducing conditions. Unsaturated conditions would tend to create more oxidizing environments, but further study is needed to determine the importance of microenvironments within disposal cells. Also, avoid organic matter in waste cells to prevent methanogenesis.

2. Limit the areal density of uranium by limiting the depth of the disposal cell. Results demonstrate that criticality concerns can be minimized even if worst-case hydrogeochemical transport and concentration mechanisms are assumed. If the depth of the disposal cell is limited so that there is not a sufficient mass of ${ }^{235} \mathrm{U}$ within a cross section of a vertical flow pathway, criticality cannot occur.

The simplified models used in this study have brought researchers one step closer to understanding the potential for criticality at an LLW facility using conservative but realistic conditions. The approach followed here, integrating hydrogeochemical modeling and nuclear criticality safety expertise, provides a rationale and basis for formulating rule changes to minimize criticality safety concerns. 



\section{REFERENCES}

American Nuclear Society, ANSI/ANS-6.1.1-1977, American National Standard, Neutron and $\gamma$-Ray Flux-toDose-Rate Factors, 1977.

Andreyev, P. F., and A. P. Chumachenko, "Reduction of Uranium by Natural Organic Substances," Geochem. Int. 1:3-7, 1964.

Apps, J. A. et al., Status of Geochemical Problems Relating to Burial of High-Level Radioactive Waste, NUREG/CR-3062/LBL-15103, U.S. Nuclear Regulatory Commission, 1982.

Arbogast, T., C. N. Dawson, and M. F. Wheeler, User's Guide to RPARSim1: The Rice Parallel Aquifer and Reservoir Simulator, Single Phase, V. 1.0, Rice University, 1994.

Baccini, P., ed. 1989. The Landfill: Reactor and Final Storage, New York: Springer-Verlag, 1989.

Baedecker, M.J., I.M Cozzarelli, and R.P Eganhouse, "Crude Oil in a Shallow Sand and Gravel Aquifer--III. Biogeochemical Reactions and Mass Balance Modeling in Anoxic Groundwater," Applied Guaiacum, 8:569-586, 1993.

Baedecker, M. J., and W. Back, "Hydrogeological Processes and Chemical Reactions at a Landfill," Ground Water 17:429-37, 1979.

Barcelona, M.J. et al., "Spatial and Temporal Gradients in Aquifer Oxidation-Reduction Conditions," Water Resour. Res., 25(5): 991-1003, 1989.

Baver, L. D., W. H. Gardner, and W. R. Gardner, Soil Physics, John Wiley and Sons, New York, 1971.

Bilzi, A. F., and E. S. Ciolkosz, "Time as a Factor in the Genesis of Four Soils Developed in Recent Alluvium in Pennsylvania," Soil Sci. Soc. Am. J., 4:122-27, 1977.

Bohn, H. L., B. L. McNeal, and G. A. O'Connor, Soil Chemistry, 2nd ed. John Wiley Sons, New York, 1985.

Bowman, C. D., and F. Venneri, Underground Autocatalytic Criticality from Plutonium and Other Fissile Material, LA-UR-94-4022, Los Alamos National Laboratory, 1994.

Brookhaven National Laboratory, Cross Section Evaluation Working Group Benchmark Specifications, BNL19302 (ENDF-202), November 1974.

Brookins, D. G., "Thermodynamic Considerations Underlying the Migration of Radionuclides in Geomedia: Oklo and Other Examples," in G. J. McCarthy, ed., Scientific Basis for Nuclear Waste Management, V. 1:355$366,1979$.

Christensen, T.H. et al., "Attenuation of Landfill Leachate Pollutants in Aquifers," Critical Reviews in Environmental Science and Technology, 24(3):119-202, 1994. 
References

Cowan, G. A., “A Natural Fission Reactor,”Sci. Am: 235:36-47. 1976.

Cremeens, D. L., "Pedogenesis of Cotiga Mound, a 2,100 Year Old Woodland Mound in Southwest West Virginia," Soil Sci. Soc. Am. J., 59:1377-88, 1995.

Ermolenko, N. F., "Trace Elements and Colloids in Soils," 2nd ed., Akademiya Nauk Belorusskoi SSR, pp 6-24, 1972.

Federal Register, Vol. 58, No. 33, p. 9552, February 22, 1993.

Fox, J. K. "Critical Parameters of Uranium Solutions in Simple Geometry," Neutron Physics Division Annual Progress Report for Period Ending September 1, 1958, ORNL-2609, Union Carbide Corp., Nuclear Div., Oak Ridge National Lab., p. 42, 1958.

Francis, C. W. et al., Selective Leaching of Uranium from Uranium-Contaminated Soils: Progress Report 1, ORNL‘'TM-12177, Oak Ridge National Laboratory, 1993.

Gelhar, L. W., C. Welty, and K. R. Rehfeldt, "A Critical Review of Data on Field-Scale Dispersion in Aquifers," Water Resour. Res., 28:1955-74, 1992.

Gile, L. H., "Pedogenic Carbonate in Soils of the Isaack's Ranch Surface, Southern New Mexico," Soil Sci. Soc. Am. J. 59:501-8, 1995.

Gile, L. H., F. F. Peterson, and R. B. Grossman, "Morphological and Genetic Sequences of Carbonate Accumulation in Desert Soils," Soil Sci. 101:347-60, 1966.

Gile, L. H., J. W. Hawley, and R. B. Grossman, "Distribution and Genesis of Soils and Geomorphic Surfaces in a Desert Region of Southern New Mexico," Soil Science Society of America, Madison, Wis., 1970.

Greene, N.M. et al., The Law Library - A Multigroup Cross-Section Library for Use in Radioactive Waste Analysis Calculations, ORNL/TM-12370, Oak Ridge National Laboratory, 1994.

Hambleton-Jones, B. B., and P. D. Toens, "The Geology and Geochemistry of Calcrete/Gypcrete Uranium Deposits in Duricrust: Namib Desert, South West Africa," Econ. Geol. 73:1407-8, 1978.

Hillel, D., Introduction to Soil Physics, Academic Press, New York, 1991.

Hopper, C. M. et al., Criticality Safety Criteria for License Review of Low-Level Waste Facilities,"NUREG/CR6284 (ORNL/TM-12845), U.S. Nuclear Regulatory Commission, 1995.

Hsi, C. D., and D. Langmuir, "Adsorption of Uranyl onto Ferric Oxyhydroxides: Application of the Surface Complexation Site-Binding Model," Geochim. Cosmochim. Acta 49:1931-41, 1985.

Iman, R. L., and W. J. Conover, "The Use of Rank Transform in Regression," Technometrics 21:499-509, 1979.

NUREG/CR-6505,

Vol. 1 
Jardine, P. M., G. V. Wilson, and R. J. Luxmoore, "Modeling the Transport of Inorganic Ions Through Undisturbed Soil Columns from Two Contrasting Watersheds," Soil Sci. Soc. Am. J. 52:1252-59, 1988.

Jardine, P. M., G. V. Wilson, and R. J. Luxmoore, "Unsaturated Solute Transport Through Forest Soils During Rain Storm Events," Geoderma 46:103-18, 1990.

Jardine, P. M., G. K. Jacobs, and G. V. Wilson, "Unsaturated Transport Processes in Undisturbed Heterogeneous Porous Media: I. Inorganic Contaminants," Soil Sci. Soc. Am. J. 57:945-53, 1993.

Jenny, H., and C.D. Leonard, "Functional Relationships Between Soil Properties and Rainfall," Soil Sci. 38: 363$381,1934$.

Kimberley, M. M., "Origin of Stratiform Uranium Deposits in Sandstone, Conglomerate, and Pyroclastic Rock," pp. 339-81, in Kimberley, M. M., ed., Uranium Deposits: Their Mineralogy and Origin, Mineralogical Association of Canada, Short Course Handbook 3, University of Toronto Press, Toronto, Canada, 1978.

Knowles, T. L. et al., "Multiple Nonreactive and Reactive Tracers to Investigate the Migration of Transuranics in Groundwater," Abstracts of the American Geophysical Union Fall Meeting, December 11-15, San Francisco, California, 1995.

Langmuir, D., "Uranium Solution-Mineral Equilibria at Low Temperatures with Applications to Sedimentary Ore Deposits," Geochim. Cosmochim. Acta 42:547-70, 1978.

Lee, S. Y., M. Elless, and F. Hoffman, Solubility Measurement of Uranium in Uranium-Contaminated Soils, ORNL/TM-12401, Oak Ridge National Laboratory, 1993.

Liu, C. W., and T. N. Narasimhan, "Redox-Controlled Multiple Species Reactive Chemical Transport, 2. Verification and Application," Water Resour. Res. 25:883-910, 1989.

Luxmoore, R. J. et al., "Physical and Chemical Controls of Preferred Path Flow Through a Forested Hillslope," Geoderma 46:139-54, 1990.

Lyngkild, J. and Christensen, T.H., "Fate of Organic Contaminants in the Redox Zones of a Landfill Leachate Pollution Plume (Vejen, Denmark)," Jour Contam Hydrol., 10:291-307, 1992.

Mangold, D. C., and C. -F. Tsang, "A Summary of Subsurface Hydrological and Hydrogeochemical Models," Rev. Geophys, 29:51-79, 1991.

Mann, A. W., and R. L. Deutscher, "Genesis Principles for the Precipitation of Carnotite in Calcrete Drainages of Western Australia," Econ. Geol. 73:1724-37, 1978.

McCarthy, J. F., J. D. Marsh, and E. Tipping, "Mobilization of Actinides from Shallow Disposal Trenches by Natural Organic Matter," Abstract, American Chemical Society National Meeting, April 1995.

McDaniel, P. A. et al., "Secondary Manganese/Iron Ratios as Pedochemical Indicators of Field-Scale Throughflow Water Movement," Soil Sci. Soc. Am. J., 56:1211-17, 1992. 
References

McKay, M. D., R. J. Beckman, and W. J. Conover, "A Comparison of Three Methods for Selecting Values of Input Variables in the Analysis of Output from a Computer Code," Technometrics 21:239-45, 1979.

Means, J. L., D. A. Crerar, and J. O. Duguid, "Migration of Radioactive Wastes: Radionuclide Mobilization by Complexing Agents," Science 200:1477-81, 1978.

Morfitt, J. W., Minimum Critical Mass and Uniform Thermal Neutron Core Flux in an Experimental Reactor, Y1023, Union Carbide Corporation, Nucl. Div., Oak Ridge Y-12 Plant, 1953.

Nash, J. T., H. C. Granger, and S. S. Adams, "Geology and Concepts of Genesis of Important Types of Uranium Deposits," pp. 63-116 in B. J. Skinner, ed., Economic Geology, Seventy-Fifth Anniversary Volume 1905-1980, The Economic Geology Publishing Co., Lancaster, Penn., 1981.

National Research Council, A Review of Ground Water Modeling Needs for the U.S. Army, National Academy Press, Washington, D.C., 1992.

Nettleton, W. D., and F. F. Peterson, “Aridisols,” pp. 165-215 in L. P. Wilding, N. E. Smeck, and G. F. Hall, eds., Pedogenesis and Soil Taxonomy, II. The Soil Orders, Developments in Soil Science 11B, Elsevier, Amsterdam, 1983.

Parkhurst, D. L., D. C. Thorstenson, and L. N. Plummer, "PHREEQE-A Computer Program for Geochemical Calculations," U.S. Geological Survey Water-Resources Investigations 80-96, U.S. Geological Survey, 1982.

Paxton, H. C., and N. L. Pruvost, Critical Dimensions of Systems Containing ${ }^{235} \mathrm{U},{ }^{239} \mathrm{Pu}$, and ${ }^{233} \mathrm{U} 1986 \mathrm{Revision}$, LA-10860, Los Alamos National Laboratory, 1987.

Pearcy, E. C. et al., "Alteration of Uraninite from the Nopal I Deposit, Pena Blanca, Mexico District, Chihuahua, Mexico, Compared to Degradation of Spent Fuel in the Proposed U. S. High-Level Nuclear Waste Repository at Yucca Mountain, Nevada," Appl. Geochem. 9:713-32, 1994.

Raffensperger, J. P., and G. Garven, "The Formation of Unconformity-Type Uranium Ore Deposits: 2. Coupled Hydrogeochemical Modeling," Am. J. Sci. 295:639-96, 1995.

Rhoades, W. A., and R. L. Childs, “The DORT Two-Dimensional Discrete Ordinates Code,” Nucl. Sci. Eng. 99:88-89, 1988.

Rothe, R. E., Benchmark Critical Experiments on High Enriched Uranyl Nitrate Solution Systems, NUREG/CR0041, RFP-2710, U.S. Nuclear Regulatory Commission, 1978.

SCALE: A Modular Code System for Performing Standardized Computer Analyses for Licensing Evaluations, NUREG/CR-0200, Rev. 4 (ORNL/NUREG/CSD-2/R4). Vols. I, II, and III, 1995. Available from Radiation Shielding Information Center as CCC-545.

Shacklette, T. H., and J. G. Boerngen, "Elemental Concentrations in Soils and Other Surficial Materials of the Conterminous United States," pp. 46 in U.S. Geological Survey Professional Paper 1270, 1984.

Soil Survey Staff, "Keys to Soil Taxonomy," SMSS Technical Monograph No. 19, 5th ed. Pocahontas Press, Blacksburg, Va., 1992.

NUREG/CR-6505, Vol. 1 
Sposito, G., The Chemistry of Soils, Oxford University Press, New York, 1989.

State of Utah, Department of Environmental Quality, Division of Water Quality, Memorandum dated February 25, 1994, from Loren Morton to Dane Finnefrock on the subject of "DWQ/USU Pathrae Contaminant Transport Modeling: Evaluation of Envirocare of Utah's August 30, 1993 Proposed Changes to the Embankment Cover Design."

Staubitz, W. W. et al., "Potential Use of Constructed Wetlands to Treat Landfill Leachate," pp. 735-42 in D. A. Hammer, ed., Constructed Wetlands for Wastewater Treatment, Lewis Publishers, Chelsea, Mich., 1989.

Toran, L.E., "Radionuclide Contamination in Groundwater: Is There a Problem?" pp. 437-55 in I. U. Zoller, ed., Groundwater Contamination and Control, Marcel Dekker, New York, 1994.

Tripathi, V. S., Uranium Transport Modeling: Geochemical Data and Submodels, Ph.D. dissertation. Stanford University, 1983.

Tuck, G., "Simplified Methods of Estimating the Results of Accidental Solution Excursions," Nucl. Tech. 23:177-99, 1974.

U.S. Department of Energy, Final Environmental Impact Statement, Remedial Actions at the Former Vitro Chemical Company Site, South Salt Lake, Salt Lake County, 1984.

U.S. Nuclear Regulatory Commission, Final Safety Evaluation Report to License the Construction and Operation of a Facility to Receive, Store, and Dispose of 1le.(2) By-Product Material Near Clive, Utah, NUREG-1486, 1994.

Utah Department of Environmental Quality, Division of Radiation Control, Radioactive Material License, UT 2300249 to Envirocare of Utah, Inc. Supplementary sheet, 1995.

van der Heijde, P. K. M., and O. A. Elnawaway, Compilation of Ground-Water Models, EPA/600/R-93/118, U.S. Environmental Protection Agency, 1993.

Wilding, L. P., N. E. Smeck, and G. F. Hall, eds., "Pedogenesis and Soil Taxonomy. I. Concepts and Interactions," Developments in Soil Science 11A, Elsevier, Amsterdam, 1983.

Wilding, L. P., N. E. Smeck, and G. F. Hall, eds., "Pedogenesis and Soil Taxonomy. II. The Soil Orders," Developments in Soil Science 11B, Elsevier, Amsterdam, 1983.

Wilson, G. V. et al., "Hydrogeochemical Processes Controlling Subsurface Transport from an Upper Catchment of Walker Branch Watershed During Storm Events, 2. Solute Transport Processes," J. Hydrol. 123:317-36, 1991.

Yeh, G. T., and V. S. Tripathi, "A Critical Evaluation of Recent Developments in Hydrogeochemical Transport Models of Reactive Multichemical Components," Water Resour. Res. 27:93-108, 1991a.

Yeh, G. T., and V. S. Tripathi, "A Model for Simulating Transport of Reactive Multispecies Components: Model Development and Demonstration," Water Resour. Res. 27:3075-94, 1991 b.

Yeh, G. T. et al., KEMOD: A Mixed Chemical Kinetic and Equilibrium Model of Aqueous and Solid Phase Geochemical Reactions, PNL-10380, Pacific Northwest Laboratory, 1995. 



\section{GLOSSARY}

Term

Areal density

Concretions

Effective neutron multiplication factor, $\mathrm{k}_{\text {eff }}$

Infinite cylinder

Infinite media

Infinite slab

Infinite neutron multiplication factor, $\mathrm{k}_{\infty}$

Lift

Linear density

$M_{n}$

Moderation

Neutron multiplication factor, $k$

Nuclear criticality

Reflection

Subcritical (subcriticality)

Uranium concentration

\section{Discussion}

Mass per unit area used to characterize the ${ }^{235} \mathrm{U}$ contaminant of an infinite slab of soil.

Nodular or irregular mineral concentration in sedimentary rocks, developed by the localized deposition of material from solution.

Ratio of the total number of neutrons produced during a time interval to the total number of neutrons lost by absorption and leakage during the same interval.

Conceptually, a cylinder of finite diameter but of infinite length.

Conceptually, material that fills an infinite volume.

Conceptually, a slab of finite thickness but of infinite length and width.

Ratio of the total number of neutrons produced during a time interval to the total number of neutrons lost by absorption during the same interval.

Layer of loose, uncompacted waste not exceeding a thickness of $0.3 \mathrm{~m}$ that is mechanically manipulated to ensure uniform density. Thinner lifts are required if necessary to meet compaction requirements. The minimum surface area for a lift is $929 \mathrm{~m}^{2}\left(10,000 \mathrm{ft}^{2}\right)$.

Mass per unit length used to characterize the ${ }^{235} U$ contaminant of an infinitely long cylinder of soil.

Neutron source multiplication factor for subcritical fissile material systems. $M_{\mathbf{n}} \approx$ $\left[1 /\left(1-\mathrm{k}_{\infty, \text { eff }}\right)\right]$.

Reduction of neutron energy by scattering neutrons without appreciable neutron capture by neutron scattering material.

Ratio of the total number of neutrons produced during a time interval to the total number of neutrons lost during same interval.

Condition of being critical. For special nuclear material systems, the condition when the rate of neutron production, excluding neutron sources whose strengths are not a function of fission rate, is equal to the rate of neutron loss; $\mathrm{k}_{e f f}$ or $\mathrm{k}_{\text {eff }}=1.0$. For studies in this report, 0.95 , rather than 1.0 , was selected as a critical value to conservatively account for materials and data uncertainty.

Scattering of neutrons back to a system that would otherwise escape from the system.

For special nuclear material systems, the condition when the rate of neutron production, excluding neutron sources whose strengths are not a function of fission rate, is less than the rate of neutron loss; $\mathrm{k}_{\text {eff }}$ or $\mathrm{k}_{\text {eff }}<1.0$. For studies in this report, values less than 0.95 , rather than less than 1.0 , are assumed to conservatively account for materials and data uncertainty.

Ratio of uranium mass to soil or water mass. 
Glossary

Term

Discussion

Uranium concentration Ratio of the uranium concentration (resulting from a uranium densification or factor (CF) dilution process) divided by the original, authorized/licensed uranium concentration within the soil or waste matrix. In this report, $0.0006 \mathrm{~g} / \mathrm{cm}^{3}$ is used as the original ${ }^{235} \mathrm{U}$ concentration.

Uranium enrichment Mass ratio of the ${ }^{235} \mathrm{U}$ isotope of uranium to total mass of uranium typically expressed in weight percent ${ }^{235} \mathrm{U}$. 


\section{APPENDIX A}

Conceptual Configurations for Nuclear Criticality Evaluations 
Appendix A
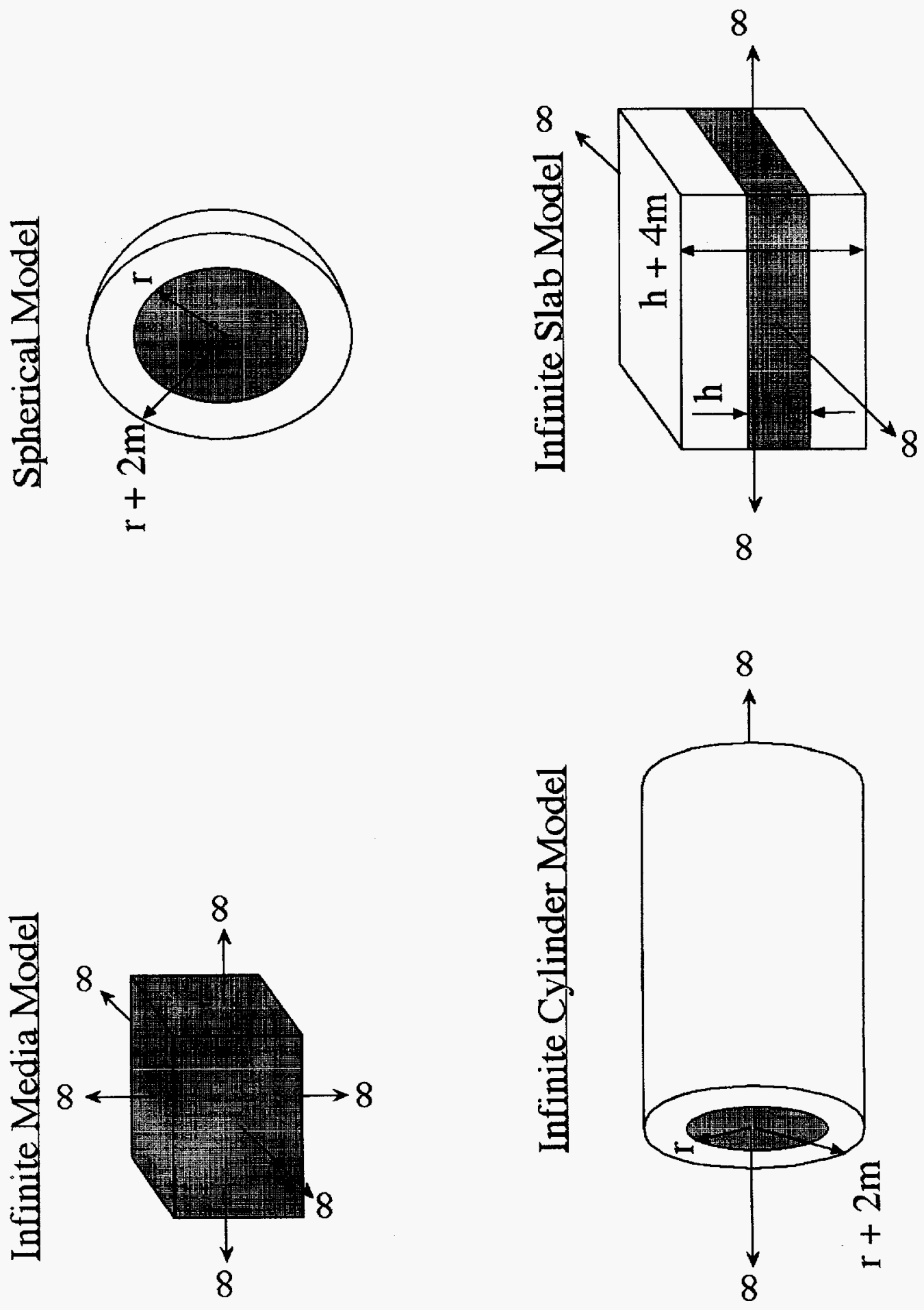

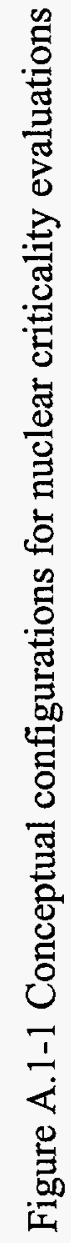

NUREG/CR-6505,

Vol. 1 


\section{APPENDIX B}

\section{Envirocare of Utah Disposal Records}


Appendix B

Table B-1 Envirocare of Utah disposal records, $\mathrm{mCi}$

\begin{tabular}{|c|c|c|c|c|c|c|}
\hline Year & $\mathrm{DU}^{a}$ & $\mathrm{NU}^{b}$ & ${ }^{234} \mathrm{U}$ & ${ }^{235} \mathrm{U}$ & ${ }^{238} \mathrm{U}$ & ${ }^{236} \mathrm{U}$ \\
\hline 1988 & & 622 & & & & \\
\hline 1989 & & 22.8 & & & & \\
\hline 1990 & & 7.94 & & & & \\
\hline 1991 & 7450 & 10 & & & & \\
\hline 1992 & 4170 & 17900 & 1490 & 82 & 643 & \\
\hline 1993 & 16300 & 1620 & 1200 & 55.7 & 324 & 1.24 \\
\hline TOT & 27920 & 20182.7 & 2690 & 137.7 & 967 & 1.24 \\
\hline
\end{tabular}

${ }^{a}$ Depleted uranium ( $<0.7 \mathrm{wt} \%{ }^{235} \mathrm{U}$ in total uranium).

${ }^{b}$ Normal uranium (0.7 wt $\%{ }^{235} \mathrm{U}$ in total uranium). 
Appendix B

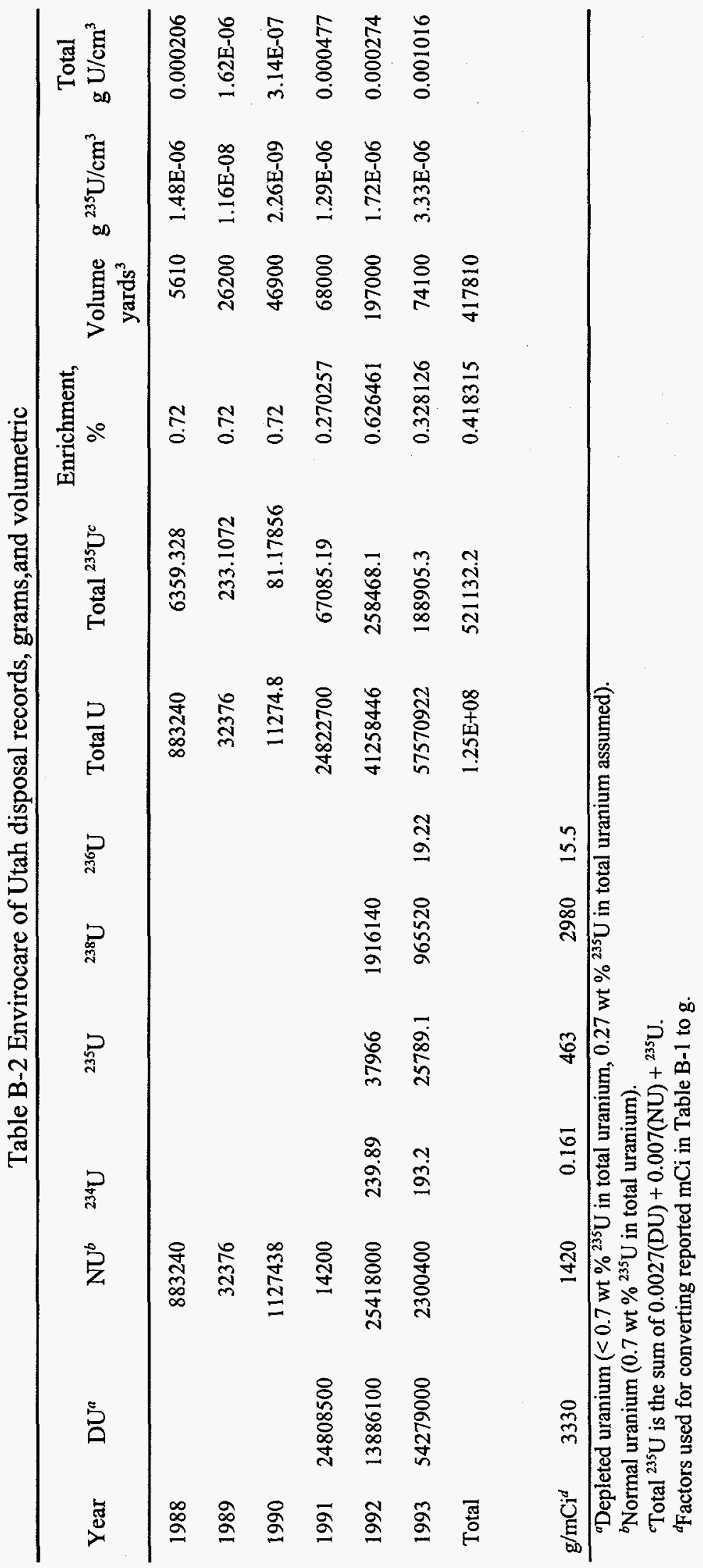


Appendix B

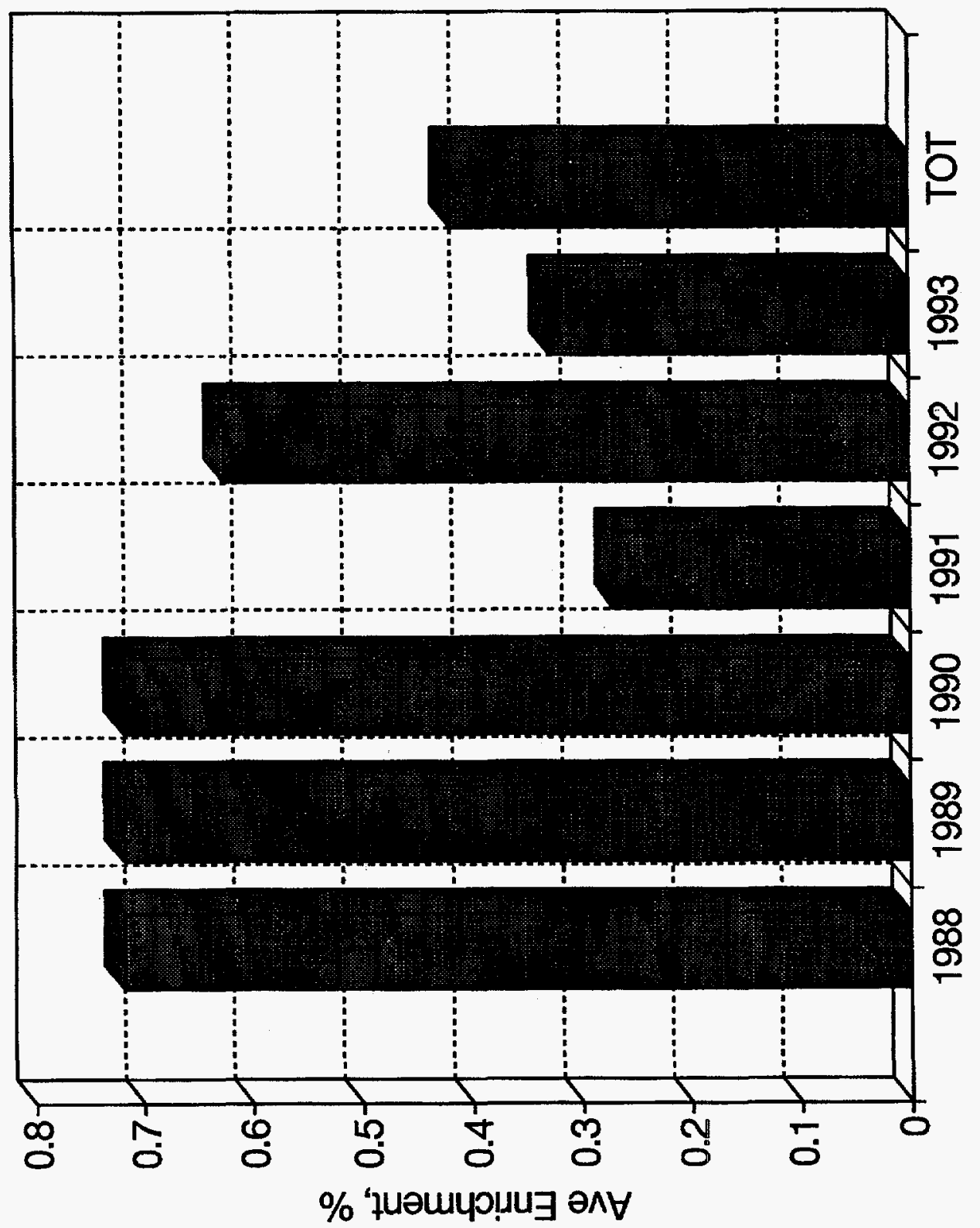

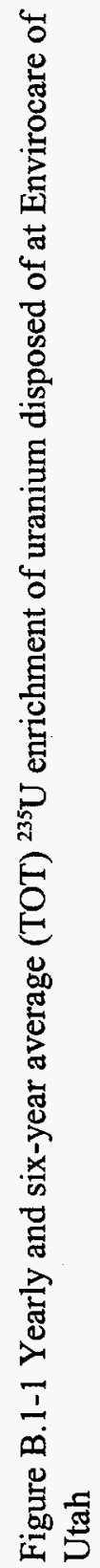

NUREG/CR-6505,

Vol. 1 
Appendix B

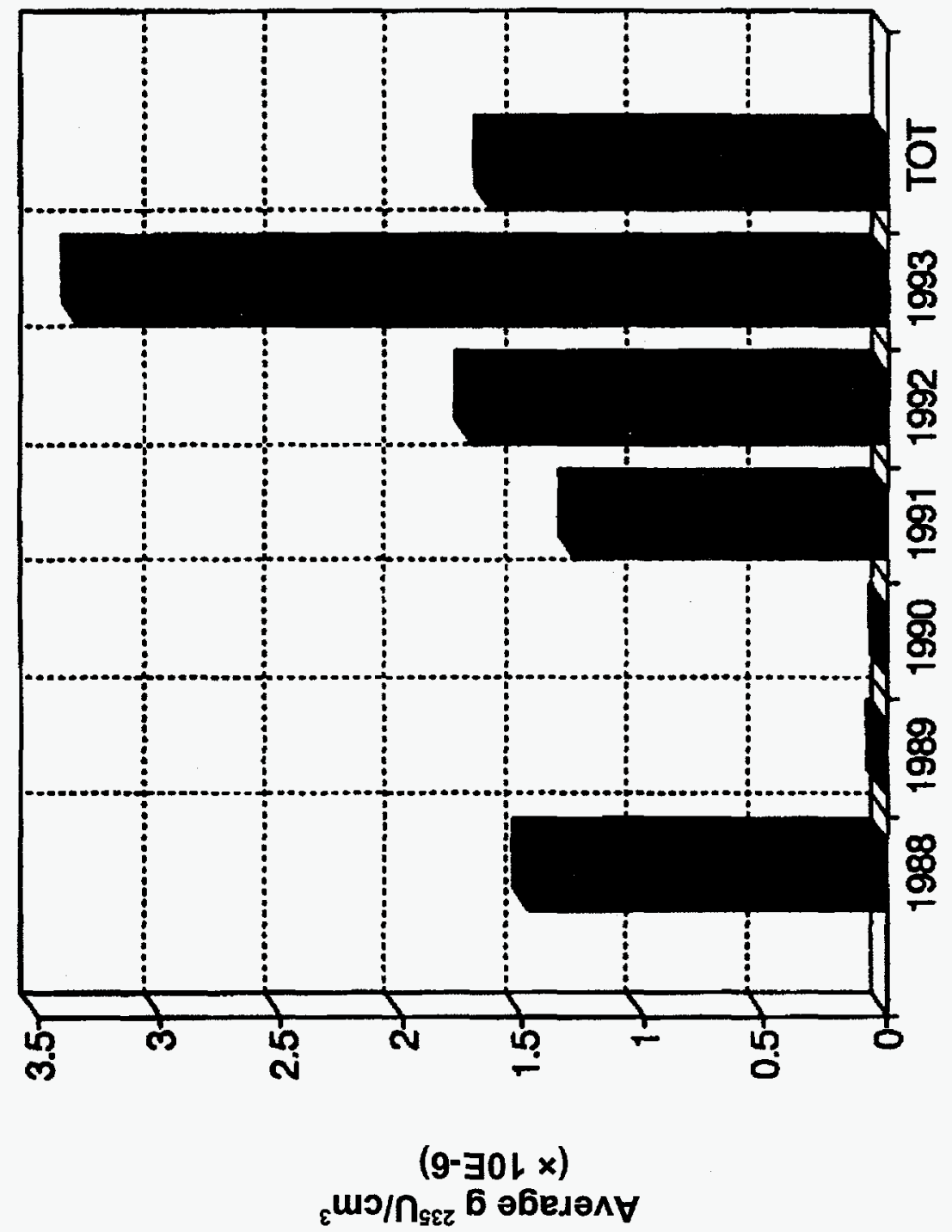

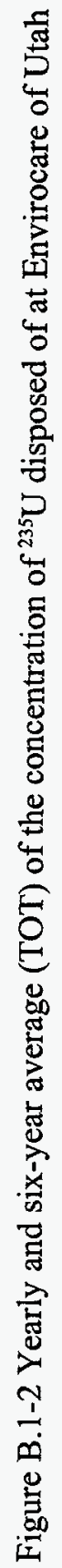





\section{APPENDIX C}

Expanded Tables 10.1-1 and 10.1-2 
Table C-1 Nominal-soil (N-S) results ${ }^{a}$

\begin{tabular}{|c|c|c|c|c|c|c|c|c|c|c|c|c|}
\hline \multirow{3}{*}{$\begin{array}{l}\text { Line } \\
\text { entry }\end{array}$} & \multirow{3}{*}{$\begin{array}{l}\text { Conc. } \\
\text { factor }\end{array}$} & \multicolumn{2}{|c|}{${ }^{235} \mathrm{U}$ content } & \multicolumn{2}{|c|}{ Water content } & \multirow[b]{2}{*}{$\begin{array}{c}k_{\infty} \text { or } \\
\text { k-infinity }\end{array}$} & \multicolumn{2}{|c|}{ Critical infinite slab ${ }^{\mathrm{b}}$} & \multicolumn{2}{|c|}{ Critical infinite cylinder ${ }^{b}$} & \multicolumn{2}{|c|}{ Critical sphere $^{\mathbf{b}}$} \\
\hline & & $\begin{array}{l}{ }^{235} \mathrm{U} / \mathrm{cm}^{3} \\
\mathrm{~g}\end{array}$ & ${ }^{235} \mathrm{U} / \mathrm{g} \mathrm{N}-\mathrm{S} \mathrm{g}$ & $\begin{array}{c}\mathrm{H}_{2} \mathrm{O} / \mathrm{cm}^{3} \\
\mathrm{~g}\end{array}$ & $\begin{array}{c}\mathrm{H}_{2} \mathrm{O} / \mathrm{g} \mathrm{N}-\mathrm{S} \\
\mathrm{g}\end{array}$ & & $\begin{array}{l}\text { Thickness } \\
\text { (cm) }\end{array}$ & $\begin{array}{c}{ }^{235} \mathrm{U} \text { areal } \\
\text { density }\left(\mathrm{kg} / \mathrm{m}^{2}\right)\end{array}$ & $\begin{array}{l}\text { Diameter } \\
(\mathrm{cm})\end{array}$ & $\begin{array}{c}{ }^{235} \mathrm{U} \text { linear } \\
\text { density }(\mathrm{kg} / \mathrm{m})\end{array}$ & $\begin{array}{l}\text { Diameter } \\
(\mathrm{cm})\end{array}$ & $\begin{array}{l}{ }^{233} \mathrm{U} \text { mass } \\
(\mathrm{kg})\end{array}$ \\
\hline & & & & & & Fig. D-1 & Fig. D-2 & Fig. D-3 & Fig. D-4 & Fig. D-5 & Fig. D-6 & Fig. D-7 \\
\hline 1 & 1.0 & 0.0006 & 0.000375 & 0.000 & 0.000000 & 0.357 & & & & & & \\
\hline 2 & 1.0 & 0.0006 & 0.000375 & 0.020 & 0.012500 & 0.338 & & & & & & \\
\hline 3 & 1.0 & 0.0006 & 0.000375 & 0.040 & 0.025000 & 0.317 & & & & & & \\
\hline 4 & 1.0 & 0.0006 & 0.000375 & 0.080 & 0.050000 & 0.281 & & & & & & \\
\hline 5 & 1.0 & 0.0006 & 0.000375 & 0.160 & 0.100000 & 0.228 & & & & & & \\
\hline 6 & 1.0 & 0.0006 & 0.000375 & 0.330 & 0.206250 & 0.163 & & & & & & \\
\hline 7 & 3.3 & 0.0020 & 0.001250 & 0.000 & 0.000000 & 0.825 & & & & & & \\
\hline 8 & 3.3 & 0.0020 & 0.001250 & 0.020 & 0.012500 & 0.803 & & & & & & \\
\hline 9 & 3.3 & 0.0020 & 0.001250 & 0.040 & 0.025000 & 0.770 & & & & & & \\
\hline 10 & 3.3 & 0.0020 & 0.001250 & 0.080 & 0.050000 & 0.706 & & & & & & \\
\hline 11 & 3.3 & 0.0020 & 0.001250 & 0.160 & 0.100000 & 0.602 & & & & & & \\
\hline 12 & 3.3 & 0.0020 & 0.001250 & 0.330 & 0.206250 & 0.457 & & & & & & \\
\hline 13 & 10.0 & 0.0060 & 0.003750 & 0.000 & 0.000000 & 1.292 & 142.950 & 8.577 & 270.140 & 34.389 & 382.220 & 175.424 \\
\hline 14 & 10.0 & 0.0060 & 0.003750 & 0.020 & 0.012500 & 1.310 & 101.720 & 6.103 & 192.520 & 17.466 & 272.700 & 63.710 \\
\hline 15 & 10.0 & 0.0060 & 0.003750 & 0.040 & 0.025000 & 1.292 & 88.100 & 5.286 & 165.280 & 12.873 & 233.480 & 39.985 \\
\hline 16 & 10.0 & 0.0060 & 0.003750 & 0.080 & 0.050000 & 1.239 & 78.040 & 4.682 & 143.000 & 9.636 & 200.600 & 25.360 \\
\hline 17 & 10.0 & 0.0060 & 0.003750 & 0.160 & 0.100000 & 1.131 & 78.860 & 4.732 & 137.920 & 8.964 & 190.040 & 21.562 \\
\hline 18 & 10.0 & 0.0060 & 0.003750 & 0.330 & 0.206250 & 0.946 & & & & & & \\
\hline 19 & 33.3 & 0.0200 & 0.012500 & 0.000 & 0.000000 & 1.529 & 66.680 & 13.336 & 157.080 & 38.758 & 236.220 & 138.032 \\
\hline 20 & 33.3 & 0.0200 & 0.012500 & 0.020 & 0.012500 & 1.625 & 46.670 & 9.334 & 110.800 & 19.284 & 167.120 & 48.878 \\
\hline 21 & 33.3 & 0.0200 & 0.012500 & 0.040 & 0.025000 & 1.652 & 38.710 & 7.742 & 91.540 & 13.163 & 138.160 & 27.617 \\
\hline 22 & 33.3 & 0.0200 & 0.012500 & 0.080 & 0.050000 & 1.657 & 31.180 & 6.236 & 72.360 & 8.225 & 108.820 & 13.494 \\
\hline 23 & 33.3 & 0.0200 & 0.012500 & 0.160 & 0.100000 & 1.619 & 24.970 & 4.994 & 55.540 & 4.845 & 82.640 & 5.910 \\
\hline 24 & 33.3 & 0.0200 & 0.012500 & 0.330 & 0.206250 & 1.506 & 20.360 & 4.072 & 42.160 & 2.792 & 61.520 & 2.438 \\
\hline 25 & 83.3 & 0.0500 & 0.031250 & 0.000 & 0.000000 & 1.567 & 41.420 & 20.710 & 119.380 & 55.966 & 187.440 & 172.407 \\
\hline 26 & 83.3 & 0.0500 & 0.031250 & 0.020 & 0.012500 & 1.663 & 31.160 & 15.580 & 88.620 & 30.841 & 138.620 & 69.734 \\
\hline 27 & 83.3 & 0.0500 & 0.031250 & 0.040 & 0.025000 & 1.717 & 26.010 & 13.005 & 73.500 & 21.215 & 114.820 & 39.630 \\
\hline 28 & 83.3 & 0.0500 & 0.031250 & 0.080 & 0.050000 & 1.766 & 20.740 & 10.370 & 57.500 & 12.984 & 89.600 & 18.832 \\
\hline 29 & 83.3 & 0.0500 & 0.031250 & 0.160 & 0.100000 & 1.788 & 16.050 & 8.025 & 42.660 & 7.147 & 66.120 & 7.568 \\
\hline 30 & 83.3 & 0.0500 & 0.031250 & 0.330 & 0.206250 & 1.759 & 12.100 & 6.050 & 29.860 & 3.501 & 45.680 & 2.495 \\
\hline 31 & 333.3 & 0.2000 & 0.125000 & 0.000 & 0.000000 & 1.693 & 17.210 & 34.420 & 74.980 & 88.310 & 126.300 & 210.979 \\
\hline 32 & 333.3 & 0.2000 & 0.125000 & 0.020 & 0.012500 & 1.672 & 16.120 & 32.240 & 64.100 & 64.541 & 106.120 & 125.147 \\
\hline 33 & 333.3 & 0.2000 & 0.125000 & 0.040 & 0.025000 & 1.687 & 14.670 & 29.340 & 56.180 & 49.577 & 92.340 & 82.451 \\
\hline
\end{tabular}


Table C-1 (continued)

\begin{tabular}{|c|c|c|c|c|c|c|c|c|c|c|c|c|}
\hline \multirow[b]{2}{*}{$\begin{array}{l}\text { Line } \\
\text { entry }\end{array}$} & \multirow[b]{2}{*}{$\begin{array}{l}\text { Conc. } \\
\text { factor }\end{array}$} & \multicolumn{2}{|c|}{${ }^{235} \mathrm{U}$ content } & \multicolumn{2}{|c|}{ Water content } & \multirow[b]{2}{*}{$\underset{\substack{k_{m} \text { or } \\
k \text {-infinity }}}{ }$} & \multicolumn{2}{|c|}{ Critical infinite slab ${ }^{b}$} & \multicolumn{2}{|c|}{ Critical infinite cylinder ${ }^{b}$} & \multicolumn{2}{|c|}{ Critical sphere ${ }^{b}$} \\
\hline & & $\begin{array}{c}{ }^{235} \mathrm{U} / \mathrm{cm}^{3} \\
\mathrm{~g}\end{array}$ & $\underset{\mathrm{g}}{{ }^{235} \mathrm{U} / \mathrm{g} \mathrm{N}-\mathrm{S}}$ & $\begin{array}{c}\mathrm{H}_{2} \mathrm{O} / \mathrm{cm}^{3} \\
\mathrm{~g}\end{array}$ & $\underset{\mathrm{g}}{\mathrm{H}_{2} \mathrm{O} / \mathrm{g} \mathrm{N}-\mathrm{S}}$ & & $\begin{array}{l}\text { Thickness } \\
\text { (cm) }\end{array}$ & $\begin{array}{c}{ }^{235} \mathrm{U} \text { areal } \\
\text { density }\left(\mathrm{kg} / \mathrm{m}^{2}\right)\end{array}$ & $\begin{array}{l}\text { Diameter } \\
(\mathrm{cm})\end{array}$ & $\begin{array}{c}{ }^{235} \mathrm{U} \text { linear } \\
\text { density }(\mathrm{kg} / \mathrm{m})\end{array}$ & $\begin{array}{l}\text { Diameter } \\
\text { (cm) }\end{array}$ & $\begin{array}{l}{ }^{235} \mathrm{U} \text { mass } \\
(\mathrm{kg})\end{array}$ \\
\hline & & & & & & Fig. D-1 & Fig. D-2 & Fig. D-3 & Fig. D-4 & Fig. D-5 & Fig. D-6 & Fig. D-7 \\
\hline 34 & 333.3 & 0.2000 & 0.125000 & 0.080 & 0.050000 & 1.730 & 12.520 & 25.040 & 45.660 & 32.749 & 74.440 & 43.196 \\
\hline 35 & 333.3 & 0.2000 & 0.125000 & 0.160 & 0.100000 & 1.790 & 10.010 & 20.020 & 34.140 & 18.308 & 55.100 & 17.518 \\
\hline 36 & 333.3 & 0.2000 & 0.125000 & 0.330 & 0.206250 & 1.847 & 7.410 & 14.820 & 23.240 & 8.484 & 37.020 & 5.313 \\
\hline 37 & 833.3 & 0.5000 & 0.312500 & 0.000 & 0.000000 & 1.808 & 8.310 & 41.550 & 51.560 & 104.396 & 91.640 & 201.476 \\
\hline 38 & 833.3 & 0.5000 & 0.312500 & 0.020 & 0.012500 & 1.763 & 8.910 & 44.550 & 47.560 & 88.827 & 82.060 & 144.665 \\
\hline 39 & 833.3 & 0.5000 & 0.312500 & 0.040 & 0.025000 & 1.741 & 8.820 & 44.100 & 43.800 & 75.337 & 74.640 & 108.864 \\
\hline 40 & 833.3 & 0.5000 & 0.312500 & 0.080 & 0.050000 & 1.731 & 8.330 & 41.650 & 37.800 & 56.110 & 63.560 & 67.223 \\
\hline 41 & 833.3 & 0.5000 & 0.312500 & 0.160 & 0.100000 & 1.750 & 7.310 & 36.550 & 29.820 & 34.920 & 49.380 & 31.523 \\
\hline 42 & 833.3 & 0.5000 & 0.312500 & 0.330 & 0.206250 & 1.800 & 5.760 & 28.800 & 20.860 & 17.088 & 33.980 & 10.272 \\
\hline
\end{tabular}

Figures are presented in Appendix D.

'Dimensions based on system $\mathrm{k}_{\mathrm{efr}}=0.95$ rather than $\mathrm{k}_{\mathrm{efr}}=1.0$ to conservatively account for methods and data uncertainty. 


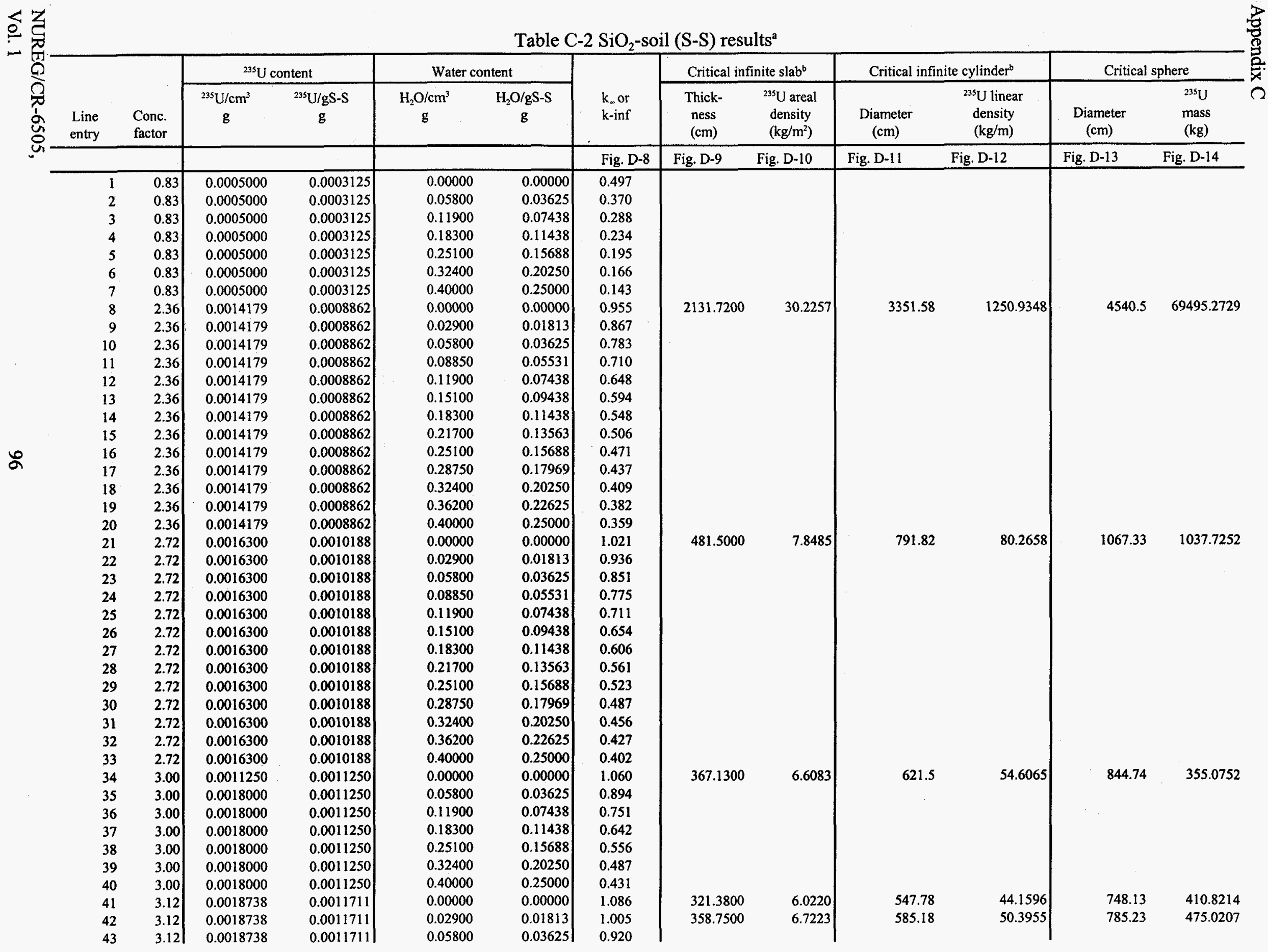


Table C-2 (continued)

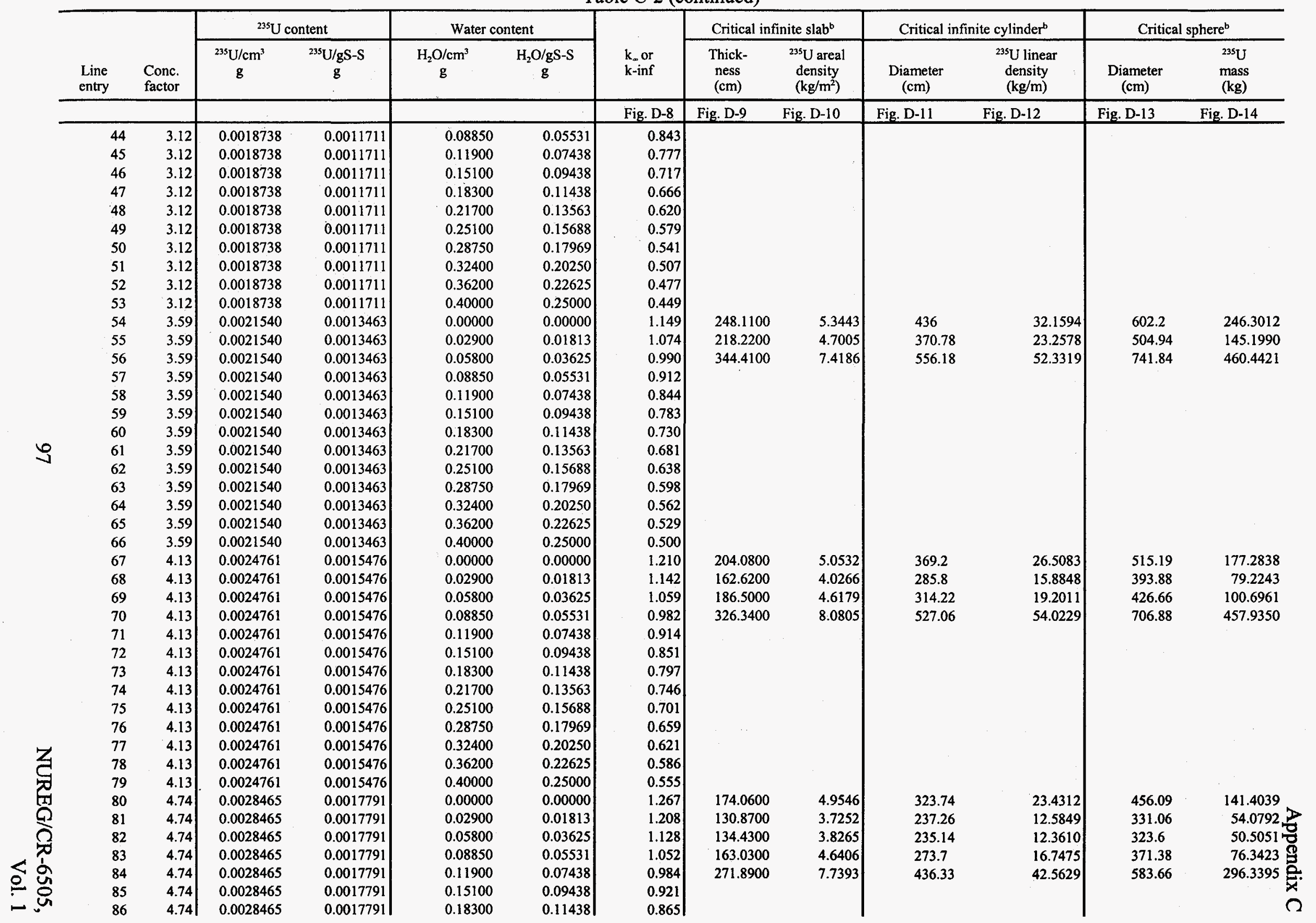


Table C-2 (continued)

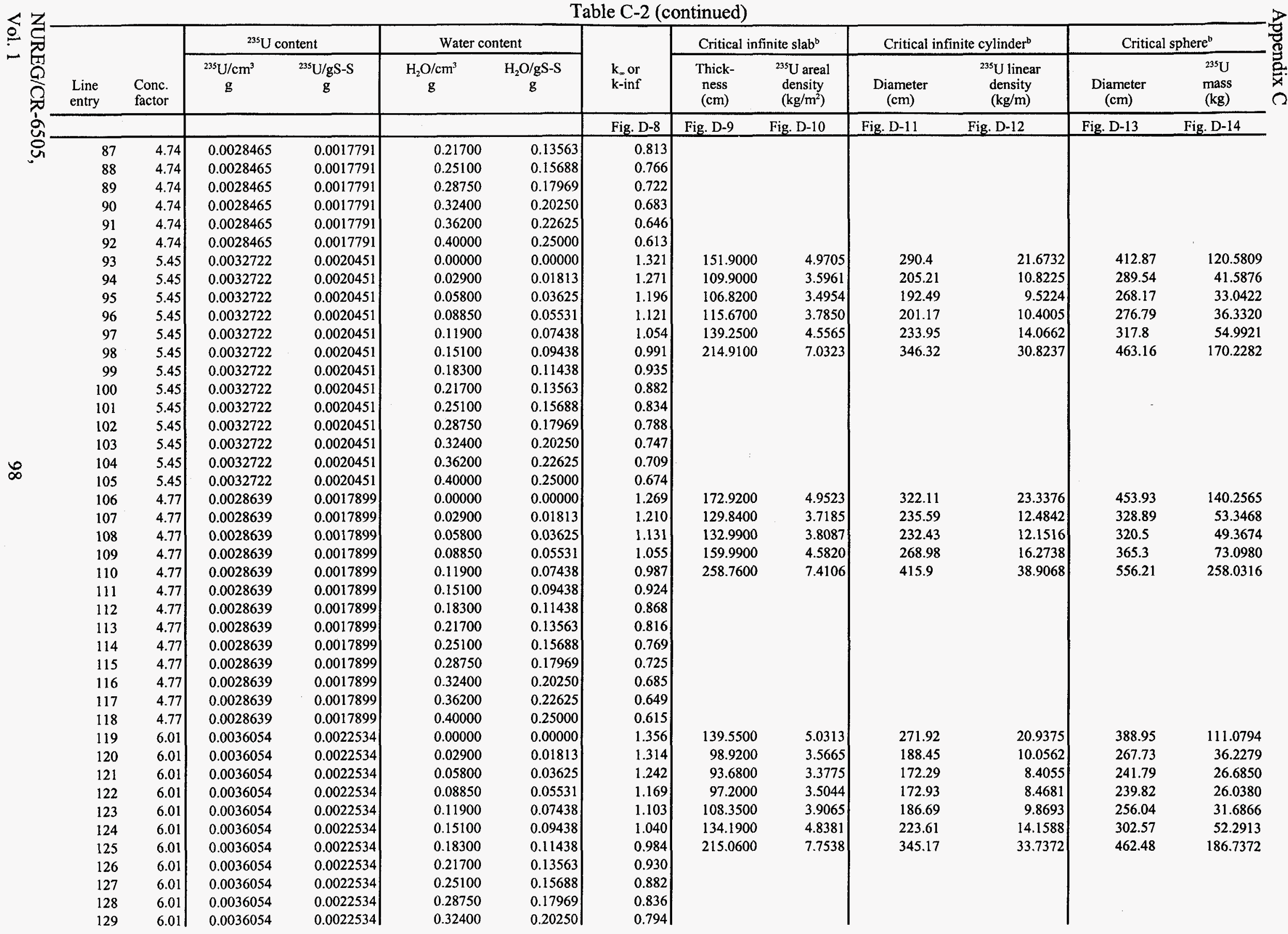


Table C-2 (continued)

\begin{tabular}{|c|c|c|c|c|c|c|c|c|c|c|c|c|c|}
\hline & \multirow[b]{2}{*}{$\begin{array}{l}\text { Line } \\
\text { entry }\end{array}$} & \multirow[b]{2}{*}{$\begin{array}{l}\text { Conc. } \\
\text { factor }\end{array}$} & \multicolumn{2}{|c|}{${ }^{235} \mathrm{U}$ content } & \multicolumn{2}{|c|}{ Water content } & \multirow[b]{2}{*}{$\begin{array}{l}\mathbf{k}_{m} \text { or } \\
\text { k-inf }\end{array}$} & \multicolumn{2}{|c|}{ Critical infinite slab ${ }^{b}$} & \multicolumn{2}{|c|}{ Critical infinite cylinder ${ }^{b}$} & \multicolumn{2}{|c|}{ Critical sphere $^{\mathrm{b}}$} \\
\hline & & & $\begin{array}{c}{ }^{235} \mathrm{U} / \mathrm{cm}^{3} \\
\mathrm{~g}\end{array}$ & $\begin{array}{c}{ }^{235} \mathrm{U} / \mathrm{gS}-\mathrm{S} \\
\mathrm{g}\end{array}$ & $\begin{array}{c}\mathrm{H}_{2} \mathrm{O} / \mathrm{cm}^{3} \\
\mathrm{~g}\end{array}$ & $\underset{\mathrm{g}}{\mathrm{H}_{2} \mathrm{O} / \mathrm{gS}-\mathrm{S}}$ & & $\begin{array}{l}\text { Thick- } \\
\text { ness } \\
(\mathrm{cm})\end{array}$ & $\begin{array}{c}{ }^{235} \mathrm{U} \text { areal } \\
\text { density } \\
\left(\mathrm{kg} / \mathrm{m}^{2}\right)\end{array}$ & $\begin{array}{l}\text { Diameter } \\
\text { (cm) }\end{array}$ & $\begin{array}{c}{ }^{235} \text { U linear } \\
\text { density } \\
\text { (kg/m) }\end{array}$ & $\begin{array}{l}\text { Diameter } \\
\text { (cm) }\end{array}$ & $\begin{array}{l}{ }^{235} \mathrm{U} \\
\text { mass } \\
(\mathrm{kg})\end{array}$ \\
\hline & & & & & & & Fig. D-8 & Fig. D-9 & Fig. D-10 & Fig. D-11 & Fig. D-12 & Fig. D-13 & Fig. D-14 \\
\hline & 130 & 6.01 & 0.0036054 & 0.0022534 & 0.36200 & 0.22625 & 0.754 & & & & & & \\
\hline & 131 & 6.01 & 0.0036054 & 0.0022534 & 0.40000 & 0.25000 & 0.719 & & & & & & \\
\hline & 132 & 7.56 & 0.0045390 & 0.0028369 & 0.00000 & 0.00000 & 1.430 & 116.7900 & 5.3011 & 238.07 & 20.2050 & 345.33 & 97.8727 \\
\hline & 133 & 7.56 & 0.0045390 & 0.0028369 & 0.02900 & 0.01813 & 1.409 & 79.7700 & 3.6208 & 159.45 & 9.0636 & 230.09 & 28.9502 \\
\hline & 134 & 7.56 & 0.0045390 & 0.0028369 & 0.05800 & 0.03625 & 1.346 & 72.4900 & 3.2903 & 140.1 & 6.9972 & 200.07 & 19.0329 \\
\hline & 135 & 7.56 & 0.0045390 & 0.0028369 & 0.08850 & 0.05531 & 1.279 & 71.0700 & 3.2259 & 133.04 & 6.3098 & 187.88 & 15.7616 \\
\hline & 136 & 7.56 & 0.0045390 & 0.0028369 & 0.11900 & 0.07438 & 1.216 & 72.8700 & 3.3076 & 132.46 & 6.2549 & 185.18 & 15.0918 \\
\hline & 137 & 7.56 & 0.0045390 & 0.0028369 & 0.15100 & 0.09438 & 1.156 & 77.7400 & 3.5286 & 137.37 & 6.7272 & 190.12 & 16.3321 \\
\hline & 138 & 7.56 & 0.0045390 & 0.0028369 & 0.18300 & 0.11438 & 1.101 & 86.5400 & 3.9281 & 149.1 & 7.9251 & 204.16 & 20.2242 \\
\hline & 139 & 7.56 & 0.0045390 & 0.0028369 & 0.21700 & 0.13563 & 1.047 & 103.8400 & 4.7133 & 173.8 & 10.7684 & 235.54 & 31.0565 \\
\hline & 140 & 7.56 & 0.0045390 & 0.0028369 & 0.25100 & 0.15688 & 0.999 & 144.4800 & 6.5579 & 234.41 & 19.5886 & 314.43 & 73.8807 \\
\hline & 141 & 7.56 & 0.0045390 & 0.0028369 & 0.28750 & 0.17969 & 0.951 & 1234.4000 & 56.0294 & 2057.26 & 1508.7887 & 2840.9 & 54491.2343 \\
\hline & 142 & 7.56 & 0.0045390 & 0.0028369 & 0.32400 & 0.20250 & 0.908 & & & & & & \\
\hline & 143 & 7.56 & 0.0045390 & 0.0028369 & 0.36200 & 0.22625 & 0.867 & & & & & & \\
\hline & 144 & 7.56 & 0.0045390 & 0.0028369 & 0.40000 & 0.25000 & 0.829 & & & & & & \\
\hline & 145 & 9.52 & 0.0057142 & 0.0035714 & 0.00000 & 0.00000 & 1.490 & 100.0400 & 5.7165 & 213.5 & 20.4570 & 313.84 & 92.4866 \\
\hline & 146 & 9.52 & 0.0057142 & 0.0035714 & 0.02900 & 0.01813 & 1.492 & 66.5200 & 3.8011 & 139.6 & 8.7461 & 204.36 & 25.5353 \\
\hline \multirow{16}{*}{$b$} & 147 & 9.52 & 0.0057142 & 0.0035714 & 0.05800 & 0.03625 & 1.440 & 58.9300 & 3.3674 & 119.65 & 6.4250 & 173.46 & 15.6154 \\
\hline & 148 & 9.52 & 0.0057142 & 0.0035714 & 0.08850 & 0.05531 & 1.381 & 56.0100 & 3.2005 & 110.13 & 5.4432 & 158.08 & 11.8191 \\
\hline & 149 & 9.52 & 0.0057142 & 0.0035714 & 0.11900 & 0.07438 & 1.323 & 55.2800 & 3.1588 & 105.61 & 5.0056 & 150.2 & 10.1383 \\
\hline & 150 & 9.52 & 0.0057142 & 0.0035714 & 0.15100 & 0.09438 & 1.267 & 55.9700 & 3.1982 & 104.12 & 4.8653 & 146.73 & 9.4517 \\
\hline & 151 & 9.52 & 0.0057142 & 0.0035714 & 0.18300 & 0.11438 & 1.214 & 57.9200 & 3.3097 & 105.16 & 4.9630 & 146.99 & 9.5021 \\
\hline & 152 & 9.52 & 0.0057142 & 0.0035714 & 0.21700 & 0.13563 & 1.163 & 61.4900 & 3.5137 & 109.02 & 5.3341 & 151.09 & 10.3196 \\
\hline & 153 & 9.52 & 0.0057142 & 0.0035714 & 0.25100 & 0.15688 & 1.115 & 67.0600 & 3.8319 & 116.23 & 6.0629 & 159.94 & 12.2412 \\
\hline & 154 & 9.52 & 0.0057142 & 0.0035714 & 0.28750 & 0.17969 & 1.068 & 76.8100 & 4.3891 & 129.96 & 7.5799 & 176.99 & 16.5882 \\
\hline & 155 & 9.52 & 0.0057142 & 0.0035714 & 0.32400 & 0.20250 & 1.025 & 94.5700 & 5.4039 & 156.4 & 10.9779 & 210.46 & 27.8909 \\
\hline & 156 & 9.52 & 0.0057142 & 0.0035714 & 0.36200 & 0.22625 & 0.983 & 142.4500 & 8.1399 & 227.79 & 23.2871 & 305.69 & 85.4669 \\
\hline & 157 & 9.52 & 0.0057142 & 0.0035714 & 0.40000 & 0.25000 & 0.945 & & & & & & \\
\hline & 158 & 10.50 & 0.0063000 & 0.0039375 & 0.00000 & 0.00000 & 1.512 & 94.2100 & 5.9352 & 205.28 & 20.8508 & 303.38 & 92.1086 \\
\hline & 159 & 10.50 & 0.0063000 & 0.0039375 & 0.05800 & 0.03625 & 1.478 & 54.5300 & 3.4354 & 113.3 & 6.3517 & 165.3 & 14.8990 \\
\hline & 160 & 10.50 & 0.0063000 & 0.0039375 & 0.11900 & 0.07438 & 1.367 & 50.1000 & 3.1563 & 97.96 & 4.7482 & 140.28 & 9.1060 \\
\hline & 161 & 10.50 & 0.0063000 & 0.0039375 & 0.18300 & 0.11438 & 1.261 & 50.9400 & 3.2092 & 94.72 & 4.4393 & 133.44 & 7.8379 \\
\hline & 162 & 10.50 & 0.0063000 & 0.0039375 & 0.25100 & 0.15688 & 1.163 & 55.9600 & 3.5255 & 99.6 & 4.9085 & 138.1 & 8.6880 \\
\hline & 163 & 10.50 & 0.0063000 & 0.0039375 & 0.32400 & 0.20250 & 1.075 & 68.4900 & 4.3149 & 117.08 & 6.7826 & 159.62 & 13.4153 \\
\hline & 164 & 10.50 & 0.0063000 & 0.0039375 & 0.40000 & 0.25000 & 0.995 & 111.8700 & 7.0478 & 174.66 & 15.0945 & 246.4 & 49.3471 \\
\hline 5 & 165 & 37.33 & 0.0224000 & 0.0140000 & 0.00000 & 0.00000 & 1.604 & 48.4500 & 10.8528 & 139.54 & 34.2559 & 218.62 & 122.5508 \\
\hline$(I)$ & 166 & 37.33 & 0.0224000 & 0.0140000 & 0.05800 & 0.03625 & 1.765 & 25.6900 & 5.7546 & 71.18 & 8.9136 & 111.22 & 16.1360 \\
\hline$Q$ & 167 & 37.33 & 0.0224000 & 0.0140000 & 0.11900 & 0.07438 & 1.751 & 21.3300 & 4.7779 & 54.94 & 5.3103 & 84.76 & 7.1420 工 \\
\hline$\Omega$ & 168 & 37.33 & 0.0224000 & 0.0140000 & 0.18300 & 0.11438 & 1.713 & 19.1400 & 4.2874 & 46.48 & 3.8008 & 70.78 & 4.1589 \\
\hline 2 & 169 & 37.33 & 0.0224000 & 0.0140000 & 0.25100 & 0.15688 & 1.668 & 17.7300 & 3.9715 & 41.1 & 2.9718 & 61.9 & 2.7818 \\
\hline 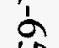 & 170 & 37.33 & 0.0224000 & 0.0140000 & 0.32400 & 0.20250 & 1.619 & 16.7700 & 3.7565 & 37.38 & 2.4582 & 55.64 & 2.0203 \\
\hline$\breve{0}$ & 171 & 37.33 & 0.0224000 & 0.0140000 & 0.39900 & 0.24938 & 1.569 & 16.0900 & 3.6042 & 34.64 & 2.1110 & 51.14 & $1.5687 \bar{x}$ \\
\hline un & 172 & 132.33 & 0.0794000 & 0.0496250 & 0.00000 & 0.00000 & 1.623 & 24.0000 & 19.0560 & 98.82 & 60.8976 & 164.52 & 185.1293 \\
\hline
\end{tabular}


Table C-2 (continued)

\begin{tabular}{|c|c|c|c|c|c|c|c|c|c|c|c|c|}
\hline \multirow[b]{2}{*}{$\begin{array}{l}\text { Line } \\
\text { entry }\end{array}$} & \multirow[b]{2}{*}{$\begin{array}{l}\text { Conc. } \\
\text { factor }\end{array}$} & \multicolumn{2}{|c|}{${ }^{235} \mathrm{U}$ content } & \multicolumn{2}{|c|}{ Water content } & \multirow[b]{2}{*}{$\begin{array}{l}k_{\text {mor }} \text { or } \\
k \text {-inf }\end{array}$} & \multicolumn{2}{|c|}{ Critical infinite $s \mathbf{a b}^{\mathfrak{b}}$} & \multicolumn{2}{|c|}{ Critical infinite cylinder ${ }^{b}$} & \multicolumn{2}{|c|}{ Critical sphere $^{\mathrm{b}}$} \\
\hline & & $\begin{array}{c}\mathrm{g}^{235} \mathrm{U} \\
\text { per } \\
\mathrm{cm}^{3}\end{array}$ & $\begin{array}{c}\mathrm{g}^{235} \mathrm{U} \\
\text { per } \\
\mathrm{gS}-\mathrm{S}\end{array}$ & $\begin{array}{c}\mathrm{gH}_{2} \mathrm{O} \\
\mathrm{per} \\
\mathrm{cm}^{3}\end{array}$ & $\begin{array}{c}\text { gH2O } \\
\text { per } \\
\text { gS-S }\end{array}$ & & $\begin{array}{l}\text { Thick- } \\
\text { ness } \\
(\mathrm{cm})\end{array}$ & $\begin{array}{c}{ }^{235} \mathrm{U} \text { areal } \\
\text { density } \\
\left(\mathrm{kg} / \mathrm{m}^{2}\right)\end{array}$ & $\begin{array}{l}\text { Diameter } \\
\text { (cm) }\end{array}$ & $\begin{array}{c}{ }^{235} \mathrm{U} \text { linear } \\
\text { density } \\
(\mathrm{kg} / \mathrm{m})\end{array}$ & $\begin{array}{l}\text { Diameter } \\
(\mathrm{cm})\end{array}$ & $\begin{array}{l}{ }^{235} \mathrm{U} \\
\text { mass } \\
(\mathrm{kg})\end{array}$ \\
\hline & & & & & & Fig. D-8 & Fig. D-9 & Fig. D-10 & Fig. D-11 & Fig. D-12 & Fig. D-13 & Fig. D-14 \\
\hline 173 & 132.33 & 0.0794000 & 0.0496250 & 0.05800 & 0.03625 & 1.767 & 14.8200 & 11.7671 & 56.02 & 19.5703 & 91.62 & 31.9735 \\
\hline 174 & 132.33 & 0.0794000 & 0.0496250 & 0.11900 & 0.07438 & 1.826 & 12.3700 & 9.8218 & 42.44 & 11.2321 & 68.52 & 13.3743 \\
\hline 175 & 132.33 & 0.0794000 & 0.0496250 & 0.18300 & 0.11438 & 1.847 & 10.9200 & 8.6705 & 34.92 & 7.6043 & 55.8 & 7.2231 \\
\hline 176 & 132.33 & 0.0794000 & 0.0496250 & 0.25100 & 0.15688 & 1.853 & 9.8900 & 7.8527 & 29.88 & 5.5676 & 47.42 & 4.4331 \\
\hline 177 & 132.33 & 0.0794000 & 0.0496250 & 0.32400 & 0.20250 & 1.849 & 9.0800 & 7.2095 & 26.2 & 4.2807 & 41.32 & 2.9329 \\
\hline 178 & 132.33 & 0.0794000 & 0.0496250 & 0.39600 & 0.24750 & 1.841 & 8.4600 & 6.7172 & 23.52 & 3.4497 & 36.88 & 2.0854 \\
\hline 179 & 469.50 & 0.2817000 & 0.1760625 & 0.00000 & 0.00000 & 1.754 & 9.6200 & 27.0995 & 63.82 & 90.1136 & 113.54 & 215.8898 \\
\hline 180 & 469.50 & 0.2817000 & 0.1760625 & 0.05800 & 0.03625 & 1.716 & 8.3400 & 23.4938 & 45 & 44.8024 & 76.96 & 67.2327 \\
\hline 181 & 469.50 & 0.2817000 & 0.1760625 & 0.11900 & 0.07438 & 1.757 & 7.6600 & 21.5782 & 35.52 & 27.9140 & 59.66 & 31.3210 \\
\hline 182 & 469.50 & 0.2817000 & 0.1760625 & 0.18300 & 0.11438 & 1.793 & 7.0800 & 19.9444 & 29.48 & 19.2279 & 48.88 & 17.2258 \\
\hline 183 & 469.50 & 0.2817000 & 0.1760625 & 0.25100 & 0.15688 & 1.820 & 6.5400 & 18.4232 & 25.18 & 14.0278 & 41.36 & 10.4358 \\
\hline 184 & 469.50 & 0.2817000 & 0.1760625 & 0.32400 & 0.20250 & 1.841 & 6.0400 & 17.0147 & 21.96 & 10.6694 & 35.76 & 6.7449 \\
\hline 185 & 469.50 & 0.2817000 & 0.1760625 & 0.38500 & 0.24063 & 1.854 & 5.6800 & 16.0006 & 19.88 & 8.7440 & 32.18 & 4.9152 \\
\hline 186 & 1666.67 & 1.0000000 & 0.6250000 & 0.00000 & 0.00000 & 1.923 & 3.1600 & 31.6000 & 36.14 & 102.5808 & 69.12 & 172.9059 \\
\hline 187 & 1666.67 & 1.0000000 & 0.6250000 & 0.05800 & 0.03625 & 1.818 & 3.7000 & 37.0000 & 31.14 & 76.1600 & 55.86 & 91.2644 \\
\hline 188 & 1666.67 & 1.0000000 & 0.6250000 & 0.11900 & 0.07438 & 1.780 & 4.0400 & 40.4000 & 26.98 & 57.1707 & 47.14 & 54.8488 \\
\hline 189 & 1666.67 & 1.0000000 & 0.6250000 & 0.18300 & 0.11438 & 1.768 & 4.1800 & 41.8000 & 23.64 & 43.8919 & 40.62 & 35.0928 \\
\hline 190 & 1666.67 & 1.0000000 & 0.6250000 & 0.25100 & 0.15688 & 1.770 & 4.1600 & 41.6000 & 20.54 & 33.1353 & 34.88 & 22.2192 \\
\hline 191 & 1666.67 & 1.0000000 & 0.6250000 & 0.32400 & 0.20250 & 1.776 & 4.0400 & 40.4000 & 18.66 & 27.3472 & 31.32 & 16.0866 \\
\hline 192 & 166667 & 10000000 & 0.6250000 & 0.34600 & 0.21625 & 1.779 & 38700 & 38.7000 & 18.04 & 25.5601 & 302 & 14.4218 \\
\hline
\end{tabular}

${ }^{2}$ The figures are presented in Appendix D.

Dimensions based on system $k_{\text {eff }}=0.95$ rather than $k_{e f f}=1.0$ to conservatively account for methods and data uncertainty 


\section{APPENDIX D}

Surface Response Figures for Tables A-1 and A-2 Data 
Appendix D

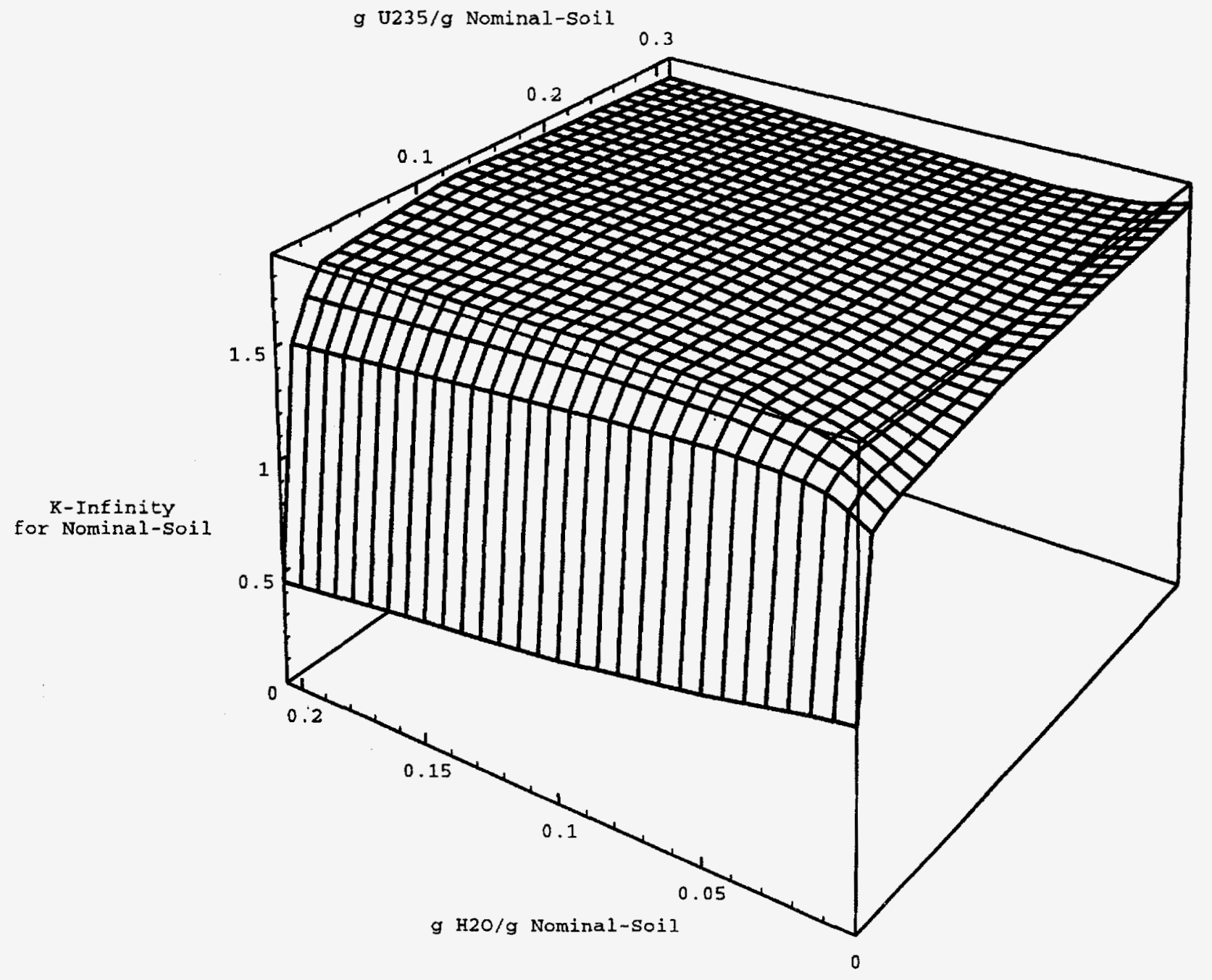

Figure D.1-1 Nominal soil k-infinity vs ${ }^{235} \mathrm{U}$ and $\mathrm{H}_{2} \mathrm{O}$

NUREG/CR-6505,

Vol. 1 
Appendix D

g U235/g Nominal-Soil

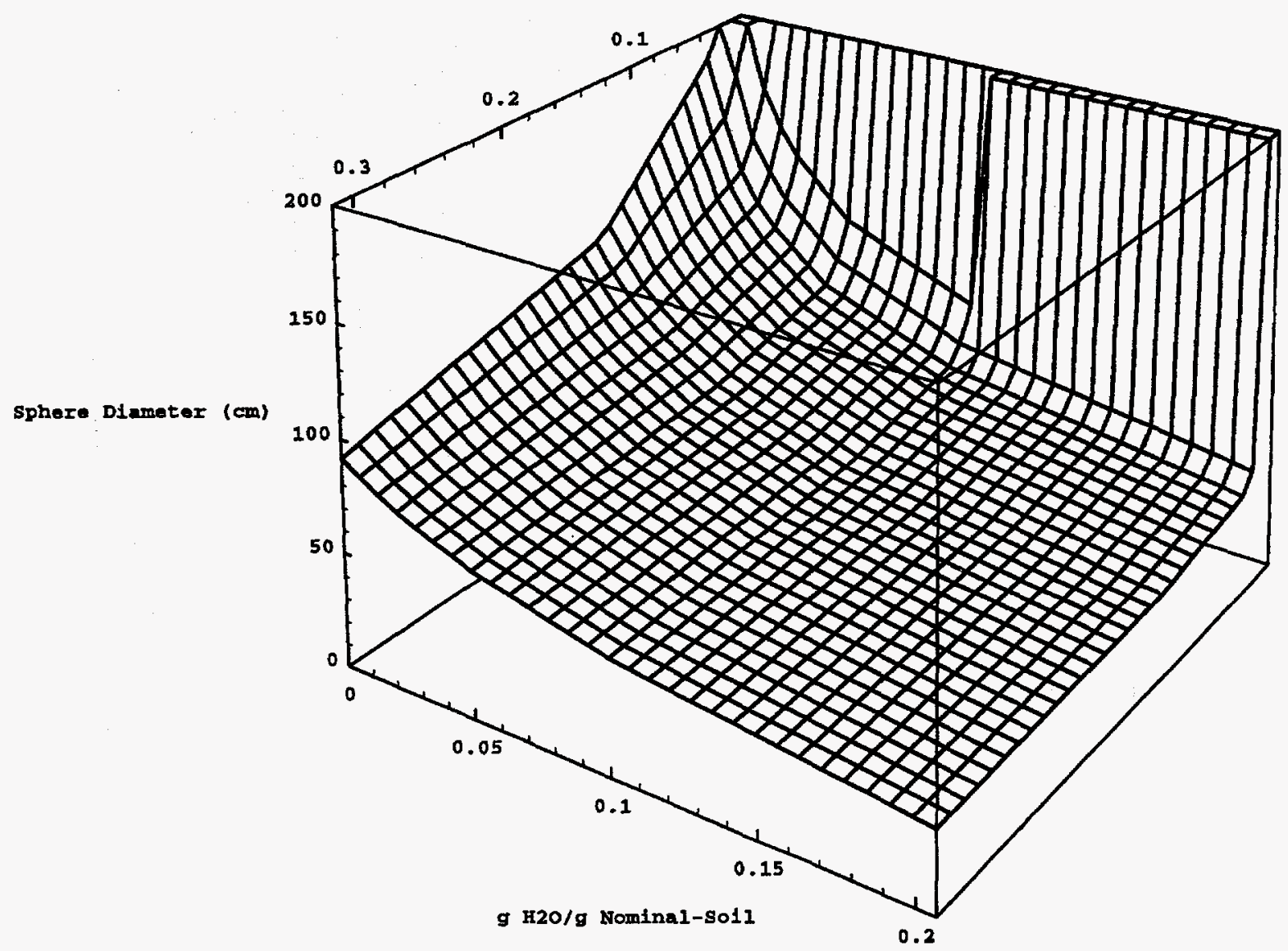

Figure D.1-2 Nominal-soil critical sphere diameter vs ${ }^{235} \mathrm{U}$ and $\mathrm{H}_{2} \mathrm{O}$ concentration 
Appendix D

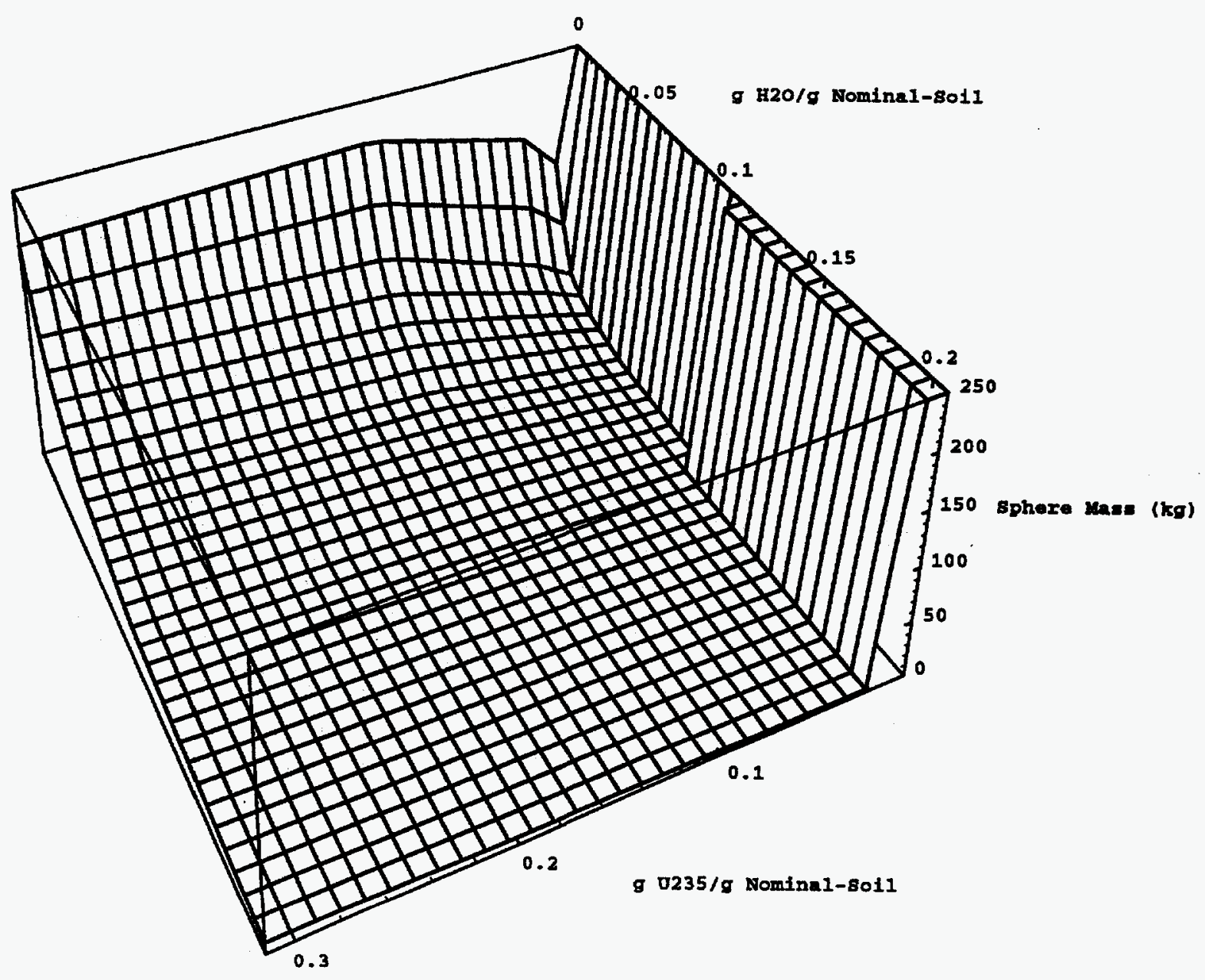

Figure D.1-3 Nominal-soil critical sphere mass vs ${ }^{235} \mathrm{U}$ and $\mathrm{H}_{2} \mathrm{O}$ concentration

NUREG/CR-6505,

Vol. 1 
Appendix D

g U235/g Nominal-8oil

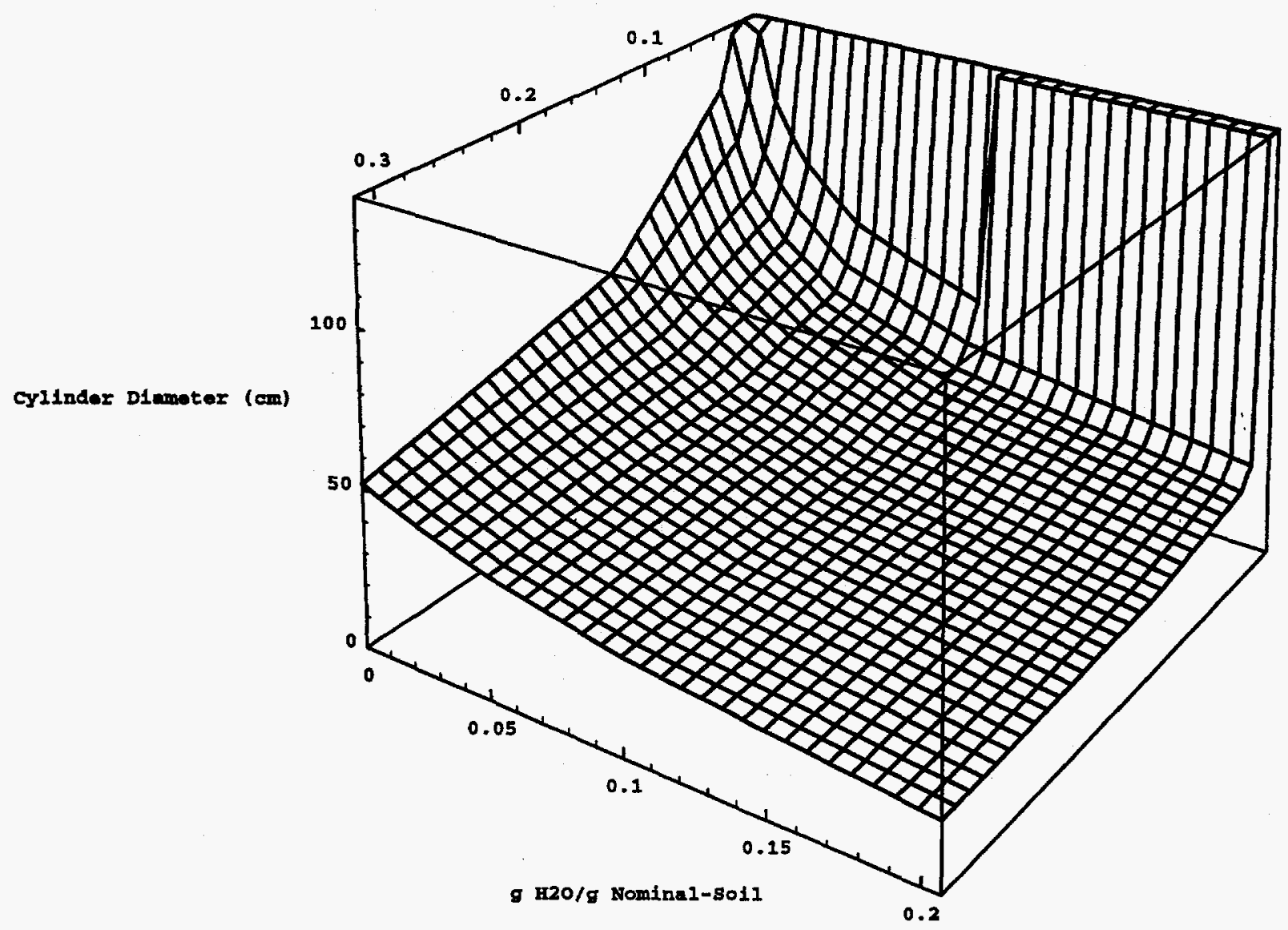

Figure D.1-4 Nominal-soil critical infinite cylinder diameter vs ${ }^{235} \mathrm{U}$ and $\mathrm{H}_{2} \mathrm{O}$ concentration

NUREG/CR-6505, 
Appendix D

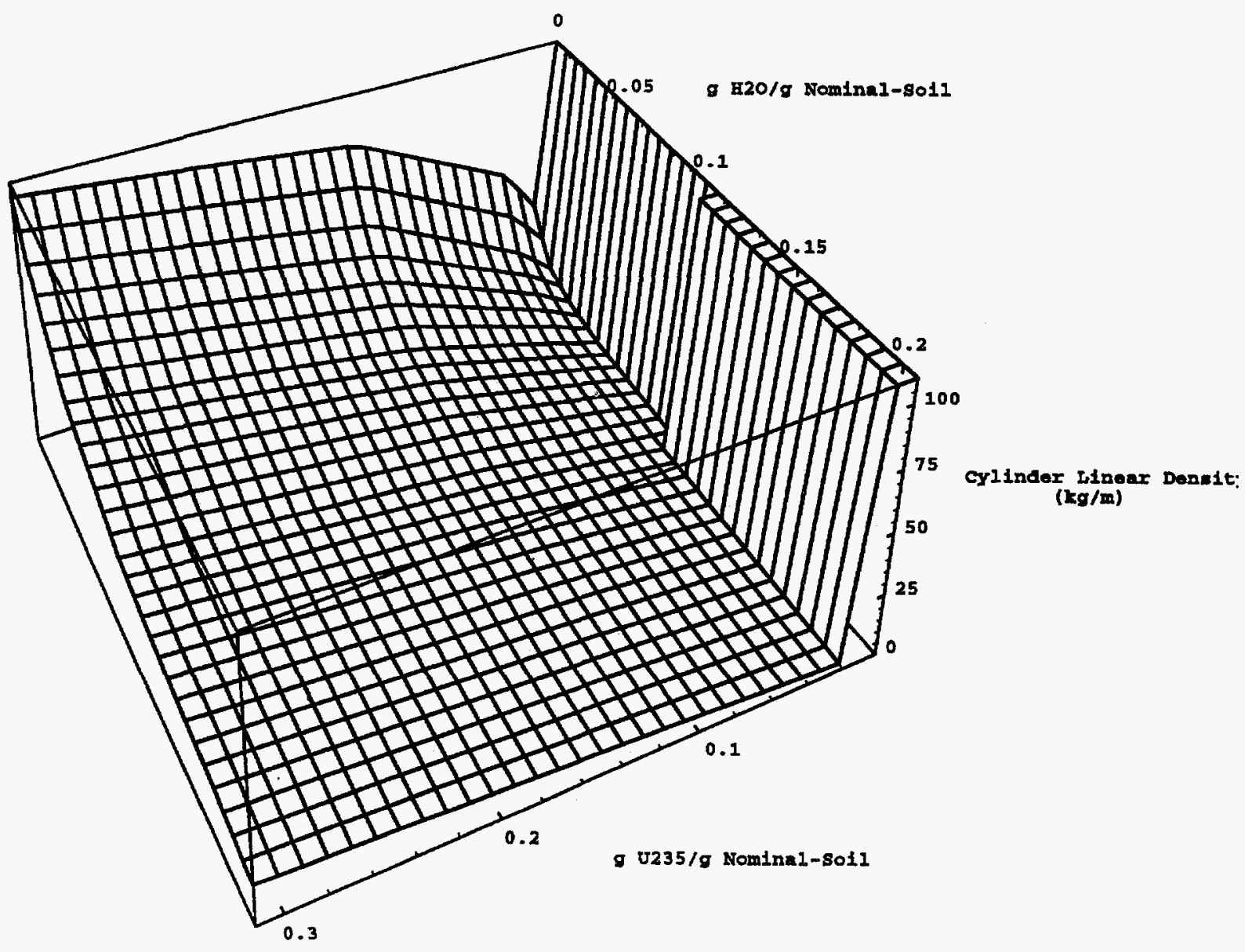

Figure D.1-5 Nominal-soil critical infinite cylinder linear density vs ${ }^{235} \mathrm{U}$ and $\mathrm{H}_{2} \mathrm{O}$ concentration

NUREG/CR-6505,

Vol. 1 
Appendix D

g 0235/g Nominal-Sol1

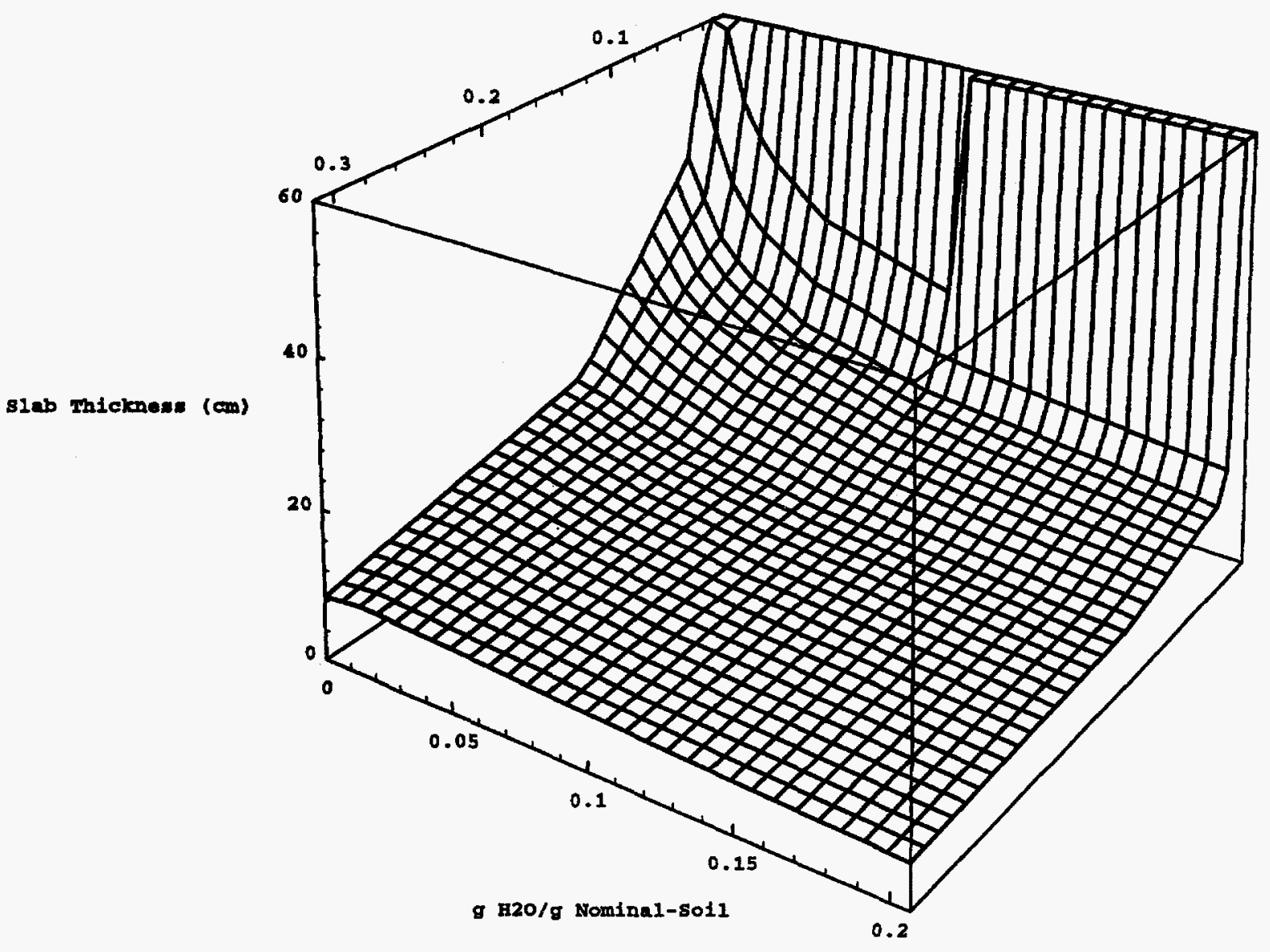

Figure D.1-6 Nominal-soil critical infinite slab thickness vs ${ }^{235} \mathrm{U}$ and $\mathrm{H}_{2} \mathrm{O}$ concentration 
Appendix D

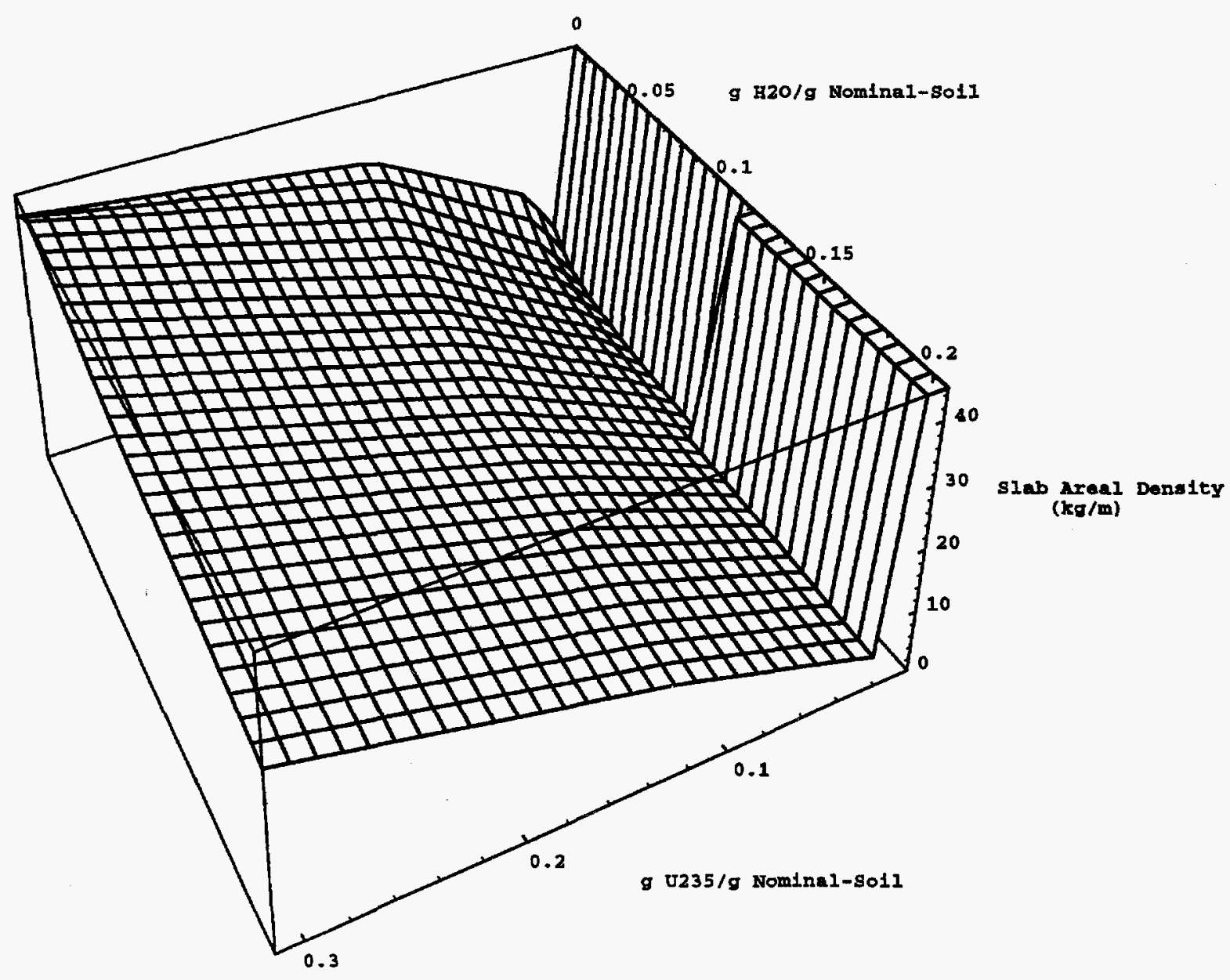

Figure D.1-7 Nominal-soil critical infinite slab areal density vs ${ }^{235} \mathrm{U}$ and $\mathrm{H}_{2} \mathrm{O}$ concentration

NUREG/CR-6505,

Vol. 1 
Appendix D

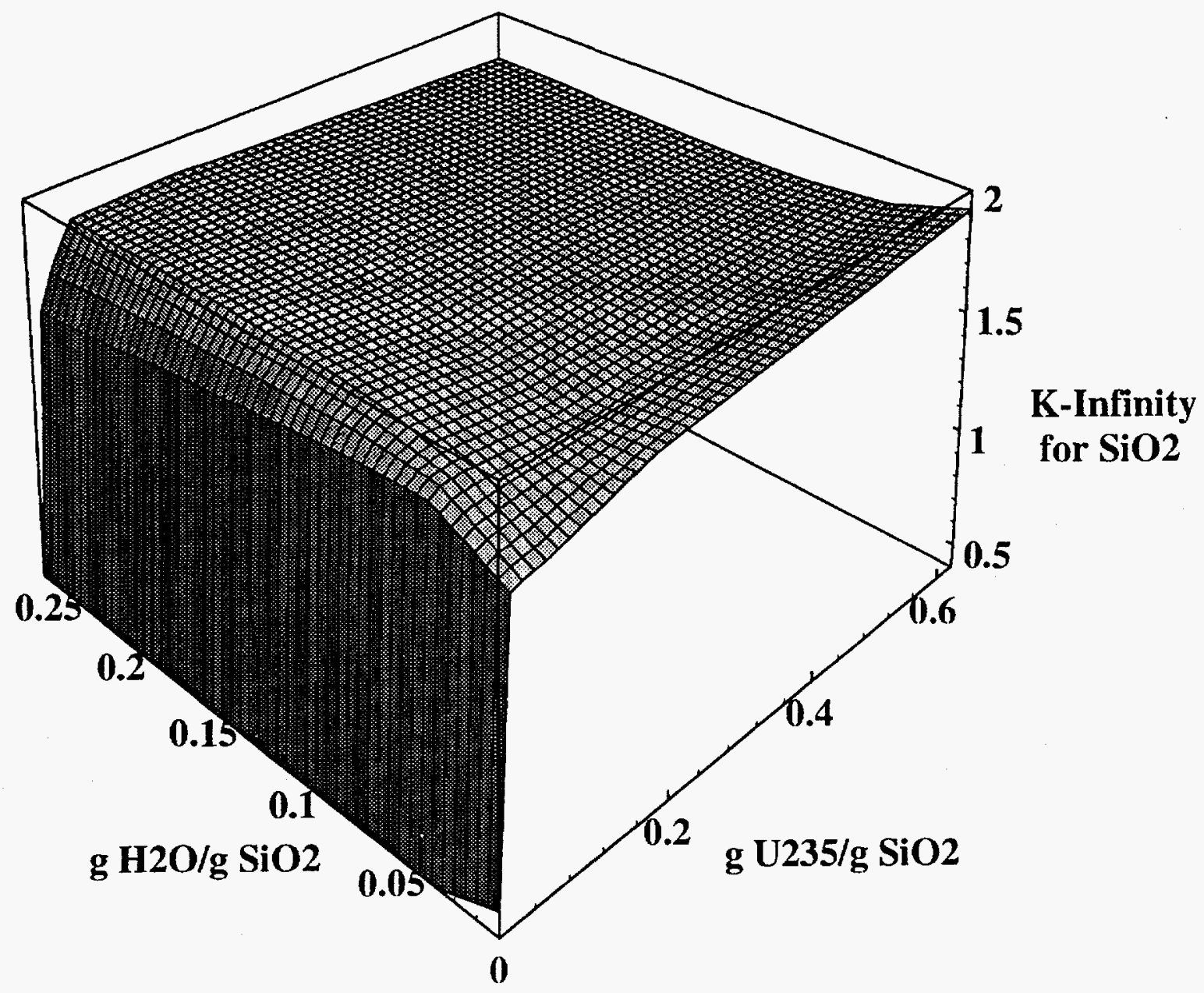

Figure D.1-8 $\mathrm{SiO}_{2}$-soil k-infinity vs $\mathrm{H}_{2} \mathrm{O}$ and ${ }^{235} \mathrm{U}$ concentration linear plot

NUREG/CR-6505, 
Appendix D

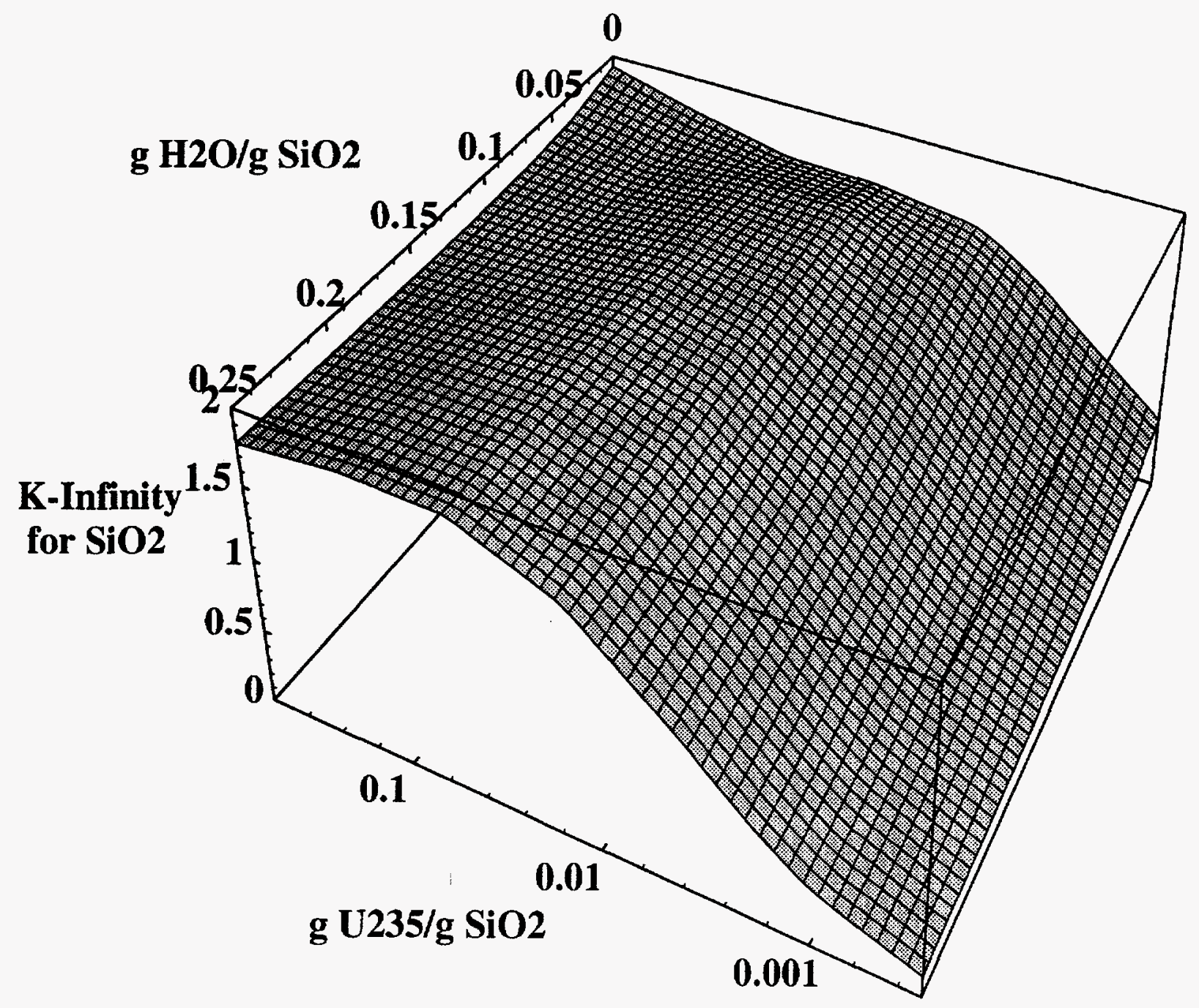

Figure D.1-9 $\mathrm{SiO}_{2}$-soil k-infinity vs $\mathrm{H}_{2} \mathrm{O}$ and ${ }^{235} \mathrm{U}$ concentration $\log$ plot

NUREG/CR-6505,

Vol. 1 
Appendix D

\section{g U235/g SiO2}

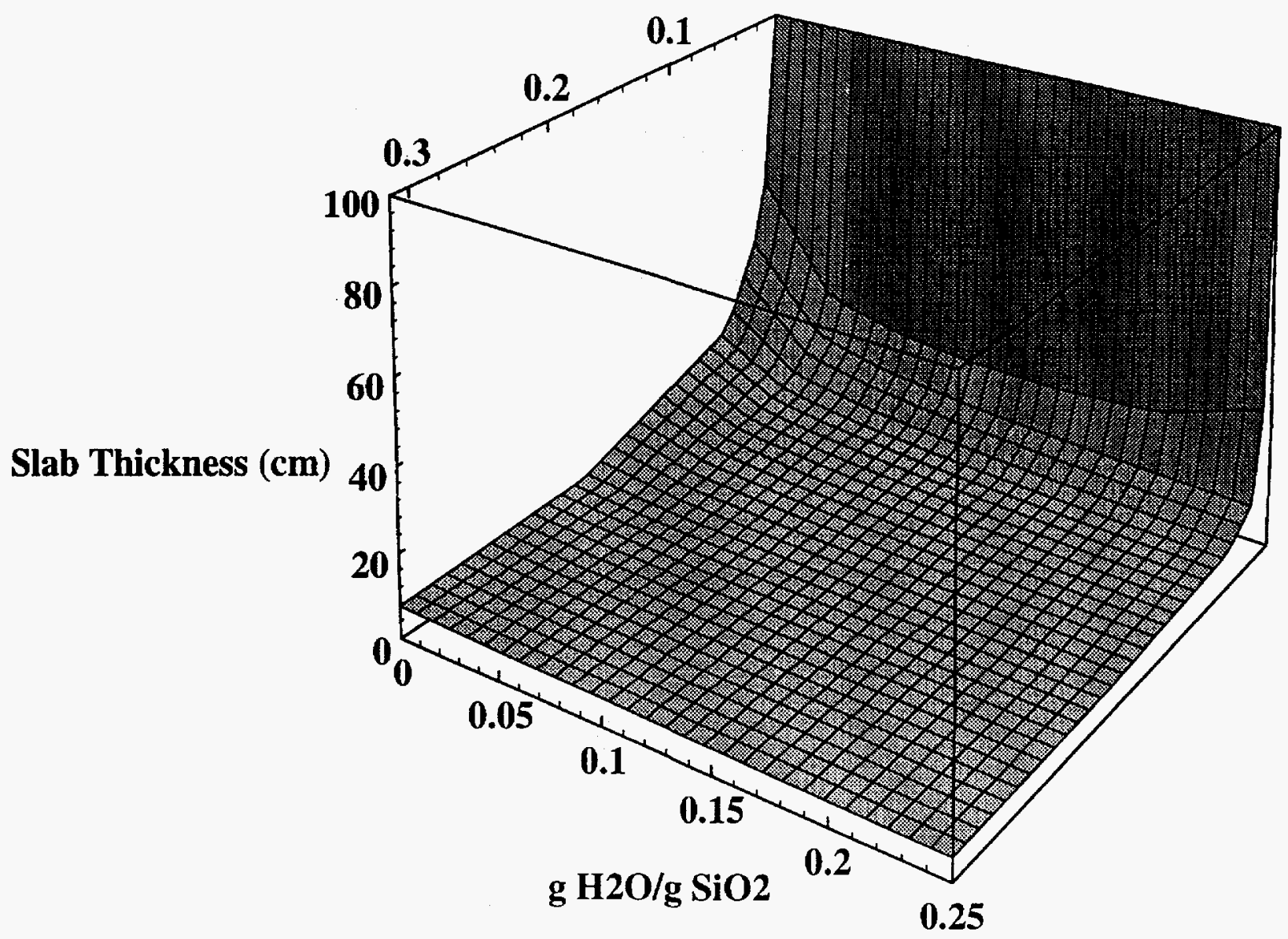

Figure D.1-10 $\mathrm{SiO}_{2}$-soil critical infinite slab thickness vs $\mathrm{H}_{2} \mathrm{O}$ and ${ }^{235} \mathrm{U}$ concentration linear plot 
Appendix D

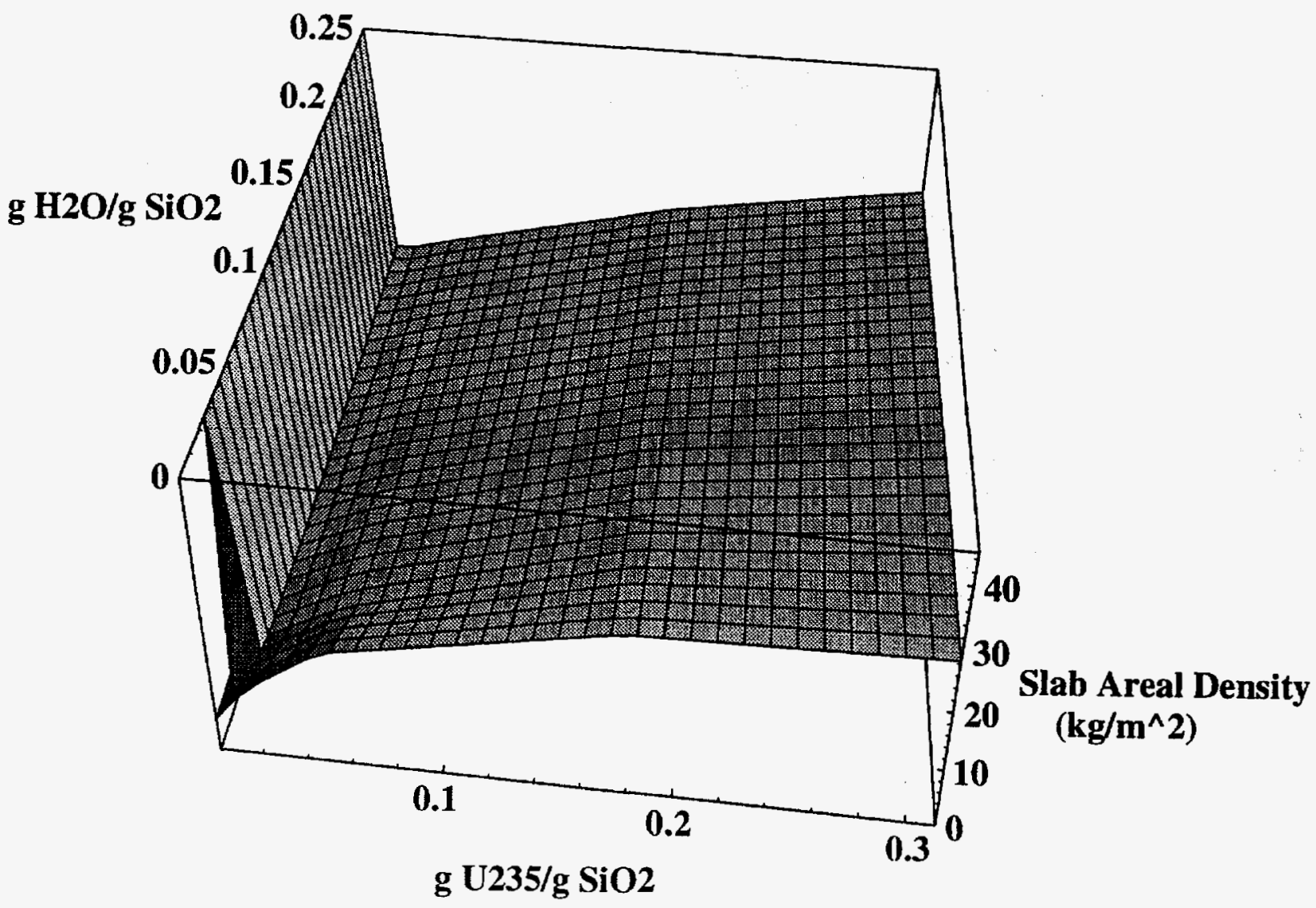

Figure D.1-11 $\mathrm{SiO}_{2}$-soil critical infinite slab areal density vs $\mathrm{H}_{2} \mathrm{O}$ and ${ }^{235} \mathrm{U}$ concentration linear plot 


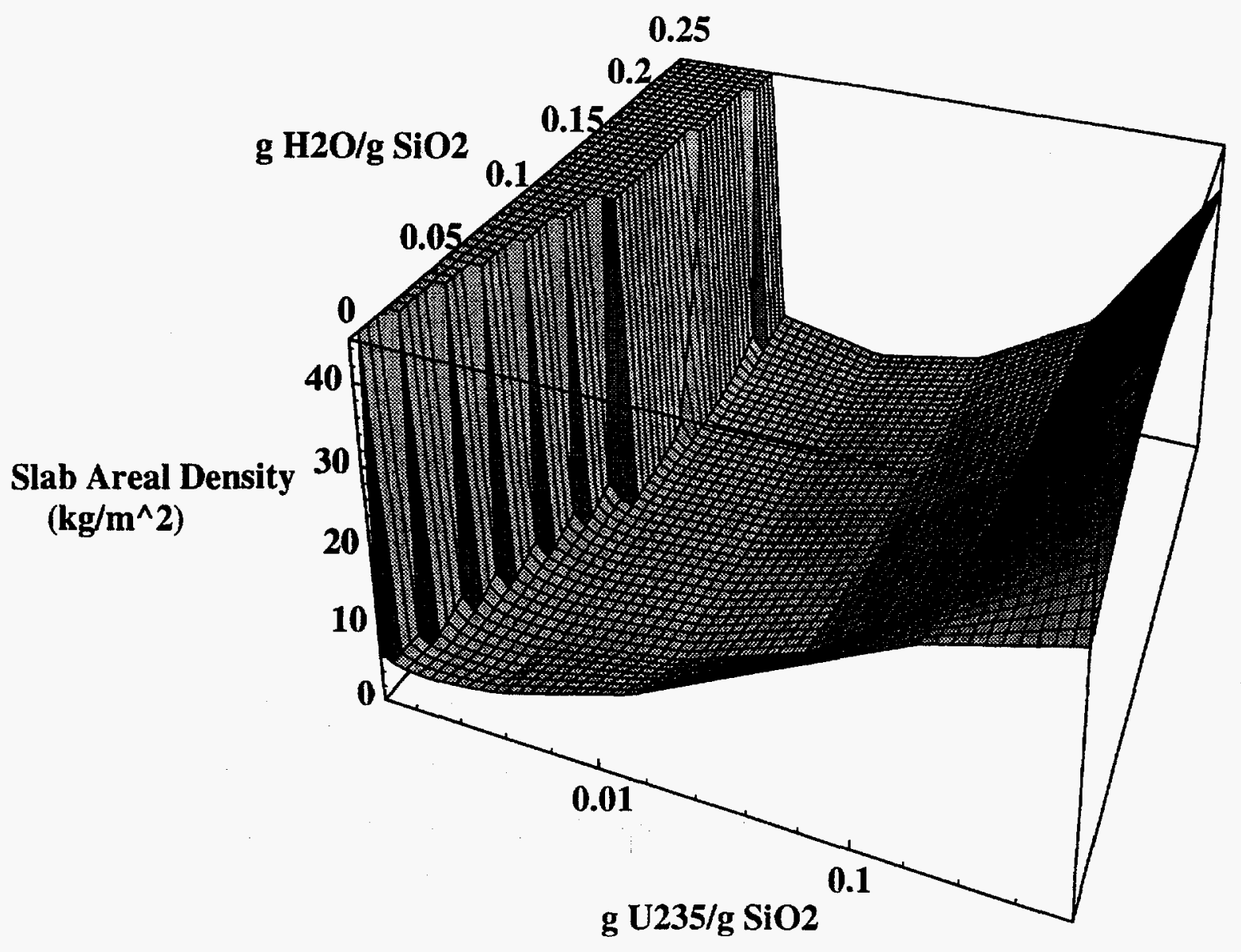

Figure D.1-12 $\mathrm{SiO}_{2}$-soil critical infinite slab areal density vs $\mathrm{H}_{2} \mathrm{O}$ and ${ }^{235} \mathrm{U}$ concentration $\log$ plot 
Appendix D

\section{g U235/g SiO2}

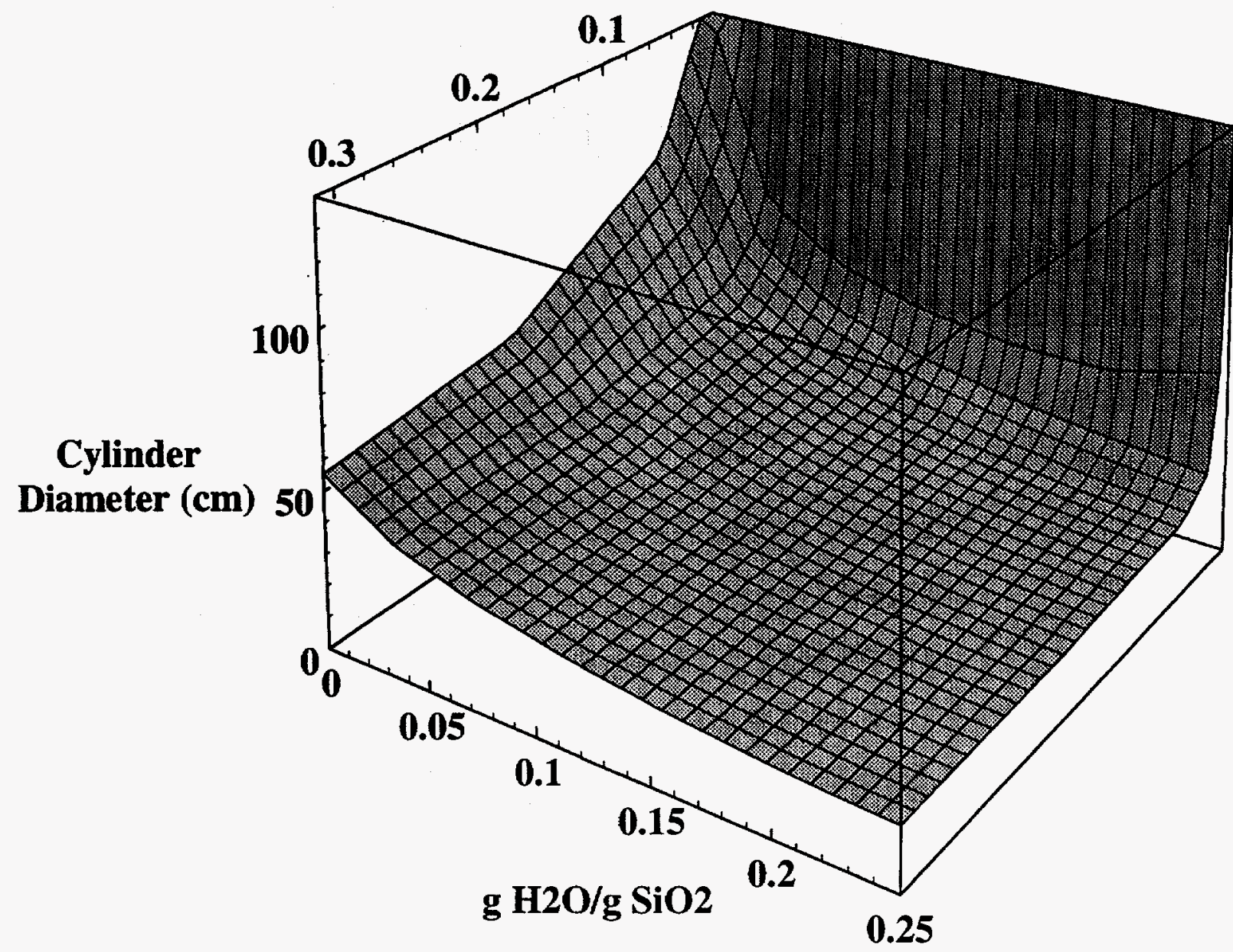

Figure D.1-13 $\mathrm{SiO}_{2}$-soil critical infinite cylinder diameter vs $\mathrm{H}_{2} \mathrm{O}$ and ${ }^{235} \mathrm{U}$ concentration linear plot 


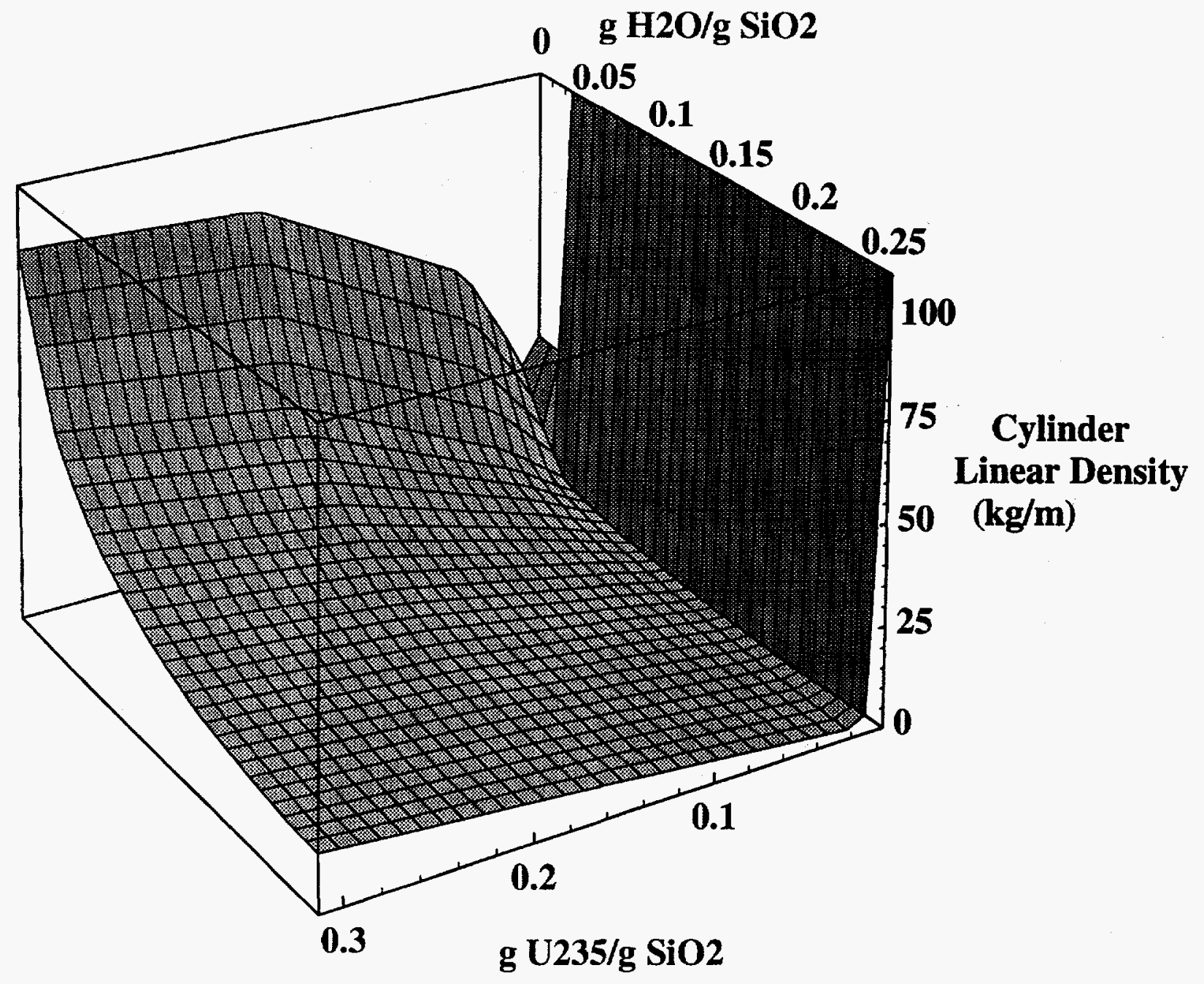

Figure D.1-14 $\mathrm{SiO}_{2}$-soil critical infinite cylinder linear density vs $\mathrm{H}_{2} \mathrm{O}$ and ${ }^{235} \mathrm{U}$ concentration linear plot 


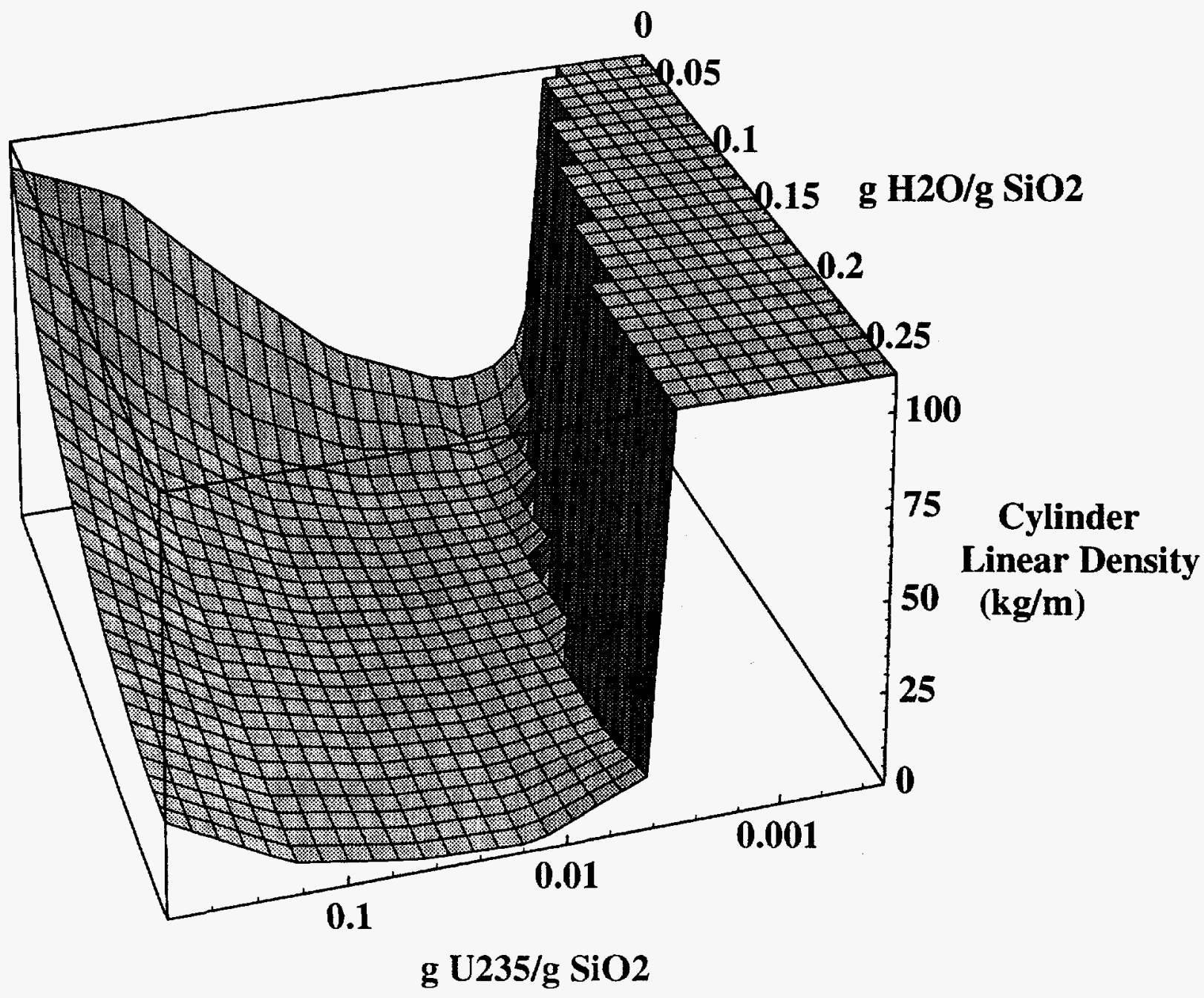

Figure D.1-15 $\mathrm{SiO}_{2}$-soil critical infinite cylinder linear density vs $\mathrm{H}_{2} \mathrm{O}$ and ${ }^{235} \mathrm{U}$ concentration $\log$ plot 
Appendix D

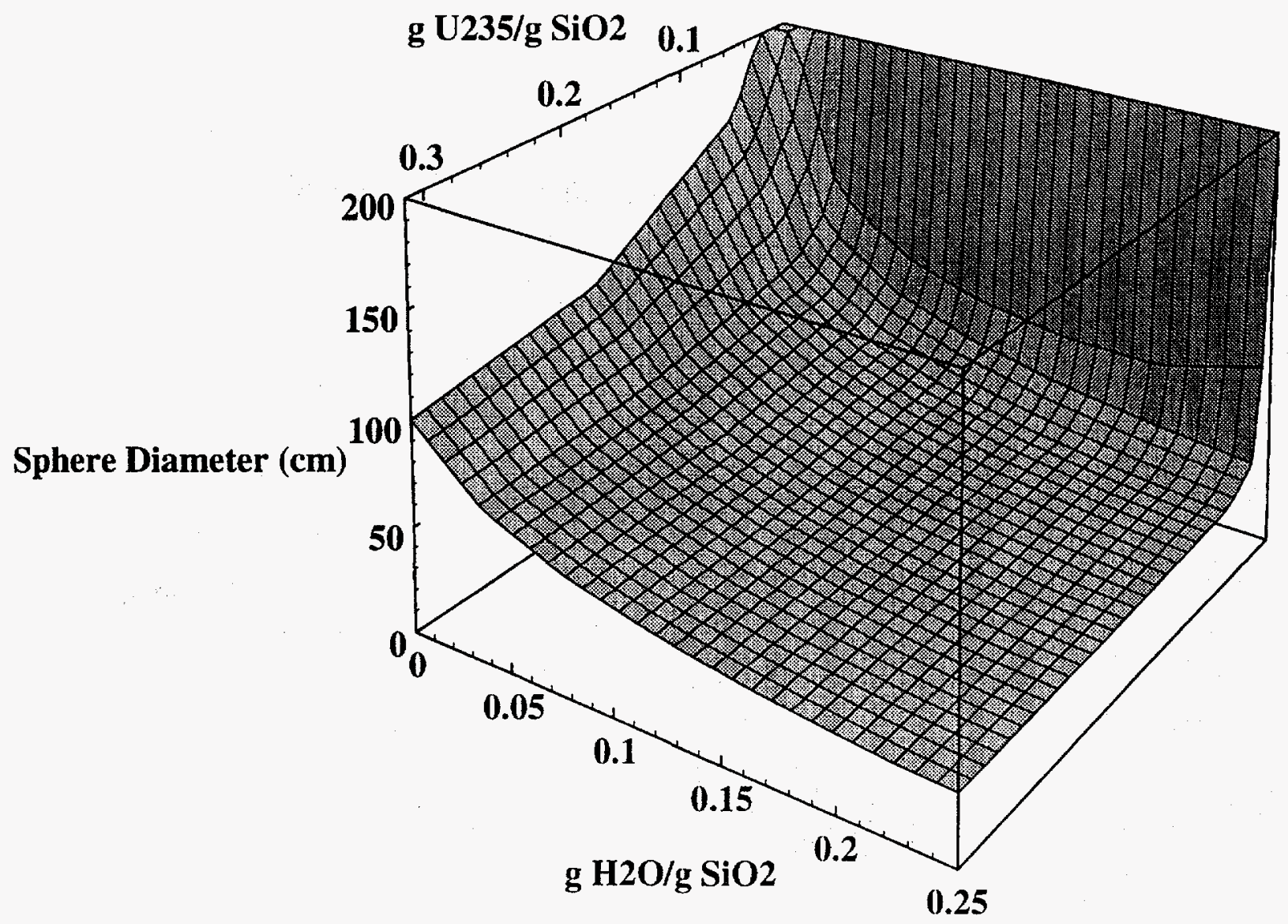

Figure D.1-16 $\mathrm{SiO}_{2}$-soil critical sphere diameter vs $\mathrm{H}_{2} \mathrm{O}$ and ${ }^{235} \mathrm{U}$ concentration linear plot 
Appendix D

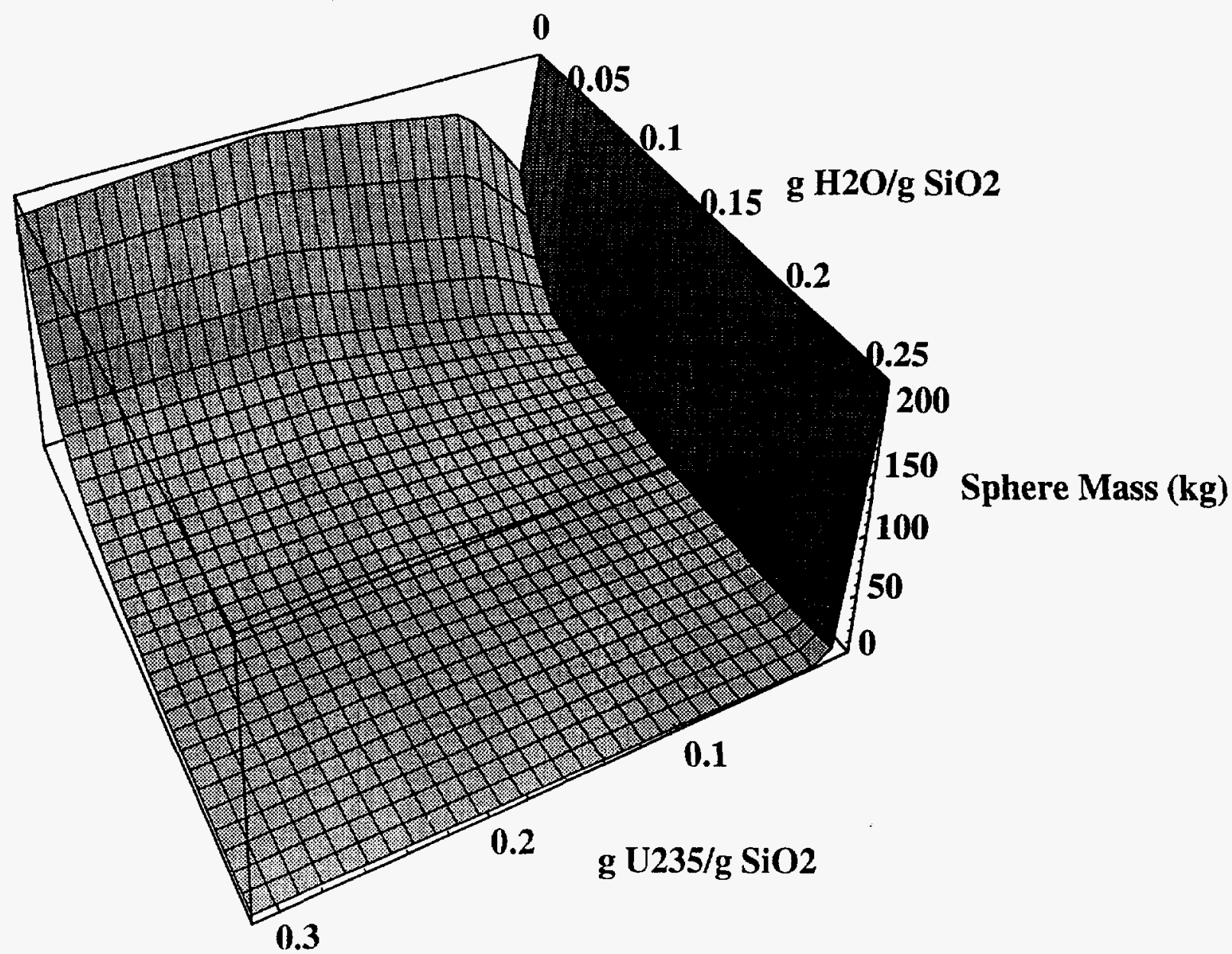

Figure D.1-17 $\mathrm{SiO}_{2}$-soil critical sphere mass vs $\mathrm{H}_{2} \mathrm{O}$ and ${ }^{235} \mathrm{U}$ concentration linear plot 


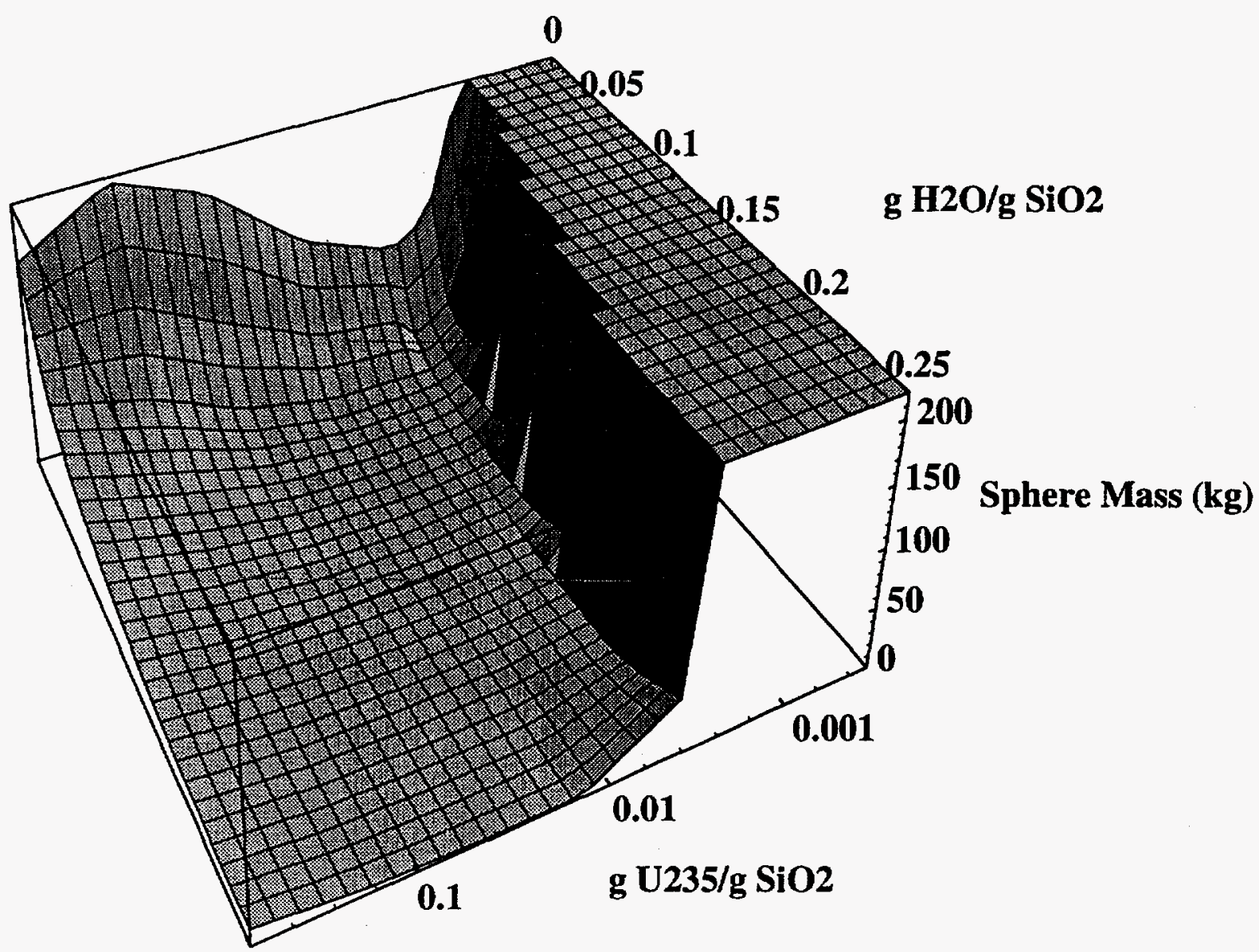

Figure D.1-18 $\mathrm{SiO}_{2}$-soil critical sphere mass vs $\mathrm{H}_{2} \mathrm{O}$ and ${ }^{235} \mathrm{U}$ concentration log plot 


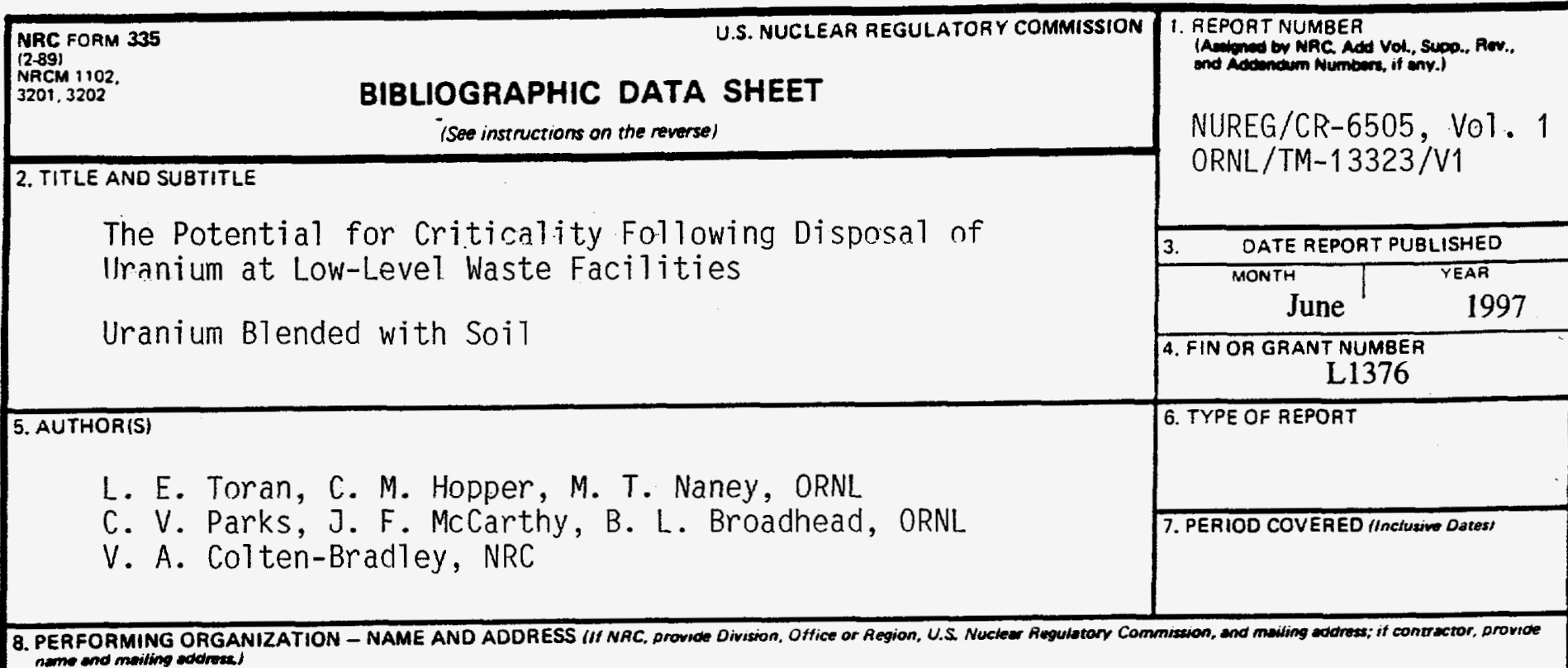

OAK RIDGE NATIONAL LABORATORY

Oak Ridge, Tennessee 37831-6370

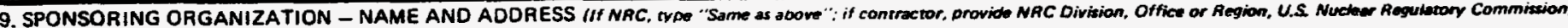
and meniling edormest

Division of Waste Management

Office of Nuclear Material Safety and Safeguards

U.S. Nuclear Regulatory Commission

Washington, DC 20555 -0001

10. SUPPLEMENTARY NOTES

11. ABSTRACT 1200 words or leat

The purpose of this study was to evaluate whether or not fissile uranium in low-level-waste (LLW) facilities can be concentrated by hydrogeochemical processes to permit nuclear criticality. A team of experts in hydrology, geology, geochemistry, soil chemistry, and criticality safety was formed to develop achievable scenarios for hydrogeochemical increases in concentration of special nuclear material (SNM), and to use these scenarios to aid in evaluating the potential for nuclear criticality. The team's approach was to perform simultaneous hydrogeochemical and nuclear criticality studies to (1) identify some achievable scenarios for uranium migration and concentration increase at LLW disposal facilities, (2) model groundwater transport and subsequent concentration increase via sorption or precipitation of uranium, and (3) evaluate the potential for nuclear criticality resulting from potential increases in uranium concentration over disposal limits. The analysis of SNM was restricted to ${ }^{235} \mathrm{U}$ in the present scope of work. The outcome of the work indicates that criticality is possible given established regulatory limits on SNM disposal. However, a review based on actual disposal records of an existing site operation indicates that the potential for criticality is not a concern under current burial practices.

uranium, low-level waste (LLW), special nuclear material (SNM), nuclear criticality, uranium migration, hydrogeochemical modeling

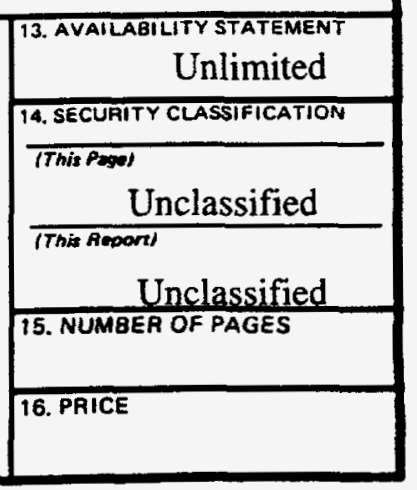

